MÁRCIA ITO

\title{
UM MODELO DE GESTÃO DE PACIENTE CRÔNICO BASEADO NOS CONCEITOS DE RELACIONAMENTO COM O CLIENTE
}

\footnotetext{
Tese apresentada à Escola Politécnica da Universidade de São Paulo para a obtenção do título de Doutor em Engenharia.
}

São Paulo 
MÁRCIA ITO

\section{UM MODELO DE GESTÃO DE PACIENTE CRÔNICO BASEADO NOS CONCEITOS DE RELACIONAMENTO COM O CLIENTE}

Tese apresentada à Escola Politécnica da Universidade de São Paulo para a obtenção do título de Doutor em Engenharia.

Área de Concentração:

Sistemas Digitais

Orientador:

Prof. Dr. José Sidnei Colombo Martini

São Paulo

2006 


\section{FICHA CATALOGRÁFICA}

Ito, Marcia

Um modelo de gestão de paciente crônico baseado nos conceitos de relacionamento com o cliente / M. Ito. -- São Paulo, 2006.

$153 \mathrm{p}$.

Tese (Doutorado) - Escola Politécnica da Universidade de São Paulo. Departamento de Engenharia de Computação e Sistemas Digitais.

1.Modelos de assistência à saúde 2.Assistência ao paciente 3.Doença crônica 4.Qualidade de vida 5.Diabetes Mellitus 6.Computação aplicada 7.Sistemas multiagentes

8.Especificação de programas e sistemas I.Universidade de São Paulo. Escola Politécnica. Departamento de Engenharia de Computação e Sistemas Digitais II.t. 
Dedico este trabalho:

Aos pacientes crônicos, aos seus cuidadores e aos profissionais que assistem esses pacientes e seus familiares.

A Eyka Watanabe Ito, minha mãe e portadora de diabetes mellitus e hipertensão, com muito amor e carinho, por ter sido a pessoa que me inspirou no desenvolvimento e na elaboração deste trabalho. 


\section{Agradecimentos}

Ao meu orientador Prof. Dr. José Sidnei Colombo Martini, agradeço especialmente. Além da paciência que demonstrou ao me orientar, ele proporcionou em nossos encontros trocas de experiências e de idéias tanto na área acadêmica quanto fora dela.

À Profa. Dra. Lúcia C. Iochida também manifesto agradecimentos especiais. Ela permitiu ampliar os meus conhecimentos na área médica e continuar as pesquisas de um tema que comecei a estudar na minha graduação em medicina.

Ao Prof. Dr. José Eduardo Deboni, por em primeiro lugar ter apresentado o meu orientador e pelo apoio e cooperação durante e principalmente na conclusão deste trabalho.

À Profa. Dra. Helena G. Peterossi, pelas discussões sobre interdisciplinaridade e multidisciplinaridade na pesquisa e na educação, temas correlacionados com este trabalho.

Ao Prof. Msc. Daniel Gatti, que me apresentou o Prof. Dr. Vicente Gosciola da PUC-SP. Assim como ao Prof. Dr. Vicente Gosciola, que prontamente me atendeu e me ajudou no estudo da técnica de escrita e de estilos de roteiros.

Ao meu professor de teatro, Marco Plá, que me ajudou a entender e interpretar roteiros e me permitiu ter uma experiência prática daquilo que estava estudando na teoria.

Ao diretor e roteirista Eder Augusto, do curta “Arroz, Feijão e Macarrão”, que me passou as suas experiências na elaboração de roteiros e, ao me chamar para uma pequena participação no curta, permitiu-me conhecer a "implementação" do roteiro em filme (produção e direção). Agradeço, também, à equipe técnica e ao elenco do curta. Esse curta foi apresentado no $15^{\circ}$. Festival Internacional de Curtas Metragens de São Paulo em 2004.

À minha amiga Tereza B. Guedes e aos meus ex-alunos da Fatec Claudio Y. S. Ling, Leandro R. Silva e Fábio A. Almeida, que me apoiaram e ajudaram na especificação dos modelos de casos de uso do negócio e do sistema.

À Profa. Msc. Cilza Bignotto, consultora de redação no Itaú Cultural e ex-professora de metodologia científica no IBTA, que fez a revisão do texto da monografia.

Aos colegas professores e funcionários do curso de Processamento de Dados da Fatec-SP, do curso de especialização em análise e projeto de sistemas da Fatec-SP e dos cursos do IBTA 
que me apoiaram e incetivaram nesta minha caminhada. Agradecimentos também aos alunos desses cursos que me compreenderam nos momentos difíceis.

Ao meu amigo e sócio, Marcelo F. Barros, à minha irmã Cristina Ito, ao meu amigo William Marandola, à minha amiga Cristina Y. Ikenaga e à minha amiga Profa. Msc. Neide A. Itocazu registro agradecimentos mais do que especiais. Além de me ajudarem no desenvolvimento do meu trabalho, eles suportaram todos os meus dramas, dúvidas, depressões, crises, etc., durante todo esse período.

Aos meus pais, que me incentivaram e deram todo o seu apoio para a conclusão desse trabalho.

Ao meu ortopedista, Dr. Jorge E. Sato, e à minha fisioteratepeuta, Bianca Domanico, pela dedicação e pronto atendimento quando precisei de sua assistência.

Aos amigos sinceros que colaboraram durante esta minha caminhada: David Capezzutti, Edward R. Gerth, Edson T. França, Carlos H. Ueki, Carlos Mancuso Jr., Kleber Couto, Ana C. V. Silva, Marta Morais, Eliane Cardinalli, Walid Aly, Wagner Varalda, Luiz Antonio Guaycuru, Antonio M. M. Morais e Valéria C. Pereira.

Enfim, a todos aqueles que ajudaram de uma maneira ou de outra na conclusão dessa tese. 
"É tão importante conhecer a pessoa que tem a doença como conhecer a doença que a pessoa tem."

Sir William Osler,

(Cendário médico inglês de origem canadense 1849-1919) 


\section{Resumo}

ITO, M. Um modelo de gestão de paciente crônico baseado nos conceitos de relacionamento com o cliente. 2006. 140 f. Tese (Doutorado) - Escola Politécnica, Universidade de São Paulo, São Paulo, 2006.

Este trabalho apresenta um modelo de acompanhamento e atendimento de pacientes crônicos baseado nos conceitos de relacionamento de clientes utilizados nas empresas, mais especificamente aqueles presentes na tecnologia CRM (Customer Relationship Management). A esse modelo denominou-se Gestão do Relacionamento com o Paciente Crônico (GRPC). A tecnologia CRM é uma estratégia com ferramentas para implementar um programa de relacionamento e fidelidade entre o cliente/consumidor e o fornecedor. O modelo GRPC, ao utilizar o conceito de CRM no atendimento ao paciente, apresenta uma estratégia de acompanhamento e monitoramento de pacientes crônicos diferente da abordagem tradicional, muitas vezes baseada somente no tratamento da doença. Da mesma forma que o CRM consegue atingir os clientes dos mais variados níveis através dos seus canais de comunicação, neste modelo propõe-se utilizar a mesma tecnologia a fim de garantir um acompanhamento efetivo e adequado a todas as camadas populacionais. Para implementar o modelo GRPC propõe-se a criação de centrais de relacionamento de pacientes crônicos, que compõem a infra-estrutura do modelo ao combinar, de maneira adequada, a troca de informações, as campanhas, a transmissão e o processamento de dados, com a finalidade de melhorar o relacionamento com o paciente, através da tecnologia de telefonia e computação. Para uma avaliação preliminar do modelo, elaborou-se uma central de monitoração de pacientes diabéticos e desenvolveu-se um sistema de monitoração para diabéticos. A modelagem da central de monitoração foi feita utilizando-se a extensão da UML para a modelagem de negócio, o que permitiu analisar a abrangência do modelo. O sistema de monitoração, denominado TeleDM, foi desenvolvido visando a realizar as simulações necessárias para os estudos desse trabalho. A partir da modelagem de negócio elaboraram-se os modelos para o desenvolvimento do sistema. Após a avaliação de suas características optou-se por implementá-lo utilizando a tecnologia de orientação a agentes e objetos, o que permitiu verificar que tal combinação é adequada na solução de sistemas complexos com as características do sistema TeleDM. 
Palavras Chaves: Modelos de Atenção à Saúde, Assistência ao Paciente, Doença Crônica, Qualidade de Vida, Diabetes Mellitus, Computação Aplicada, Sistemas Multiagentes, Especificação de Programas e Sistemas 


\begin{abstract}
ITO, M. The chronic patient relationship management model based on the concepts of customers' relationship. 2006. 140 f. Thesis (Doctoral) - Escola Politécnica, Universidade de São Paulo, São Paulo, 2006.

This paper shows a chronic patient follow-up and attendance model based on the concepts of customers' relationship used in the companies, mainly those existent in CRM technology (Customer Relationship Management). The model was designated as Chronic Patient Relationship Management (CPRM). The CRM technology is a strategy with tools to implement a relationship and fidelity program between the client / customer and the supplier. The CPRM model, by using the CRM concept on patient attendance, presents a strategy to follow-up and monitoring the chronic patient different from the usual traditional approach, which many times only consists in illness treatment. In the same way as the CRM, this model is able to reach clients of every condition through its communication channels; and suggests the use of the same technology in order to guarantee an effective and suitable follow-up for all social layers. To implement the CPRM model, the creation of relationship centers for chronic patients, thus building the model's infrastructure when properly connecting the information exchange, campaigns, and data processing and transmitting, for the purpose of improving the relationship with the patient through telephone and computing technology. For a preliminary assessment of the model, a monitoring center was elaborated for diabetic patients, as well as a system for diabetes monitoring. The modeling of the center was done using the UML extension for business modeling, which allowed analyzing the model's coverage. The monitoring system known, as TeleDM was developed to execute the simulations needed for this work's studies. The models for the system's development were elaborated from the business modeling. After evaluating its features, the choice was implementing it with agent and object-oriented technology, thus allowing checking this combination suitability for complex systems solution with the TeleDM system features.
\end{abstract}

Key Words: Health Attentions' Models, Patient Assistance, Chronic Disease, Life Quality, Diabetes Mellitus, Applied Computation, Multiagent Systems, Programs and Systems' Specification. 


\section{Lista de Ilustrações}

Figura 2.1 - Progressão das doenças em relação à porcentagem da população mundial dos países industrializados desenvolvidos e emergentes em 1990 e 2020. Fonte: Organização Mundial da Saúde (121)

Figura 2.2 - Esquema de monitoração de um paciente crônico adaptado do modelo de Cramp, Carson (28)... 25

Figura 3.1 - Proposta de integração das informações no modelo GRPC ....................................................... 40

Figura 3.2 - Componentes adaptados do CRM para o modelo GRPC .............................................................. 41

Figura 3.3 - Componente Colaborativo do GRPC e o seu relacionamento com o GRPC operacional e analítico

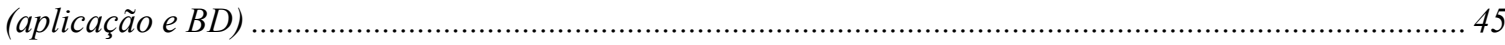

Figura 3.4 - Diagrama de atividade do controle da glicemia .........................................................................5 57

Figura 3.5 - Diagrama de caso de uso de negócio da central de monitoração de diabéticos ........................... 59

Figura 3.6 - Diagrama de atividade do controle da glicemia .................................................................... 61

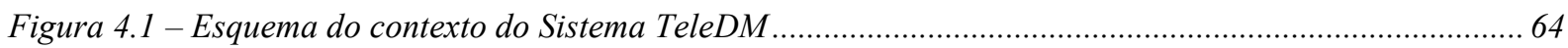

Figura 4.2 - Componentes do Modelo GRPC que foram desenvolvidos no sistema TeleDM.......................... 65

Figura 4.3 - Diagrama de Caso de Uso derivado do Modelo de Caso de Uso de Negócio.............................. 68

Figura 4.4 - Diagrama de Caso de Uso Final do subsistema monitoração de diabéticos ................................. 69

Figura 4.5 - Diagrama de Classe do Ambiente Físico ................................................................................. 83

Figura 4.6 - Os estados possíveis no ciclo de vida do ambiente CENINT .................................................. 85

Figura 4.7 - Estados possíveis no gerenciamento do contratante do ambiente CENINT ..................................86

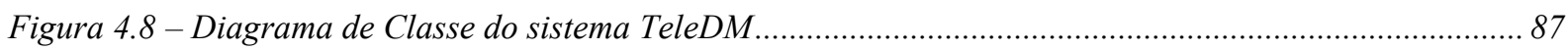

Quadro 5.1 - Relato das ações executadas pelo agente atendente ao apresentar o menu principal. ................. 95

Quadro 5.2 - Relato das ações executadas pelo agente atendente ao escolher o plano "identificar pela matrícula"

Quadro 5.3 - Relato das ações executadas pelo agente atendente após a resposta do usuário quanto a ter ou não o número de matrícula

Quadro 5.4 - Relato das ações executadas pelo agente atendente após o usuário fornecer a matrícula correta96

Quadro 5.5 - Relato das ações executadas pelo agente atendente após o usuário fornecer a matrícula que não pertence a ele

Quadro 5.6 - Relato das ações executadas pelo agente atendente após o usuário dizer que não sabe o número de matrícula.

Quadro 5.7 - Relato das ações executadas pelo agente atendente após o usuário fornecer a matrícula inexistente.

Quadro 5.8 - Relato das ações executadas pelo agente atendente ao atender um usuário que não está cadastrado no sistema.

Quadro 5.9 - Relato das ações executadas pelo agente enfermeiro para a contratação do agente diabetologista 
Quadro 5.10 - Relato das ações executadas pelo agente diabetologista na leitura do valor da glicemia no

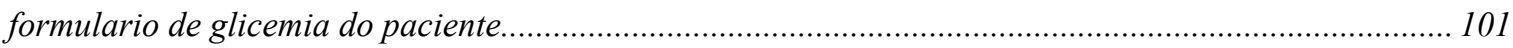

Quadro 5.11 - Relatório final emitido pelo sistema no caso clínico 1 .............................................................. 102

Quadro 5.12 - Relatório final emitido pelo sistema no caso clínico 2 ....................................................... 102

Quadro 5.13 - Relatório final emitido pelo sistema no caso clínico 3 ...................................................... 103

Quadro 5.14 - Relatório final emitido pelo sistema no caso clínico 4 ............................................................... 103

Quadro 5.15 - Relatório final emitido pelo sistema no caso clínico 5 ...................................................... 104

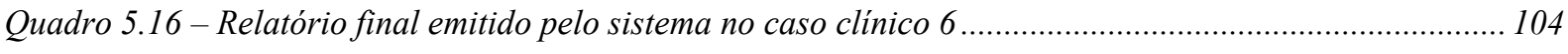

Quadro 5.17 - Relatório final emitido pelo sistema no caso clínico 7 .............................................................. 105

Quadro 5.18 - Relatório final emitido pelo sistema no caso clínico 8 ....................................................... 105

Quadro 5.19 - Relatório final emitido pelo sistema no caso clínico 9 ...................................................... 106

Quadro 5.20 - Relatório final emitido pelo sistema no caso clínico 10 ............................................................. 106

Quadro 5.21 - Relatório final emitido pelo sistema no caso clínico 11 ..................................................... 107

Quadro 5.22 - Relatório final emitido pelo sistema no caso clínico 12 ................................................ 107

Quadro 5.23 - Relatório final emitido pelo sistema no caso clínico 13 ......................................................... 108

Gráfico 5.1 - Gráfico da simulação do paciente sem controle com os valores de glicemia e diagnósticos no período de 30 dias.

Gráfico 5.2 - Gráfico da simulação do paciente com tendência hiperglicêmica com os valores de glicemia e diagnósticos no período de 30 dias.....

Gráfico 5.3 - Gráfico da simulação do paciente com tendência hipoglicêmica com os valores de glicemia e diagnósticos no período de 30 dias.

Gráfico 5.4 - Gráfico da simulação do paciente com tendência normoglicêmica 1 com os valores de glicemia e diagnósticos no período de 30 dias.

Gráfico 5.5 - Gráfico da simulação do paciente com tendência normoglicêmica 2 com os valores de glicemia e diagnósticos no período de 30 dias.

Gráfico 5.6 - Gráfico da simulação do paciente com tendência normoglicêmica 3 com os valores de glicemia e diagnósticos no período de 30 dias.....

Gráfico 5.7 - Gráfico da simulação do paciente sem controle, com os valores de glicemia e tipo de comunicação no período de 30 dias.

Gráfico 5.8 - Gráfico da simulação do paciente com tendência hiperglicêmica, com os valores de glicemia e tipo de comunicação no período de 30 dias.

Gráfico 5.9 - Gráfico da simulação do paciente com tendência hipoglicêmica, com os valores de glicemia e tipo de comunicação no período de 30 dias

Gráfico 5.10 - Gráfico da simulação do paciente com tendência normoglicêmica 1, com os valores de glicemia e tipo de comunicação no período de 30 dias....

Gráfico 5.11 - Gráfico da simulação do paciente com tendência normoglicêmica 2, com os valores de glicemia e tipo de comunicação no período de 30 dias

Gráfico 5.12 - Gráfico da simulação do paciente com tendência normoglicêmica 3, com os valores de glicemia e tipo de comunicação no período de 30 dias. 
Gráfico 5.13 - Gráfico da simulação do paciente sem controle, com os valores de glicemia e solicitação de consulta presencial pelo sistema no período de 30 dias

Gráfico 5.14 - Gráfico da simulação do paciente com tendência hiperglicêmica, com os valores de glicemia e solicitação de consulta presencial pelo sistema no período de 30 dias.....

Gráfico 5.15 - Gráfico da simulação do paciente com tendência hipoglicêmica, com os valores de glicemia e solicitação de consulta presencial pelo sistema no período de 30 dias.

Gráfico 5.16 - Gráfico da simulação do paciente com tendência normoglicêmica 1, com os valores de glicemia e solicitação de consulta presencial pelo sistema no período de 30 dias

Gráfico 5.17 - Gráfico da simulação do paciente com tendência normoglicêmica 2, com os valores de glicemia e solicitação de consulta presencial pelo sistema no período de 30 dias

Gráfico 5.18 - Gráfico da simulação do paciente com tendência normoglicêmica 3, com os valores de glicemia e solicitação de consulta presencial pelo sistema no período de 30 dias 


\section{Lista de Tabelas}

Tabela 2.1 - Índice mundial de adesão ao tratamento das principais doenças crônicas Fontes: OMS e The

Journal of American Medical Association - 2003 (13)....................................................................... 29

Tabela 3.1 - Tabela comparativa entre os conceitos do modelo atual e do GRPC.......................................... 38

Tabela 4.1 - Encontrando os possíveis casos de uso do sistema TeleDM...................................................67

Tabela 4.2 - Evolução dos conceitos para o desenvolvimento de software desde o seu início até os dias atuais

Fonte: ODELL, J. Objects and Agents: How do they differ? (87) ........................................................... 73

Tabela 4.3 - As entidades de negócio, sua descrição e respectivas classes ................................................. 82

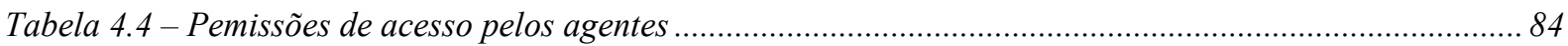

Tabela 5.1 - Tabela de decisão dos casos clínicos. A nomenclatura das ações aparecem de forma reduzida para

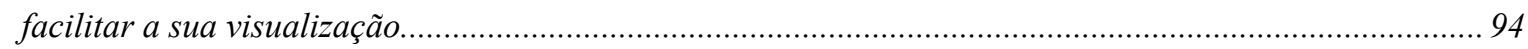

Tabela 5.2 - Tabela com a quantidade de diagnósticos por simulação .................................................... 112

Tabela 5.3 - Tabela com a quantidade de comunicação com o médico.......................................................... 116

Tabela 5.4 - Tabela com a quantidade de orientações por simulação............................................................ 120 


\section{Sumário}

1. INTRODUÇÃO .....................................................................................................16

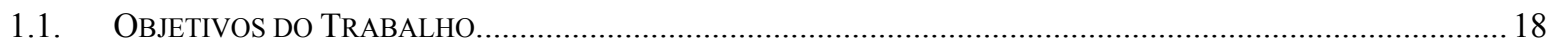

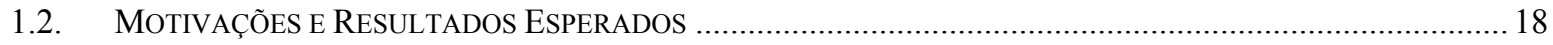

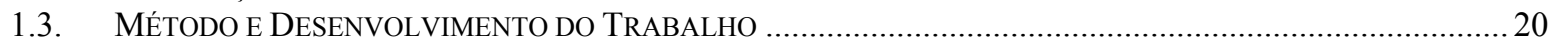

2. ACOMPANHAMENTO DE PACIENTES CRÔNICOS E CLIENTES .................22

2.1. ACOMPANHAMENTO E TRATAMENTO DE PACIENTE CRÔNICO .................................................................2 23

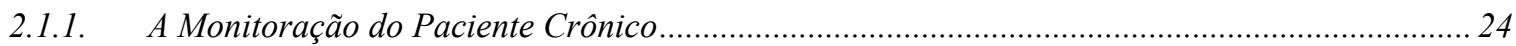

2.1.2. A Aderência do Paciente ao seu Tratamento ............................................................................ 27

2.1.3. Principais Sistemas Existentes de Monitoração ao Paciente Crônico...........................................2 29

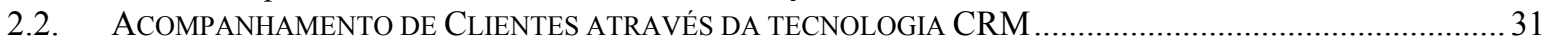

\section{MODELO DE GESTÃO DE RELACIONAMENTO DO PACIENTE CRÔNICO}

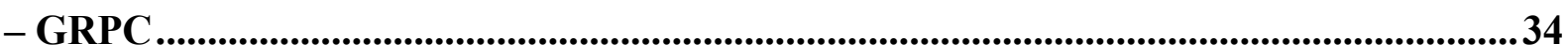

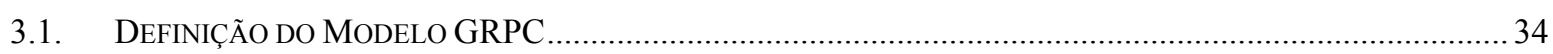

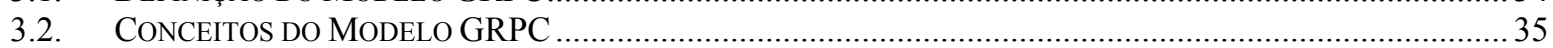

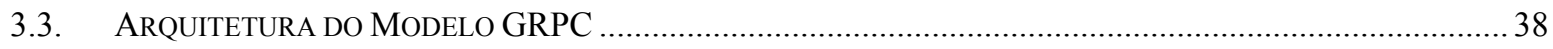

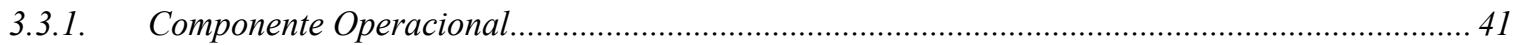

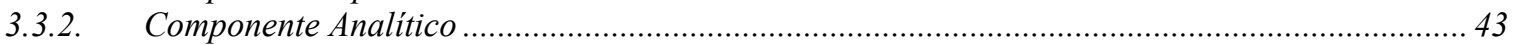

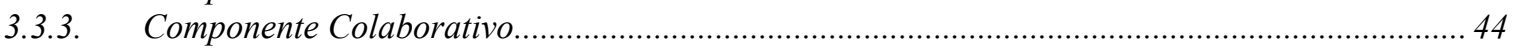

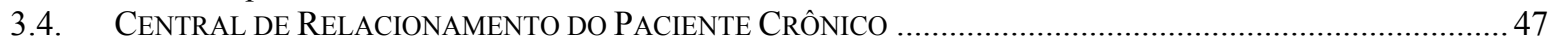

3.4.1. Serviços da Central de Relacionamento do Paciente Crônico........................................................ 48

3.5. Exemplo de uma Central de Relacionamento do Paciente Crônico: Central de

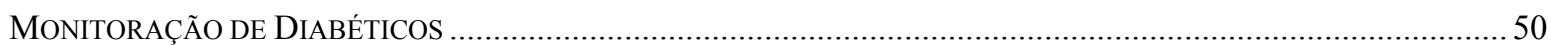

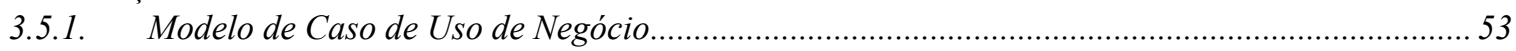

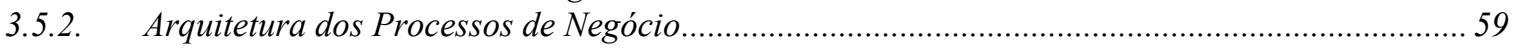

4. SISTEMA TELEDM - PROTÓTIPO DO SOFTWARE DE MONITORAÇÃO DE

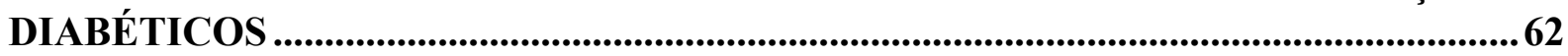

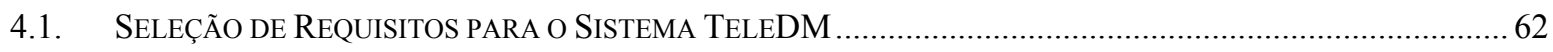

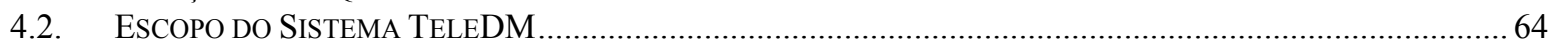

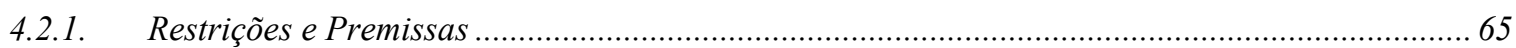

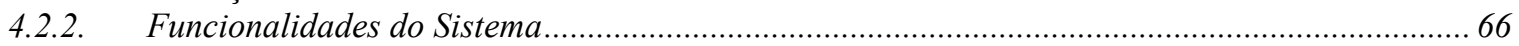

4.3. Seleção da TeCnologia Para o DeSEnVolvimento do Sistema TeleDM...................................... 72

4.3.1. O Ambiente Físico Representado pela Arquitetura Orientada a Objetos ...................................... 75

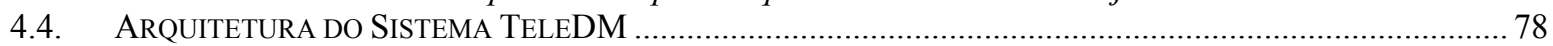

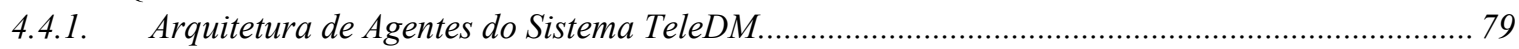

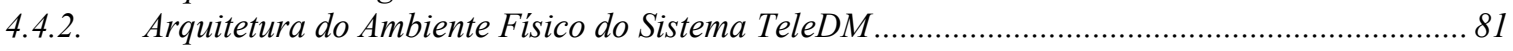

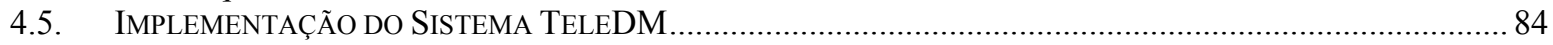

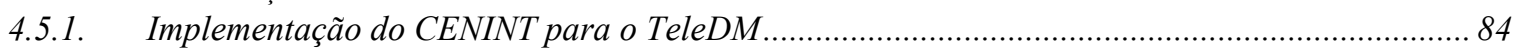

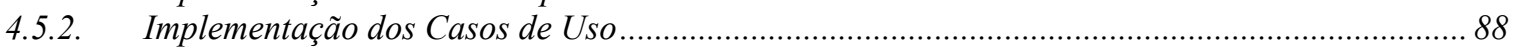

5. SIMULAÇÕES DE CASOS ESPECÍFICOS ..................................................91

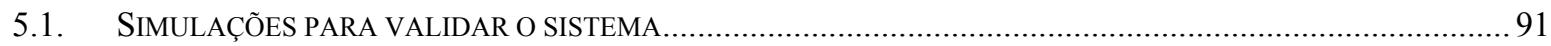

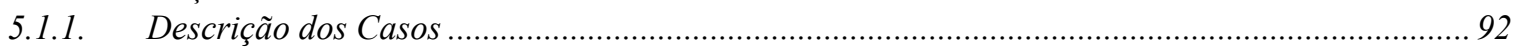

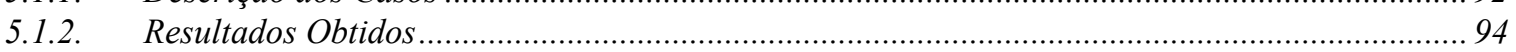

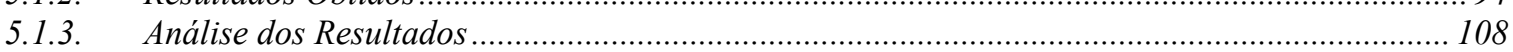

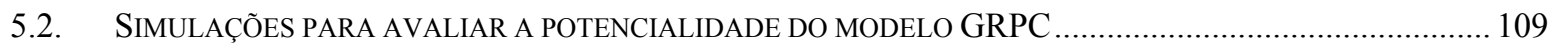

5.2.1. Adaptações do Sistema TeleDM para a Simulação (TeleDM_Sim) ……………………............ 110

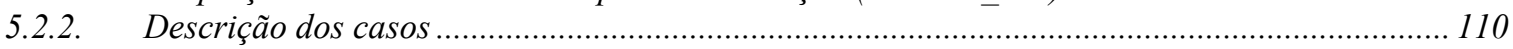

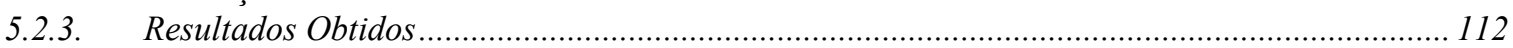


5.2.4. Análise dos Resultados.

6. CONCLUSÕES E CAMINHOS EM CONTINUIDADE .........................................125

REFERÊNCIAS......................................................................................................130

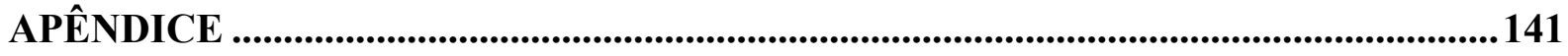




\section{Introdução}

A sociedade do final do século XX, por influência do paradigma tecnológico baseado na informação, desdobrou-se em uma nova estrutura social, marcada pela presença e o funcionamento de um sistema de redes interligadas. Mudanças foram introduzidas nos padrões de comportamento da sociedade em razão das transformações tecnológicas e econômicas, fazendo com que a relação entre os indivíduos e a própria sociedade, com o processo de inovação técnica, tenha sofrido alterações consideráveis. Essas mudanças ocorreram não apenas em novas práticas sociais, mas em alterações da sua própria vivência do espaço e do tempo como parâmetros da experiência social.(19) (40)

O Paradigma da Tecnologia da Informação, baseado num sistema de comunicação, está promovendo tanto a integração global da produção e distribuição de palavras, sons e imagens de culturas, como personalizando-os ao gosto das identidades dos indivíduos. Cada vez mais, as pessoas organizam seu significado em torno do que fazem, com base no que elas são ou acreditam ser. Assim, tem-se o delineamento de uma sociedade globalizada e centrada no uso e aplicação da informação e que não se encontra dividida segundo uma jurisdição territorial, mas sobretudo, segundo um padrão complexo de redes interligadas. (19) (40) (91)

A humanidade está passando por um período de intensas mudanças. Todos os tipos de inovações estão surgindo com rapidez acelerada: novos produtos, processos, insumos, mercados e organizações. Mudanças trazem consigo a necessidade de novos procedimentos e o afastamento daqueles até então dominantes. De acordo com Thomas Khun (67), a ciência avança pela vitória de novos paradigmas sobre verdades estabelecidas. É assim que, para existir a mudança, é necessário expandir os limites do conhecimento. Em outras palavras, para que o novo ocupe seus espaços é preciso dominar uma heurística diferente, um método distinto de resolver e controlar problemas. (19) (73)

Notadamente neste início de milênio, o aporte de múltiplas e variadas disciplinas faz-se necessário e se impõe como forma de compreender e modificar o mundo, pois permite a abertura de novas áreas do conhecimento e a realização de objetivos comuns, a partir de

pontos de vistas diferentes. É também desta forma que se observa a aplicação das novas tecnologias nas mais variadas áreas do conhecimento. (19) (37) 
As organizações de saúde, com o desenvolvimento das tecnologias da informação e da comunicação, estão interessadas em utilizar essas novas tecnologias para apoiar, expandir ou aumentar a qualidade dos cuidados e serviços aos pacientes. (21) (73) As principais aplicações incluem (20):

- telemedicina - serviço de saúde no qual o médico examina o paciente através do uso de uma tecnologia de telecomunicação;

- e-saúde - serviço baseado na tecnologia da informação e que incorpora algumas atividades relacionadas à saúde, como: educação ao paciente e seu cuidador, serviços administrativos e cuidados com o paciente;

- home telecare - serviço de atendimento ao paciente em sua própria casa, utilizando os recursos da tecnologia da informação.

Uma das influências das novas tecnologias na área de negócio pode ser constatada a partir do conceito de que ter e manter um bom relacionamento com o cliente, fornecendo o que ele necessita, na hora e no local que desejar, é uma forma de aumentar as vendas. Surge, então, o conceito de CRM (Customer Relationship Management), no qual o cliente pode contatar a empresa por meio de diversos canais de comunicação. O importante é manter uma conversa contínua sem que o cliente tenha que informar dados essenciais mais de uma vez. A definição é não fazer algo para o cliente, mas sim com o cliente, transformando o modelo tradicional de abordagem. A tecnologia da informação é que permite uma aplicação efetiva da abordagem CRM nas empresas. (90)

O conceito de CRM tornou-se possível devido a vários fatores; dentre eles, destaca-se a evolução do software, como relata Pressman:

"O software de computadores tornou-se uma força motora. É o motor que dirige a tomada de decisão nos negócios. Serve de base à moderna investigação científica e à solução de problemas de engenharia. É um fatorchave que diferencia os produtos e serviços modernos. Está embutido em sistemas de todas as naturezas: transportes, médicos, telecomunicações, militares, processos industriais, produtos de escritório... a lista é quase sem fim. O software é virtualmente inevitável no mundo moderno. E, à medida que entramos no vigésimo primeiro século, irá se tornar um motor para novos avanços em tudo, da educação elementar à engenharia genética." ( (91) p.3)

O impacto do software na sociedade e na cultura do século XXI é tão presente que, atualmente, praticamente todos os países dependem de complexos sistemas com base em computadores. A fim de suprir tais necessidades, a comunidade de software tenta, 
continuamente, desenvolver tecnologias que tornem mais fácil e rápida, e menos custosa, a construção de softwares de alta qualidade. (91) (109)

Entretanto, devido à sua complexidade essencial, desenvolver software de alta qualidade para aplicações complexas do mundo real não é fácil. Parte desta complexidade encontra-se no fato de que o software é constituído de muitas partes que, por sua vez, possuem inúmeras interações. A engenharia de software vem desenvolvendo modelos e técnicas que facilitam lidar com esta complexidade. (63)

Para lidar com sistemas complexos, no entanto, não bastam as técnicas. Por décadas, projetistas de software desenvolveram sistemas baseados exclusivamente em requisitos técnicos, sendo que a arquitetura ficava implícita no resultado final. De acordo com Bass, Clements e Kazman (5), a arquitetura de software de um programa ou sistema computacional é a estrutura ou estruturas do sistema, que abrange os componentes de software, as propriedades externamente visíveis desses componentes e as relações entre eles. Representar o software é importante, pois constitui um facilitador da comunicação entre todas as partes interessadas no seu desenvolvimento, destaca as decisões iniciais que terão impacto em um projeto e descreve, na forma de modelo, o software que será desenvolvido. (5) (23) (91)

\subsection{Objetivos do Trabalho}

O objetivo deste trabalho é apresentar um modelo de Gestão do Relacionamento com o Paciente Crônico (GRPC) utilizando os conceitos da tecnologia CRM para estimular a aderência dos pacientes crônicos ao seu tratamento. Para desenvolver o software que compõe a infra-estrutura da tecnologia de informação do modelo GRPC é apresentada uma arquitetura orientada a agentes em que o seu ambiente físico é implementado com a orientação a objetos.

\subsection{Motivações e Resultados Esperados}

Doenças crônicas como o diabetes mellitus e a hipertensão arterial vêm apresentando tendência de prevalência crescente desde a revolução industrial e, assim, figuram-se entre os principais problemas de saúde da humanidade. O acompanhamento e o monitoramento desses 
pacientes se fazem necessários para que eles possam ter uma sobrevida maior, pois minimizam ou retardam o desenvolvimento das complicações decorrentes da doença. Muitas vezes o tratamento exige mudança na rotina diária do paciente e de todos à sua volta para garantir o cuidado com a sua saúde e a melhora na qualidade de vida. Portanto, uma preocupação constante é encontrar estratégias de intervenção para o controle da doença que se adaptem melhor ao paciente, considerando sua integralidade e suas peculiaridades individuais e visando a uma melhor qualidade de vida, principalmente daqueles com problemas sócioeconômicos. (2) (97) (100)

Atualmente, os sistemas de saúde existentes variam muito na sua qualidade e efetividade no atendimento a todos os níveis populacionais. O modelo tradicional de acompanhamento do paciente crônico, através de consultas em clínicas, ambulatórios e postos de saúde, pode ainda ser melhorado para melhor atender à comunidade a qual se destina. Por outro lado, os serviços médicos utilizam cada vez mais procedimentos de alto custo e, com isso, encarecem os procedimentos diagnósticos e terapêuticos. No modelo tradicional não se pode responsabilizar somente o profissional da saúde por uma eventual indisponibilidade de tempo, dada a sua grande carga de atendimento a pacientes. Tais profissionais têm uma carga alta de trabalho, ficando com tempo limitado para oferecer um acompanhamento mais amplo e de maior qualidade para os seus pacientes. Uma conseqüência direta destes fatores é a baixa aderência ${ }^{1}$ dos pacientes, principalmente os crônicos, com relação ao acompanhamento e aos diversos aspectos do tratamento de sua doença. (44) (77)

Como o objetivo não é diminuir a qualidade dos serviços médicos para reduzir os custos, uma solução, então, é aumentar a eficiência. Isto nos leva a maximizar a demanda da utilização racional de recursos e de médicos e minimizar as despesas em clínicas e hospitais. Ao utilizar, de forma equilibrada, os recursos diagnósticos e terapêuticos, aumenta-se a eficiência, a qualidade e diminuem-se os custos no sistema de saúde. (77)

D. Human, secretário geral da Associação Médica Mundial, apresenta a necessidade de cuidados centrados no paciente como prioridade no desenvolvimento de uma força-tarefa para a promoção da saúde no século XXI (121). Essa idéia norteia o uso da tecnologia da

\footnotetext{
${ }^{1}$ De acordo com (120), aderência é definida como uma extensão do tratamento na qual o paciente segue as recomendações médicas.
} 
informação para o desenvolvimento de mecanismos a fim de que o paciente crônico seja um participante ativo em todos os aspectos do sistema de saúde do qual faz parte.

Afinal, a Organização Mundial da Saúde (OMS) afirma que a tecnologia da informação e a comunicação têm papéis-chave no aumento da qualidade do sistema de saúde. Sistemas de informação adaptados às necessidades dos cuidados centrados no paciente são essenciais para a organização, monitoração e resultados de tratamentos dos pacientes.(121)

O resultado esperado nesse trabalho é demonstrar que é possível, utilizando a tecnologia CRM, propor um modelo que, quando implantado, aumente a aderência dos pacientes crônicos ao seu tratamento, ao otimizar o acompanhamento deles pelos seus respectivos médicos. O modelo é elaborado para fornecer ao profissional maior visibilidade de seus pacientes, o que lhe permitirá instituir uma terapêutica personalizada.

Uma finalidade decorrente do modelo é produzir uma ferramenta que auxilie o médico na monitoração de seus pacientes. Essa ferramenta é um dos softwares que compõem a infraestrutura de tecnologia da informação do modelo proposto. Este software permite aumentar a eficiência do atendimento, pois o paciente tem acesso ao sistema 24 horas por dia, sentindo-se assim assistido e, em casos de anormalidade, o médico é avisado automaticamente. Nessa situação, o paciente recebe orientações para cada caso em tempo real, e é agendado para uma consulta somente quando necessário, o que otimiza a quantidade de consultas presenciais a que é submetido.

\subsection{Método e Desenvolvimento do Trabalho}

Inicialmente, foram definidos a abrangência e o escopo do trabalho ao estudar o problema a ser solucionado, bem como revistos os conceitos da tecnologia CRM que pudessem ser adaptados para auxiliar no acompanhamento de pacientes crônicos. Em seguida, elaborou-se o modelo, adaptando-se a tecnologia CRM para um modelo de gestão do paciente crônico. Um exemplo foi elaborado ao desenvolver uma central de relacionamento para pacientes diabéticos a partir do modelo proposto.

Foi desenvolvido um protótipo do software de monitoração primária que compõe a infraestrutura tecnológica do modelo. Para o desenvolvimento do software, foram selecionadas funcionalidades mínimas para realizar a monitoração de diabéticos. 
Desenvolver o protótipo do software de monitoração de diabéticos compreende implementar um sistema semi-inteligente, que toma decisões simples de orientação imediata ao paciente. Atualmente, a Inteligência Artificial tem utilizado a tecnologia de orientação a agentes para a implementação de sistemas desse tipo (95). Por isso, optou-se por utilizar a tecnologia orientada a agentes para o desenvolvimento do software, cujo processo foi baseado no modelo iterativo. O desenvolvimento da arquitetura do software compreende um método adaptado das disciplinas do Processo Unificado (UP) (62), de tal forma que a elaboração da arquitetura comporte a tecnologia de orientação a agentes.

Foram realizadas simulações com o software desenvolvido, com o objetivo de analisar os resultados fornecidos pelo sistema quanto a:

- $\quad$ orientações fornecidas pelo sistema em relação ao esperado pelo especialista;

- potencialidade do modelo quanto à otimização das consultas presenciais e o acompanhamento do paciente por parte do seu médico.

Essas simulações permitiram uma avaliação preliminar do comportamento do modelo em situações de variações nos valores glicêmicos e do estado clínico do paciente no momento da medida. 


\section{Acompanhamento de Pacientes Crônicos e Clientes}

A evolução da tecnologia tornou possíveis práticas antes impensáveis ou difíceis de executar; por exemplo, o rastreamento de uma carga por qualquer parte do planeta. Essas possibilidades trouxeram grandes mudanças para a humanidade, permitindo transformações na sociedade e no ambiente que a cerca. (19) (73) (113)

Grande parte dessas mudanças fez com que a informação seja considerada hoje o ativo mais importante de uma empresa, pois é ela que auxilia a alta gestão a atingir as metas corporativas. A informação é fundamental no apoio às estratégias e processos de tomada de decisão, bem como no controle das operações empresariais. É, ainda, um instrumento de gestão e estratégia para a obtenção de vantagens competitivas. Assim, os sistemas de informação foram desenvolvidos para auxiliar na obtenção mais rápida de informações precisas e confiáveis. A tecnologia resultante é denominada de tecnologia da informação. (10)

A tecnologia da informação constitui-se de métodos e ferramentas pelos quais a comunicação e as tecnologias computacionais adquirem e processam os dados em informações para disseminá-las, aumentando a efetividade de organizações modernas. (17) (115)

Atualmente a tecnologia da informação é utilizada em larga escala nas organizações, por exemplo, para o acompanhamento de clientes pelas empresas, utilizando a tecnologia CRM (Customer Relationship Management). (101)

A tecnologia da informação está presente inclusive nas organizações de saúde, pois elas necessitam de informações precisas e de qualidade no acompanhamento de pacientes, principalmente naqueles com doenças crônicas. É assim que nos últimos 15 anos os sistemas de saúde, tanto públicos quanto privados, vêm fazendo grande uso da tecnologia de informação. (46)

Para entender melhor as necessidades e a importância do acompanhamento de pacientes crônicos, o processo de monitoração desses pacientes assim como os aspectos referentes à baixa adesão do paciente ao seu tratamento são apresentados na seção 2.1. Nesta mesma seção 
também são descritos alguns sistemas computacionais desenvolvidos para auxiliar na monitoração de pacientes crônicos.

Da mesma forma que existe o acompanhamento de pacientes crônicos, as empresas vêem a necessidade de fazer um acompanhamento de seus clientes. O CRM é uma tecnologia que possibilita esse acompanhamento. Os principais aspectos do CRM são abordados na seção 2.2 para que se obtenha uma noção de como seus conceitos podem ser utilizados em outras áreas de conhecimento.

\subsection{Acompanhamento e Tratamento de Paciente Crônico}

As mudanças na área da saúde, nos últimos anos, permitiram o aumento na expectativa de vida, a diminuição da mortalidade infantil e o sucesso nos esforços da saúde pública no combate às doenças infecciosas. Com essas doenças, ditas agudas, sob controle, começa-se a notar o aumento na prevalência de doenças crônicas, como o diabetes mellitus e a hipertensão arterial. (121)

Notando esse aumento, a OMS fez uma projeção do panorama das doenças para o ano de 2020. Pela Figura 2.1 constata-se que em 2020 as doenças crônicas, incluindo acidentes que resultam em algum tipo de deficiência permanente e doenças mentais, serão responsáveis por $78 \%$ das doenças globais.(121)

É por isso que existe uma preocupação mundial em criar formas de conviver com as doenças crônicas nos próximos anos. Assim, de acordo com a OMS (121), é preciso alterar os modelos que priorizam o combate às doenças agudas para aqueles que atendam as necessidades com relação às doenças crônicas. (53) (121) 
Projeção da Progressão Mundial das Doenças

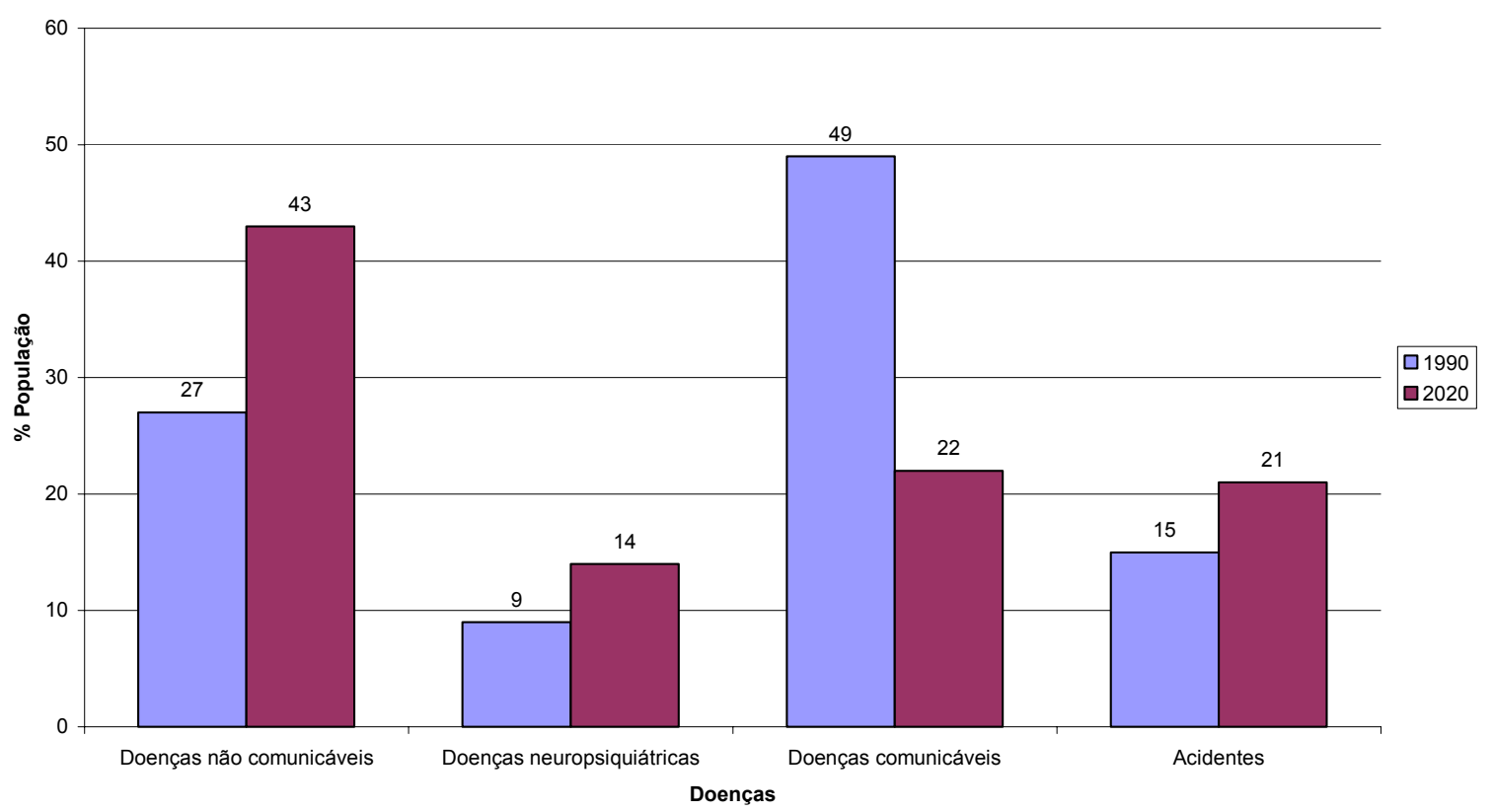

Figura 2.1 - Progressão das doenças em relação à porcentagem da população mundial dos países industrializados desenvolvidos e emergentes em 1990 e 2020. Fonte: Organização Mundial da Saúde (121)

Nesse novo modelo, não basta pensar somente no tratamento, pois a cura nem sempre existe; é preciso saber conviver com a doença e o doente. Critérios como aumentar a qualidade de vida destes pacientes, assim como fazer sua monitoração, são tão importantes quanto o diagnóstico e o tratamento. É por isso que vem surgindo uma proposta cujo foco está no cuidado centrado no paciente e na identificação das competências necessárias para conseguilo. (34) (53) (122)

Nos próximos itens são abordadas a importância e as características da monitoração e aderência ao tratamento destes pacientes. A finalidade é controlar e impedir, ou retardar a evolução para as complicações das doenças crônicas, tendo sempre em mente a qualidade de vida do paciente, assim como o seu contexto psicossocial.

\subsubsection{A Monitoração do Paciente Crônico}

Diferentemente das doenças agudas, as crônicas demandam uma atenção contínua, com avaliações periódicas de saúde. Enquanto os sinais e sintomas das doenças agudas desaparecem num curto espaço de tempo, não precisando de um acompanhamento 
prolongado, os sinais e sintomas das crônicas perduram por anos. Portanto, pacientes crônicos necessitam de cuidados médicos, com ênfase na prevenção. Monitorar adequadamente esses pacientes pode prevenir o agravamento da doença e evitar ou retardar a ocorrência de complicações. (15) (18) (69) (121)

Monitorar pacientes crônicos não é algo simples, já que cada doença possui suas características e, portanto, uma forma de intervenção. Além disso, muitos destes tratamentos se modificam ao longo do tempo, não somente com relação ao medicamento, mas também a seus atributos, como dosagem, freqüência e efeitos. De qualquer forma, em todos os casos é importante, ao longo do tempo, conhecer o estado do controle da doença (controlado, não controlado e crítico), assim como a sua tendência (piora, melhora). (18) (64)

Para que se possa acompanhar e controlar a doença crônica é necessário um entendimento adequado do processo de monitoração de pacientes crônicos. Cramp, Carson (28), com essa finalidade, propuseram um modelo baseado em retroalimentação (feedback). Esse modelo é composto por quatro elementos que se relacionam entre si para monitorar adequadamente o paciente e que correspondem ao decisor, ao efetor, ao sistema controlado e ao sistema de informação. Uma adaptação ao modelo é sugerida neste trabalho, e esquematizada na Figura 2.2: o médico (decisor), a partir de um padrão desejado, determina o tipo de tratamento que atua (efetor) no estado do paciente (sistema controlado), que gera uma nova informação que, por sua vez, alimenta o sistema de informação. Esse último produz novas informações e faz com que o médico tome novas decisões. O sistema todo pode ainda sofrer intervenções por distúrbios externos que alteram o estado do paciente que alimenta o sistema de informação.

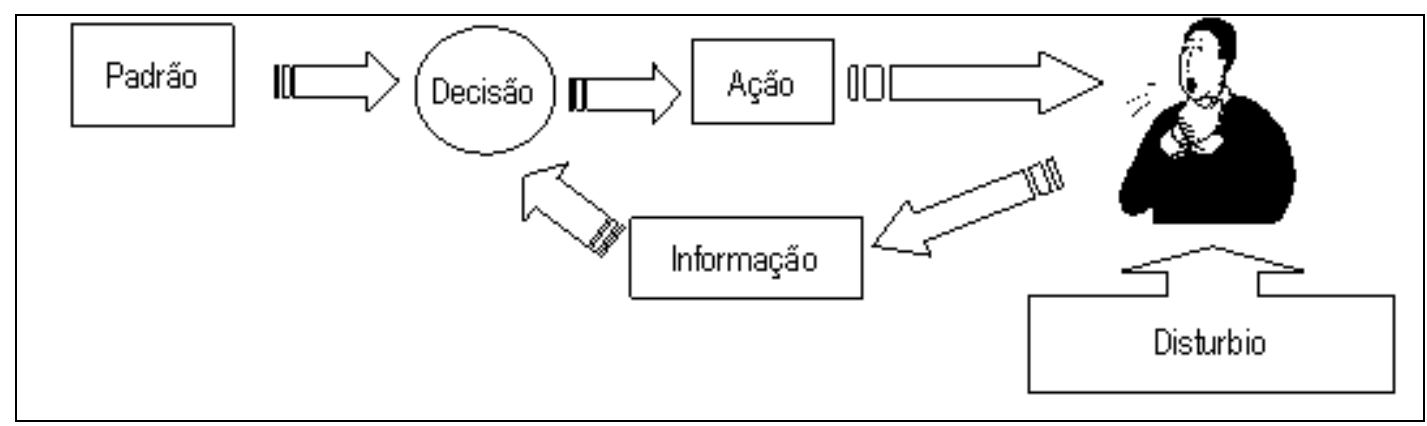

Figura 2.2 - Esquema de monitoração de um paciente crônico adaptado do modelo de Cramp, Carson (28)

Uma adequada monitoração de pacientes crônicos é efetiva quando aloca e utiliza os recursos de hospitais e de setores primários da saúde de uma maneira sinérgica e de modo a satisfazer as necessidades do doente. A integração de vários profissionais de saúde na monitoração de 
pacientes crônicos decorre, em parte, do reconhecimento de que é necessária uma alta qualidade nos cuidados a saúde desse paciente, cuidados que excedem o tempo disponível, as habilidades e os conhecimentos de qualquer profissional de saúde. É por isso que programas de controle de doenças crônicas envolvem médicos, enfermeiros, nutricionistas, psicólogos, farmacêuticos, assistentes sociais, educadores, entre outros. (7) (18) (121)

Constata-se, então, que a monitoração de pacientes crônicos envolve uma grande quantidade de dados clínicos que precisam ser disponibilizados para um variado número de profissionais, por um longo período de tempo. A existência dessas informações à disposição do profissional da saúde proporciona um melhor acompanhamento da evolução dos pacientes e avaliação contínua do atendimento. (4) (58)

Conrad (27) propõe a integração médica com o objetivo de coordenar os serviços de cuidados ao paciente, independentemente de pessoas, funções, atividades, locais e tempo. Envolve a coordenação de entradas (equipamentos, suprimentos, recursos humanos, informação e tecnologia) e saídas intermediárias (prevenção, diagnóstico e serviços de reabilitação) para aumentar a qualidade, reduzir custos e aumentar o valor dos serviços de cuidados ao paciente.

Os programas de cuidados aos pacientes crônicos ilustram a necessidade da integração médica, que é complexa e profunda. Os mecanismos que permitem esta integração médica com os programas de saúde são: equipes multidisciplinares, gerenciamento de casos clínicos, educação do paciente, programas de prevenção e integração dos cuidados primários e especialistas de saúde. (7)

A OMS, por sua vez, recomenda mudanças nas competências para o cuidado de pacientes crônicos (121). Essas mudanças não invalidam as competências atuais; na verdade, apresentam novas competências necessárias que complementam as já existentes. São elas:

- Organizar o cuidado ao redor do paciente. Esse conceito é designado atualmente como o atendimento centrado no paciente;

- Ser comunicativo e saber trabalhar em equipe; conseguir se comunicar e trabalhar em parceira tanto com os pacientes quanto com os outros membros da equipe;

- Ser pró-ativo no sentido de sempre primar pela qualidade e segurança do atendimento; 
- Assistir e monitorar os pacientes ao longo do tempo, utilizando e compartilhando informações através da tecnologia disponível;

- Considerar o atendimento ao paciente relacionado com o sistema de saúde pública.

Nota-se que o conceito de integração médica encontra-se de acordo com o recomendado pela OMS, principalmente com relação ao uso do conceito do atendimento centrado no paciente. Verifica-se então, neste milênio, a necessidade da criação de centros ou serviços que implementem a integração médica e que tenham as competências designadas pela OMS. Porém, de nada adianta a monitoração, se esses pacientes não tiverem consciência da necessidade do tratamento contínuo de sua doença. Portanto, outro fator importante é promover a aderência dos pacientes ao seu tratamento.

\subsubsection{A Aderência do Paciente ao seu Tratamento}

A não aderência ao tratamento pelo paciente agudo é um fator preocupante, pois é responsável, por exemplo, pelo aumento na incidência de infecções, bem como pelo progressivo aumento na proporção de casos de resistência a medicamentos, em especial antibióticos ou quimioterápicos de primeira linha. (2) (120)

No caso da doença crônica, é importante conscientizar o paciente da necessidade de adesão ao tratamento; caso contrário, poderá haver a longo ou a curto prazos, o agravamento da doença e o surgimento precoce de complicações (69) (120). É como afirma o diretor executivo da Sociedade Brasileira de Cardiologia, Raimundo Marques Nascimento Neto (43): "A comunidade médica e a população têm que ser conscientizadas sobre a importância não apenas de iniciar o tratamento, mas de atingir a meta proposta. Caso contrário, o benefício é mínimo."

O conceito de adesão ao tratamento médico tem várias interpretações. Nos países desenvolvidos, por exemplo, a grande preocupação, extensivamente estudada, é a aderência ao uso do medicamento. Em países com uma população com baixo poder aquisitivo e baixa escolaridade, onde muitas vezes o paciente tem dificuldade em adquirir o medicamento, a preocupação está em assegurar que os pacientes não abandonem o serviço e que tenham hábitos saudáveis na medida do possível. A não aderência ao tratamento está relacionada a 
diversos fatores, tais como: não usar os medicamentos, não comparecer às consultas, não seguir a dieta recomendada, não mudar o estilo de vida, não seguir outras recomendações do tratamento ou não seguir práticas de saúde preventiva. Resumidamente, pode-se dizer que a aderência é o grau de coincidência entre o comportamento do paciente com o que lhe foi prescrito pelo médico ou outro profissional da equipe de saúde. (2) (3) (69) (120)

Estudos comprovam que o problema da baixa adesão ao tratamento médico é tão grave que, somente nos Estados Unidos, a não aderência ao uso de medicamentos é a causa de aproximadamente 125.000 mortes anuais, além de ser responsável por $10 \%$ a $25 \%$ das internações em hospitais. Com relação aos custos, os dados se tornam alarmantes, pois os gastos associados à não aderência ao tratamento podem ser de mais de US\$ 300 bilhões ao ano. (3) (31)

Além de suas características individuais e psicossociais, as exigências no monitoramento do paciente crônico, influenciam o ajustamento psicológico dos pacientes e também de seus familiares aos serviços de saúde, instituições educacionais ou de trabalho, e também aos cuidados diários do paciente. Nesse contexto, a rotina diária do paciente e de seus familiares sofre alterações para cumprir as exigências do tratamento como, por exemplo, deslocar-se até o consultório ou o laboratório para a monitoração do seu estado de saúde. Atender a todas essas exigências não é uma tarefa fácil para alguns pacientes e suas famílias. Estudos mostram a correlação entre o impacto das recomendações do tratamento na rotina de vida da família, o ajustamento psicológico do paciente e de seu cuidador e a adesão ao tratamento de doenças crônicas. (2) (69) (107)

As exigências que cada diagnóstico estabelece relativamente aos procedimentos a serem adotados faz com que o conceito e as medidas de adesão sejam relacionados às recomendações diversas quanto ao uso de medicamentos, ao comparecimento a consultas agendadas e ao controle do estado físico (ex.: o controle glicêmico do diabético). Observando estes indicadores, tem-se que, mundialmente, a taxa média de adesão ao tratamento é baixa entre os portadores de doenças crônicas, como demonstra a Tabela 2.1. (2) (13) 
Tabela 2.1 - Índice mundial de adesão ao tratamento das principais doenças crônicas Fontes: OMS e The Journal of American Medical Association - 2003 (13)

\begin{tabular}{lc}
\hline \multicolumn{1}{c}{ Doença } & Taxa de Adesão \\
\hline Diabetes tipo 2 & $15 \%$ \\
Dislipidemias & $25 \%$ \\
Asma & $28 \%$ \\
Depressão & $40 \%$ \\
Hipertensão & $43 \%$ \\
\hline
\end{tabular}

A indústria farmacêutica tenta reverter o quadro investindo na criação de alternativas que facilitem a vida do paciente e reduzam o custo do tratamento. Uma das estratégias é desenvolver substâncias de efeito prolongado; outra alternativa é elaborar medicamentos que possam ter dois ou mais princípios ativos, a fim de diminuir a quantidade de comprimidos ou cápsulas a ser consumida diariamente pelo paciente. Modificar o modo de administração do medicamento é outro campo a ser explorado, por exemplo usar a insulina inalada em vez da injetável. (13) (81) (83)

Estudos demonstram, porém, que as características relacionadas com os medicamentos são apenas um dos fatores para a baixa adesão do paciente ao tratamento. O paciente é influenciado por outros fatores, tais como as barreiras econômicas, clínicas e culturais, ou ainda o apoio social e a efetiva comunicação entre o paciente e seu médico - fatores cruciais do relacionamento médico paciente. Portanto, é necessário um planejamento criterioso de estratégias de intervenção que promovam a adesão do paciente e de sua família, principalmente nas situações que exigem cuidados diversos e contínuos. (32) (112) (120)

A tecnologia da informação vem sendo utilizada para auxiliar na monitoração desses pacientes. A seguir é feito um breve relato das tecnologias disponíveis no mercado, com a finalidade de ajudar na monitoração de doenças crônicas pelos pacientes.

\subsubsection{Principais Sistemas Existentes de Monitoração ao Paciente Crônico}

Hoje, a monitoração baseada por computador é mais do que colher os parâmetros dos pacientes. Esse tipo de sistema apresenta funções de armazenamento de dados em banco de dados, geração de relatórios e capacidade de análise e de apoio à decisão. Assim, tem-se sistemas de monitoração de doenças crônicas, além dos sistemas de monitorização de sinais 
vitais, como os encontrados nas unidades de terapia intensiva (UTIs). Nas doenças crônicas, os dados clínicos monitorados são aqueles que auxiliam no adequado controle e na escolha da terapêutica a ser instituída. Nesse caso, deseja-se que a monitoração possa ser feita sem a necessidade de internação do paciente, o que é denominado de home healthcare medical device. (18) (44) (50) (103)

Atualmente, dentre os sistemas de monitoração de doenças crônicas, muitos são voltados para a monitoração de diabetes mellitus e de asma. Alguns apontam pesquisas para serviços relacionados com o câncer e a doença de Alzheimer; porém, nenhum deles permite monitoração em casa. A qualidade e a efetividade desses produtos (sistemas) é avaliada pelo FDA (Food and Drug Administration). (50)

A seguir descreve-se o panorama desses sistemas de monitoração para diabéticos, pois são utilizados para a construção de um exemplo do modelo que é proposto no capítulo 3.

\subsubsection{Diabetes Mellitus (DM)}

O DM é uma doença crônica que afeta a produção e/ou a ação da insulina pelo pâncreas. A insulina é responsável pela absorção da glicose pelo organismo. A falta de insulina faz com que os níveis de glicose sangüínea aumentem, o que pode levar uma pessoa ao coma. O não tratamento do DM causa cegueira, problemas cardíacos, hipertensão, disfunções renais, amputações e até a morte.(126)

O National Diabetes Information Clearinghouse (NDIC) tem como objetivo disseminar as informações do National Institute of Diabetes and Digestive and Kidney Disease (NIDDK). O NIDDK é parte do National Institute of Health (NIH), uma das oito agências do Serviço de Saúde Pública dos Estados Unidos. No período de 1983 a 1993, o NIDDK realizou um estudo denominado DCCT (Diabetes Control and Complications Trial), demonstrando que a monitoração contínua dos níveis de glicemia e de insulina pode prevenir as complicações do diabetes mellitus. Recomenda-se, para tanto, o acompanhamento dos níveis da hemoglobina glicosilada (HbAc), de glicose no sangue e na urina, e testes relacionados com a função renal. (50) (84) 
Os principais sistemas de monitoração para diabéticos são: glicosímetros portáteis e testes de HbAc. Os testes de urina não utilizam sistemas de monitoração através de software; assim, não serão aqui considerados. Os glicosímetros portáteis permitem uma auto-monitoração da glicemia. Existem hoje no mercado pelo menos 25 marcas diferentes de glicosímetro, com as mais variadas funções embutidas no aparelho. Há como fazer o teste de HbAc em casa; porém, esse procedimento não é indicado, pois o custo é elevado e não existem regras que permitam uma auto-monitoração, ou seja, o resultado não ajudaria no controle do diabetes mellitus pelo próprio paciente. (38)

Existem também aplicativos que captam os resultados dos glicosímetros portáteis e oferecem gráficos e relatórios das medidas feitas. Estes aplicativos podem ser encontrados em computadores pessoais, em sites da Internet, em celulares e em PDA (Personal Digital Assistant). (50) (70)

Após esse panorama a respeito das doenças crônicas, segue um breve relato da tecnologia CRM. Essa tecnologia ajuda as empresas no acompanhamento e na gestão do relacionamento de seus clientes. O objetivo aqui não é esgotar o assunto, e sim apresentar os aspectos que justificam a sua utilização na elaboração do modelo proposto no capítulo 3. Os detalhes da arquitetura e implementação dos conceitos do CRM são descritos no capítulo 3, onde serão correlacionados com o modelo proposto.

\subsection{Acompanhamento de Clientes através da tecnologia CRM}

Até 1990 não existia uma preocupação por parte das empresas em construir relações duradouras com os clientes, pois o objetivo principal era atrair novos clientes através dos produtos (22). As mudanças começaram a acontecer depois que Shapiro \& Sviokla (102) mencionaram que o custo em adquirir um novo cliente é aproximadamente cinco vezes maior do que a sua manutenção. Um estudo mais amplo feito por Reichheld (93) demonstrou que os clientes fiéis são mais rentáveis que os novos clientes. Além disso, a facilidade que hoje existe para adquirir e trocar produtos e serviços é tão grande que o desafio das empresas não é somente deixar o cliente satisfeito - até porque isso o concorrente também faz - e sim conquistar clientes fiéis. O atendimento centrado no cliente é denominado marketing de relacionamento. 
O marketing de relacionamento é utilizar um conjunto de técnicas e processos de marketing, vendas, comunicação com a finalidade de (110):

- Identificar os clientes de forma individualizada e nominal,

- Criar um relacionamento, entre eles e a empresa, que durem por várias transações,

- Administrar o relacionamento em benefício dos clientes e da empresa.

Para implementar o marketing de relacionamento existe a técnica de "marketing 1:1" que propõe uma abordagem individualizada com o cliente. Para que esse relacionamento individual possa existir, a utilização da tecnologia da informação é fundamental, pois é preciso trabalhar com grandes volumes de informações sobre o cliente, interagir com agilidade e produzir um atendimento personalizado, conforme as características e preferências de cada indivíduo. (90) (22)

A tecnologia CRM permite implementar o marketing 1:1 de relacionamento com os clientes, ao auxiliar as empresas no gerenciamento e no acompanhamento de forma integrada das interações do cliente com a empresa (90). Segundo o Gartner Group, a definição de CRM é:

“...uma estratégia de negócio voltada ao atendimento e à antecipação das
necessidades dos clientes atuais e potenciais de uma empresa. Do ponto de
vista tecnológico, CRM envolve capturar os dados do cliente ao longo de
toda a empresa, consolidar todos os dados capturados interna e externamente
em um banco de dados central, analisar os dados consolidados, distribuir os
resultados dessa análise aos vários pontos de contato com o cliente e usar
essa informação ao interagir com o cliente através de qualquer ponto de
contato com a empresa." ((90) p. 59) Pela definição, verifica-se que a empresa não apenas deve estar preparada para atender o cliente no primeiro toque do telefone, como também para responder o e-mail ou o fax assim que eles cheguem e incorporar todos os dados de contato no banco de dados, aqui denominado database marketing. Esse preparo é necessário para gerar uma comunicação contínua e possível por qualquer canal de comunicação (telefone, mala direta, e-mail ou contato pessoal). A captura centralizada desses dados permite conhecer o perfil do cliente, detectar ameaças e oportunidades sinalizadas através de reclamações, de pedidos de esclarecimentos e de informações sobre a concorrência dados pelo cliente. (76) (90)

A tecnologia CRM é, portanto, mais do que software, é uma forma sofisticada e eficiente de transformar a maneira como empresas podem aumentar a rentabilidade dos clientes atuais. $\mathrm{O}$ 
uso da Internet como canal de relacionamento e de vendas facilita e viabiliza o acompanhamento do cliente pela empresa, permitindo uma proximidade maior entre eles e aumentando com isso o número de clientes fiéis aos produtos e serviços da empresa. (22) (76) (90)

É nesse contexto que se criam as centrais de relacionamento de clientes, pois é necessário um local que gerencie todo e qualquer contato do cliente com a empresa, seja através da internet, fax ou telefone, respondendo em tempo real a qualquer solicitação ou pedido de compras. As centrais de relacionamento evoluem naturalmente das centrais de atendimento existentes nas empresas, criadas para oferecer uma oportunidade ao cliente de se comunicar com a organização para solicitar informações ou reclamar sobre algum problema. Como o cliente já está acostumado a utilizar esse canal, ele é, muitas vezes, utilizado para se tornar a central de relacionamento da empresa. (76) (89)

Dessa forma, um dos fatores mais importantes para o sucesso da implantação das centrais de relacionamento são os recursos humanos, que precisam ser treinados e capacitados em todos os níveis, não só para melhorar a qualidade no atendimento, mas também para usar adequadamente as informações que transformam possibilidades de negócio em lucro. (90)

Enfim, essa integração pressupõe que a empresa esteja disposta a manter um relacionamento baseado em processos operacionais mais ágeis e a selecionar a tecnologia adequada, o que requer metodologia, expertise e experiência comprovada nesse tipo de solução. É uma grande mudança no conceito de atendimento ao cliente, que extrapola a prática existente em qualidade e possibilita melhorar o acompanhamento desse cliente pela empresa conseqüentemente aumentando sua fidelidade. (22) (76) (90)

Após esse panorama do acompanhamento do paciente crônico e do uso dos sistemas de informação para o acompanhamento de clientes através da tecnologia CRM, no próximo capítulo será apresentado um modelo que utiliza os conceitos da tecnologia CRM para realizar o acompanhamento de pacientes crônicos. 


\section{Modelo de Gestão de Relacionamento do Paciente Crônico - GRPC}

Ao estudar o contexto do paciente crônico, sua doença e formas de acompanhamento, conclui-se que é necessário um modelo de tratamento e acompanhamento que permita o controle adequado da doença, baseado nas melhores práticas e no contexto psicossocial do paciente. Ao mesmo tempo, é preciso manter sua qualidade de vida, de tal modo que ele se sinta assistido do ponto de vista médico e amparado como indivíduo.

O modelo GRPC (Gestão de Relacionamento do Paciente Crônico) pretende alcançar os objetivos mencionados. Ao incentivar a gestão do relacionamento do paciente com o seu médico através do acompanhamento personalizado de cada paciente, procura atender suas reais necessidades individuais, em tempo real, fornece uma orientação clínica adequada e estimula a aderência ao tratamento recomendado. A tecnologia CRM (Customer Relantionship Management), por sua vez, ao trabalhar a gestão do relacionamento de clientes, demonstra-se em princípio adequada para ser adaptada ao modelo GRPC.

Tem-se, então, que o presente trabalho se desenvolve num campo multidisciplinar. Assim, do ponto de vista médico, a metodologia científica é baseada em estudos estatísticos, o que faz com que as assertivas absolutas sejam evitadas, inclusive pela complexidade do objeto de estudo. Por outro lado, na engenharia de sistemas digitais e computação, o estudo é baseado em modelos que simplificam o objeto de estudo. E ao utilizar planos lógicos formais nesses modelos para avaliação e análise, chega-se a uma conclusão mais precisa sobre a questão.

A partir dessa premissa, apresenta-se a seguir a definição, os conceitos e a arquitetura do modelo GRPC. A justificativa do uso da tecnologia CRM para a elaboração do modelo GRPC é também detalhada.

\subsection{Definição do Modelo GRPC}

O modelo de atendimento tradicional a pacientes tem seu foco na doença. Nesse caso, a estratégia é monitorar a evolução da mesma, controlando-a a partir de seus sinais, sintomas e 
do desenvolvimento de suas complicações. Hoje, porém, uma abordagem no atendimento centrado no paciente vem ganhando destaque e sendo recomendada pela OMS (121). Nessa abordagem considera-se, além do aspecto biológico da doença, a experiência do paciente, seu contexto psicossocial e a tomada de decisão de forma compartilhada entre o médico e o paciente. (34) (64)

O atendimento na saúde preconiza uma mudança de foco, de modo a não dar atenção somente à doença, mas também ao paciente. $\mathrm{Na}$ abordagem de estudos sobre o relacionamento com $\mathrm{o}$ cliente, semelhante a essa nova abordagem do relacionamento com o paciente, as empresas concluíram que ter foco somente no produto, padronizado para qualquer tipo de cliente, não o mantém fiel à empresa. Nessa linha de pensamento, Peppers \& Rogers Group (90) afirma que para ter clientes fiéis é necessário mudar o foco do produto para o cliente. Acrescenta que para isso é preciso fazer uma gestão do relacionamento com os clientes e propõe o uso da tecnologia da informação para auxiliar nesta gestão. É neste contexto que se desenvolve o conceito de CRM (Customer Relantionship Management), apto a prover a empresa de meios mais eficazes e integrados para atender, reconhecer e cuidar do cliente, transformando dados em informações a qual disseminadas pela organização, permitem que o cliente seja “conhecido" e cuidado por todos (22) (90).

Observa-se, desta forma, que ambas as áreas desejam mudar o foco atual para uma abordagem centrada em seus clientes. Assim, propõe-se criar o modelo GRPC, adaptando os conceitos e componentes do CRM, que é um modelo de gestão de relacionamento, com o objetivo de melhorar a qualidade e efetividade no acompanhamento de pacientes crônicos. O objetivo é ter pacientes fiéis ao seu tratamento, ou seja, pessoas que possuam consciência, orientação e acompanhamento adequado para que sua doença se mantenha controlada e não evolua rapidamente para as suas complicações.

\subsection{Conceitos do Modelo GRPC}

Entende-se que a aplicação do modelo GRPC oferece confiança, credibilidade e segurança ao paciente para que ele siga o seu tratamento, pois existe uma maior interatividade entre ele e seu médico. No modelo tradicional, o principal benefício que se busca alcançar é o controle 
metabólico $^{2}$ da doença com base no uso de medicamentos, de resultado de exames complementares $^{3}$, de recomendações padronizadas de alterações de estilo de vida, como planos de dietas e exercícios. Esse tipo de prática faz com que o relacionamento entre o médico e o seu paciente seja, por vezes, marcado por desconfiança e autoritarismo. O médico acredita que o paciente não segue as suas recomendações e o paciente considera o médico um "carrasco que não o deixa fazer nada".

O modelo GRPC, ao fornecer subsídios para a gestão do relacionamento entre médico e paciente, torna mais fácil a interação para ambos os lados. Para o paciente é possível questionar e, obtendo respostas, entender as atitudes do médico. Já para o médico, é mais fácil compreender as dúvidas e dificuldades dos pacientes, e buscar alternativas para atender as necessidades particulares de cada um deles. Assim, favorece-se a criação de uma parceria entre ambos, com o objetivo de melhorar o controle da evolução da doença.

Os indicadores de controle da doença no modelo tradicional são resultados de exames subsidiários ${ }^{4}$, normalmente realizados muitos dias antes da consulta, e da avaliação do estado clínico no dia da consulta. Como não há avaliação contínua, é difícil atacar o problema tão logo ele apareça e, em muitos casos, a intervenção ocorre tardiamente.

No modelo GRPC, por sua vez, o paciente pode fornecer informações para o seu médico de várias formas. A coleta de dados de alguns exames, por exemplo, pode ser feita diariamente, como no caso da medida da pressão arterial e da glicemia. Além disso, qualquer mudança no estado clínico detectada pelo paciente pode ser relatada, o que auxilia na tomada de decisão do médico quanto ao tratamento imediato deste paciente.

Outro benefício do modelo GRPC é que, pelos seus canais de comunicação, pode-se coletar informações que permitam encontrar outros indicadores para avaliar o controle da doença. Os índices de satisfação do paciente e de evolução da doença podem, por exemplo, servir de indicadores do grau de efetividade do modelo.

\footnotetext{
${ }^{2}$ Controle metabólico é o controle dos parâmetros fisiológicos (processos físico-químicos que ocorrem nas células, tecidos, órgãos e sistemas dos seres vivos) por meio de testes ou exames, com uso de equipamentos adequados.

${ }^{3}$ De acordo com Kloetzer (69), os exames complementares são "aqueles que não se baseiam nos cincos sentidos mas sim, numa evidência indireta do estado de saúde".

${ }^{4}$ Sinônimo de exame complementar.
} 
No modelo tradicional, a coleta de informações é prejudicada, pois a quantidade de consultas e exames que um paciente pode fazer em determinado período depende da disponibilidade de tempo do médico, do paciente e do sistema de saúde. Por exemplo, se o paciente depender do sistema público de saúde brasileiro, uma consulta ou exame pode levar meses para ser marcada. No caso de instituições privadas, a necessidade de autorizações para determinados procedimentos e exames pode ocasionar demora para agendar uma consulta ou retorno. A existência de vários canais de comunicação, no modelo GRPC, com profissionais treinados nos protocolos das doenças crônicas e com o auxílio de sistemas semi-inteligentes, permite que seja feita uma coleta de informações direcionadas e contínuas.

No modelo atual, a marcação de uma consulta depende do paciente e do sistema de saúde, não somente das recomendações do médico que o atendeu. Isso pode diminuir ainda mais a coleta de informações e, por conseqüência, o adequado controle de sua doença.

No modelo GRPC, quando o paciente fornece as informações, um sistema de apoio à decisão avalia os dados coletados. A partir dessa avaliação o sistema orienta o paciente de acordo com as diretrizes clínicas baseadas em dados de pesquisa e, se necessário, aciona o seu médico. $\mathrm{O}$ médico, ao analisar os dados do paciente, pode solicitar o agendamento de uma consulta, o que é feito no próximo contato do paciente. Caso o paciente não o faça, profissionais especializados entram em contato com ele. Nesse caso, o atendente é orientado a tentar saber por que o paciente não entrou em contato com o serviço médico. Não existe uma postura de cobrança e exigência, pois o objetivo principal é alertar o paciente e conscientizá-lo da necessidade de sua participação no controle de sua doença.

O médico, ao acessar as informações coletadas, tem condições de fazer um acompanhamento personalizado, realizando a consulta presencial quando necessário e tomando decisões preventivas antes que as complicações apareçam. No modelo atual, geralmente a orientação é "padronizada" conforme informações genéricas de livros, manuais e consensos. Essa padronização faz com que a orientação seja a mesma, independente das características individuais e circunstanciais de cada paciente. Já no modelo GRPC, a orientação é personalizada, pois é possível conhecer o paciente e adaptar as orientações às suas necessidades individuais.

Assim, com os conceitos do modelo GRPC, pretende-se melhorar o tratamento da doença crônica e a adesão do paciente a ele, além de estabelecer novos padrões de acompanhamento e 
atendimento de pacientes crônicos pelos profissionais de saúde. A tabela 3.1 sintetiza os conceitos do modelo proposto.

Tabela 3.1 - Tabela comparativa entre os conceitos do modelo atual e do GRPC

\begin{tabular}{|c|c|c|}
\hline Conceito & Modelo Atual & Modelo GRPC \\
\hline Foco & Doença & Paciente \\
\hline Estratégia & Controle da doença & $\begin{array}{l}\text { Controle da evolução da } \\
\text { doença no paciente } \\
\text { (individualmente) } \\
\text { considerando-se o seu } \\
\text { contexto biológico e } \\
\text { psicossocial }\end{array}$ \\
\hline Abordagem & $\begin{array}{l}\text { Uso de medicamentos e } \\
\text { orientações } \\
\text { "padronizadas" }\end{array}$ & $\begin{array}{l}\text { Interatividade, confiança, } \\
\text { conscientização, } \\
\text { credibilidade e orientações } \\
\text { personalizadas }\end{array}$ \\
\hline $\begin{array}{l}\text { Coleta de informações e } \\
\text { orientações }\end{array}$ & $\begin{array}{l}\text { Depende da } \\
\text { disponibilidade do médico, } \\
\text { do paciente e do serviço - } \\
\text { consultas presenciais }\end{array}$ & $\begin{array}{l}\text { Outros canais de } \\
\text { comunicação, além das } \\
\text { consultas presenciais }\end{array}$ \\
\hline Relacionamento & $\begin{array}{l}\text { Desconfiança e } \\
\text { autoritarismo }\end{array}$ & Parceria \\
\hline Indicadores & $\begin{array}{l}\text { Resultados de exames e } \\
\text { avaliação clínicas } \\
\text { esporádicas }\end{array}$ & $\begin{array}{l}\text { Resultados de exames e } \\
\text { avaliação clínicas } \\
\text { freqüentes, índice de } \\
\text { satisfação e aderência }\end{array}$ \\
\hline
\end{tabular}

\subsection{Arquitetura do Modelo GRPC}

O modelo GRPC propõe criar, além da interação direta entre o médico e o paciente, outros canais de contato utilizando as tecnologias de comunicação e informação, com a finalidade de auxiliar no controle da evolução da doença e melhorar a qualidade de vida do paciente.

O CRM apresenta estratégias para atender e antecipar as necessidades dos clientes. Do ponto de vista tecnológico, o cliente é o objeto central do modelo do sistema. Todos os seus dados são capturados, consolidados e analisados. Os resultados obtidos são, então, distribuídos aos pontos de contato que possuem canais de comunicação com o cliente e que variam desde a interação direta até o uso de tecnologias de telefonia, internet e vídeo-conferência. Com essas informações, faz-se uma análise do comportamento do cliente e, a partir dela, desenvolve-se um conjunto de políticas, práticas e infra-estrutura tecnológica a fim de fidelizar o cliente por intermédio da excelência no atendimento. 
A arquitetura do CRM tem como principais apoios as tecnologias de datawarehouse e data mining. Essas tecnologias aliam-se a um banco de dados corporativo de clientes e a um conjunto de aplicações especializadas, focadas na segmentação, nas preferências e na análise de necessidades dos clientes. (22) (90) (101)

O CRM apresenta uma arquitetura que integra as tecnologias de comunicação e informação, possibilitando que as informações dos clientes estejam disponíveis para acesso em todos os canais de comunicação. Neste sentido, verifica-se que a adaptação da arquitetura do CRM pode atender ao modelo GRPC.

Além disso, as dificuldades na aderência ao tratamento e no acompanhamento e controle adequado das doenças ocorrem por várias razões; entre elas, pelo fato de as informações encontrarem-se espalhadas tanto entre departamentos das instituições de saúde como entre as instituições que atendem os pacientes. Como não há compartilhamento dessas informações, fica a critério do paciente e de seus cuidadores informar os dados que acham relevantes. Em alguns casos, essa visão fragmentada dos procedimentos e informações dos pacientes compromete a qualidade do atendimento. O modelo GRPC propõe a integração dos setores da saúde envolvidos no acompanhamento do paciente crônico, tais como: hospitais, consultórios, laboratórios, farmácias, locais de pronto atendimento e indústrias farmacêuticas, da mesma forma que o CRM integra as várias áreas da empresa para aprimorar a qualidade da gestão do cliente.

A figura 3.1 demonstra a atual fragmentação dos processos relacionados ao paciente e a proposta do modelo GRPC com aplicações que permitem o compartilhamento e a integração das informações importantes para acompanhar o tratamento do paciente crônico. 


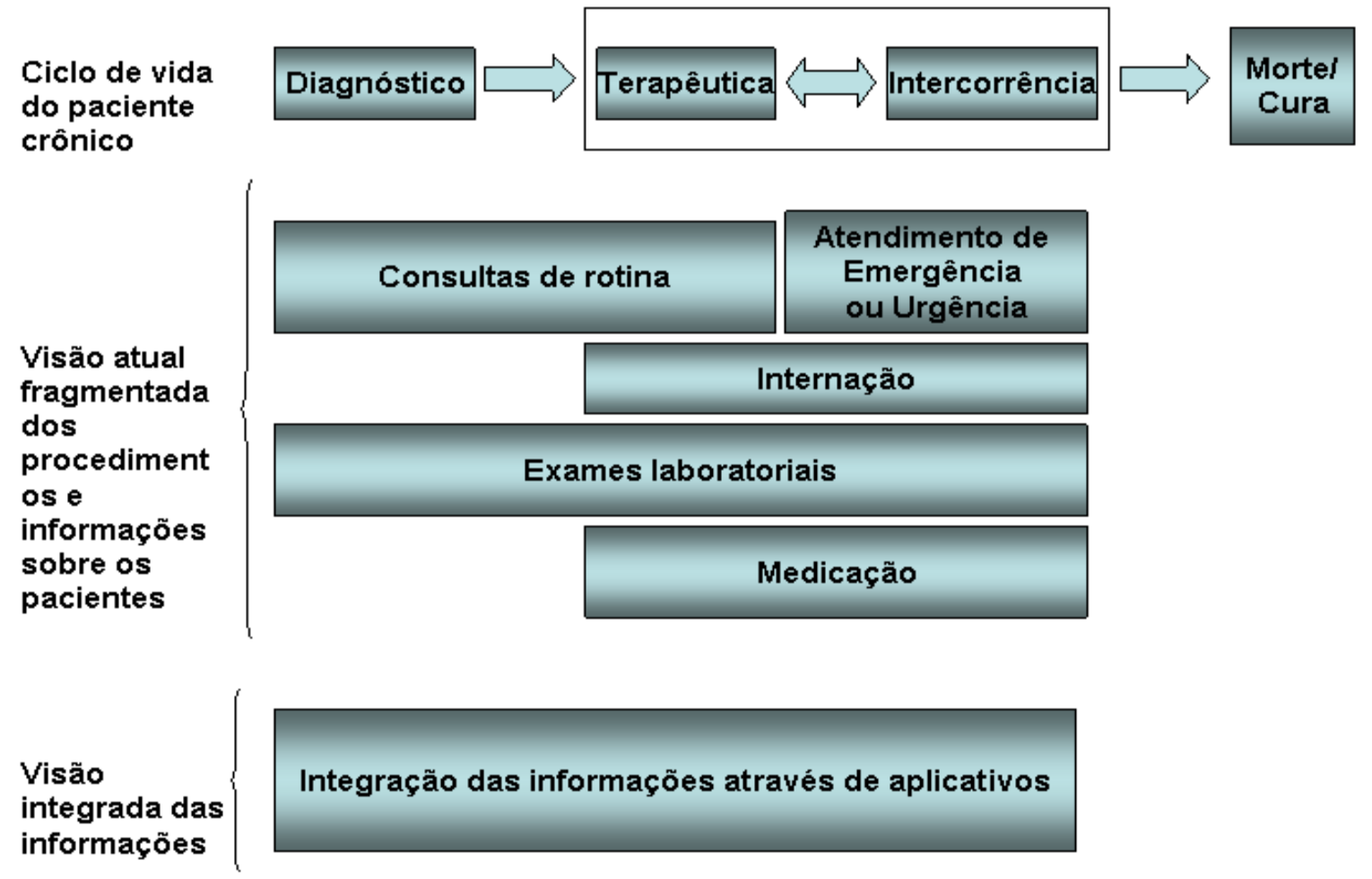

Figura 3.1 - Proposta de integração das informações no modelo GRPC

Dessa forma, é fácil visualizar como procedimentos e coletas de informações são fragmentadas nas várias instituições ao longo do ciclo de vida do paciente. Cada instituição responde por um processo específico e não se relaciona com outras. Informações e procedimentos relevantes para outras unidades ficam encapsuladas em cada instituição.

A falta de informação compartilhada faz com que seja necessária a repetição ou a criação de procedimentos para a coleta da informação que existe em outras instituições, tornando morosa a tomada de decisão por parte dos médicos. A falta de informação sobre o procedimento realizado em outra instituição, por sua vez, pode prejudicar a tomada de decisão, pois nem sempre o paciente consegue relatar o que foi feito com ele.

O modelo GRPC propõe, através da tecnologia da informação, a integração e o compartilhamento das informações entre as unidades, permitindo diminuir os riscos e aumentar a velocidade na tomada de decisão.

Diferente do CRM, onde o desafio inicial é integrar as áreas da organização, o modelo GRPC indica a integração entre as organizações. Dessa forma, a arquitetura tecnológica para apoiar o 
GRPC precisa ser robusta, distribuída e permitir a integração entre plataformas e aplicações de diferentes tipos.

Toda a infra-estrutura que compõe a arquitetura do CRM está dividida nos componentes operacional, colaborativo e estratégico. Esses componentes integram os processos interfuncionais, derrubando as barreiras dos departamentos nas organizações. A Figura 3.2 apresenta a adaptação dos componentes do CRM para o modelo GRPC, a fim de permitir o compartilhamento de informações entre o médico e o paciente e assim melhorar a qualidade e a efetividade do acompanhamento de pacientes crônicos. Nos próximos itens cada um desses componentes do GRPC é detalhado; também é feita a sua correlação com o CRM.

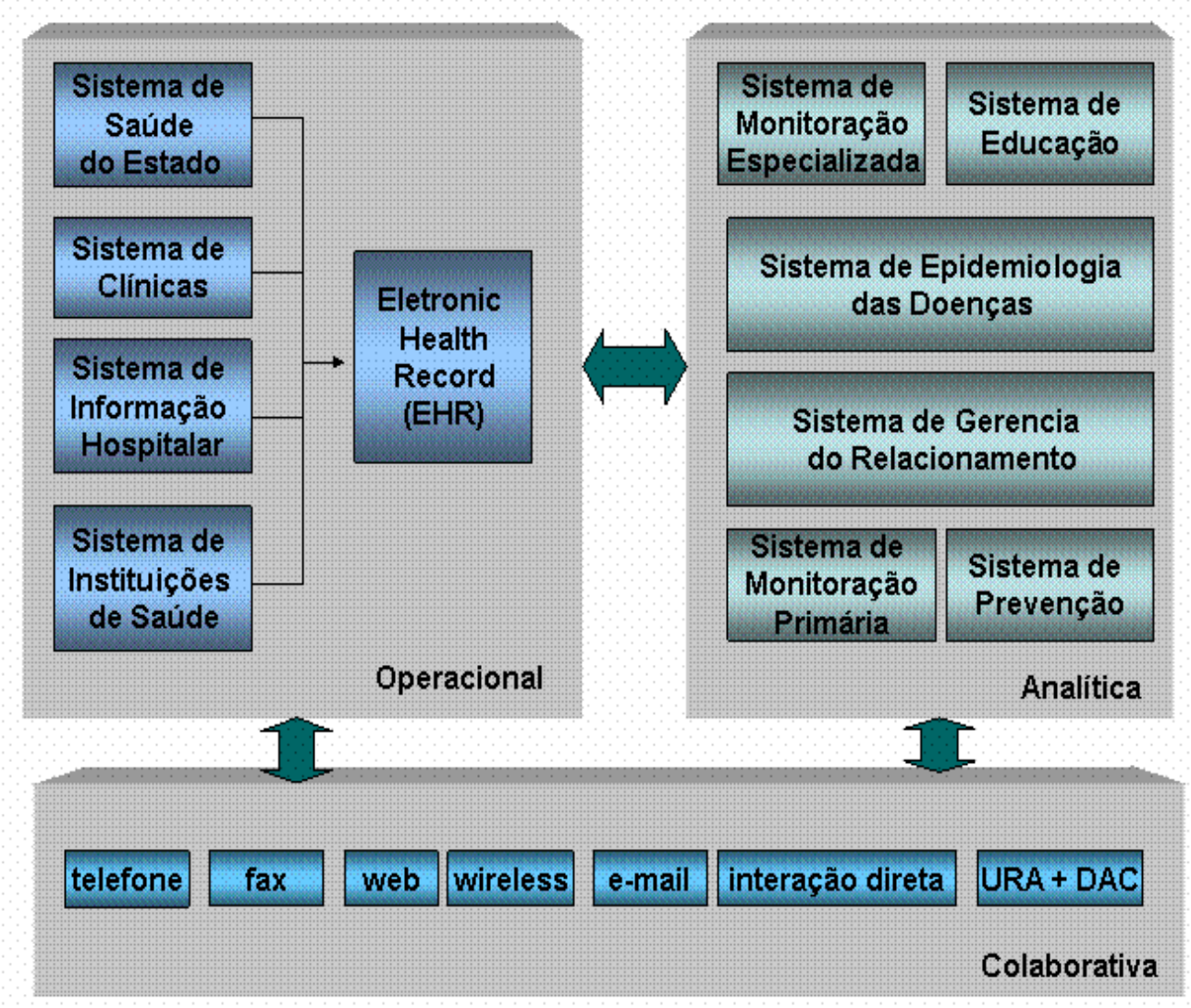

Figura 3.2 - Componentes adaptados do CRM para o modelo GRPC

\subsubsection{Componente Operacional}

O CRM operacional compreende os processos de negócios e tecnologias que auxiliam na captura dos dados referentes a uma interação direta com o cliente. Essas operações 
compreendem as aplicações que, integradas ou não, são responsáveis pela captura das informações que permitem a adequada gestão do cliente ${ }^{5}$. (22) (90)

Como apresentado anteriormente, os dados do paciente encontram-se disseminados nas várias instituições por onde ele passa. Assim, para o GRPC Operacional é preciso criar os processos de negócios e tecnologias que auxiliem na integração, consolidação e compartilhamento das informações do paciente para o médico. Esses processos são encontrados atualmente nos sistemas EHR (Eletronic Health Record) (figura 3.3). De acordo com a National Electronic Health Record Taskforce ( (82) apud (98) p. 5), define um EHR como:

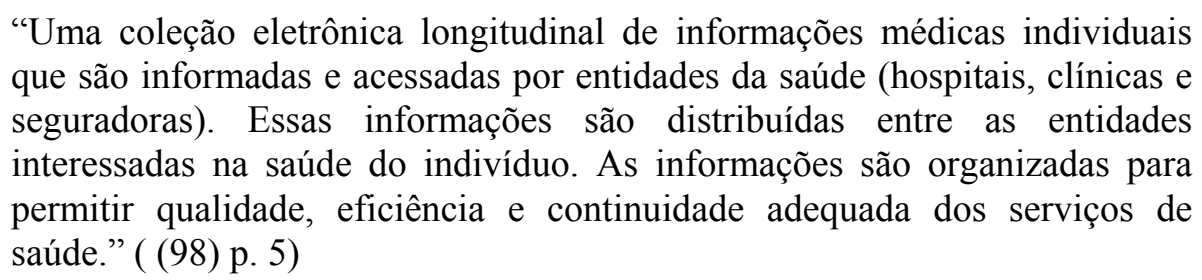

Nota-se então que os sistemas EHR integram as informações do paciente que encontram-se espalhadas nos diversos setores das instituições (laboratório, diagnóstico por imagem, ambulatório, etc.), nos diversos sistemas (ERP, processadores de textos, planilhas e sistemas isolados) e entre as intituições (hospitais, clínicas, pronto atendimento, serviços sociais, etc.). (25) (75)

Assim, os sistemas EHR contribuem para atender de forma efetiva e eficiente os pacientes, pois permitem unificar todas as respectivas informações clínicas. Transferem, automaticamente, informações sobre o paciente entre as entidades de saúde. Dessa forma, aumentam a velocidade de serviços, reduzem duplicações de exames e prescrições, diminuem a incidência de erros e aumentam a produtividade e os benefícios na assistência à saúde. (14) (25) (75)

Analisando a proposta dos sistemas EHR, conclui-se que eles são adequados para compor o GRPC operacional. No modelo GRPC o EHR integra e consolida as informações dos pacientes advindas do sistema de saúde pública, de clínicas, de informação hospitalar e de instituições de saúde. Em seguida, disponibiliza-as para os demais componentes do modelo (Figura 3.2).

\footnotetext{
${ }^{5}$ Essas aplicações são os sistemas de front office (automação de vendas, marketing e atendimento), sistemas de back office (sistemas transacionais de retaguarda, como os softwares de gestão empresarial), sistemas de mobile office (por exemplo: sistemas móveis de vendas, atendimento em campo).
} 


\subsubsection{Componente Analítico}

O CRM analítico é a inteligência do processo e contempla as ferramentas necessárias para a análise dos dados coletados, como segmentação, perfil de clientes e campanhas, para aprimorar as decisões de negócio. Esse componente auxilia os usuários da tecnologia CRM, em tempo real, a obter informações a respeito dos relacionamentos, reclamações e requerimentos provenientes de todos os canais de contato com o cliente. Entre as ferramentas mais importantes utilizadas no CRM analítico tem-se o datawarehouse e o data mining. (22) (76) (90)

O datawarehouse é uma técnica que permite consolidar os dados armazenados em vários bancos de dados operacionais, de uma forma que seja fácil extrair informações para auxiliar na tomada de decisão dos profissionais da organização. Uma das características que diferenciam o datawarehouse de uma aplicação comum de banco de dados é a análise dos dados em várias dimensões, como por exemplo tempo e assunto, entre outras. (57) (68)

$\mathrm{O}$ data mining é um conjunto de técnicas que permitem identificar informações úteis em bancos de dados. Ao extrair estas informações, os profissionais têm como utilizá-las para tomar decisões, além de fazer estimativas, previsões e predições sobre seus clientes e produtos. Para o data mining não é imperativo que o banco seja um datawarehouse. Porém, sua utilização possibilita realizar de melhor maneira as operações mencionadas. (22) (101)

Seguindo a linha de análise dos dados do CRM analítico, os componentes do GRPC analítico têm como objetivo a análise de desempenho nos níveis estratégicos, táticos e da inteligência do atendimento personalizado do paciente. Assim, toda e qualquer extração de informação a partir do processamento, análise e avaliação dos dados coletados encontra-se no GRPC analítico. Além de segmentar as fichas dos pacientes, analisar perfis e avaliar campanhas há também as ferramentas que auxiliam na monitoração de cada caso. Assim, o GRPC analítico compõe-se do sistema de monitoração (primária e especializada), do sistema de educação, do sistema de prevenção, do sistema de gerência do relacionamento e do sistema de epidemiologia da doença (figura 3.2). Cada um desses sistemas é detalhado a seguir.

Os sistemas de monitoração permitem a análise dos dados coletados e avaliações objetivas no controle das condições do paciente, emitindo respostas automáticas e sinais de alerta para o seu médico. Para a monitoração dos pacientes crônicos, as ferramentas utilizadas são os 
sistemas de apoio à decisão e acesso a especialistas. Os sistemas de monitoração, nesse modelo, são divididos em primária e especializada.

No sistema de monitoração primária a atenção é dada para o acompanhamento e controle diário do estado clínico do paciente, como por exemplo, a tomada de ações imediatas de acordo com o seu estado atual.

No sistema de monitoração especializada, a ação é classificada e direcionada aos profissionais da equipe de saúde, de acordo com as áreas de atuação: planejamento nutricional, avaliação da eficiência da terapêutica, planejamento de exercícios físicos, avaliação da evolução do perfil da doença, entre outros.

Os sistemas de prevenção e educação utilizam ferramentas que permitem traçar o perfil e o comportamento do paciente. Elas possibilitam localizar pontos em que campanhas de prevenção e educação sejam adequadas para os vários segmentos de pacientes. Assim, os sistemas de prevenção e educação têm como finalidade propocionar meios de conscientização e orientação do paciente com relação a sua doença.

Já o sistema de gerência do relacionamento permite analisar e avaliar sugestões e irregularidades de cada paciente com relação ao controle da sua doença. É através desse sistema que se verifica o comprometimento do paciente com relação à monitoração de sua doença.

Os sistemas epidemiológicos da doença analisam os dados sob o ponto de vista populacional e podem evidenciar novas situações e prognósticos, permitindo pesquisar novas tendências de prevalência das doenças. Esses e outros benefícios no uso do data mining em dados clínicos são apontados por Nigrin (85) em seu trabalho.

\subsubsection{Componente Colaborativo}

O CRM colaborativo engloba a integração de todos os canais (internos e externos) de relacionamento entre a empresa e os clientes. A colaboração ocorre através da tecnologia que permite a automação e a integração entre todos os canais e pontos de contato entre o cliente e a empresa. É fundamental que esses pontos de contato estejam preparados para interagir com 
o cliente e disseminar as informações levantadas para os sistemas do CRM Operacional. (90) $(101)$

Da mesma forma, o GRPC fornece vários canais de comunicação do paciente para com o seu médico. Neste ponto o GRPC é flexível e permite que se possa utilizar desde uma tecnologia avançada, portanto de alto custo, até uma tecnologia simples e adequada para alcançar todas as camadas populacionais (Figura 3.3). O modelo envolve um mistura de telecomunicações e canais de comunicação como telefone, fax, celular, web, chat, e-mail, fórum virtual, vídeoconferência e wireless.

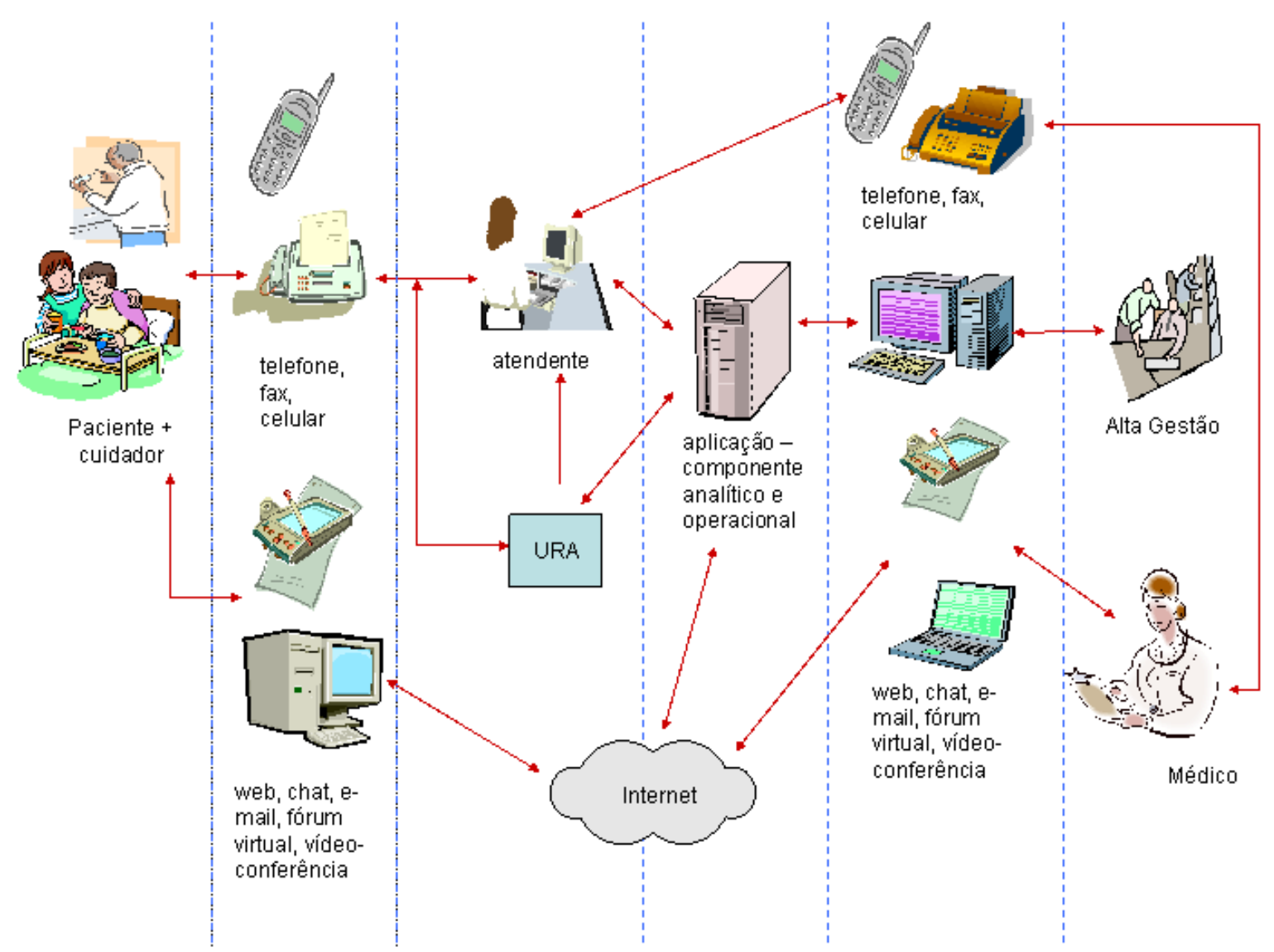

Figura 3.3 - Componente Colaborativo do GRPC e o seu relacionamento com o GRPC operacional e analítico (aplicação e BD)

Para que todas essas tecnologias possam trabalhar integradas são necessárias ferramentas automatizadas para controlar e organizar o contato do paciente. No CRM colaborativo existem várias tecnologias associadas para facilitar o contato do cliente com a empresa (22) (90). O componente colaborativo do GRPC propõe utilizar as mesmas tecnologias para a sua 
implementação. A seguir, as principais tecnologias utilizadas no CRM colaborativo e a sua utilidade no modelo GRPC são apresentadas.

A URA (Unidade de Resposta Audível) é uma ferramenta que auxilia no atendimento virtual de um cliente, pois dispensa a necessidade de uma pessoa para atender o cliente. A URA é um equipamento de atendimento automático de ligações em que a interação é feita por meio do teclado do telefone e/ou do reconhecimento de voz. É utilizada para operações simples e que não necessitam da intervenção humana, como por exemplo fornecer extratos bancários. (48) (76)

Em coletas de informações simples e de fácil direcionamento, a URA é uma alternativa para um rápido atendimento do paciente, principalmente para aqueles que não dispõem de muito tempo. É o caso da coleta de resultado de exame ou de um questionário de rotina.

O PABX (Private Automatic Branch Exchange) é outro recurso muito utilizado no CRM colaborativo (48). O uso do PABX é recomendado para o direcionamento das ligações, e no caso do GRPC, gerencia os chamados dos pacientes. Na prática, o PABX é conectado aos troncos de entradas dos ramais das URAs ou diretamente nos telefones dos atendentes (48).

O DAC (Distribuidor Automático de Chamada) controla o fluxo de chamadas telefônicas e as distribui de acordo com regras pré-estabelecidas. O DAC atende ao chamado com mensagens gravadas que podem propor para o cliente aguardar na linha. Semelhante ao que ocorre com o PABX, é recomendado que se utilizem as duas tecnologias para que se possa usufruir dos serviços de ambos (22) (48)

Para a integração tecnológica entre a telefonia e o sistema de informação há o CTI (Computer Telephony Integration). Trata-se de uma ferramenta que permite reconhecer a chamada, transferi-la para o atendente adequado ou não ocupado, apresentar as informações desse cliente para o atendente e controlar o servidor de fax. (22) (48)

As funcionalidades do CTI auxiliam no atendimento do paciente pelo telefone, direcionandoo para os serviços adequados. O CTI encaminha os envios de fax do paciente para o e-mail do atendente, que analisa o conteúdo e toma as devidas providências.

É possível utilizar as ferramentas da Internet para realizar o contato com o paciente, obter a coleta de dados e transmitir informações educacionais ou relativas à monitoração. 
Conclui-se, então, que as ferramentas utilizadas no CRM colaborativo podem contribuir para o adequado funcionamento do modelo GRPC.

\subsection{Central de Relacionamento do Paciente Crônico}

Com o advento do CRM, mudanças nos setores da empresa que possuem algum tipo de contato com o cliente são necessárias. Para implementar o CRM colaborativo é preciso organizar a empresa de tal forma que o cliente seja atendido, independente do meio utilizado para o contato. É importante que o cliente, ao ser atendido, não precise repetir informações dadas durante o contato, ou antes dele. Para a empresa, é interessante ter contatos iniciados pelo cliente, pois pode, com isso, aumentar o relacionamento, ter novas oportunidades de venda e conhecer melhor o cliente. (22) (76) (89)

Nas empresas, as centrais de atendimento ao cliente que oferecem serviços limitados (registro de reclamações, dúvidas, sugestões e suporte) são as indicadas para evoluírem ao que se chama Centro de Interação com o Cliente (CIC). O CIC é a peça mais importante para um CRM de sucesso, já que ele é o centro corporativo de todas as interações com o cliente. Ele tem o poder de transformar contatos feitos para solicitar atendimento em oportunidades de aumento de receita, como a venda de um produto. E à medida que a empresa captura informações sobre os clientes e as transforma em novos produtos e serviços, aumenta ainda mais a sua participação no mercado. O CIC, além do contato por telefone, permite interações por carta, fax e através das ferramentas da Internet. (48) (76) (89)

Da mesma forma que o CRM necessita organizar o contato do cliente em centrais de interação, o modelo GRPC propõe a criação de centrais de relacionamento com o paciente crônico (CRC). O CRC é uma combinação adequada de informações, campanhas, transmissão e processamento de dados, com a finalidade de melhorar o relacionamento do médico com o paciente por meio da tecnologia de comunicação e informação. É composta por uma infraestrutura que organiza as informações e os canais de comunicação com o paciente.

O CRC não tem a mesma infra-estrutura e responsabilidades de uma clínica ou centro de saúde. É um local que concentra as informações captadas dos vários pontos em que o paciente foi atendido, faz o processamento delas através do componente analítico do GRPC e as 
fornece às instituições e ao médico. Além disso, é um local de contato para o paciente disponível 24 horas por dia, 7 dias da semana. O paciente, tendo alguma dúvida ou necessitando informar algo relevante ao seu tratamento, pode fazê-lo sem precisar esperar pela consulta ou pela disponibilidade do médico em atendê-lo fora do horário.

No CIC, a automação no atendimento é um ponto crítico. A partir dela é possível atender um grande volume de clientes e ao mesmo tempo realizar um relacionamento colaborativo entre o cliente e o agente que vai atendê-lo. $\mathrm{O}$ atendimento pode ser feito por uma pessoa ou não. Quando o agente é virtual utiliza-se a Unidade de Resposta Audível (URA). (22) (48)

A automação do atendimento no CRC segue os mesmos princípios do CIC. Os pacientes atendidos pelo CRC podem variar muito quanto ao diagnóstico e cada um deles deve ser atendido de forma diferenciada. $\mathrm{O}$ acesso a todas as informações necessárias para esse tipo de atendimento é feito ao utilizar a tecnologia da informação aliada às tecnologias de comunicação, como acontece no CIC.

De acordo com Pepper \& Rogers Group (89) e Madruga (76), construir um CIC não é apenas instalar equipamentos e sistemas, ou seja, disponibilizar a infra-estrutura, pois um relacionamento forte e duradouro é construído com base na interação entre pessoas. É preciso automatizar o relacionamento e não robotizá-lo. Assim, é necessária a capacitação dos colaboradores da empresa, tanto em ambiente técnico, para o uso da nova tecnologia, quanto em relação ao comportamento, para um atendimento centrado no cliente.

No modelo GRPC há o mesmo conceito; para que o modelo e as centrais de relacionamento funcionem é preciso que os profissionais de saúde entendam e pratiquem um atendimento centrado no paciente. Isso exige mudanças nas atitudes, como por exemplo criar uma rotina para acessar as informações dos pacientes e a partir dela planejar o acompanhamento de seus casos.

\subsubsection{Serviços da Central de Relacionamento do Paciente Crônico}

Após a elaboração dos objetivos do $\mathrm{CRC}$, alguns serviços a serem oferecidos pela central foram definidos. A central é um canal de comunicação entre o paciente e o seu médico, onde ambos podem usufruir desses serviços. O cliente (pacientes, médicos, profissionais da saúde e 
instituições), para entrar em contato com a central, pode optar entre as várias formas de interação (figura 3.4) escolhendo aquela que ele possui ou à qual esteja melhor adaptado.

Ao utilizar o telefone ou o celular é necessário que o usuário se identifique para que a ferramenta de Integração computador-telefone (CTI - Computer Telephony Integration) possa direcioná-lo para os serviços permitidos. Após a identificação, o cliente seleciona se deseja ser atendido pelo atendente da central ou pela URA.

No contato direto do atendente com o paciente, o sistema de informação apresenta o histórico de contatos passados, características do paciente, informações sobre consultas anteriores, orientações e marcação de consultas indicadas pelo médico. Durante o contato, os scripts inteligentes guiam o atendente para que ele possa fornecer todo o apoio necessário ao paciente. O seu uso reduz o tempo de treinamento dos atendentes e a incidência de erros na entrada de dados (76). Para elaborá-los deve-se considerar o fluxo e o desdobramento do contato com o paciente. Um exemplo seria quando, no momento de uma intercorrência, o sistema de apoio à decisão põe em operação um script, através do qual o atendente obtém as informações necessárias para indicar a melhor orientação a ser dada.

Para o médico, o sistema apresenta o histórico de contatos, as suas características e o acesso às informações dos pacientes atendidos por ele. $\mathrm{O}$ médico pode solicitar o agendamento de uma consulta, pedir a realização de exames, fornecer novas orientações, mudar a conduta do tratamento e pedir a validação de alguma informação junto ao paciente ou à instituição que o atendeu. Essas mesmas funcionalidades são disponibilizadas ao médico pela internet.

O usuário da central sempre obtém um retorno do contato feito. $\mathrm{O}$ paciente, ao comunicar o resultado de seu exame feito em casa (glicemia, pressão arterial, temperatura corporal, entre outros) é informado sobre a sua condição clínica e orientado sobre como proceder. Isso é possível através da implantação de sistemas de apoio à decisão. Os resultados de exames feitos em laboratório são coletados diretamente do sistema do laboratório. Quando isso não for possível, os dados são inseridos no sistema pelo próprio médico ou por profissionais de apoio, após a consulta presencial.

Ao implantar o GRPC analítico na central pode-se segmentar e traçar o perfil dos pacientes a fim de realizar campanhas, prevenções e oferecer orientações e condutas personalizadas. 
O CRC possui uma ouvidoria que viabiliza um canal de comunicação para o acompanhamento dos serviços oferecidos. Por esse canal registram-se as irregularidades e sugestões fornecidas por todos: pacientes, médicos, instituições e inclusive os funcionários da própria central. A partir desse trabalho medidas são tomadas com a finalidade de melhorar a qualidade dos serviços.

Além desses serviços, o CRC permite verificar a ausência de contato de pacientes, o apoio ao atendimento de intercorrências, a emissão de alertas automáticos ao médico e a indicação de um local de pronto atendimento ao paciente.

\subsection{Exemplo de uma Central de Relacionamento do Paciente Crônico: Central de Monitoração de Diabéticos}

Como visto no capítulo 2, o diabetes mellitus é uma das doenças crônicas que apresentam um grande número de alternativas para a monitoração dos pacientes por ela acometidos. Existem desde glicosímetros ${ }^{6}$ de fácil manuseio até formas de atendimento que facilitam o controle da glicemia. (38) (72) (80)

As soluções de atendimento ao paciente diabético propostas até o momento limitam-se ao uso da internet (47) (55) (71) (78), ao telefone (128) e ao PDA (Personal Digital Assistants) (114). Essas soluções, além de apresentarem apenas um canal de comunicação, não permitem um relacionamento personalizado entre o médico e o seu paciente.

Nos trabalhos com interação pela internet e PDA os pacientes não recebem um retorno imediato sobre a situação da sua doença naquele momento. Os serviços oferecidos são os de envio de dados e o recebimento de orientações de médicos especialistas que acessam os dados coletados. A principal limitação é que os excluídos digitais não podem usufruir desse tipo de atendimento. $\mathrm{O}$ paciente recebe a orientação de médicos que não conhecem a sua história e evolução. Como os dados coletados são somente os relacionados com os aspectos clínicos da doença, pode se ter uma orientação "padronizada" e limitada.

\footnotetext{
${ }^{6}$ Aparelhos que permitem medir e armazenar o resultado da glicemia sanguínea.
} 
Young (128), em seu trabalho, implantou o PACCTS (Pro-Active Call Center Treatment Support), que estabelece objetivos muito próximos aos da Central de Relacionamento do Paciente Crônico que são: controlar a glicemia promovendo um gerenciamento do estilo de vida, promover a aderência ao tratamento e incentivar a auto-monitoração. Porém, nessa proposta, os atendentes trabalham somente com os aspectos relacionados com a educação e prevenção. Os horários das ligações feitas pelos atendentes são agendados, assim como as ligações feitas pelos pacientes ao PACCTS.

Mesmo com essas limitações, os trabalhos mencionados demonstram haver uma melhora nas condições de saúde dos pacientes que utilizam esses tipo de atendimento em relação ao tratamento convencional. (47) (55) (71) (78) (128)

A proposta do CRC, comparada aos trabalhos mencionados, é mais abrangente, pois pretende, além do controle da glicemia, aumentar o relacionamento do paciente com o seu médico ao proporcionar vários canais de comunicação. Além disso, da mesma forma que o CRM propõe a evolução da central de atendimento para as centrais de interação com o cliente, as centrais de monitoração podem agregar a proposta da central de relacionamento. Por isso é proposto como exemplo de CRC uma Central de Monitoração do Paciente Diabético (CMD). As tecnologias que foram utilizadas de forma fragmentada nos trabalhos anteriores são integradas para implementar a arquitetura do modelo GRPC e a proposta do CRC.

Pelas características da central de monitoração, verifica-se que a infra-estrutura principal para a existência dela é o uso da tecnologia da informação. Assim, é preciso desenvolver um sistema de informação adequado que interligue os meios de comunicação e forneça as informações corretas e no momento certo.

Por décadas, projetistas de software desenvolveram aplicativos baseados exclusivamente em requisitos técnicos, os quais nem sempre atendiam às necessidades de seus clientes. É por isso que a compreensão sobre os processos de negócio ${ }^{7}$ torna-se importante para identificar qual o tipo de apoio computacional necessário na organização. (35) (92)

\footnotetext{
${ }^{7}$ Coleção de atividades que trabalham juntas para produzir um conjunto definido de produtos e serviços que irão agregar valores ao cliente. (29)
} 
Objetivando uma abordagem para a análise da empresa e, por conseqüência, dos processos, criaram-se técnicas de modelagem de negócio, que permite identificar, analisar e avaliar a forma como a organização executa os seus processos. (29) (49)

Dentre as várias técnicas para a modelagem de processo de negócio destaca-se o IDEF (Integrated Computer-aided Manufacturing Definition) (56), que surgiu em meados da década de 1970 e foi desenvolvido a partir do SADT (Structured Analysis Design Techniques). É possível, a partir do IDEF, definir os requisitos técnicos do sistema. Porém, atualmente, a UML (Unified Modeling Language) (12), a linguagem de modelagem padrão para o desenvolvimento de sistemas orientados a objetos, surge como alternativa para a modelagem de negócio. (35)

A UML é uma linguagem utilizada para especificar, visualizar, construir e documentar sistemas, através de modelos. É o padrão visual que descreve a estrutura e o comportamento de um sistema. A proposta da UML é fornecer elementos que permitam descrever de forma visual os sistemas complexos com a tecnologia da orientação a objetos. A UML está baseada no conceito de modelo ${ }^{8}$. Nessa concepção, o analista cria modelos que descrevem todos os diferentes aspectos do sistema a ser desenvolvido. O modelo apresenta diversas visões, cada uma descrevendo um aspecto específico do sistema. Assim, a cada fase do desenvolvimento de software são adicionados detalhes aos modelos. Com a UML pode-se modelar o funcionamento estático e dinâmico do sistema, denominados respectivamente de estrutura estática e comportamento dinâmico. (12) (36)

Dentre as propostas existentes para modelagem de negócio com UML, a da Rational University (92) destaca-se, pois os seus modelos são facilmente mapeados para as visões da UML. Porém, ela não é simplesmente uma técnica de mapeamento para o desenvolvimento de sistemas orientado a objetos. Afinal, ela permite entender a estrutura dinâmica da organização na qual um sistema deve ser implantado; compreender os problemas atuais, identificar possibilidades de melhorias e assegurar que clientes, usuários e desenvolvedores tenham um entendimento comum da organização.

A modelagem de negócio da Rational University (92) baseia-se no caso de uso de negócio e na arquitetura do processo de negócio. O primeiro é uma extensão do conceito de caso de

\footnotetext{
${ }^{8}$ Modelo é a descrição de alguma coisa. O projetista precisa criar modelos que descrevam os vários aspectos do produto
} 
uso da UML para a modelagem de negócio, que é detalhado no item 3.5.1, enquanto que o segundo tem como objetivo detalhar os processos de negócio. Os modelos arquiteturais definem a estrutura do negócio e ajudam a entender o negócio e as funcionalidades. (51) (60)

A seguir o resultado das etapas realizadas na modelagem de negócio são apresentadas, assim como a explanação sobre os conceitos de modelo de caso de uso de negócio e arquitetura de negócio.

\subsubsection{Modelo de Caso de Uso de Negócio}

Antes de iniciar o projeto é importante ter uma visão do negócio que será estudado para entender os processos e a estrutura da organização. A finalidade aqui não é descrever a organização em detalhes, mas apenas o necessário para ser possível priorizar as partes que serão o foco do projeto. (92) O que foi tratado nos capítulos anteriores buscou fornecer uma visão de negócio da CMD.

Após ter essa visão, desenvolve-se o esboço do diagrama de caso de uso de negócio e escolhem-se os casos de uso de negócio que serão descritos em detalhes para a elaboração da arquitetura. (92)

O caso de uso é uma técnica criada por Jacobson (61) para modelar sistemas. O conceito é considerar que o sistema é uma caixa preta composta por funcionalidades denominadas casos de uso. Todos os elementos que interagem ou influenciam de alguma forma o sistema são representados por atores. O caso de uso é uma funcionalidade completa, sempre iniciada por um ator, e que resulta num valor para ele. Para representar o relacionamento entre o caso de uso e o ator utiliza-se uma linha contínua "ligando" ambos os elementos. O diagrama de caso de uso é a representação de todos os casos de uso relacionados aos seus respectivos atores.

Para a modelagem de negócio, a organização é o sistema, portanto os elementos que interagem ou influenciam no negócio são atores de negócio. O ator de negócio é o papel desempenhado pelo interessado no negócio. Uma forma de encontrar os atores de negócio é definir o público-alvo, que no caso da CMD é composto por: 
- Alta Gestão - representada por entidades que possuem poder de decisão sobre as políticas de saúde da central de monitoração;

- Instituição de Saúde - instituição de saúde que deseja participar do programa da central de monitoração;

- Médico - profissional da instituição de saúde responsável pelo tratamento e acompanhamento do seu paciente;

- Paciente diabético - enfermo diagnosticado como diabético em uso de insulina e que é atendido pelo médico cadastrado na central de monitoração.

Estendendo o conceito de caso de uso, tem-se que o caso de uso de negócio é uma seqüência de ações realizadas no negócio que produz um resultado concreto para um ator individual do negócio. Na CMD, ao analisar os serviços que uma central de relacionamento pode oferecer e as funcionalidades existentes nos trabalhos de Young (128), Hyuk et. al (55), McMahon et. al (78) e Meystre et. al (80) foram definidos os seguintes casos de uso de negócio:

- Acompanhar a execução de serviços - viabilizar um canal de comunicação direta para o acompanhamento dos serviços oferecidos pela central;

- Acompanhar o tratamento do paciente - apresentar informações sobre o acompanhamento do paciente pela central, coletar dados sobre as consultas que acontecem fora da central, permitir que o médico prescreva orientações clínicas aos pacientes que serão dadas pela central ao paciente; além disso, o médico, através da análise da evolução do paciente, avalia a continuidade do mesmo no programa;

- Gerenciar o relacionamento com o paciente - avaliar o relacionamento do paciente através de contatos periódicos, assim como o acompanhamento ao seu tratamento;

- Monitorar a glicema - estabelecer a monitoração da glicemia dos pacientes diabéticos que participam do programa;

- Selecionar paciente - fazer a seleção dos pacientes, pelo médico, que irão participar do programa da central; 
- Esclarecer o tratamento - proporcionar um meio, ao paciente, para que a qualquer momento ele possa esclarecer uma dúvida sobre o seu tratamento;

- Estabelecer políticas de saúde - tornar possível a análise das bases de dados da central pela alta gestão, estabelecendo um relacionamento constante de aprendizado, além de determinar ações e estratégias na central;

- Selecionar a instituição - fazer a seleção das instituições que desejam participar do programa;

- Selecionar o médico - realizar a seleção dos médicos, pela alta gestão, que poderão ter seus pacientes acompanhados pela central. Esses médicos devem ser funcionários das instituições que foram aprovadas para participar do programa.

Após selecionar os casos de uso de negócio que fazem parte do escopo do projeto, é preciso detalhar cada caso de uso de negócio. De acordo com Heumman (51), detalhar o caso de uso de negócio é descrever o processo (fluxo de trabalho) que resulte no valor para o ator de negócio, e não na forma como ele resolve o problema.

O fluxo de trabalho é o conjunto de atividades realizadas para obter um resultado esperado (fluxo básico) ou não esperado (fluxo alternativo). O fluxo básico e o fluxo alternativo são descritos em linguagem natural. Para realizar essa atividade é necessário reunir informações sobre o processo representado pelo caso de uso de negócio: entender o relacionamento dos atores de negócio com o caso de uso de negócio e descrever os objetivos e desempenho, assim como detalhar e estruturar o fluxo de trabalho do caso de uso de negócio.

Neste trabalho, decidiu-se realizar uma simulação para verificar a viabilidade da monitoração do paciente no modelo GRPC. Ao analisar o diagrama de caso de uso de negócio da Central, verifica-se que o caso de uso de negócio "monitorar a glicemia" é o responsável por este processo. Esse caso de uso de negócio define o escopo do projeto e, portanto, deve ser detalhado. A seguir é descrito o seu detalhamento: 


\section{Fluxo Básico}

i. O atendente registra a glicemia - $\mathrm{O}$ paciente entra em contato periodicamente e informa o resultado da glicemia medida. $\mathrm{O}$ atendente anota no formulário de ocorrências do paciente data, horário e valor da glicemia do paciente.

ii. O atendente informa os procedimentos a serem seguidos - $\mathrm{O}$ atendente indica os procedimentos que devem ser seguidos pelo paciente, por meio da consulta ao sistema de apoio à decisão que utiliza os resultados de exames e as condições gerais informadas para chegar a uma conclusão.

iii. $\mathrm{O}$ atendente encerra o contato - $\mathrm{O}$ atendente finaliza o contato de controle de diabetes mellitus com orientações de promoção de saúde elaboradas pelo departamento educacional e se despede do paciente.

\section{Fluxos Alternativos}

i. O paciente deseja fornecer sugestões - Se o paciente quiser sugerir algo, o atendente transfere a sua chamada para o setor de ouvidoria da CMD, por intermédio do caso de uso de negócio “Acompanhar Execução de Serviços”.

ii. O médico é informado de intercorrência - Após encerrar o contato e em casos de emergência o médico é avisado que o seu paciente necessita um contato imediato (por telefone), ou foi agendado para consulta antecipada, ou foi para uma unidade de pronto atendimento.

iii. O paciente não entra em contato - Após dois dias de ausência de contato do paciente, o atendente deve verificar o que está acontecendo. Se o atendente não encontrar o paciente, deverá tentar novo contato após 1 hora e por até três vezes no dia. Nesse caso, o atendente deverá atualizar o formulário de controle do paciente com a data e o horário da tentativa, além do status de "não encontrado". Caso não consiga falar com o paciente por uma semana, o atendente deverá contatar o médico avisando do ocorrido.

O diagrama de atividade da UML na modelagem de negócio descreve graficamente os detalhes do fluxo de trabalho. Um diagrama de atividades de um fluxo de trabalho contém a ordem das tarefas ou atividades realizadas. A atividade pode ser uma tarefa manual ou 
automatizada. Na modelagem de negócio recomenda-se o uso de raias para agrupar as tarefas definindo as responsabilidades dos papéis que as exercem. A Figura 3.4 apresenta o diagrama de atividade do controle da glicemia. Nesse diagrama as tarefas que o paciente, o atendente e o sistema de apoio à decisão devem fazer foram definidos.

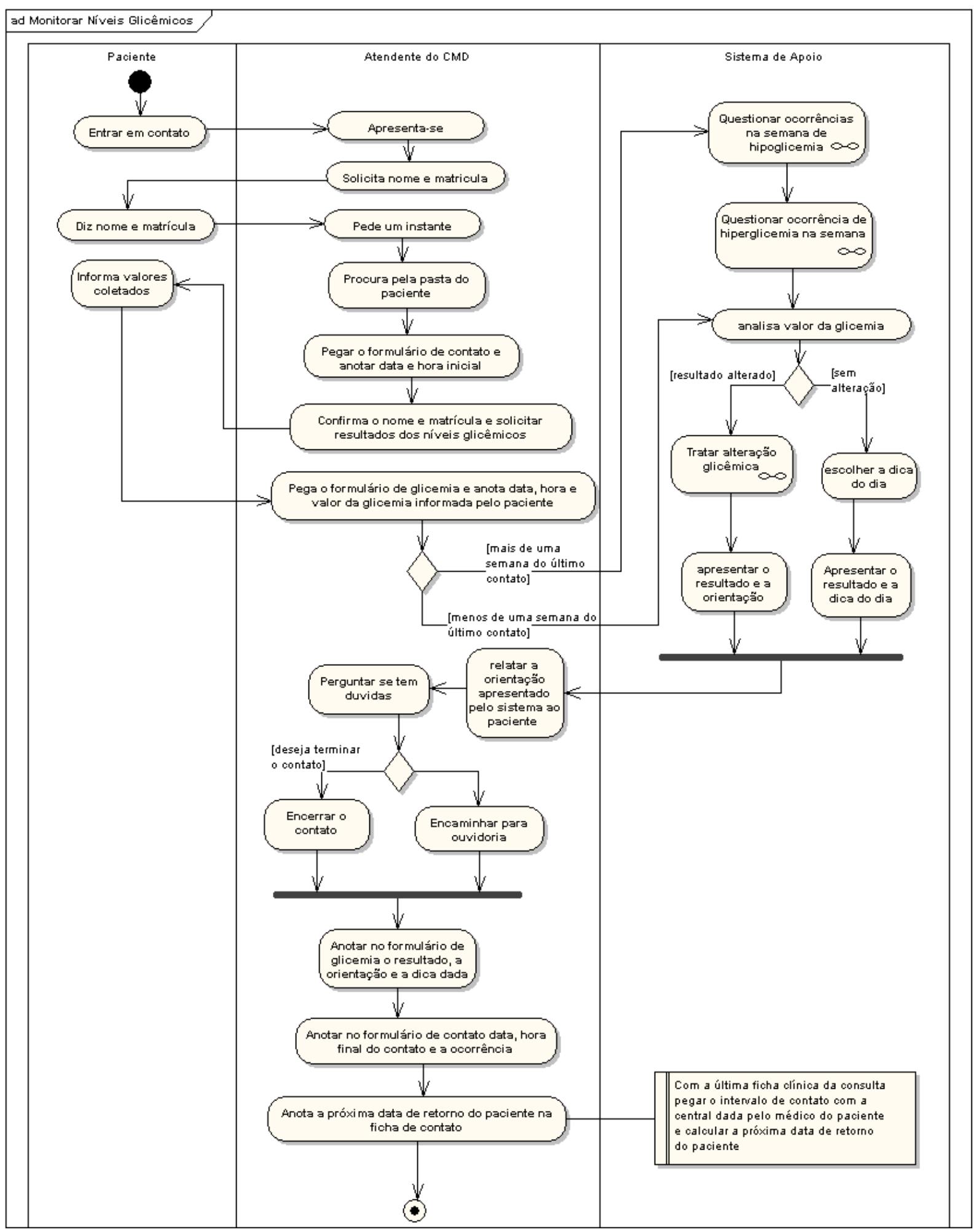

Figura 3.4 - Diagrama de atividade do controle da glicemia 
Ao detalhar os casos de uso de negócio é possível descobrir novos processos de negócio e estruturar os relacionamentos dos casos de uso no diagrama de caso de uso de negócio. Esse diagrama representa o conjunto dos casos de uso de negócio relacionados com os seus respectivos atores de negócio. O relacionamento entre o caso de uso de negócio e o ator de negócio é representado por uma linha contínua, como no caso de uso da UML. A Figura 3.5 apresenta o diagrama de caso de uso de negócio da CMD. Da mesma forma que existem relacionamentos de inclusão, extensão e generalização entre os casos de uso da UML, na extensão para negócio também existem. Aqui os conceitos não se modificam. (12) (36)

O relacionamento de inclusão ocorre quando um caso de uso base exige um conjunto de atividades necessárias para a sua execução no fluxo básico; porém, não é o objetivo do caso de uso base. Por exemplo, no caso de uso base "venda de um produto no balcão", para terminá-lo é necessário que o cliente faça o pagamento. Porém, o pagamento não é o objetivo do caso de uso base; o objetivo é vender. Nessa situação cria-se um caso de uso "pagamento" e um relacionamento de inclusão entre o caso de uso criado e o base. A representação é uma linha tracejada da base para o caso de uso incluso, acrescida da palavra inclusão entre os sinais de maior e menor ( $<<$ inclusão $>>)$.

O relacionamento de extensão ocorre quando um caso de uso base tem um conjunto de atividades necessárias numa exceção e que configuram o fluxo básico de um novo caso de uso. Por exemplo, no caso de uso base "empréstimo de livro", se o livro estiver emprestado, o leitor pode reservá-lo. Entretanto, reservar o livro configura um outro caso de uso e um relacionamento de extensão é criado entre os dois. A representação é uma linha tracejada do caso de uso estendido para o caso base, acrescida da palavra extensão entre os sinais de maior e menor $(<<$ extensão $>>)$.

O relacionamento de generalização ocorre quando um caso de uso genérico (pai) possui um fluxo básico em que somente alguns pontos são diferentes em seus casos de uso específicos (filho). Por exemplo, no caso de uso pai "pesquisar livros", a pesquisa difere somente na escolha dos tipos de pesquisa e na busca no banco de dados. Criam-se casos de uso filhos para cada uma das alternativas de pesquisa, por autor, por título ou por assunto. A representação é uma linha contínua em que os casos de uso filhos apontam para o seu pai. 


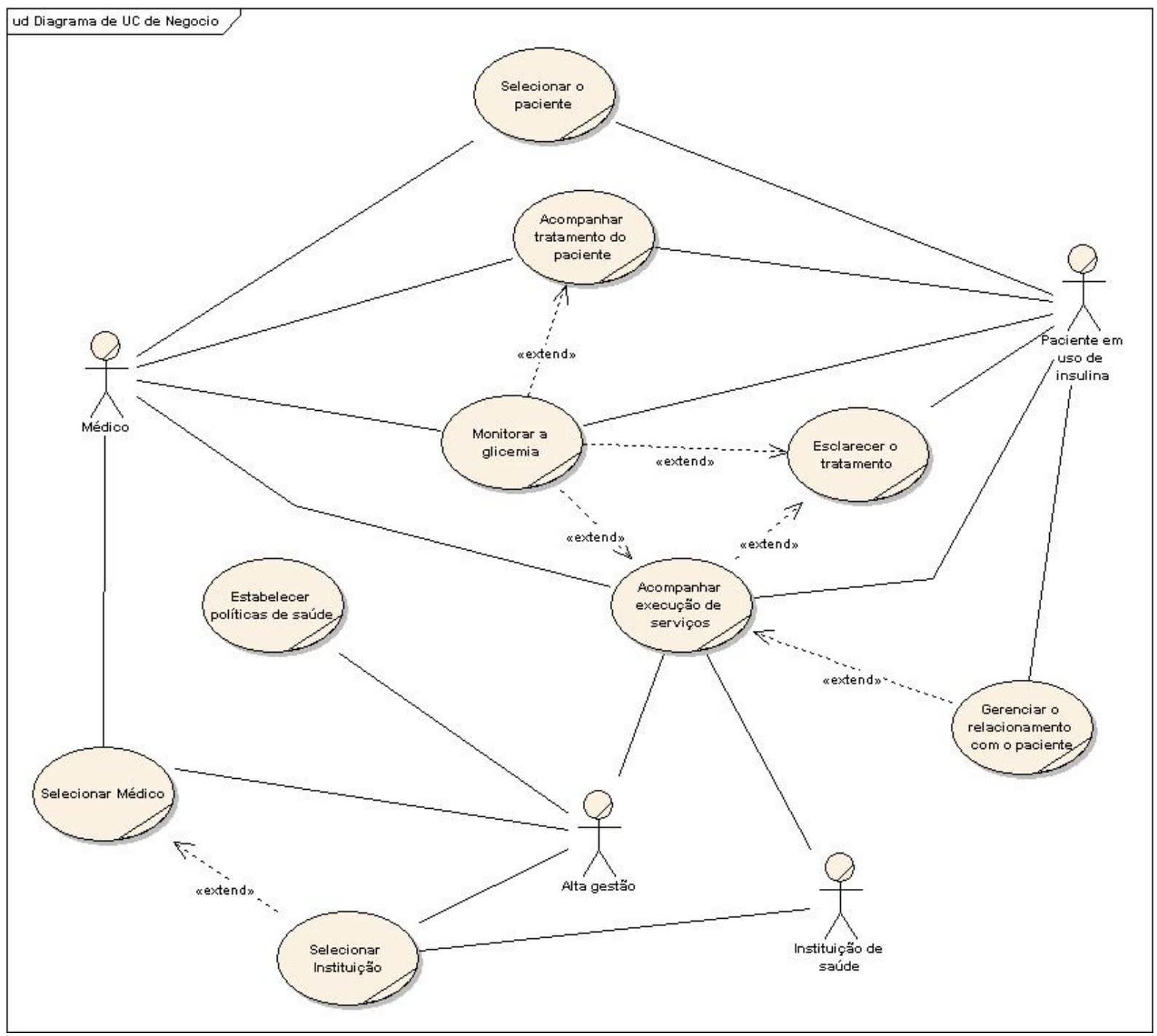

Figura 3.5 - Diagrama de caso de uso de negócio da central de monitoração de diabéticos

\subsubsection{Arquitetura dos Processos de Negócio}

Sabendo como um caso de uso de negócio se comporta é preciso identificar quem realiza as ações desse comportamento e o que é preciso para executar o comportamento desejado. Isso é feito através da elaboração do modelo de objeto de negócio, que é composto por trabalhadores e entidades de negócio.

O trabalhador de negócio representa um papel e as responsabilidades daqueles que executam os serviços da organização. Eles são identificados pelos papéis que se encontram nas raias do diagrama de atividade ou na descrição do fluxo básico e alternativo. No caso de 
uso de negócio "monitorar a glicemia", os trabalhadores de negócio são: o atendente, o médico coordenador e o médico especialista.

As entidades de negócio representam as "coisas" manipuladas ou utilizadas pelos trabalhadores de negócio na execução do caso de uso. Geralmente, uma entidade de negócio é um documento ou uma parte do produto, mas pode representar algo menos tangível. $\mathrm{O}$ aval positivo do paciente ao telefone quando questionado se deseja participar do programa da central de monitoração é um exemplo de uma entidade de negócio que não representa um documento ou parte do produto. As entidades de negócio no caso de uso "monitorar a glicemia" são: ficha clínica, ficha clínica de consulta, ficha do paciente, formulário de controle de paciente, formulário de glicemia, intercorrência, lista de não assíduos, pasta do paciente e o sistema de apoio à decisão.

O diagrama de objeto de negócio representa graficamente os trabalhadores de negócio e as entidades de negócio que participam num determinado caso de uso de negócio. No diagrama, uma linha contínua interligando um trabalhador de negócio a uma entidade de negócio significa que o trabalhador manipula ou utiliza aquela entidade para executar o caso de uso de negócio. A Figura 3.6 representa o diagrama de objeto de negócio do caso de uso "monitorar a glicemia".

Após elaborar a modelagem de negócio é possível encontrar os processos de negócio que podem e devem ser informatizados, entender como os sistemas existentes se enquadram na organização, derivar os seus requisitos e saber onde o sistema novo irá se encaixar nos processos da organização. São feitas a análise e a avaliação das automações possíveis no negócio e definem-se os requisitos. Os dados que serão manipulados e suas regras são identificados através das entidades de negócio. (51) (92)

\footnotetext{
${ }^{9}$ Utilizou-se o termo "coisas" porque as entidades de negócio representam desde comportamentos como o aval positivo do paciente até papéis, exames, documentos em geral, entre outros. Assim, "coisas" (things em inglês) parece ser o termo mais adequado para englobar a diversidade das entidades de negócio.
} 


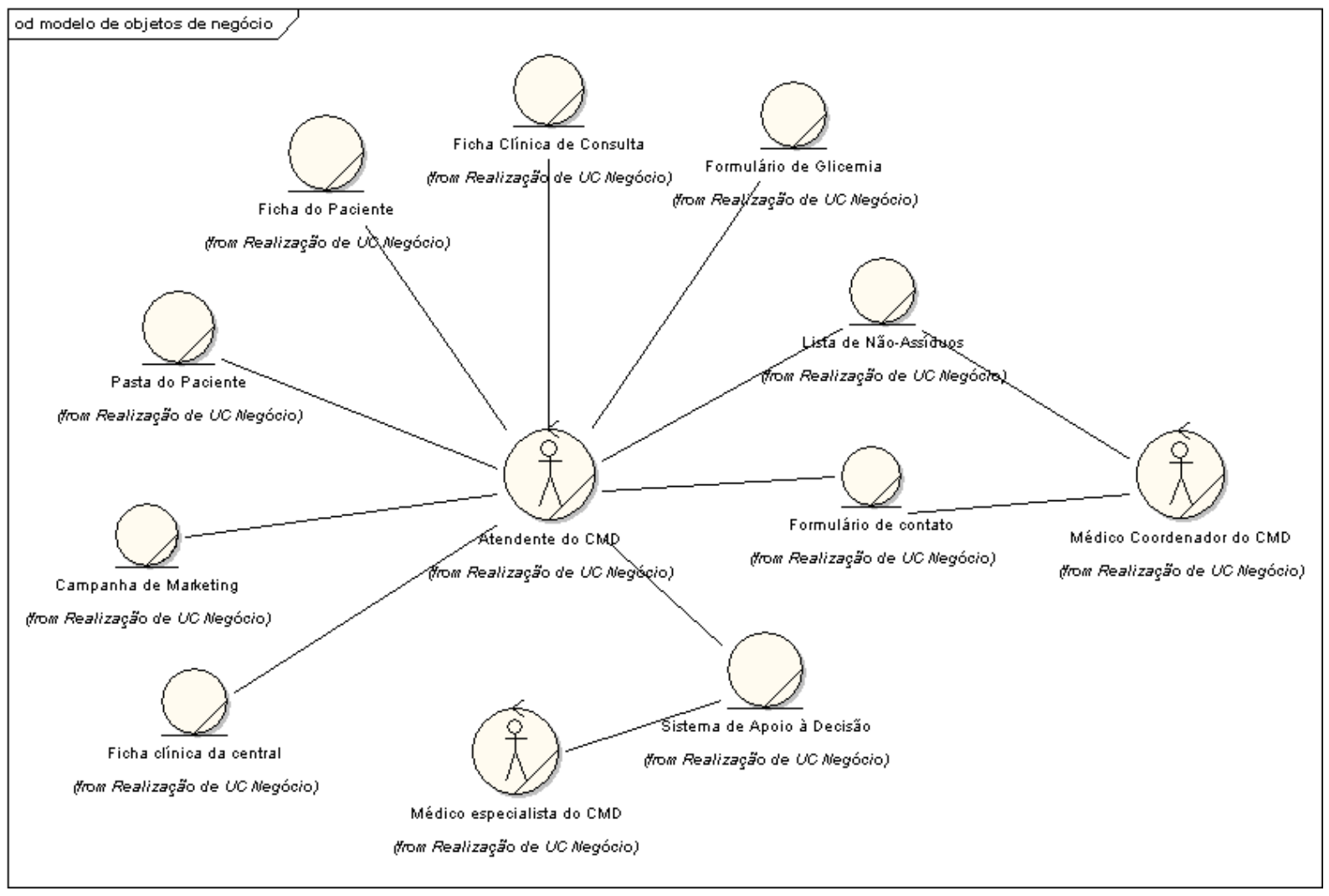

Figura 3.6 - Diagrama de atividade do controle da glicemia

Pela modelagem de negócio conclui-se que o sistema de informação que dará suporte à Central de Monitoração do Paciente Diabético é grande e complexo. Para o desenvolvimento deste trabalho selecionou-se um caso de uso de negócio para ser desenvolvido. No próximo capítulo são apresentadas a seleção de requisitos relacionados com o caso de uso de negócio escolhido, a justificativa da tecnologia utilizada para o desenvolvimento do software, a arquitetura e a implementação do sistema desenvolvido. 


\section{Sistema TeleDM - Protótipo do Software de Monitoração de Diabéticos}

Ao definir e conceituar o modelo GRPC verificou-se que para viabilizá-lo, na prática, é necessária criar uma infra-estrutura de tecnologia de telecomunicação e informação e um local que a comporte. O CRC foi proposto como local que pudesse comportar o modelo. Pela literatura, verificou-se a existência de centros de monitoração para pacientes diabéticos que possuem parte da infra-estrutura exigida para a implantação de um CRC. Assim, uma central de monitoração para diabéticos foi modelada em termos de seus processos, com o objetivo de demonstrar a viabilidade do modelo GRPC e da evolução de uma central de monitoração para o CRC.

Já para comprovar a viabilidade da monitoração do paciente no modelo GRPC foram realizadas simulações computacionais. Desse modo, para as simulações, elaborou-se o sistema TeleDM, que implementa o processo de monitoração do paciente diabético. A seguir, é apresentado o desenvolvimento desse sistema.

\subsection{Seleção de Requisitos para o Sistema TeleDM}

Ao analisar os modelos de casos de uso de negócio e a arquitetura dos processos de negócio da CMD, formulou-se a definição dos requisitos do sistema, que são descritos a seguir:

a. Controlar de forma personalizada os níveis glicêmicos do diabético, por meio de uma análise imediata do resultado de exame, fornecendo orientações automáticas em caso de anormalidade ou sugerindo condutas (“dicas”) que trazem benefício ao paciente;

b. Permitir que o paciente entre em contato com a central através do telefone, do celular ou do fax, utilizando a URA e o DAC, além do PDA e de ferramentas da Internet;

c. Controlar, acompanhar e apoiar a assiduidade no contato do paciente com a central;

d. Elaborar manuais ou páginas na internet com as perguntas mais freqüentes (FAQ) sobre o tratamento, a fim de orientar as dúvidas dos pacientes; 
e. Elaborar e acompanhar campanhas de prevenção e educação do diabético;

f. Produzir relatórios, quadros estatísticos e gráficos para o acompanhamento do diabético pelo médico;

g. Emitir alertas para os médicos em casos de anormalidade ocorridos com seus pacientes;

h. Apoiar o atendimento de intercorrências, emitindo alertas ao médico, indicando locais de pronto atendimento mais próximo ao paciente e orientando o paciente ou o seu cuidador enquanto aguarda o resgate;

i. Permitir que o médico possa acompanhar o seu paciente por intermédio do computador, PDA e celular;

j. Permitir que o médico solicite o agendamento de consultas e exames, além do envio de orientações aos seus pacientes;

k. Implementar os principais protocolos de acompanhamento ao paciente diabético, recomendados pelas organizações de saúde;

1. Implementar o EHR, permitindo que se tenha acesso a todas as fontes de informações do paciente acompanhado pela central;

m. Gerenciar o relacionamento do paciente com a central, emitindo relatórios mensais aos responsáveis;

n. Acompanhar e auxiliar o contato do médico com a central;

o. Acompanhar os serviços prestados pela central aos pacientes e aos médicos;

p. Fornecer segurança no acesso às informações da central.

O objetivo do sistema TeleDM é permitir a simulação da monitoração do paciente no modelo GRPC, como foi definido no item 3.5.1. Assim, desses requisitos tem-se que os itens (a), (b) e (h) estão relacionados com o processo de monitoração do diabético, e portanto foram escolhidos para serem implementados.

O escopo do sistema, as restrições e as suas funcionalidades são apresentados nas próximas seções. 


\subsection{Escopo do Sistema TeleDM}

O contexto para o desenvolvimento do sistema TeleDM envolve o processo de monitoração do paciente diabético e os requisitos escolhidos em 4.1. Dessa forma, por meio da coleta com periodiciadade regular (a ser definida pelo médico do paciente e de acordo com as características e necessidades de cada paciente, por exemplo, diária ou semanal) da glicemia do paciente e utilizando protocolos de procedimentos para o controle do diabetes mellitus, faz-se a monitoração desses pacientes fornecendo um retorno imediato da conclusão do resultado de seu exame em casos de normalidade. Em casos de anormalidade, nos quais a intervenção de um profissional de saúde se faz necessária, o atendente imediatamente entra em contato com o médico e encaminha o paciente ao local adequado para o seu atendimento. A Figura 4.1 representa de forma esquemática o escopo do projeto.

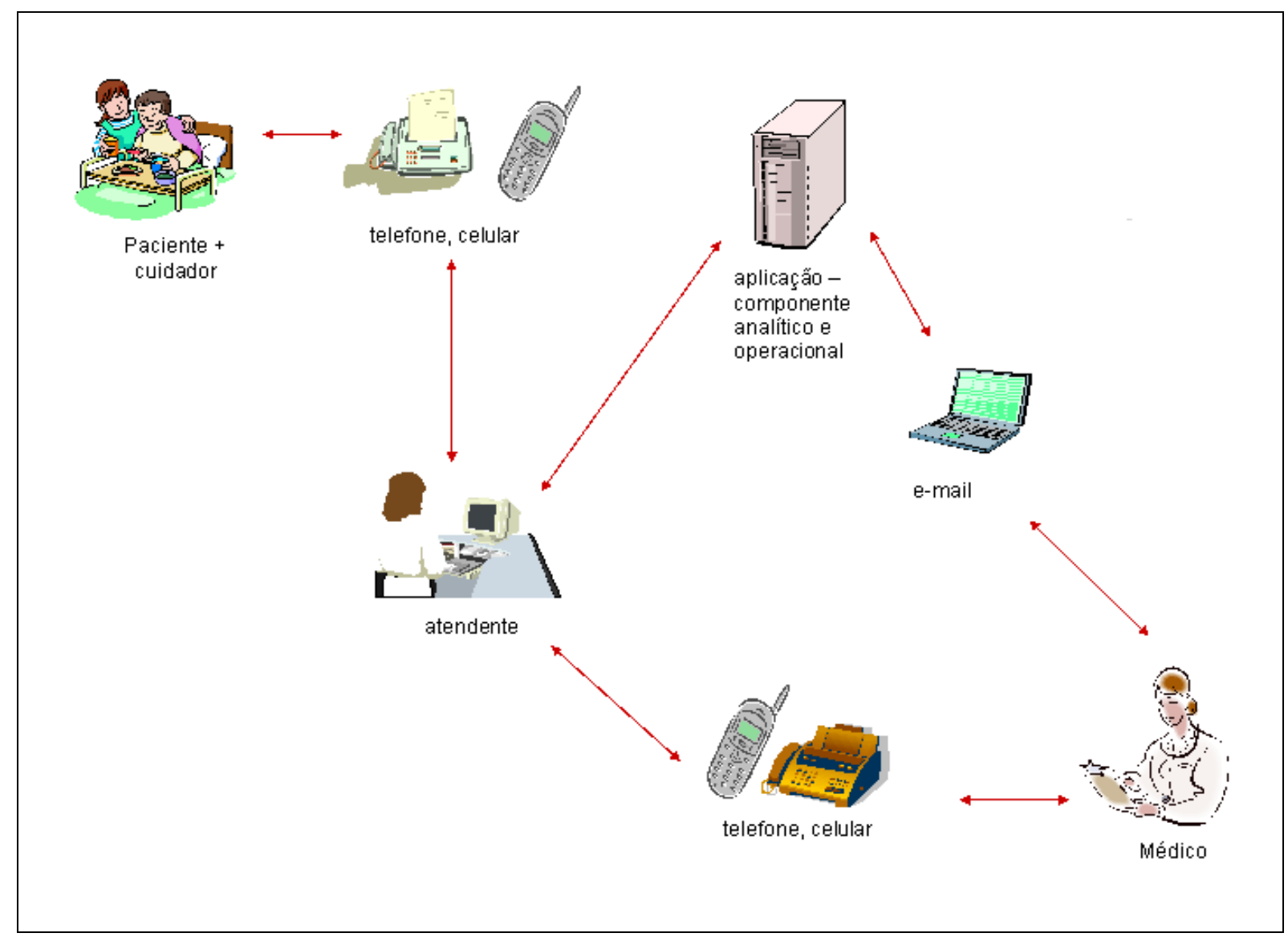

Figura 4.1 - Esquema do contexto do Sistema TeleDM

Em relação à arquitetura do modelo GRPC, implementaram-se os componentes: operacional, analítico e colaborativo, conforme demonstrado na Figura 4.2. Para o componente operacional, coletaram-se as informações referentes aos contatos dos pacientes com a central, 
o que se chamou de Registro do Paciente Diabético. O componente analítico compreende o sistema de monitoração primária; e o colaborativo, o telefone como meio de comunicação.

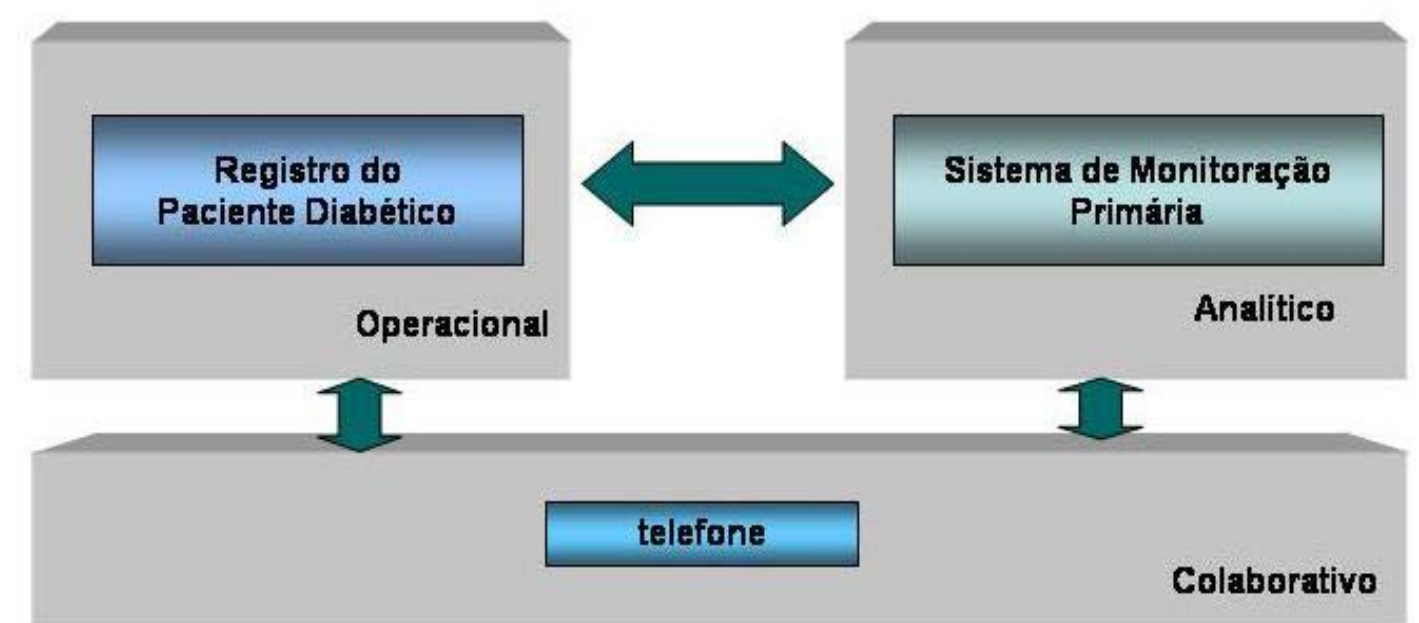

Figura 4.2 - Componentes do Modelo GRPC que foram desenvolvidos no sistema TeleDM

\subsubsection{Restrições e Premissas}

Algumas restrições foram impostas no desenvolvimento do Sistema TeleDM, de modo a simplificar o seu desenvolvimento. Tais aspectos, que fazem parte do escopo deste trabalho, são listados a seguir:

- O paciente tem somente um canal de comunicação, que é o telefone, não sendo simulado o uso do DAC e da URA. O contato é sempre feito através de um atendente pois, para a simulação, o uso dessas tecnologias não interfere no processo de diagnóstico e orientação do paciente.

- Não é fornecida, em casos de normalidade no resultado de exame, uma informação (“dica") que traga algum tipo de benefício ao tratamento, pois a simulação concentra-se na monitoração através do sistema especialista.

- Em caso de anormalidade e na necessidade de envio de um alerta ao médico, este é feito através do envio de um e-mail e de um telefonema. Não foi simulado qualquer outro tipo de aviso como, por exemplo, o envio de sinal para o bip do médico.

- O sistema não localiza o pronto atendimento mais próximo do paciente quando ele necessitar desse serviço. A simulação não prevê pedir a localização do paciente no momento do contato. 


\subsubsection{Funcionalidades do Sistema}

Para representar as funcionalidades do sistema utilizou-se o diagrama de casos de uso. Como foi visto no item 3.4.1, o diagrama de caso de uso representa todas as funcionalidades do sistema, facilmente derivadas do modelo de casos de uso de negócio (51) (92).

De acordo com a Rational University (92), para derivar o modelo de casos de usos do sistema, deve-se analisar os casos de uso de negócio e verificar a possibilidade da sua automação.

Inicialmente definem-se os subsistemas do projeto. Assim, cada caso de uso de negócio que for automatizado será um subsistema do projeto. No presente trabalho, o caso de uso de negócio "monitorar a glicemia" torna-se o subsistema "monitoração de diabéticos", pois ele foi escolhido para compor o sistema TeleDM.

O próximo passo é verificar se todas as atividades do trabalhador de negócio serão automatizadas. Se isso ocorrer, o trabalhador de negócio não é candidato a ator do sistema (92). Com um sistema de apoio à decisão que fornece respostas automáticas no controle da glicemia, as atividades do médico especialista são totalmente informatizadas. Nessa situação, o médico especialista não é um ator do sistema.

Os trabalhadores de negócio que não têm suas atividades totalmente informatizadas e que por isso interagem com o sistema tornam-se atores do sistema (92). Esse fato ocorre com o atendente. Além disso, de acordo com Jacobson (61), os casos de uso representam as funcionalidades que o sistema realiza e que fornecem um benefício a um ator específico. Assim, o paciente e o seu médico, apesar de não interagirem diretamente com o sistema, são atores, pois se beneficiam do sistema.

Os casos de usos são definidos analisando-se o fluxo de trabalho do caso de uso de negócio e agrupando as atividades que serão automatizadas nos casos de usos correspondentes. A tabela 4.1 mostra a análise do caso de uso de negócio "monitorar a glicemia". 
Tabela 4.1 - Encontrando os possíveis casos de uso do sistema TeleDM

\begin{tabular}{|c|c|c|}
\hline $\begin{array}{c}\text { Trabalhador ou } \\
\text { Ator de Negócio } \\
\end{array}$ & Conjunto de atividades & Caso de Uso \\
\hline \multirow[t]{4}{*}{ Atendente } & Médico é informado de intercorrência & - Comunicar intercorrência \\
\hline & Paciente não entra em contato & $\begin{array}{l}\text { - } \quad \text { Verificar assiduidade } \\
\text { - Notificar ausência }\end{array}$ \\
\hline & Controle da glicemia do paciente & $\begin{array}{l}\text { - } \quad \text { Monitorar níveis glicêmicos } \\
\text { - } \quad \text { Comunicar intercorrência } \\
\text { - Receber dica }\end{array}$ \\
\hline & $\begin{array}{l}\text { Informar os procedimentos a serem } \\
\text { seguidos }\end{array}$ & $\begin{array}{l}\text { - Monitorar níveis glicêmicos } \\
\text { - Receber dica }\end{array}$ \\
\hline
\end{tabular}

A descrição sumária dos casos de uso "monitorar diabéticos" é apresentada a seguir e encontra-se representada na Figura 4.3:

- Comunicar Intercorrência - Nos casos em que é preciso informar o médico do paciente sobre os procedimentos recomendados, como em casos de necessidade de agendar uma consulta ou para a remoção do paciente a uma unidade de pronto atendimento, o sistema emite um alerta para o atendente, que imediatamente telefona e/ou envia um e-mail para ele;

- Monitorar Níveis Glicêmicos - A monitoração dos níveis glicêmicos ocorre quando o paciente, periodicamente, entra em contato com a central e relata sua medida de glicemia e alterações no seu estado clínico. O sistema analisa o resultado e fornece uma orientação ao paciente;

- Notificar Ausência - Diariamente o sistema avisa aos atendentes, a respeito de pacientes cuja falta de assiduidade esteja comprometendo a eficácia do seu programa de monitoramento. Nesse caso, o atendente entra em contato para saber o motivo da ausência e explica a importância de seguir o programa. Caso o paciente não queira mais participar do programa, esta informação é armazenada no sistema. O paciente é informado de que o seu médico será avisado e de que deve aguardar o contato dele. O atendente não está autorizado a excluir os pacientes do programa;

- Selecionar Dica - O sistema seleciona uma dica de campanha a ser dada para o paciente de acordo com o seu histórico clínico;

- Verificar Assiduidade - O sistema averigua se existe algum paciente cuja falta de assiduidade esteja comprometendo o programa de controle personalizado. $\mathrm{O}$ 
comprometimento será caracterizado quando da ausência de contato do paciente por mais de duas vezes consecutivas.

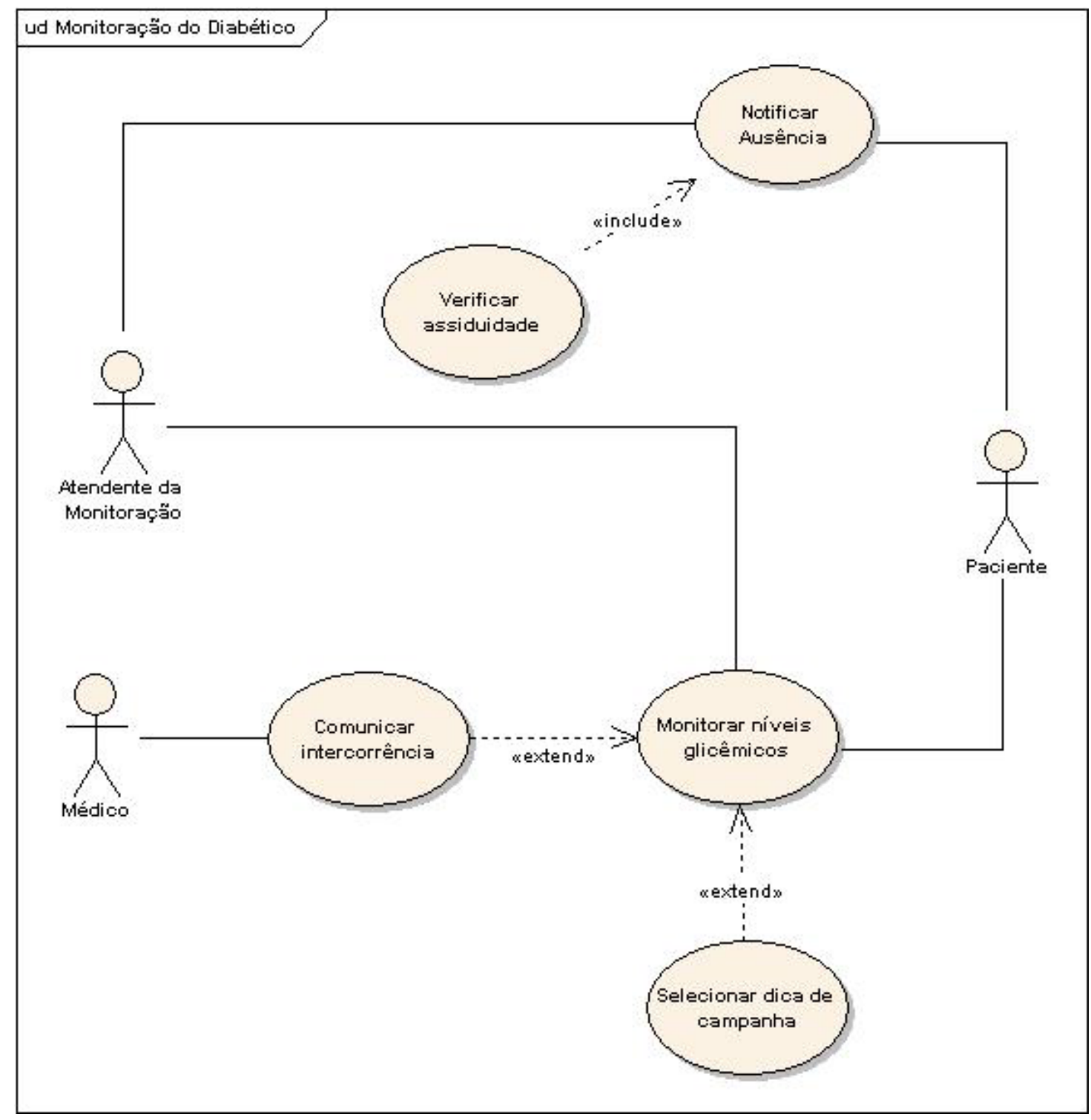

Figura 4.3 - Diagrama de Caso de Uso derivado do Modelo de Caso de Uso de Negócio

Devido às restrições impostas no sistema, conforme apresentado em 4.2.1, algumas alterações foram realizadas no diagrama de caso de uso derivado da modelagem de negócio. Os casos de uso "notificar ausência", "verificar assiduidade" e "selecionar dica" foram retirados do diagrama. O caso de uso "identificar o paciente" foi adicionado, pois é necessário saber quem é o contato que deseja controlar a sua glicemia no momento. O diagrama de caso de uso resultante encontra-se na Figura 4.4. 


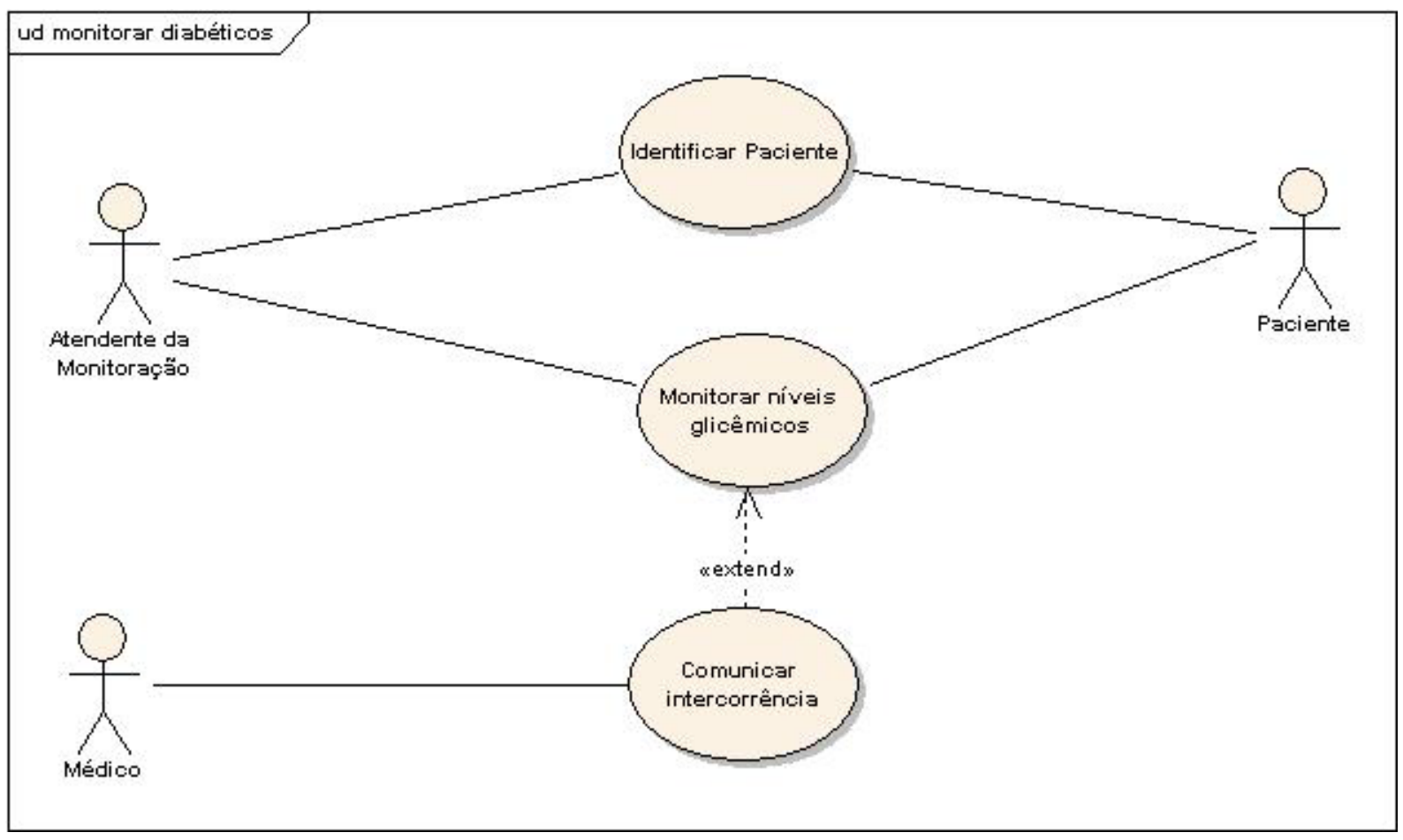

Figura 4.4 - Diagrama de Caso de Uso Final do subsistema monitoração de diabéticos

Da mesma forma que se detalham os processos nos casos de uso de negócio, devem ser especificados os casos de uso para documentar o seu comportamento (1) (74). Existem dois tipos de fluxos para especificar os casos de uso:

- Fluxo básico - quando a atividade é realizada com sucesso, ou seja, o objetivo do caso de uso é alcançado (comportamento ideal);

- Fluxo alternativo - quando ocorre um evento que provoca um desvio no fluxo básico, ou seja, a atividade não é realizada com sucesso.

Existem muitos estilos para descrever a especificação dos casos de uso. Recomenda-se numerar e colocar um título em cada passo, para que se obtenha uma visão geral do fluxo sem precisar ler todos os detalhes. Ao contrário do que ocorre na modelagem de negócio, não é obrigatório representar os detalhes dos fluxos de eventos no diagrama de atividade. Essa representação é indicada somente nos casos em que existam muitas regras de negócio, para que sua visualização fique mais fácil com o uso do diagrama de atividade. (12) (23) (96)

A especificação de cada caso de uso do sistema TeleDM está listada a seguir:

a. Caso de Uso: Identificar Paciente 


\section{Fluxo Básico}

i. O atendente comunica ao sistema que um paciente entrou em contato.

ii. O atendente informa ao sistema a matrícula do paciente.

iii. O sistema resgata os dados de identificação do paciente: matrícula, nome e telefone. O sistema identifica quais são as possibilidades de interação que o contato pode ter.

iv. O sistema resgata do sistema operacional a data e a hora inicial do contato e guarda esses dados.

v. O sistema apresenta ao atendente os dados de identificação e as possibilidades de contato. $\mathrm{O}$ atendente verifica se os dados resgatados pertencem ao paciente, questionando seu nome e telefone.

\section{Fluxo Alternativo}

i. O paciente não possui o número de matrícula - Caso o contato não tenha o seu número de matrícula, o atendente avisa o paciente que a sua adesão à central está em andamento. Se o paciente tiver dúvidas, é encaminhado para o setor de "acompanhamento de serviços".

ii. O paciente não lembra o número de matrícula - $\mathrm{O}$ atendente pergunta se ele é um paciente. Em seguida, pergunta o seu nome e o nome de sua mãe. $\mathrm{O}$ atendente informa então o nome do paciente e de sua mãe ao sistema e continua a partir do passo iii do fluxo básico.

iii. $\mathrm{O}$ paciente erra o número de matrícula $-\mathrm{O}$ atendente pergunta o seu nome e o nome da mãe dele. Na seqüência, informa o nome do paciente e de sua mãe ao sistema e continua a partir do passo iii do fluxo básico.

iv. O sistema não encontrou os dados do paciente - Mesmo com o nome da mãe e o do paciente o sistema não encontrou os dados. O atendente deve então avisar ao paciente de que seu cadastro está com problemas e encaminhá-lo para o setor de "acompanhamento de serviços".

v. A matrícula informada não é a do paciente que entrou em contato - A matrícula fornecida ao sistema não pertence ao paciente que entrou em contato. $\mathrm{O}$ atendente não confirma os dados. Em seguida, informa o nome do paciente e de sua mãe ao sistema e continua a partir do passo iii do fluxo básico. 
b. Caso de Uso: Monitorar Níveis Glicêmicos

\section{Fluxo Básico}

i. O atendente informa ao sistema o valor da glicemia, a data e a hora da medição.

ii. O sistema analisa o resultado da glicemia de acordo com as regras informadas pelo especialista.

iii. O sistema apresenta o resultado da glicemia e orientações.

iv. $\mathrm{O}$ atendente avisa o sistema de que o contato terminou. $\mathrm{O}$ sistema resgata do sistema operacional a data e a hora final do contato e armazena esses dados.

\section{Fluxo Alternativo}

i. O médico precisa ser notificado da conduta dada ao paciente - $\mathrm{O}$ sistema notifica o episódio de hipoglicemia ou hiperglicemia ao médico do paciente por intermédio do caso de uso "comunicar intercorrência".

c. Caso de Uso: Comunicar Intercorrência

\section{Fluxo Básico}

i. O sistema busca os dados do médico do paciente, escolhe o e-mail de notificação padrão e envia uma mensagem para o médico comunicando que o paciente encontrase em um estado anormal de glicemia (hipo ou hiperglicemia).

ii. O atendente é informado das ações tomadas pelo sistema, bem como das orientações de procedimentos específicos que ele precisa realizar imediatamente.

Fluxo Alternativo

i. O sistema não consegue enviar e-mail - Se o sistema não conseguir enviar a mensagem em três tentativas consecutivas, ele solicita ao atendente para telefonar ao médico, a fim de comunicar o conteúdo do e-mail não enviado. 


\subsection{Seleção da Tecnologia para o Desenvolvimento do Sistema TeleDM}

Realizou-se um estudo das características do sistema TeleDM para que se pudesse escolher a tecnologia a ser utilizada no seu desenvolvimento. As características encontradas foram:

- O sistema precisa ter capacidade para resolver problemas (analisar o resultado de glicemia e a partir dele definir uma conduta) e responsabilidades (avisar, ou não, o médico; e enviar ou não, o paciente a um pronto atendimento);

- As interações entre os elementos de software para implementar as funcionalidades incluem: negociação, compartilhamento de informação e coordenação, pois o sistema TeleDM possui regras e tomadas de decisões, como as citadas no item anterior;

- A solução não pode ser inteiramente descrita do princípio ao fim, devido às diversas mudanças que podem ocorrer nas regras de análise do resultado da glicemia e definição da conduta.

A Tecnologia Orientada a Agentes facilita o desenvolvimento de sistemas com as características do TeleDM. Nessa tecnologia os elementos de software são projetados para resolverem problemas e responsabilidades, apresentarem interação flexível e permitirem implementar a coordenação, a negociação e a troca de informações (9) (63) (65).

Segundo Mea (79) a telemedicina, ao ser vista como uma comunidade de entidades interativas com o objetivo de apoiar a colaboração e o compartilhamento de recursos no campo médico, é facilmente implementada ao utilizar o paradigma da orientação a agentes.

Assim sendo, o principal elemento nessa tecnologia é o agente. Em termos conceituais o agente deriva da noção de agência. De acordo com esse conceito, o agente atua no lugar de alguém, pois ele tem a capacidade de se comunicar com outros para realizar a tarefa que lhe foi designada (116). No software, os agentes representam papéis de pessoas do mundo real que têm as suas atividades implementadas no sistema. Da mesma forma que existem interações entre as pessoas para a execução de tarefas, nos sistemas desenvolvidos com a tecnologia de agentes há comunicação entre os agentes para realizar as suas atividades, ou em outras palavras, alcançar os seus objetivos. (104) (125) 
Apesar da simplicidade do conceito, não existe um consenso entre os autores sobre a definição de agente. Cada autor define-o segundo a sua perspectiva. (104) (125)

Para a arquitetura proposta neste trabalho utilizaremos a seguinte definição de Wooldridge (125) "Um agente é um sistema computacional que está situado em algum ambiente e que é capaz de ações autônomas neste ambiente de modo a alcançar os seus objetivos.”

Posta a definição de agente, é preciso entendê-la no âmbito do desenvolvimento de software para facilitar a compreensão e a implementação de sistemas nessa tecnologia. Desse modo, observa-se que, na verdade, o agente evolui de conceitos anteriores, conforme apresentado na tabela 4.2 .

Tabela 4.2 - Evolução dos conceitos para o desenvolvimento de software desde o seu início até os dias atuais Fonte: ODELL, J. Objects and Agents: How do they differ? (87)

\begin{tabular}{|c|c|c|c|c|}
\hline Unidade $\backslash$ Conceito & Monolítico & Modular & $\begin{array}{c}\text { Orientado a } \\
\text { Objetos }\end{array}$ & $\begin{array}{c}\text { Orientado a } \\
\text { Agentes }\end{array}$ \\
\hline Comportamento & $\begin{array}{l}\text { Não } \\
\text { modular }\end{array}$ & Modular & Modular & Modular \\
\hline Estado & Externo & Externo & Interno & Interno \\
\hline Invocação & Externo & $\begin{array}{l}\text { Externo } \\
\text { (chamada de } \\
\text { função) }\end{array}$ & $\begin{array}{l}\text { Externo } \\
\text { (mensagem) }\end{array}$ & $\begin{array}{l}\text { Interno } \\
\text { (regras e } \\
\text { objetivos) }\end{array}$ \\
\hline
\end{tabular}

No início do desenvolvimento de sistemas havia somente o conceito monolítico, no qual o sistema todo era concebido como um único bloco. Os programadores tinham total controle sobre os programas e seu estado. As chamadas de suas funcionalidades eram feitas pelo operador de computadores. À medida que os sistemas começaram a ficar mais complexos e a exigir memórias maiores e processadores mais poderosos, os programadores sentiram a necessidade de introduzir algum tipo de organização no código ${ }^{10}$. Surgiu, então, o conceito de modularidade. Os programas passaram a ser organizados em fragmentos menores denominados subrotinas, utilizadas em várias situações, o que aumentou, a integridade local. As subrotinas, porém, não possuem controle sobre os estados das variáveis que manipulam e são executadas por inteiro quando chamadas. (30) (87) (124)

A orientação a objetos, por sua vez, acrescenta ao conceito modular uma das características

\footnotetext{
${ }^{10}$ Sistema de símbolos usado para representar informações e instruções, de modo que um programa possa ser processado pelo computador (52)
} 
que se obtém ao decompor os sistemas por componentes: a possibilidade de ter controle sobre o estado das variáveis que manipula. Nessa tecnologia, os objetos são passivos, pois não possuem controle sobre suas ações. As ações são executadas apenas quando solicitadas. O objeto que executa não pode interagir com o objeto que solicitou a execução da ação. (12)

Do mesmo modo, a orientação a agentes acrescenta à tecnologia anterior o conceito de autonomia. Os agentes possuem controle não somente do estado de suas variáveis, mas também sobre as suas ações. Eles têm as suas próprias regras e objetivos e isso faz com que pareçam "objetos ativos com iniciativa". Assim, ao contrário dos objetos que não interagem entre si de forma dinâmica, na tecnologia orientada a agentes isso é possível. Um agente pode questionar outro na execução de alguma ação, comunicá-lo de que há falta de dados para executá-la, pedir outras informações para complementá-la, ou até mesmo recusar a sua execução. Na prática, dois sistemas de fabricantes diferentes poderiam trocar dados com segurança e sem a necessidade de pertencerem à mesma plataforma. Por exemplo, o agente do aplicativo A somente fornece a informação caso o agente do aplicativo B tenha permissão e os requisitos necessários para isso. Com relação à utilização de componentes no sistema, ocorre uma diminuição, já que o agente encapsula toda a infra-estrutura de comunicação e manipulação das informações. Desse modo, o desenvolvedor preocupa-se apenas em projetar as responsabilidades e os objetivos dos agentes que farão parte do sistema. (59) (87) (125)

Para operarem, os agentes precisam existir dentro de um ambiente que define as propriedades do mundo no qual atuam. Uma vez que os agentes precisam entender e conhecer o ambiente em que se encontram, é necessário criar uma estrutura adequada que os comporte e os represente. Por sua vez, o ambiente pode ser classificado em: físico e de comunicação. (95) (119)

O ambiente físico se refere ao meio em que o agente se encontra e no qual precisa interagir a fim de alcançar seus objetivos ou até decidir qual deve perseguir. Por exemplo, o agente pode interagir com o mundo através de sensores e câmeras. Nesse caso, o modelo do ambiente físico é mais simples, pois as interações que os agentes fazem com o ambiente são diretas. Entretanto, existem situações em que ele é totalmente representado por software. Nessa situação, ele contém os princípios e os processos que governam e apóiam uma população de entidades. Os modelos propostos relacionam-se com o tipo de interação que o agente tem com 
o ambiente. (86) (95) (119) Há modelos que permitem ao agente, por exemplo, ter uma percepção do ambiente, como o Robocup Soccer Server (94) e o modelo ativo de percepção (118). Existem outros que relacionam os agentes e as suas ações no ambiente, como por exemplo o de ação síncrona (39) e o de ação com sincronização regional (117).

O ambiente de comunicação é o meio pelo qual os agentes se inter-relacionam, ou seja, se comunicam. Ele contém os princípios e os processos que governam e apóiam a troca de idéias, conhecimentos, informações e dados. Além disso, possui funções e estruturas que são empregadas para permitir a comunicação e o protocolo de interação entre os agentes e os grupos de agentes. Hunhs \& Stephens (54), FIPA (42), JADE (8), Retsina (111) são algumas das propostas existentes para a implementação do ambiente de comunicação. (86) (119)

De acordo com Weyns et. al:

"Explorar alternativas arquiteturais para relacionar os agentes aos seus ambientes oferece um amplo escopo para uma nova disciplina na engenharia de software. Assim, enquanto pesquisas em relação ao ambiente não forem consideradas importantes para o desenvolvimento de sistemas orientados a agentes, o potencial será do ambiente nesses sistemas não revelados”. ( (119) p. 42)

Schwambach, Pezzin, Falbo (99), notando esta lacuna, propõem em seu trabalho a utilização da tecnologia de orientação a objetos para implementar o ambiente dos agentes. A partir dessa proposta, aplicou-se neste trabalho o paradigma da orientação a objetos para o desenvolvimento do ambiente físico do sistema TeleDM.

A seguir demonstra-se como o uso da teoria de agentes e objetos pode representar o mundo real. O objetivo principal é apontar os elementos do ambiente físico dos agentes que são representados pelos objetos da tecnologia de orientação a objetos.

\subsubsection{O Ambiente Físico Representado pela Arquitetura Orientada a Objetos}

A técnica de produção de modelos é antiga e utilizada em todas as áreas de conhecimento, quando se deseja simplificar a representação do sistema ${ }^{11}$ estudado. A redução da

\footnotetext{
${ }^{11}$ De acordo com Simcsik (108), a definição clássica de sistema "é um grupo de elementos inter-relacionados, independentes e integrados em subsistemas ou não, que, através da partilha de uma ou mais propriedades de coletividade, tem como função produzir e/ou obter determinados objetivos e/ou resultados, como meio de sobrevivência."
} 
complexidade ocorre pela decomposição da realidade em elementos "fáceis de entender". O modelo é uma abstração semanticamente bem encapsulada do sistema, demonstrando a organização e o comportamento dele. (12)

$\mathrm{Na}$ engenharia de software, os modelos comunicam a estrutura e o comportamento do software, permitem visualizar e controlar a arquitetura, gerenciam os riscos e possibilitam compreender melhor o aplicativo que se está construindo, expondo oportunidades de simplificação e reusabilidade. Aliás, a reusabilidade é muito útil no desenvolvimento de software, pois ter códigos prontos que possam ser utilizados novamente aumenta a produtividade.(12)

Outro aspecto da modelagem é que os melhores modelos são aqueles que refletem a realidade. Como os modelos são desenvolvidos para simplificar a realidade, é importante que eles não a distorçam. Para o desenvolvimento de software, o modelo adequado é aquele em que, dada uma situação real, seja possível modelar uma solução que permita facilmente transformá-lo em um sistema computacional. (12) (91) (109)

A orientação a objetos, nesse sentido, parece ser um modo natural de pensar sobre o mundo e de projetar programas de computador. Quando se pensa, por exemplo, em bola, tela, botão, etc., percebe-se que todos eles podem ser representados por objetos na orientação a objetos. (12) (36)

Todavia, a abstração na orientação a objetos é natural somente quando se modelam elementos estáticos que não possuem um comportamento complexo. Quando é preciso modelar elementos que controlam outros de forma ativa, a dificuldade fica evidente. Por exemplo, ao desenvolver uma solução orientada a objetos para trocar o pneu de um carro, é relativamente fácil encontrar os objetos: pneu, carro, macaco e chave de roda. Porém, a afirmação de que esses objetos bastam para modelar a troca de pneu não soa natural, pois nesse caso não há a necessidade de uma pessoa que manipule os objetos. Eles por si só realizam as ações - o que confude as pessoas, já que não são atos que ocorrem no mundo real. Resumindo, percebe-se que modelar elementos estáticos é natural na orientação a objeto, enquanto que o comportamento dinâmico não é simples, pois exige uma capacidade de abstração maior.

Diferentemente, na orientação a agentes temos entidades autônomas e ativas que atuam num ambiente físico que é composto por elementos estáticos. A facilidade está em modelar os 
elementos ativos que controlam os outros e que são representados pelos agentes. No exemplo da troca de pneu, é fácil encontrar o elemento ativo: o mecânico ou o motorista que troca o pneu. Porém, como não há preocupação em representar o ambiente físico é difícil saber qual a representação para o carro, ou até saber se o macaco e a chave de roda são agentes ou não para a solução do problema.

Ao aliar as tecnologias de orientação a objetos e agentes, consegue-se uma forma de representar tanto os elementos ativos quanto os estáticos e, portanto, de obter modelos próximos à representação do mundo real.

No exemplo de cálculo da média final de um aluno que um professor realza, o professor é um elemento ativo, com objetivos e critérios próprios, e melhor representado por um agente. Porém, o professor não consegue alcançar o seu objetivo sem acessar os elementos de seu ambiente, necessários para a execução da tarefa a ele designada. Em suma, o professor precisa da prova do aluno para olhar as notas e a matrícula, de uma calculadora para inserir as notas e calcular a média e do boletim para escrever a média final. No caso, olhar, inserir e escrever são interações do professor que ocorrem com elementos estáticos: provas, calculadora e boletim. A calculadora é um elemento estático, pois mesmo realizando a ação de calcular, não tem vontade própria; por exemplo, não recusa calcular a média de dois números. Por outro lado, de acordo com Wooldridge (125) e Russell (95), da mesma forma que os humanos têm olhos, ouvidos, mãos e outros órgãos para interagir com o ambiente, o agente também tem a sua forma de interação com o seu ambiente. Pode-se concluir que a prova, a calculadora e o boletim são elementos estáticos que representam o ambiente físico do agente professor.

Os elementos estáticos são melhor representados pela orientação a objetos. Afinal, segundo Booch, Rumbaugh, Jacobson (12), a orientação a objetos lida naturalmente com o conceito de objeto, que é uma abstração de elementos encontrados na realidade que se deseja modelar. Assim, é possível dizer que o ambiente físico pode ser representado por objetos da orientação a objetos.

Como o ambiente físico pode ser representado pelos objetos, é necessário definir a forma de interação entre os objetos e os agentes. A interação, nesse caso, representa o ato de "sentir", "olhar", "manipular", entre outros que o agente exerce sobre o seu ambiente. Na orientação a objetos, a forma de ter acesso às operações dos objetos é enviando uma mensagem a eles. 
Dessa forma, a interação entre o ambiente físico e os agentes ocorre através de troca de mensagens entre o agente e o objeto.

O uso das teorias de agentes e objetos facilita a modelagem de sistemas computacionais, tornando-os mais próximos da realidade que automatizam.

Nas próximas seções apresenta-se a utilização dessa modelagem na elaboração da arquitetura e na implementação do sistema TeleDM.

\subsection{Arquitetura do Sistema TeleDM}

Segundo Bass, Clements, Kazman (5), "a arquitetura do software é a estrutura ou estruturas do sistema as quais incluem os elementos de software, suas propriedades visíveis externamente e o relacionamento entre eles" ${ }^{\prime 12}$. Nessa definição, os elementos de software são as partes que constituem o sistema, e as propriedades visíveis externamente são aquelas não relacionadas com os detalhes de sua codificação. Isto implica que todo sistema computacional tem uma arquitetura de software, pois todos os sistemas computacionais contêm elementos que relacionam entre si para implementá-los.

Afirmar que os sistemas apresentam uma arquitetura não significa, porém, que todos a conheçam. Fazer com que a equipe de desenvolvimento conheça a arquitetura do sistema é importante, porque torna possível avaliar antecipadamente se os requisitos do software foram atingidos, tomar decisões significativas sobre a organização do sistema e selecionar os elementos de software (estrutura e relacionamento). (5) (12) (23)

Por tudo isso, verifica-se a necessidade de documentar a arquitetura para que se consiga resolver os problemas mencionandos anteriormente e comunicá-los a todos os interessados no sistema.

No sistema TeleDM é definida a arquitetura de agente a ser utilizada e o ambiente físico em que eles interagem.

\footnotetext{
${ }^{12}$ Na definição de Bass, Clements, Kazman da edição de 1998 ( (6) apud (91) p. 358) utilizava-se o termo "componente" em vez de "elemento de software. Houve a mudança porque hoje o termo "componente" designa um elemento de software específico da orientação a objetos.
} 


\subsubsection{Arquitetura de Agentes do Sistema TeleDM}

De acordo com o conceito de que os agentes são papéis responsáveis pela execução de tarefas no sistema, na modelagem de negócio, o ator e o trabalhador de negócio representam papéis de pessoas que podem ter ou não as suas atividades automatizadas. Desta forma, os atores e os trabalhadores de negócio que têm as suas atividades automatizadas são candidatos a agentes.

Os atores de negócio médico e paciente que participam do caso de uso de negócio "monitorar a glicemia" não têm suas atividades implementadas pelo sistema e, portanto, não são candidatos a agentes.

O trabalhador de negócio atendente tem parte de suas atividades automatizadas e, por isso, precisa ter o seu papel representado no sistema. Ao analisar as atividades do atendente verificou-se que ele exerce dois papéis diferentes:

- Atendente - ao atender o contato com o paciente;

- Enfermeiro - ao coletar as informações clínicas e resultados de exame, ao entregar essas informações ao médico especialista e ao orientar o paciente de acordo com o que foi recomendado pelo médico.

Por esse motivo, foram criados os agentes: atendente e enfermeiro. O agente atendente é responsável por atender um indivíduo que entre em contato com a central, definir o tipo de atendimento e buscar pelo agente que realiza o serviço solicitado. $\mathrm{O}$ agente enfermeiro é responsável por coletar o valor da glicemia, requisitar o serviço de análise do resultado a outro agente e informar o resultado e a orientação fornecida.

O médico especialista, que é um trabalhador de negócio, tem as suas atividades implementadas no sistema e, portanto, é um candidato a agente. No sistema TeleDM o nome deste agente é diabetologista, nome técnico dado pela medicina a um especialista em diabetes mellitus. O agente diabetologista, com as informações fornecidas pelo agente enfermeiro, analisa-as e fornece as orientações a serem dadas ao paciente. Se necessário, interage diretamente com o usuário do sistema para coletar dados adicionais.

Após encontrar e definir os papéis que os agentes exercem, é preciso escolher a plataforma de agente para a implementação desses papéis. Escolheu-se a plataforma CENINT (59), pois 
a sua implementação é compatível com o problema em questão e totalmente conhecida pelo desenvolvedor, além de estar inteiramente disponível para esse projeto.

O modelo de agente nessa plataforma baseia-se nos trabalhos de Boisser (11), Sichman (106) e Cardoso (16), além das regras de interação entre agentes e objetos. A seguir são listadas as características do modelo:

- O agente comunica-se com outro agente e eles decidem quando devem se comunicar;

- O agente decide quando deve executar os seus planos e raciocinam ${ }^{13}$ sobre as atividades dos outros agentes;

- O ambiente em que o agente atua é composto por objetos da tecnologia orientada a objetos;

- O agente é responsável por um conjunto de objetos que representam o ambiente em que atua;

- O acesso aos objetos pelo agente ocorre através de troca de mensagens entre o agente e o objeto;

- O agente só pode ter acesso ao objeto que está sob a sua responsabilidade;

- O agente pode requisitar o acesso (consulta ou alteração) a um objeto que não se encontra sob a sua responsabilidade; caso o acesso seja liberado, ele tem permissão de manipular apenas aquele que lhe foi "entregue".

Todo agente deve possuir uma estrutura interna que informa aos demais agentes as suas próprias características (104). Nesse trabalho, a estrutura interna do agente é a mesma que foi implementada em Ito (59) e Sichman (105) e se compõe de:

- Objetivos - Metas que o agente deve alcançar de acordo com o que ele precisa fazer naquele momento. Ele pode ter mais de um objetivo, cada um deles para resolver um determinado problema.

\footnotetext{
${ }^{13} \mathrm{O}$ termo raciocinar está relacionado com o mecanismo de raciocínio social. Isso significa que o agente utiliza a informação sobre os outros para inferir algumas conclusões. (105)
} 
- Ações - Tarefas que os agentes sabem executar. Cada tarefa tem um valor que determina o custo para executá-la.

- Recursos - Os recursos sobre os quais o agente tem controle e o valor ao utilizá-los.

- Planos - Os conjuntos de ações que o agente precisa executar para alcançar um objetivo. Ele pode ter mais de um plano para o mesmo objetivo. O plano escolhido é aquele em que o custo total (soma dos valores das ações) for menor.

Para este trabalho foi necessário implementar a execução dos objetivos, planos e ações, pois a plataforma, em seu trabalho original, foi implementada somente até a escolha do parceiro que auxiliaria a alcançar o objetivo. A implementação da execução do objetivo é detalhada na seção 4.5. Os demais detalhes de arquitetura (protocolo de comunicação e regras de contratação do parceiro) não foram alterados do trabalho original ${ }^{14}$.

\subsubsection{Arquitetura do Ambiente Físico do Sistema TeleDM}

$\mathrm{O}$ ambiente físico é tudo aquilo que o agente manipula para realizar as suas atividades. $\mathrm{O}$ ambiente físico do sistema TeleDM é todo representado por software, por não existirem interações com câmeras ou sensores.

Na modelagem de negócio, as entidades de negócio são as "coisas" que os trabalhadores de negócio utilizam para executar as suas tarefas. Os agentes, por sua vez, representam os papéis dos trabalhadores de negócio cujas atividades são automatizadas. Pode-se dizer, então, que as entidades de negócio manipuladas e automatizadas nas atividades representam o ambiente físico dos agentes do sistema.

No TeleDM, as entidades de negócio que representam o ambiente dos agentes são: formulário de contato, arquivo de paciente, ficha do paciente, pasta do paciente, formulário de glicemia e sistema de apoio à decisão.

\footnotetext{
${ }^{14}$ Outras informações sobre estes detalhes podem ser consultadas em Ito (59).
} 
Para implementar o ambiente físico com a tecnologia da orientação a objetos é preciso analisar as entidades de negócio e definir as classes ${ }^{15}$ que as representam. Em seguida, devese distribuir os atributos e operações da entidade de negócio nas respectivas classes. A análise das entidades de negócio encontra-se na tabela 4.3.

Tabela 4.3 - As entidades de negócio, sua descrição e respectivas classes

\begin{tabular}{|l|l|l|}
\hline \multicolumn{1}{|c|}{$\begin{array}{c}\text { Entidade de } \\
\text { Negócio }\end{array}$} & \multicolumn{1}{|c|}{ Descrição da Entidade de Negócio } & Nome das Classes \\
\hline $\begin{array}{l}\text { Formulário de } \\
\text { Contato }\end{array}$ & $\begin{array}{l}\text { É a entidade responsável por controlar as ocorrências e } \\
\text { contatos do paciente com a central. Deve conter nome, } \\
\text { telefone do paciente, data, hora e o registro da } \\
\text { ocorrência. }\end{array}$ & $\begin{array}{l}\text { - Paciente } \\
\text { Contato } \\
\text { Telefone }\end{array}$ \\
\hline Ficha do Paciente & $\begin{array}{l}\text { É uma entidade responsável por armazenar as } \\
\text { informações cadastrais do paciente.Contém os dados } \\
\text { do paciente e do médico que o atende. }\end{array}$ & $\begin{array}{l}\text { - Paciente } \\
\text { - }\end{array}$ \\
\hline $\begin{array}{l}\text { Formulico } \\
\text { Glicemia }\end{array}$ & $\begin{array}{l}\text { É uma entidade responsável por conter as informações } \\
\text { referente ao controle da glicemia do paciente. Contém } \\
\text { a data, a hora e o valor do resultado da glicemia, além } \\
\text { do resultado da análise e as orientações dadas pelo } \\
\text { sistema. }\end{array}$ & $\begin{array}{l}\text { Telefone } \\
\text { Contato }\end{array}$ \\
\hline Pasta do Paciente & $\begin{array}{l}\text { É uma entidade que contém todos os procedimentos } \\
\text { ministrados no paciente ao longo do período em que o } \\
\text { mesmo permanece na central. Contém a ficha do } \\
\text { paciente, o formulário de glicemia e o formulário de } \\
\text { contato. }\end{array}$ & $\begin{array}{l}\text { Não se aplica; o } \\
\text { agente atendente } \\
\text { possui formas de } \\
\text { encontrar essa } \\
\text { entidade. }\end{array}$ \\
\hline $\begin{array}{l}\text { Arquivo de } \\
\text { Paciente }\end{array}$ & $\begin{array}{l}\text { É a entidade onde se encontram as pastas dos } \\
\text { pacientes. }\end{array}$ & $\begin{array}{l}\text { É a entidade responsável pela análise e avaliação do } \\
\text { nível glicêmico do paciente. }\end{array}$ \\
\hline $\begin{array}{l}\text { Sistema de Apoio } \\
\text { à Decisão }\end{array}$ & $\begin{array}{l}\text { Não se aplica; o } \\
\text { agente diabetologista } \\
\text { realiza a análise e } \\
\text { avaliação do nivel } \\
\text { glicêmico do } \\
\text { paciente. }\end{array}$ \\
\hline
\end{tabular}

Ao final, têm-se as seguintes classes:

- Contato - Registra os contatos feitos por alguém junto à central;

- Endereço - Representa o endereço completo da pessoa. Uma pessoa pode encontrar-se em mais de um endereço; um médico, por exemplo, que pode ter como referências a clínica e o hospital em que atende;

\footnotetext{
${ }^{15}$ Classe é a descrição de um conjunto de objetos que possuem as mesmas propriedades e semântica. O objeto é uma instância da classe. (12)
} 
- Lista Paciente - Contém a lista de pacientes que são atendidos pela central;

- Médico - Controla as informações relacionadas ao médico do paciente;

- Glicemia - Registra os dados de monitoração da glicemia do paciente;

- Paciente - Controla as informações do paciente;

- Telefone - Representa os números de telefones para contato.

Após encontrar as classes, estabelecem-se os relacionamentos que existem entre eles e elabora-se o diagrama de classe. Esse diagrama representa a estrutura estática de classes do sistema, onde a estrutura descrita é sempre válida em qualquer ponto do seu ciclo de vida. (12) (36) O diagrama de classe resultante do sistema TeleDM encontra-se na Figura 4.5.

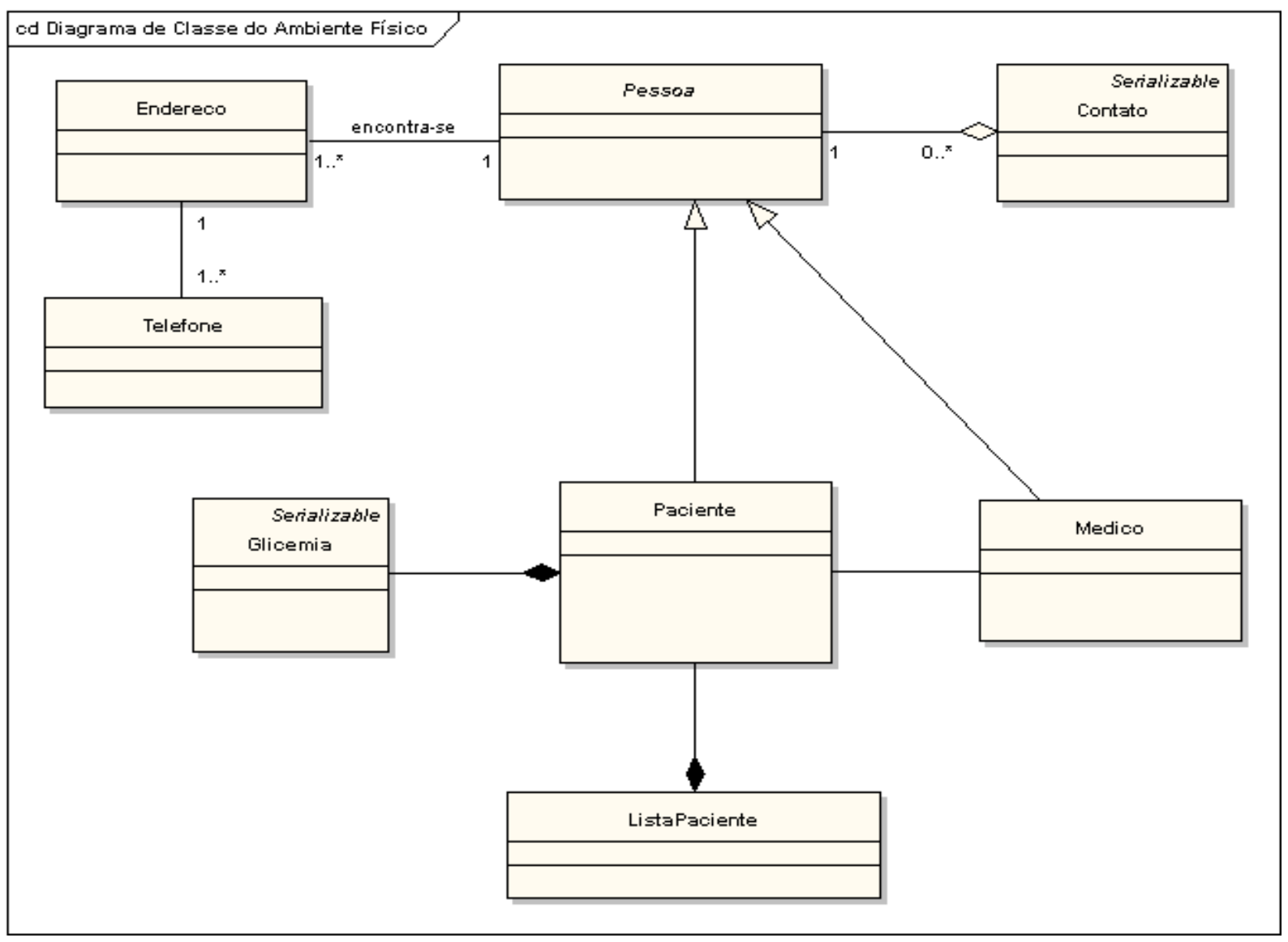

Figura 4.5 - Diagrama de Classe do Ambiente Físico

Em seguida, as permissões de acesso a cada classe devem ser estabelecidas. Para isso analisou-se a ação que o agente faz sobre o objeto - pegar, guardar (salvar), escrever (incluir/alterar), apagar (excluir) e olhar (consultar). Quando o agente não precisa dele para as 
suas atividades, o acesso é definido como "Não tem acesso". Aqueles que têm a permissão de escrever são os responsáveis pela classe. As permissões estabelecidas encontram-se na tabela 4.4 .

Tabela 4.4 - Pemissões de acesso pelos agentes

\begin{tabular}{|l|l|l|l|}
\hline \multirow{2}{*}{\multicolumn{1}{|c|}{ Classe }} & \multicolumn{2}{c|}{ Agente } \\
\cline { 2 - 4 } & \multicolumn{1}{|c|}{ Atendente } & \multicolumn{1}{c|}{ Enfermeiro } & \multicolumn{1}{c|}{ Diabetologista } \\
\hline Contato & Escrever, Olhar, Pegar e Salvar & Olhar & Não tem acesso \\
\hline Endereço & Escrever, Olhar, Pegar e Salvar & Olhar & Não tem acesso \\
\hline Lista Paciente & Não tem acesso & Não tem acesso & Não tem acesso \\
\hline Médico & Escrever, Olhar, Pegar e Salvar & Olhar & Não tem acesso \\
\hline Glicemia & Não tem acesso & $\begin{array}{l}\text { Escrever, Olhar, } \\
\text { Pegar e Salvar }\end{array}$ & Escrever e Olhar \\
\hline Paciente & Escrever, Olhar, Pegar e Salvar & Olhar & Não tem acesso \\
\hline Telefone & Escrever, Olhar, Pegar e Salvar & Olhar & Não tem acesso \\
\hline
\end{tabular}

\subsection{Implementação do Sistema TeleDM}

A plataforma utilizada para a implementação dos agentes e objetos foi a JDK 1.4.2. A escolha da linguagem de programação Java ${ }^{\mathrm{TM}}$ ocorreu por que o CENINT foi desenvolvido nessa plataforma. A razão pela qual ele foi desenvolvido nela encontra-se em Ito (59).

A seguir são apresentados os detalhes da implementação do CENINT para o desenvolvimento dos agentes do sistema TeleDM e dos casos de uso: "identificar paciente", "monitorar níveis glicêmicos" e "comunicar intercorrência".

\subsubsection{Implementação do CENINT para o TeleDM}

No CENINT, a tarefa "executar o plano escolhido" não foi desenvolvida em seu trabalho original (59), porque a plataforma foi concebida com o objetivo de estudar a comunicação entre os agentes. Porém, para o sistema TeleDM, a sua implementação é indispensável. Por esse motivo, os estados "executando o plano" e "gerenciando parceiro" foram desenvolvidos nesse trabalho. A Figura 4.6 apresenta os estados possíveis no ciclo de vida de um agente do CENINT. 


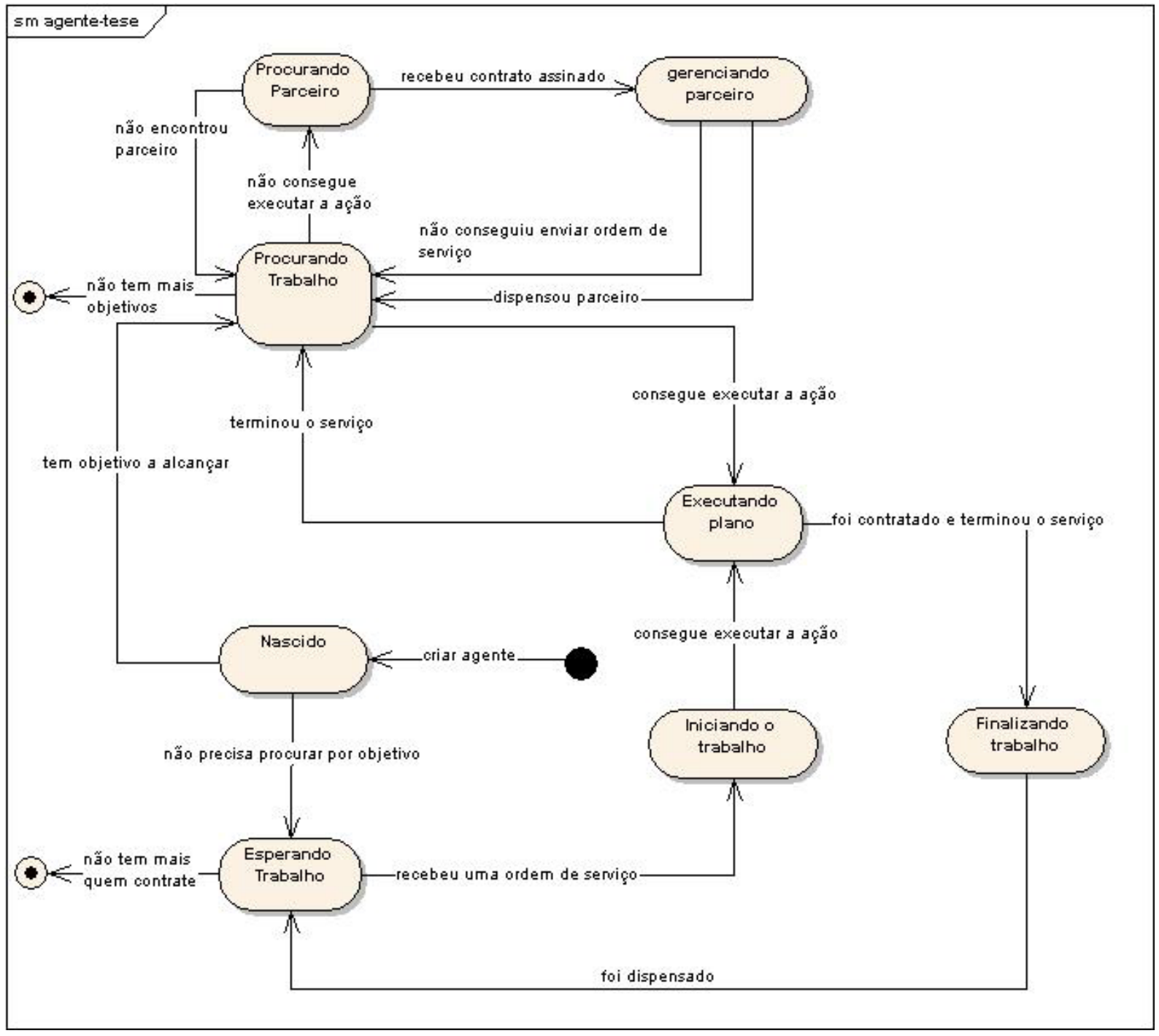

Figura 4.6 - Os estados possíveis no ciclo de vida do ambiente CENINT

O agente, ao ser criado e tendo um objetivo a alcançar, escolhe um plano e o analisa. Se conseguir realizar todas as ações do plano, é dito autônomo. Caso contrário, ele sai em busca de um parceiro, um agente que possa realizar a ação que não consegue fazer. Detalhes sobre a escolha de parceiro no CENINT encontram-se em Ito (59). Uma vez encontrado o parceiro, um contrato é firmado entre as partes e a gerência do contratante se inicia.

A gerência do contratante envolve o envio de uma ordem de serviço, a espera da execução do serviço e a finalização do contrato. A figura 4.7 apresenta os estados implementados no CENINT para a gerência do contratante. Nesse diagrama observa-se que o agente contratante, após enviar a ordem de serviço, fica esperando pela execução da tarefa. Logo que o agente contratante recebe o resultado da ação feita, ocorre o término do contrato. 


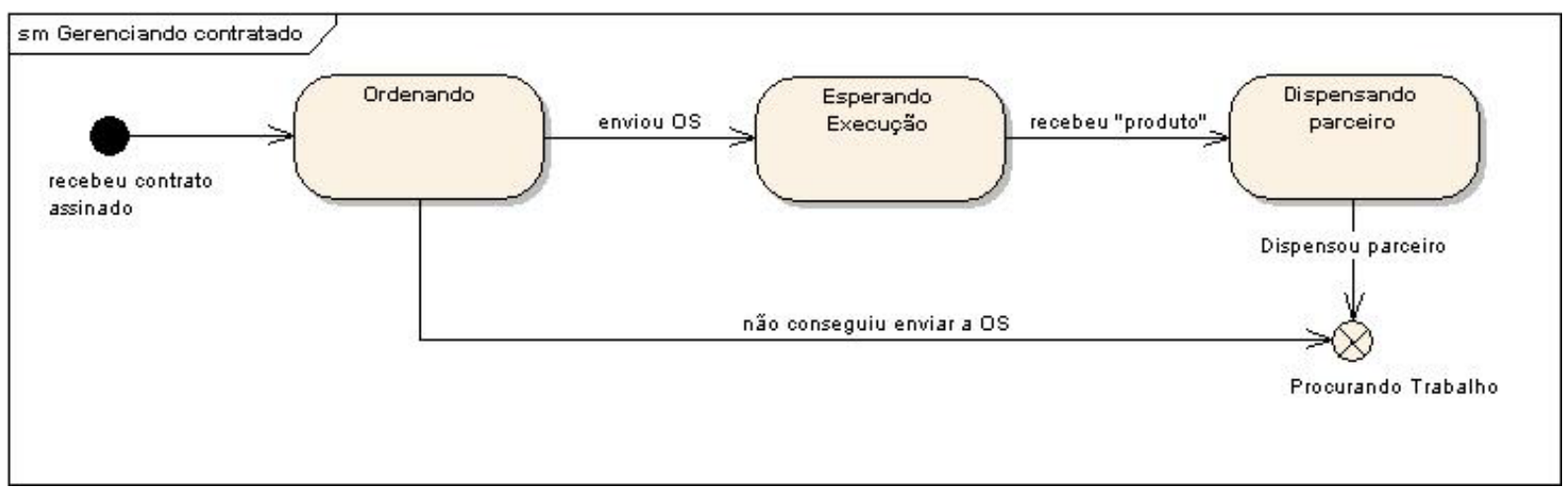

Figura 4.7 - Estados possíveis no gerenciamento do contratante do ambiente CENINT

O agente, uma vez contratado, fica esperando pela ordem de serviço. Ao receber a ordem de serviço, inicia os trabalhos verificando se algum objeto do ambiente físico lhe foi entregue. Caso tenha sido, faz uma cópia dele e guarda as informações de sua localização na classe PersonCloset, para acessá-lo quando necessário. Em seguida, executa o serviço e finaliza-o, enviando o resultado obtido para o agente contratante. Esses estados foram implementados nesse trabalho.

Para a execução do plano foi preciso criar uma classe, chamada Role, responsável por controlar as atividades do papel do agente. Já as ações que cada papel desempenha e a execução do plano é representada de forma abstrata na classe Person. Para implementá-la, é necessário criar uma subclasse para cada papel que o agente representa. Assim, os agentes: enfermeiro, atendente e diabetologista são classes-filhas da classe Person.

O diagrama de classe dos agentes do sistema TeleDM encontra-se na figura 4.8. Para outros detalhes sobre as demais classes do ambiente CENINT, consultar Ito (59). 


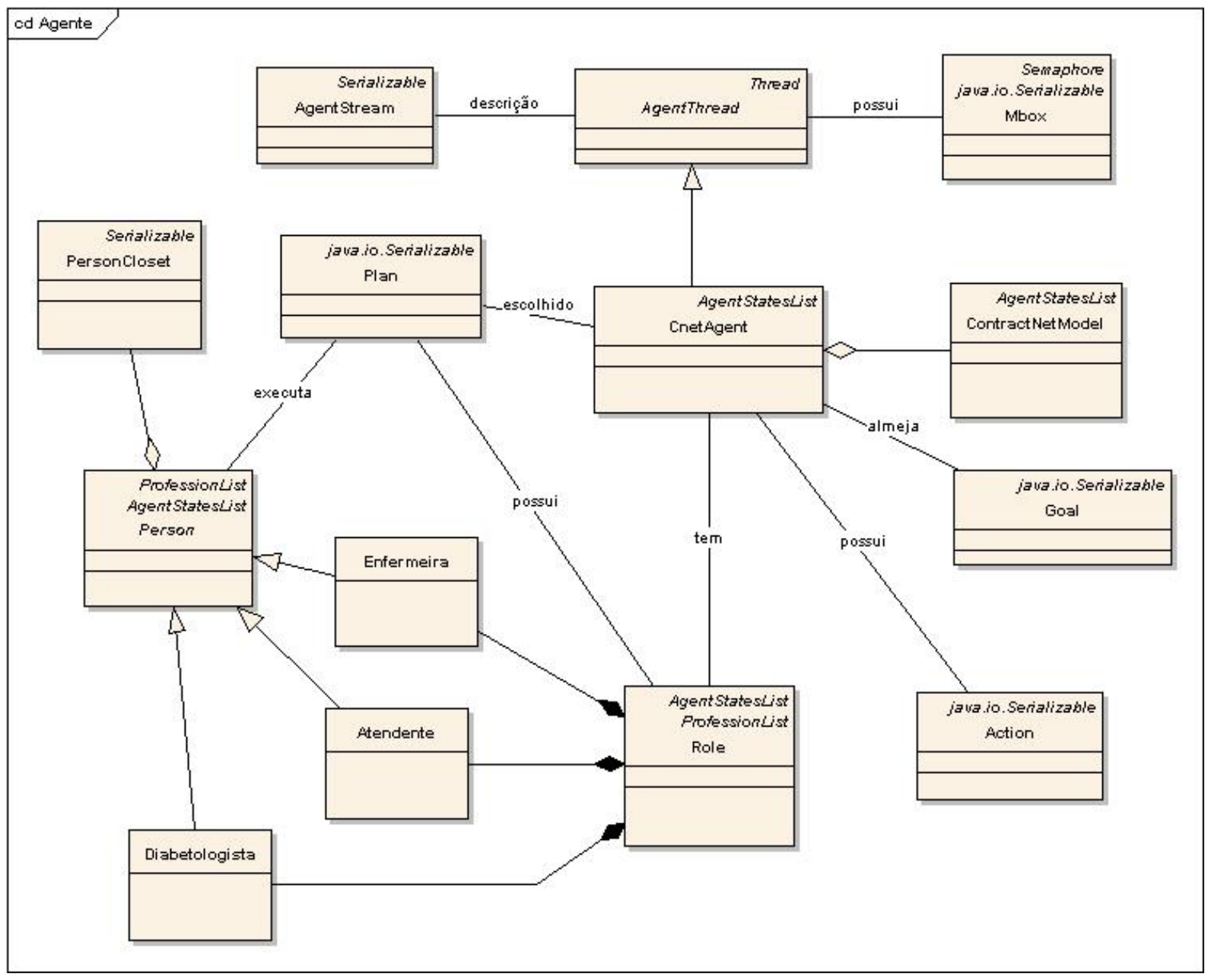

Figura 4.8 - Diagrama de Classe do sistema TeleDM

Para o controle dos agentes do sistema TeleDM, criaram-se as classes CMSociety, que é uma subclasse da classe Society, e a CMOrganization, que é uma subclasse da classe Organization. A classe Society, na plataforma CENINT, é responsável por formar a comunidade de agentes, desde a sua criação e destruição até o controle da organização ${ }^{16}$, assim como o estabelecimento da comunicação. Por outro lado, a classe Organization, no CENINT, é responsável por monitorar as atividades dos agentes, como escalonar as tarefas e organizar os agentes que estão trabalhando em conjunto, mantendo a sincronização das tarefas realizadas.

Para auxiliar no controle da execução do sistema foram implementadas operações que

\footnotetext{
${ }^{16}$ Segundo Boisser (11) e Garcia, Sichman (45), “a organização de um grupo de agentes pode ser vista simplificadamente como um conjunto de restrições adotadas para que possam atingir seus objetivos mais facilmente."
} 
permitem gerar um arquivo texto em forma de relatório com as ações executadas pelo agente. O exemplo desse relatório encontra-se no apêndice A - Relatório das ações executadas pelo agente diabetologista numa consulta.

O próximo passo, após complementar o desenvolvimento do CENINT, é definir os objetivos, planos e ações dos agentes (atendente, diabetologista e enfermeiro) e implementá-los. A elaboração dessas definições, a representação dos diálogos entre os agentes e a manipulação dos objetos do ambiente físico pelos agentes são apresentados no próximo item.

\subsubsection{Implementação dos Casos de Uso}

Segundo vários autores, dentre eles Einhorn, Jo (33), Qi Yan et. al (127) e Kavi et. al (66), os casos de uso, além de permitirem capturar os requisitos do sistema, também ajudam a descobrir os objetivos que os agentes devem almejar. É por isso que muitos deles propõem estereótipos ${ }^{17}$ de casos de uso para modelar os serviços e funcionalidades dos agentes no sistema.

No sistema TeleDM, também foi utilizado esse conceito para encontrar os objetivos dos seus agentes. Porém, encontrá-los diretamente da especificação dos casos de uso não é simples, pois os mesmos descrevem o comportamento de forma abstrata, o que dificulta a descoberta dos objetivos de cada agente. Segundo Armour, Miller (1), esta descrição só é uma vantagem quando não há a necessidade de especificar o que ocorre em todas as possibilidades de execução do caso de uso, como o que acontece na análise de requisitos. Assim, de acordo com esse autor, quando houver a necessidade de descrever situações específicas pode-se utilizar o conceito de instâncias de casos de uso.

\footnotetext{
${ }^{17} \mathrm{Na}$ UML, estereótipos são extensões de seu vocabulário. Eles permitem criar novos tipos de elementos derivados de outros existentes na UML, mas que são específicos para o modelo em questão. (12)
} 
A UML 2.0 (36) define as instâncias de casos de uso como cenários que representam uma utilização atual do sistema. Sob o ponto de vista de Salinesi:

"Um cenário descreve o comportamento do sistema, em uma dada situação,
como um único fluxo de interações com os usuários que tentam alcançar
seus objetivos. Cenários alternativos descrevem diferentes formas para
encontrar o mesmo objetivo, com um final normal ou excepcional, eles
devem ser descritos separadamente." ( (96) p. 146)

Os cenários permitem adicionar, capturar e entender as variantes comportamentais dos casos de uso. Como não há obrigatoriedade da sua modelagem, não existe uma representação padrão para elas. (1) (96)

É importante notar, ainda, que para encontrar os objetivos, planos e ações dos agentes, além da interação entre eles e o ambiente, é preciso conhecer os seus comportamentos em situações específicas. Empregou-se, assim, o uso das instâncias de casos de uso para esse fim.

Tanto para casos de uso quanto para os cenários não há um estilo padrão para a descrição dos seus fluxos de eventos. Nota-se que a forma adotada pelos principais autores, como Booch, Rumbaugh, Jacbson (12), Windle, Abreo (123), Cockburn (24) e Armour, Miller (1), não permite demonstrar de maneira clara e objetiva a interação do agente com o ambiente, assim como o diálogo dos agentes, seus objetivos, planos e ações durante a execução de um cenário.

Ao buscar na literatura um método para elaborar um texto que evidenciasse todas essas características, foram analisadas técnicas de produção de roteiros para cinema e televisão.

O roteiro é um texto apropriado para a descrição das instâncias de casos de uso para o desenvolvimento de sistemas orientados a agentes, pois contém uma descrição detalhada das ações e diálogos entre personagens, bem como as interações destes com o cenário (26) (41). Nesse caso, os personagens são os agentes e usuários do sistema, e o cenário do ambiente. Para este trabalho, os fluxos de eventos (básico e alternativos) que possuem algum tipo de implementação no sistema são considerados como um ou mais cenários.

Ao detalhar os cenários notou-se que um conjunto de ações e interações se repetiam nas várias instâncias. O roteiro, por sua vez, subdivide-se em cenas. Segundo Comparato (26), não existe uma definição específica para cena, mas pode-se dizer que elas são as unidades específicas de ação e o lugar em que se conta a história (41). Não se viu problema em utilizar o conceito de cena para representar essas partes que se repetiam na descrição dos cenários. 
Para se ter uma visão dos caminhos possíveis de percorrer para executar uma instância de caso de uso, utilizou-se o diagrama de atividade. Nele, a cena é o estereótipo de uma atividade.

Ao elaborar o roteiro encontram-se os agentes que fazem parte da execução do caso de uso. No texto, o nome do agente aparece em letras maiúsculas, itálico e sublinhado; já o do usuário surge apenas em maiúsculas.

Os demais elementos para a implementação dos casos de uso são encontrados ao se fazer uma análise do roteiro final. $\mathrm{O}$ objetivo do agente são as cenas; as ações são as tarefas executadas e descritas ao longo da cena. O plano é a seqüência das ações descritas na cena. Os diálogos representam as interações entre os agentes, e os parágrafos, a interação do agente com o ambiente. $\mathrm{O}$ nome dos objetos do ambiente que são manipulados pelo agente encontra-se em negrito no texto.

Uma vez definidos os objetivos, planos e ações dos agentes, é possível implementar as ações nas suas respectivas classes. Cada ação equivale a uma operação da classe. A manipulação dos objetos pelo agente ocorre durante a execução de uma ação; logo, as chamadas das operações dos objetos encontram-se no corpo do método ${ }^{18}$.

Um exemplo da implementação de um caso de uso utilizando o método mencionado nesse item encontra-se no apêndice B - Implementação do Caso de Uso "Monitorar Níveis Glicêmicos".

No próximo capítulo apresentam-se as simulações, os resultados e as análises das simulações realizadas com o sistema TeleDM.

\footnotetext{
${ }^{18}$ Método é um bloco de instruções que executam uma operação da classe. (12)
} 


\section{Simulações de Casos Específicos}

Após desenvolver o sistema TeleDM foram realizados dois tipos de simulações. A primeira, para avaliar a arquitetura do sistema e validar as suas respostas. A segunda, para avaliar a potencialidade do modelo GRPC no auxílio do acompanhamento de pacientes diabéticos.

Ressalta-se que não é intenção do sistema TeleDM cobrir todas as situações que permitem avaliar o resultado imediato da glicemia. O propósito da simulação é demonstrar ser possível, por meio do modelo, otimizar a quantidade de consultas presenciais e de fornecer apoio ao paciente diabético com relação à monitoração dos seus níveis glicêmicos. Desse modo, implemetou-se algumas regras genéricas para comprovar a viabilidade do seu uso no sistema de monitoração do modelo GRPC. A arquitetura do sistema TeleDM permite que, em trabalhos futuros, seja possível acrescentar ou alterar as orientações implementadas no sistema.

Nas próximas seções são apresentados os detalhes das simulações realizadas e as análises dos seus resultados.

\subsection{Simulações para validar o sistema}

O objetivo das simulações nesta seção é avaliar a funcionalidade da arquitetura elaborada para

o sistema TeleDM, assim como as respostas fornecidas pelo sistema em situações prédefinidas.

As características da arquitetura que foram avaliadas são:

- Cooperação entre os agentes - verificar se os agentes conseguem cooperar entre si para resolver um problema;

- Transparência de funcionamento - verificar se os agentes conseguem alcançar seus objetivos de forma transparente, pois os usuários não precisam saber quantos e quais agentes estão trabalhando para resolver o problema; 
- Propriedades dos agentes - verificar se os agentes obedecem às características determinadas no item 4.4.1.

As funcionalidades que foram avaliadas são:

- Identificação do paciente - verificar, nas situações previstas, se o agente atendente consegue identificar o paciente ou, em caso contrário encaminhá-lo para o setor "acompanhamento de serviço";

- Monitoração do paciente - verificar se o agente enfermeiro e o agente diabetologista conseguem avaliar o resultado de glicemia, orientar o paciente e emitir alertas do paciente ao médico, nas situações previstas.

Para obter os resultados da funcionalidade "monitoração do paciente", o agente enfermeiro, ao final de cada contato, gera um relatório em formato texto com os dados do paciente, o resultado da glicemia, o diagnóstico e a orientação.

A seguir, expõe-se uma descrição dos casos utilizados para realizar a simulação, os resultados obtidos e a análise deles.

\subsubsection{Descrição dos Casos}

Para produzir os casos possíveis utilizaram-se os cenários dos casos de uso. Para cada cenário foi elaborada uma situação.

As seguintes situações foram simuladas:

- Paciente identificado pela matrícula - a matrícula corresponde ao paciente que entrou em contato;

- Paciente enganou-se de matrícula - a matrícula foi encontrada no sistema, porém não corresponde ao paciente que entrou em contato. O paciente então é identificado pelo seu nome e o nome da mãe;

- Paciente não sabe a matrícula - o paciente avisa o atendente de que não sabe o número de matrícula; então é identificado pelo seu nome e o nome de sua mãe; 
- Paciente errou a matrícula - a matrícula não foi encontrada no sistema, porém ele é identificado pelo seu nome e o nome da mãe;

- Paciente não foi identificado - a matrícula e o nome do paciente não foram encontrados no sistema. Neste caso ele é encaminhado para o setor de "acompanhamento de serviço".

Já a funcionalidade "monitoração do paciente" envolve decisões e orientações fornecidas pelo agente diabetologista. Nessa circunstância é difícil utilizar somente os cenários de caso de uso para compor as situações, porque dependendo da atribuição da variável, a conduta e os diagnósticos podem ser diferentes num mesmo cenário. Foram elaborados, então, casos clínicos que cobriam todas as situações previstas. Para facilitar a composição dos casos clínicos uma tabela de decisão ${ }^{19}$ foi elaborada (tabela 5.1).

\footnotetext{
${ }^{19}$ Técnica utilizada para descrever um processo que deve produzir alguma saída ou executar ações com base em decisões complexas. Essas decisões, geralmente, usam diversas variáveis que assumem muitos valores diferentes. (129)
} 
Tabela 5.1 - Tabela de decisão dos casos clínicos. A nomenclatura das ações aparecem de forma reduzida para facilitar a sua visualização

\begin{tabular}{|c|c|c|c|c|c|c|c|c|c|c|c|c|c|}
\hline Caso Clínico & 1 & 2 & 3 & 4 & 5 & 6 & 7 & 8 & 9 & 10 & 11 & 12 & 13 \\
\hline glicemia entre 60 e 110 & $\mathrm{~V}$ & 1 & 1 & 1 & 1 & 1 & 1 & 1 & 1 & 1 & 1 & 1 & 1 \\
\hline glicemia menor 40 & 1 & $\mathrm{~V}$ & $\mathrm{~V}$ & $\mathrm{~V}$ & $\mathrm{~V}$ & 1 & $\perp$ & $\perp$ & 1 & 1 & 1 & 1 & 1 \\
\hline glicemia entre 60 e 40 & 1 & 1 & 1 & 1 & 1 & $\mathrm{~V}$ & $\mathrm{~V}$ & $\mathrm{~V}$ & 1 & 1 & 1 & 1 & 1 \\
\hline glicemia entre 110 e 200 & 1 & 1 & 1 & 1 & 1 & 1 & 1 & 1 & $\mathrm{~V}$ & $\mathrm{~V}$ & $\mathrm{~V}$ & 1 & 1 \\
\hline glicemia maior que 200 & 1 & 1 & 1 & 1 & 1 & 1 & 1 & 1 & 1 & 1 & 1 & $\mathrm{~V}$ & $\mathrm{~V}$ \\
\hline consciente & 1 & $\mathrm{~V}$ & $\mathrm{~V}$ & $\mathrm{~F}$ & $\mathrm{~F}$ & $\mathrm{~V}$ & $\mathrm{~V}$ & $\mathrm{~F}$ & $\mathrm{~V}$ & $\mathrm{~V}$ & $\mathrm{~F}$ & $\mathrm{~V}$ & $\mathrm{~F}$ \\
\hline com infecção & 1 & 1 & 1 & 1 & 1 & 1 & 1 & 1 & $\mathrm{~V}$ & $\mathrm{~F}$ & 1 & 1 & 1 \\
\hline confuso & 1 & $\mathrm{~V}$ & $\mathrm{~F}$ & 1 & 1 & $\mathrm{~V}$ & $\mathrm{~F}$ & 1 & 1 & 1 & 1 & 1 & 1 \\
\hline teve convulsão & 1 & 1 & 1 & $\mathrm{~V}$ & $\mathrm{~F}$ & 1 & 1 & $\mathrm{~F}$ & 1 & 1 & 1 & 1 & 1 \\
\hline \multicolumn{14}{|l|}{ Cenários } \\
\hline $\begin{array}{l}\text { Paciente com hiperglicemia sem } \\
\text { intercorrência }\end{array}$ & & & & & & & & & & $\mathbf{X}$ & & $\mathbf{X}$ & \\
\hline $\begin{array}{l}\text { Paciente com hiperglicemia e } \\
\text { intercorrência }\end{array}$ & & & & & & & & & $\mathbf{X}$ & & $\mathbf{X}$ & & $\mathbf{X}$ \\
\hline Paciente normoglicêmico & $\mathbf{X}$ & & & & & & & & & & & & \\
\hline Paciente com hipoglicemia leve & & & & & & & $\mathbf{X}$ & & & & & & \\
\hline Paciente com hipoglicemia moderado & & & & & & $\mathbf{X}$ & & $\mathbf{X}$ & & & & & \\
\hline Paciente com Hipoglicemia grave & & $\mathbf{X}$ & $\mathbf{X}$ & $\mathbf{X}$ & $\mathbf{X}$ & & & & & & & & \\
\hline \multicolumn{14}{|l|}{ Ações } \\
\hline Parabenizar & $\mathbf{X}$ & & & & & & & & & & & & \\
\hline Reforçar para manter orientação & & & & & & & & & & $\mathbf{X}$ & & & \\
\hline Marcar consulta presencial & & & & & & & & & $\mathbf{X}$ & & & $\mathbf{X}$ & \\
\hline Procurar ajuda e ir ao PA & & & $\mathbf{X}$ & & & $\mathbf{X}$ & & $\mathbf{X}$ & & & $\mathbf{X}$ & & $\mathbf{X}$ \\
\hline Tomar líquido açucarado & & & & & & & $\mathbf{X}$ & & & & & & \\
\hline Chamar resgate & & $\mathbf{X}$ & & $\mathbf{X}$ & $\mathbf{X}$ & & & & & & & & \\
\hline Proteger a língua & & & & $\mathbf{X}$ & $\mathbf{X}$ & & & & & & & & \\
\hline Comunicar por e-mail & & $\mathbf{X}$ & $\mathbf{X}$ & $\mathbf{X}$ & $\mathbf{X}$ & $\mathbf{X}$ & $\mathbf{X}$ & $\mathbf{X}$ & $\mathbf{X}$ & & $\mathbf{X}$ & $\mathbf{X}$ & $\mathbf{X}$ \\
\hline Comunicar por telefone & & $\mathbf{X}$ & $\mathbf{X}$ & $\mathbf{X}$ & $\mathbf{X}$ & $\mathbf{X}$ & & $\mathbf{X}$ & & & $\mathbf{X}$ & & $\mathbf{X}$ \\
\hline
\end{tabular}

De posse das situações para a identificação do paciente e dos casos clínicos da monitoração do paciente foi possível realizar as simulações cujos resultados e análises são apresentados nos próximos itens.

\subsubsection{Resultados Obtidos}

\section{a. Identificação do Paciente}

Em todas as simulações, ao iniciar a execução do software o agente atendente apresenta o menu principal (Quadro 5.1). 


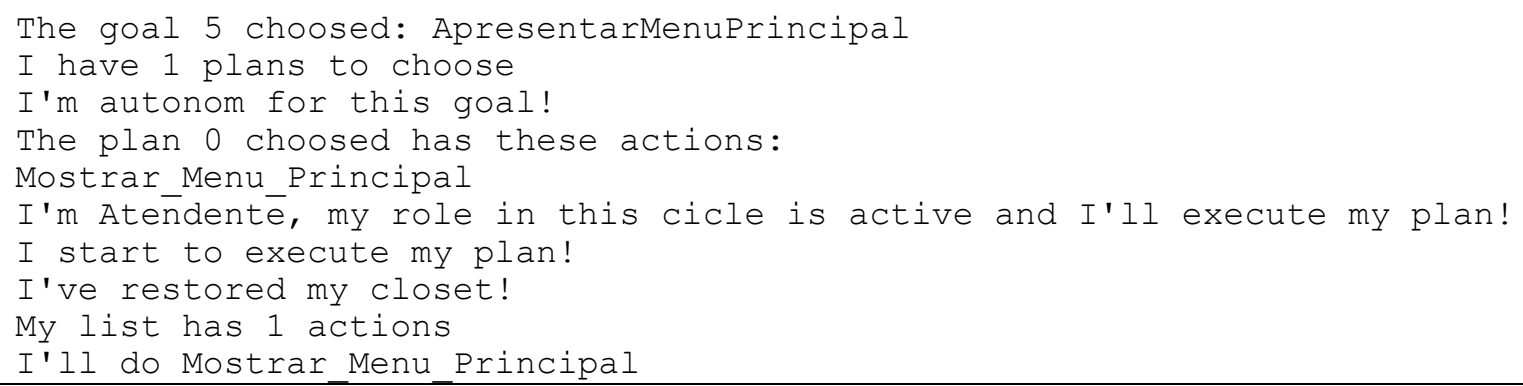

Quadro 5.1 - Relato das ações executadas pelo agente atendente ao apresentar o menu principal.

O usuário, ao escolher a opção "atender o contato", faz com que o agente atendente selecione o plano (plano 1) para alcançar o seu objetivo. O plano 1 é aquele que identifica o contato pela matrícula. O agente percebe que consegue resolver sozinho o problema e inicia a interação com o usuário, questionando se o contato possui o número de matrícula. $\mathrm{O}$ quadro 5.2 apresenta o relatório das ações executadas pelo agente atendente até esse momento.

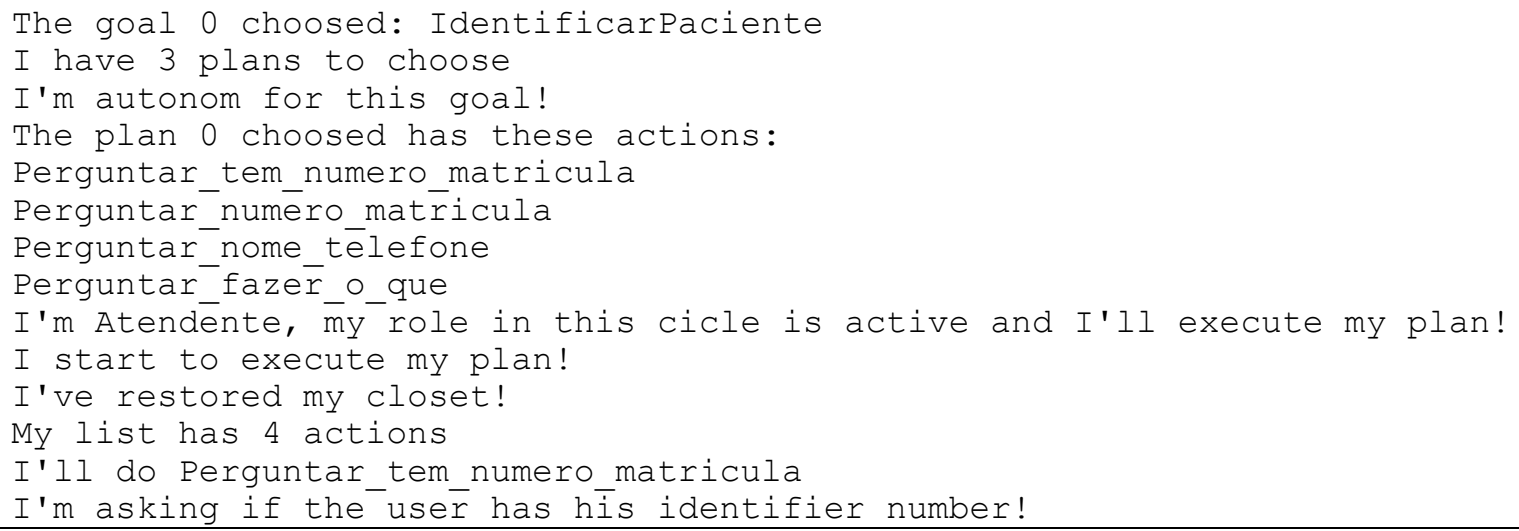

Quadro 5.2 - Relato das ações executadas pelo agente atendente ao escolher o plano "identificar pela matrícula"

É a partir desse ponto que, dependendo da simulação, o agente prossegue com a execução do plano atual (plano 1), ou procura por um outro plano (plano 2). O quadro 5.3 apresenta as ações executadas e a decisão tomada pelo agente atendente em ambos os casos. 


\begin{tabular}{|c|c|}
\hline Mantém o plano & Muda de plano \\
\hline $\begin{array}{l}\text { I'm asking if the user has his } \\
\text { identifier number! } \\
\text { The patient has the identifier! } \\
\text { I'll do Perguntar_numero_matricula }\end{array}$ & $\begin{array}{l}\text { I'm asking if the user has his } \\
\text { identifier number! } \\
\text { The patient doesn't have the } \\
\text { identifier! } \\
\text { The result of my work is: false } \\
\text { I'm Atendente, my role in this cicle } \\
\text { is active and I'll find a work! } \\
\text { I'm Atendente, my role in this cicle } \\
\text { is active and I'll find a work! So } \\
\text { I'll choose a plan! } \\
\text { I have } 2 \text { plans to choose } \\
\text { I'm autonom for this goal! } \\
\text { The plan o choosed has these } \\
\text { actions: } \\
\text { Perguntar_tipo_contato } \\
\text { Perguntar_nome_paciente } \\
\text { Perguntar_nome_mae } \\
\text { Procurar_paciente_e_mae } \\
\text { Mostrar_numero_matricula } \\
\text { Perguntar fazer o que }\end{array}$ \\
\hline
\end{tabular}

Quadro 5.3 - Relato das ações executadas pelo agente atendente após a resposta do usuário quanto a ter ou não o número de matrícula

A seguir são apresentadas, para cada cenário simulado, as ações executadas pelo agente atendente como resultado de cada simulação. Os dados utilizados são de um paciente fíctício:

- Matrícula-01;

- Nome - João da Silva;

- Telefone - 9999-9999;

- Nome da mãe - Maria da Silva.

\section{Simulação do cenário "paciente identificado pela matrícula":}

Nessa simulação o paciente conhece o seu número de matrícula e é identificado por meio dele. O quadro 5.4 apresenta as ações executadas pelo agente atendente a partir do momento em que o usuário fornece o número de matrícula.

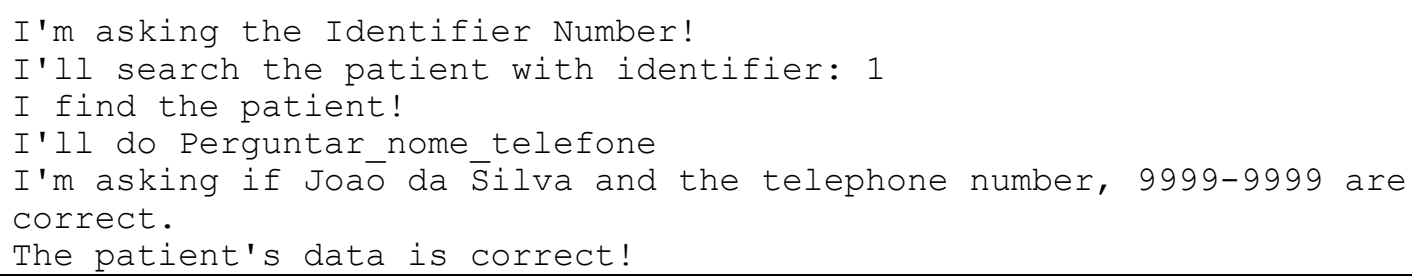

Quadro 5.4 - Relato das ações executadas pelo agente atendente após o usuário fornecer a matrícula correta 


\section{Simulação do cenário "paciente enganou-se de matrícula":}

Nesta simulação o paciente forneceu uma matrícula que coincidentemente existe na base de dados, porém não pertence a ele. O número de matrícula fornecido é 2, e pertence ao paciente fictício "Pedro da Silva". Esse fato obriga o agente a utilizar o plano 2 para conseguir alcançar o seu objetivo. O quadro 5.5 apresenta as ações executadas pelo agente atendente a partir do momento em que o usuário fornece o número de matrícula.

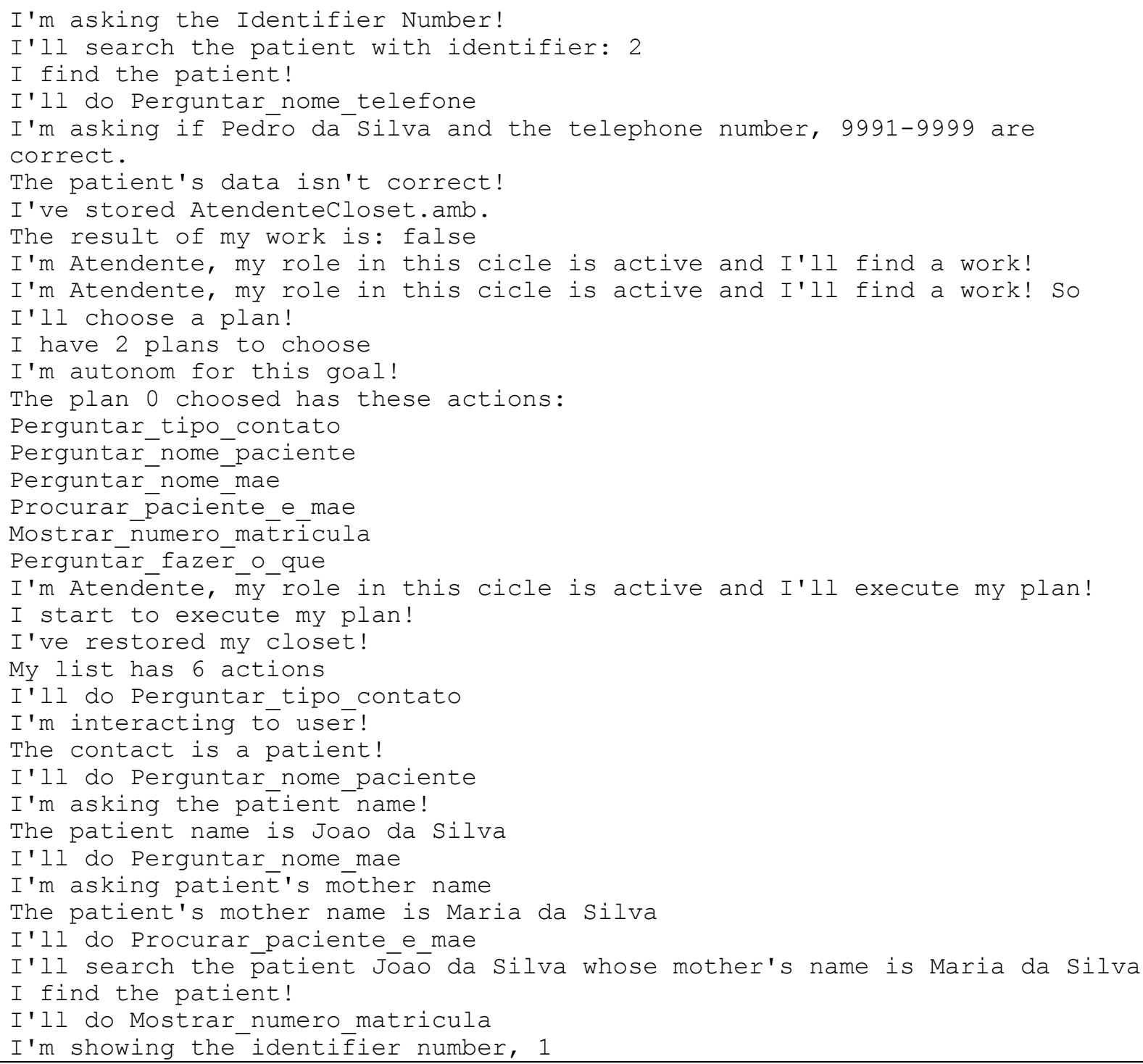

Quadro 5.5 - Relato das ações executadas pelo agente atendente após o usuário fornecer a matrícula que não pertence a ele

\section{Simulação do cenário "paciente não sabe a matrícula":}

Nessa simulação o paciente não conhece o seu número de matrícula. Nesse caso, o agente atendente procura pelo plano 2 para conseguir identificar o contato. $\mathrm{O}$ quadro 5.6 apresenta as 
ações executadas pelo agente atendente a partir do momento em que ele inicia a execução do plano 2 .

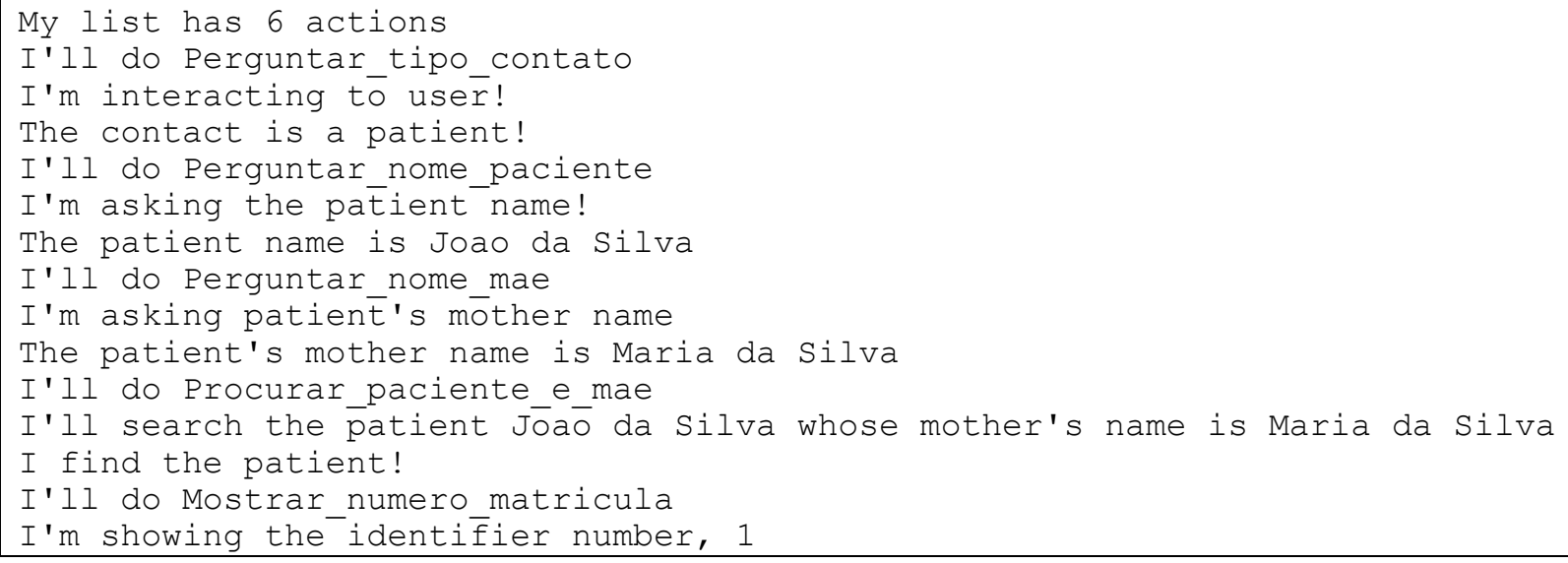

Quadro 5.6 - Relato das ações executadas pelo agente atendente após o usuário dizer que não sabe o número de matrícula

\section{Simulação do cenário "paciente errou a matrícula":}

Nessa simulação o paciente forneceu uma matrícula que não existe na base de dados. $\mathrm{O}$ número de matrícula fornecido é 100. Esse fato obriga o agente a utilizar o plano 2, para conseguir alcançar o seu objetivo. O quadro 5.7 apresenta as ações executadas pelo agente atendente a partir do momento em que o usuário fornece o número de matrícula.

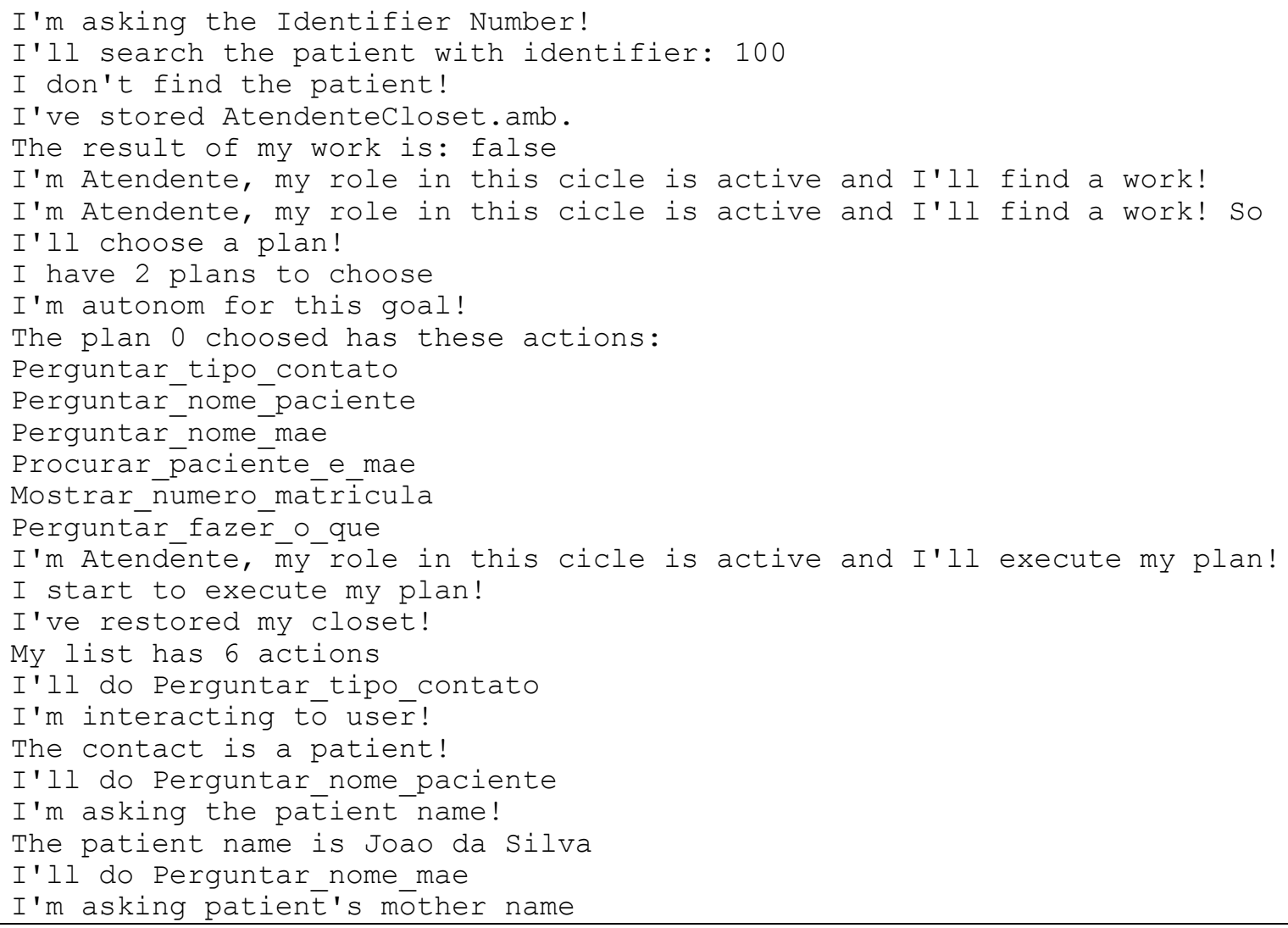




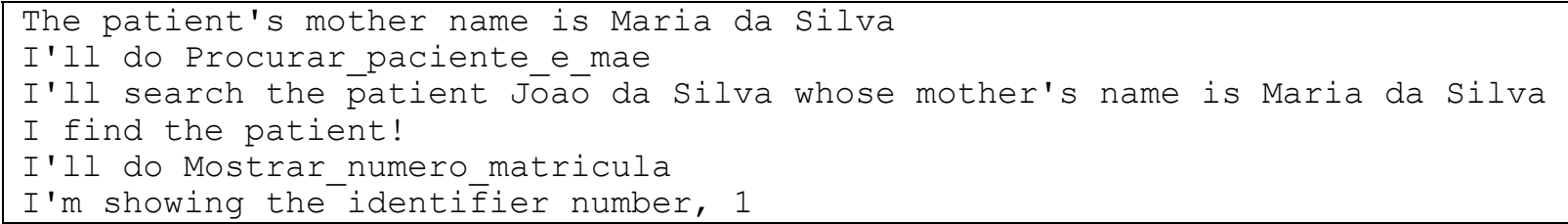

Quadro 5.7 - Relato das ações executadas pelo agente atendente após o usuário fornecer a matrícula inexistente

\section{Simulação do cenário "paciente não foi identificado":}

Nessa simulação o paciente recebeu o número de matrícula, porém não foi cadastrado no sistema por falta de documentação. Nesse caso, o agente atendente não consegue identificar o paciente e pede que ele procure pelo setor de acompanhamento de serviço. O paciente fíctício é Claudio da Silva, com matrícula 50 e nome da mãe Bete da Silva. O quadro 5.8 apresenta as ações executadas pelo agente atendente a partir do momento em que o usuário fornece o número de matrícula.

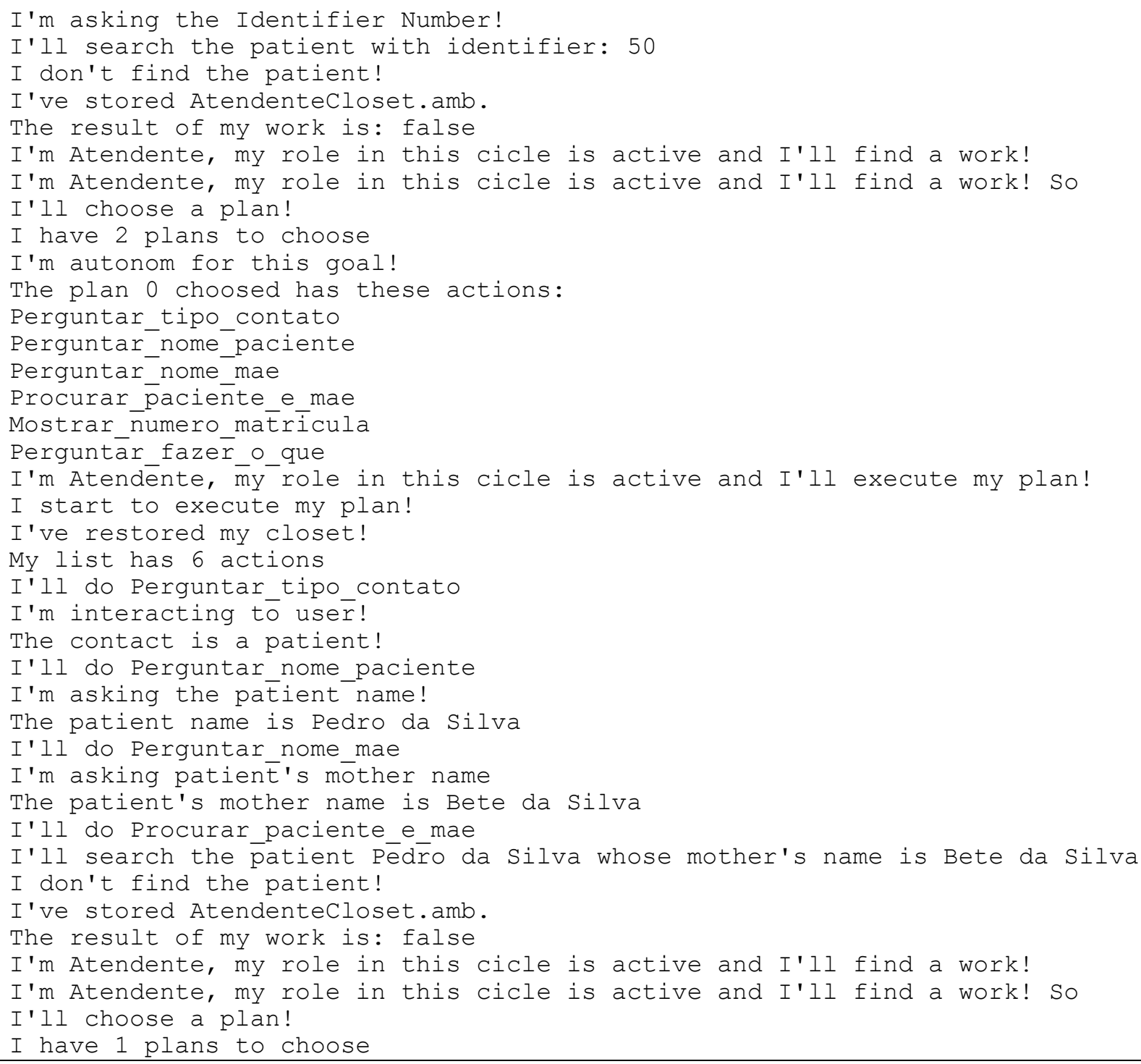




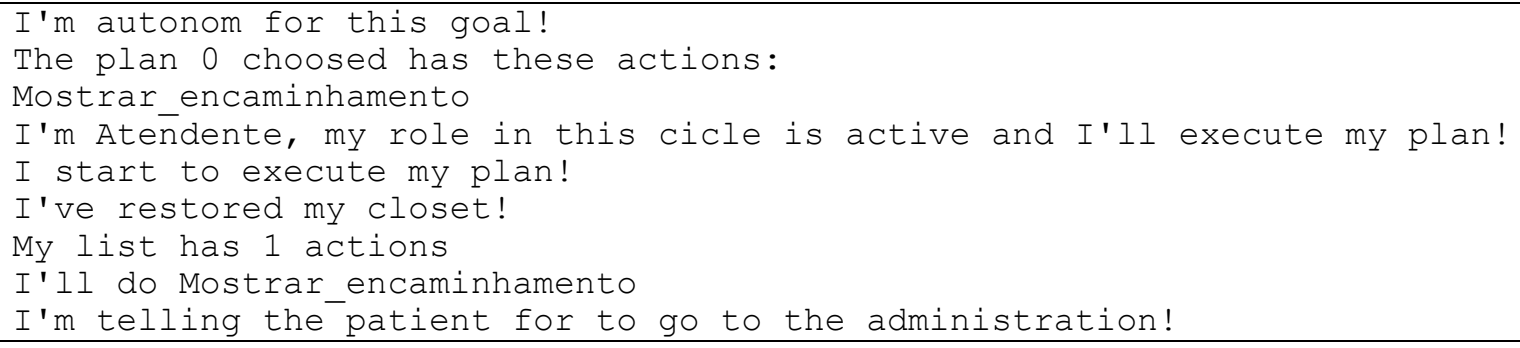

Quadro 5.8 - Relato das ações executadas pelo agente atendente ao atender um usuário que não está cadastrado no sistema

b. Monitoração do Paciente

Nas simulações com os casos clínicos há a interação entre o enfermeiro e o diabetologista; além disso, a manipulação dos objetos pelos agentes ocorre com mais freqüência.

O quadro 5.9 apresenta as ações de contratação; em negrito, ressalta-se a interação entre o agente enfermeiro e o diabetologista.

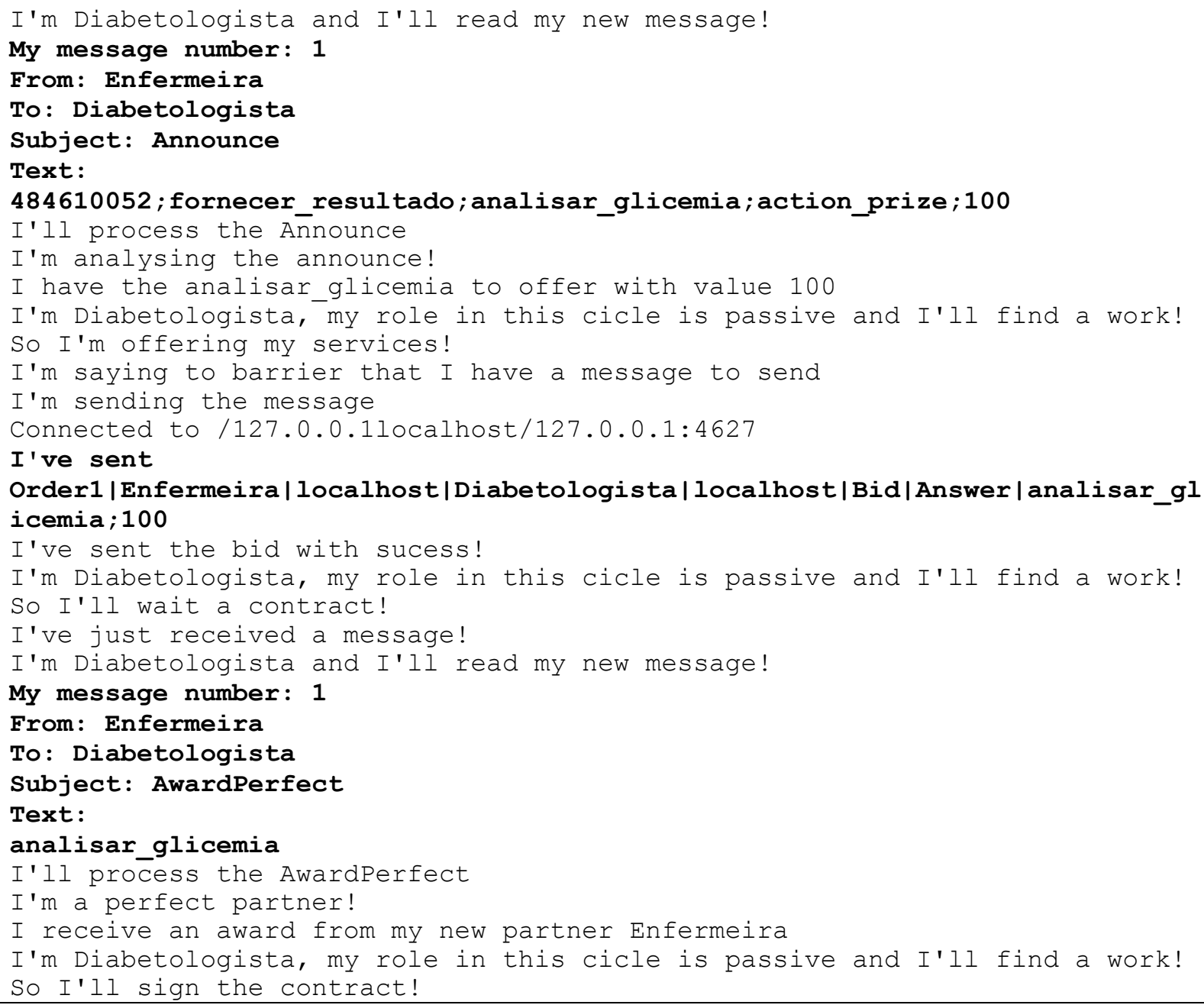

Quadro 5.9 - Relato das ações executadas pelo agente enfermeiro para a contratação do agente diabetologista 
O quadro 5.10 mostra o agente diabetologista executando a "leitura" do valor da glicemia no formulário de glicemia do paciente e "escrevendo" o diagnóstico nele.

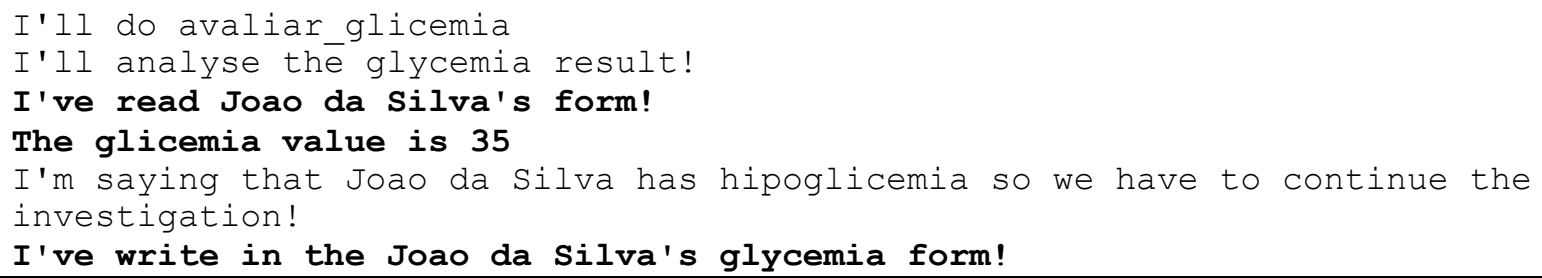

Quadro 5.10 - Relato das ações executadas pelo agente diabetologista na leitura do valor da glicemia no formulario de glicemia do paciente

$\mathrm{O}$ apêndice A apresenta as ações executadas, a manipulação dos objetos e as trocas de mensagens feitas pelo agente diabetologista durante a simulação de um caso clínico. Optou-se por omitir as ações executadas pelos agentes nas simulações dos casos clínicos; afinal, o objetivo principal é verificar se os resultados fornecidos pelo agente diabetologista encontram-se dentro do esperado.

O paciente fictício João da Silva, com o número de matrícula 01, foi utilizado em todas as simulações dos casos clínicos. O horário estipulado para a medida é $10 \mathrm{~h} 00$ e as variáveis que foram alteradas a cada simulação são: data, valor e estado clínico (com infecção, consciente, confuso e convulsão). O médico que atende o paciente João da Silva também é fictício e os seus dados são:

- Nome - Gilberto Dibeto

- Telefone - 5555-5555

- e-mail: dibeto@cmd.org.br

Os casos clínicos seguem a seqüência da tabela 5.1. Nas simulações iniciais os resultados obtidos foram os esperados. Ao passar pelo especialista que forneceu os parâmetros houve a necessidade de refinar as orientações e sua redação. A seguir apresenta-se o resultado das simulações, após as alterações no texto das orientações para os pacientes. 


\section{Simulação do caso clínico 1:}

A data utilizada foi 01/01/2005 e o valor de glicemia, 80. O resultado encontra-se no quadro 5.11 .

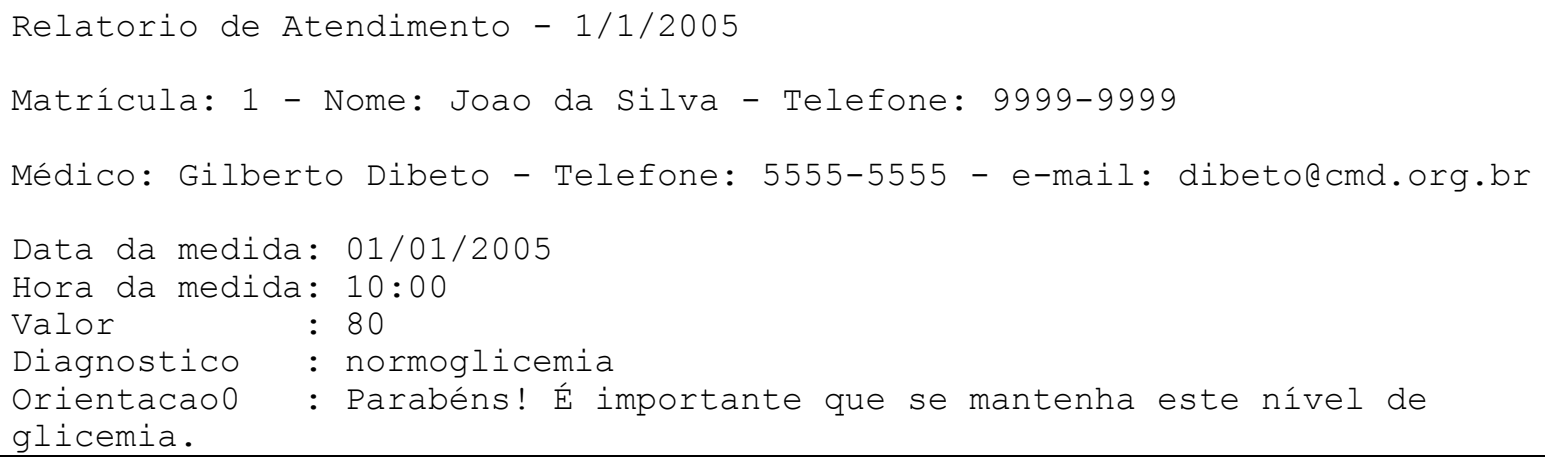

Quadro 5.11 - Relatório final emitido pelo sistema no caso clínico 1

\section{Simulação do caso clínico 2:}

A data utilizada foi $02 / 01 / 2005$ e o valor de glicemia, 30. O paciente está consciente e confuso. O resultado encontra-se no quadro 5.12.

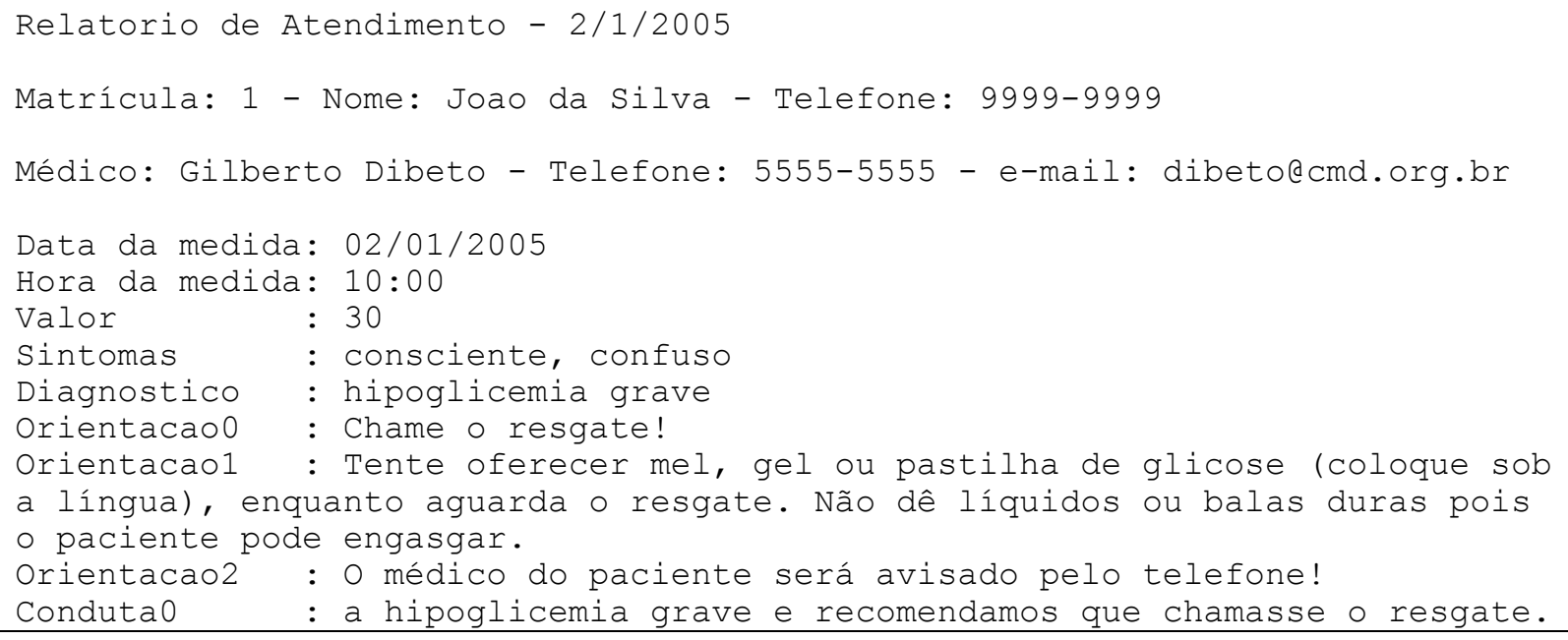

Quadro 5.12 - Relatório final emitido pelo sistema no caso clínico 2

\section{Simulação do caso clínico 3:}

A data utilizada foi 03/01/2005 e o valor de glicemia, 35. O paciente está consciente. O resultado encontra-se no quadro 5.13. 


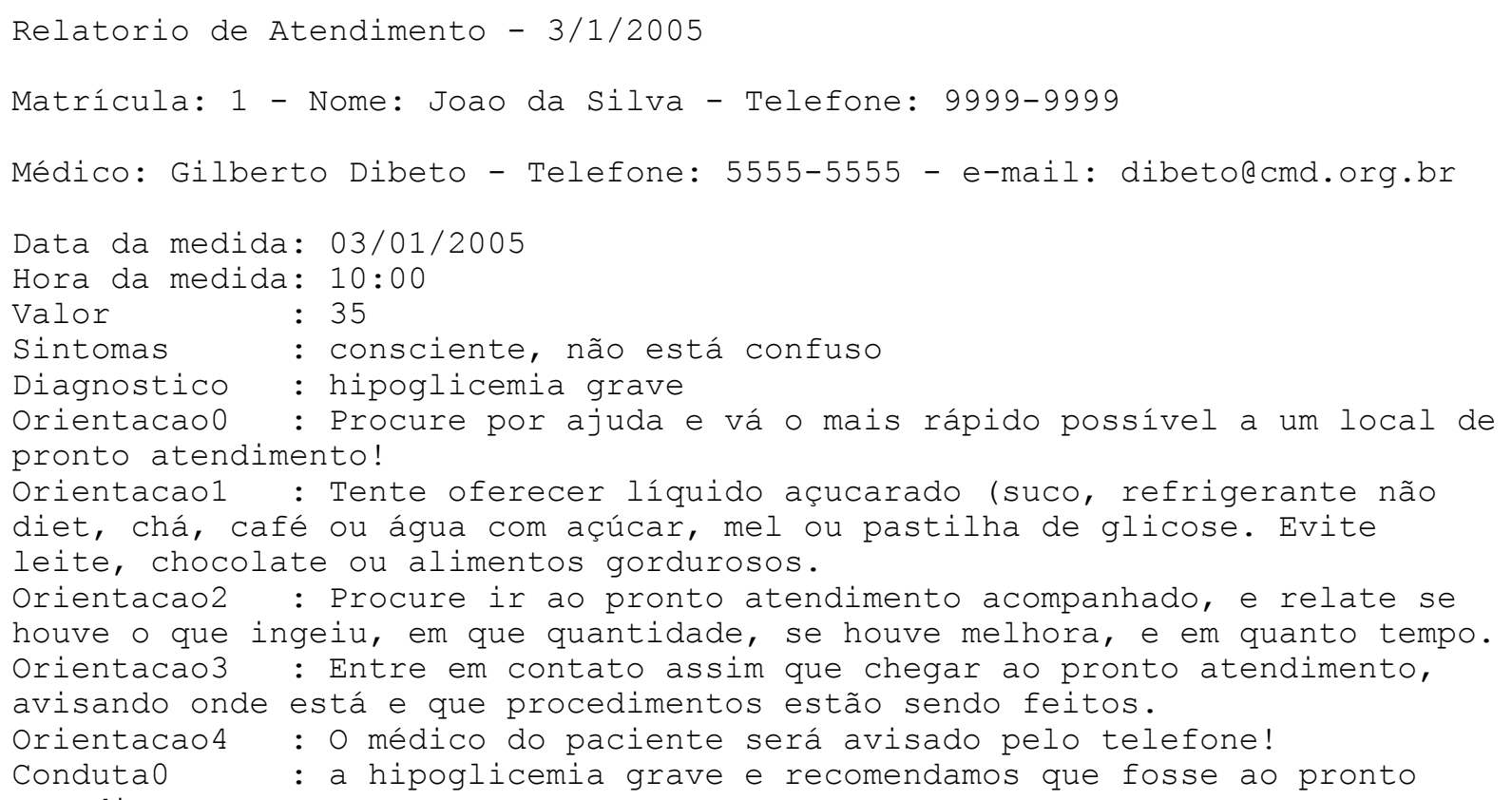

\section{Quadro 5.13 - Relatório final emitido pelo sistema no caso clínico 3}

\section{Simulação do caso clínico 4:}

A data utilizada foi 04/01/2005 e o valor de glicemia, 20. O paciente está inconsciente e teve episódio de convulsão. O resultado encontra-se no quadro 5.14.

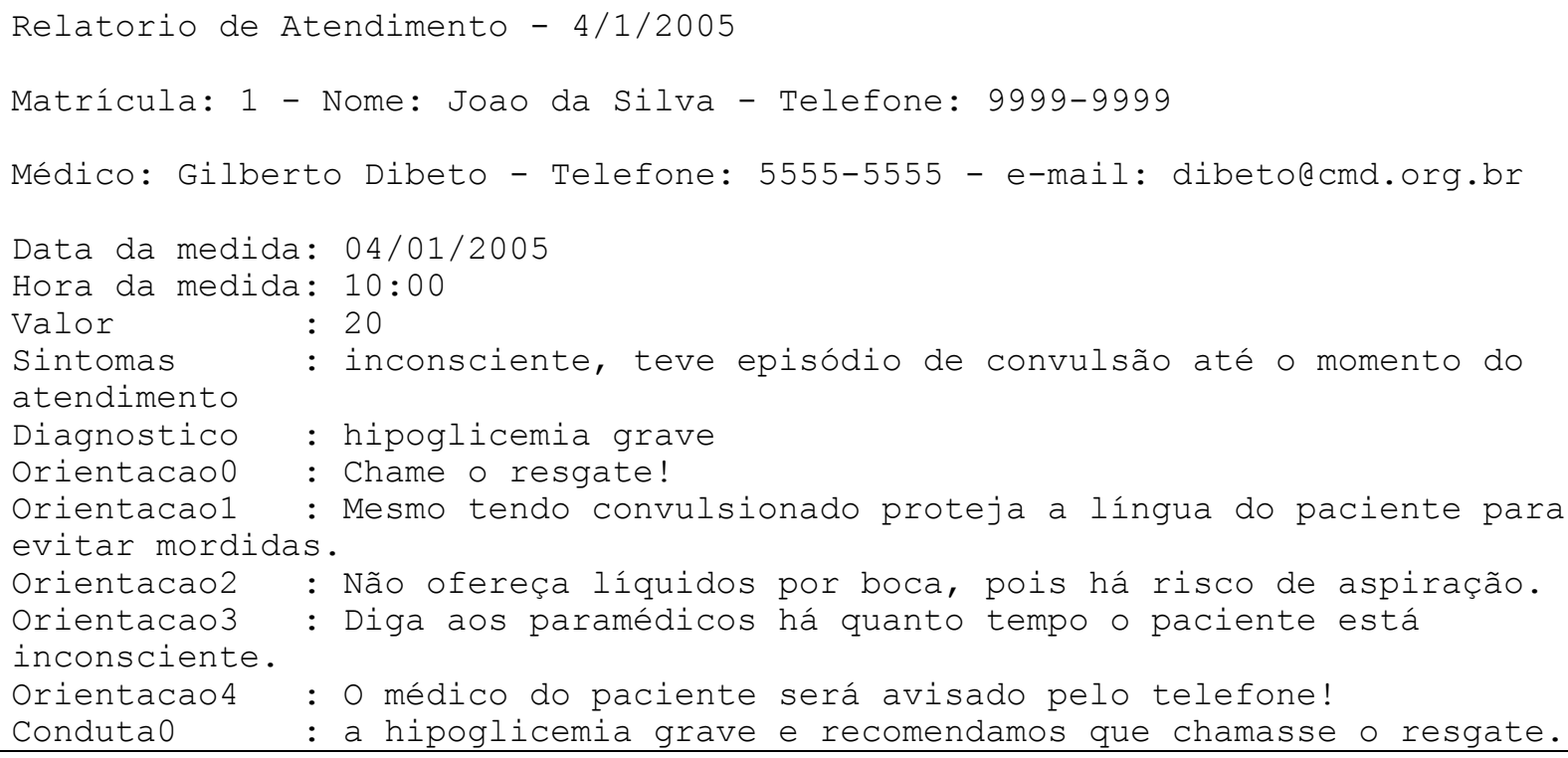

Quadro 5.14 - Relatório final emitido pelo sistema no caso clínico 4 


\section{Simulação do caso clínico 5:}

A data utilizada foi 05/01/2005 e o valor de glicemia, 20. O paciente está inconsciente e não teve episódio de convulsão. O resultado encontra-se no quadro 5.15.

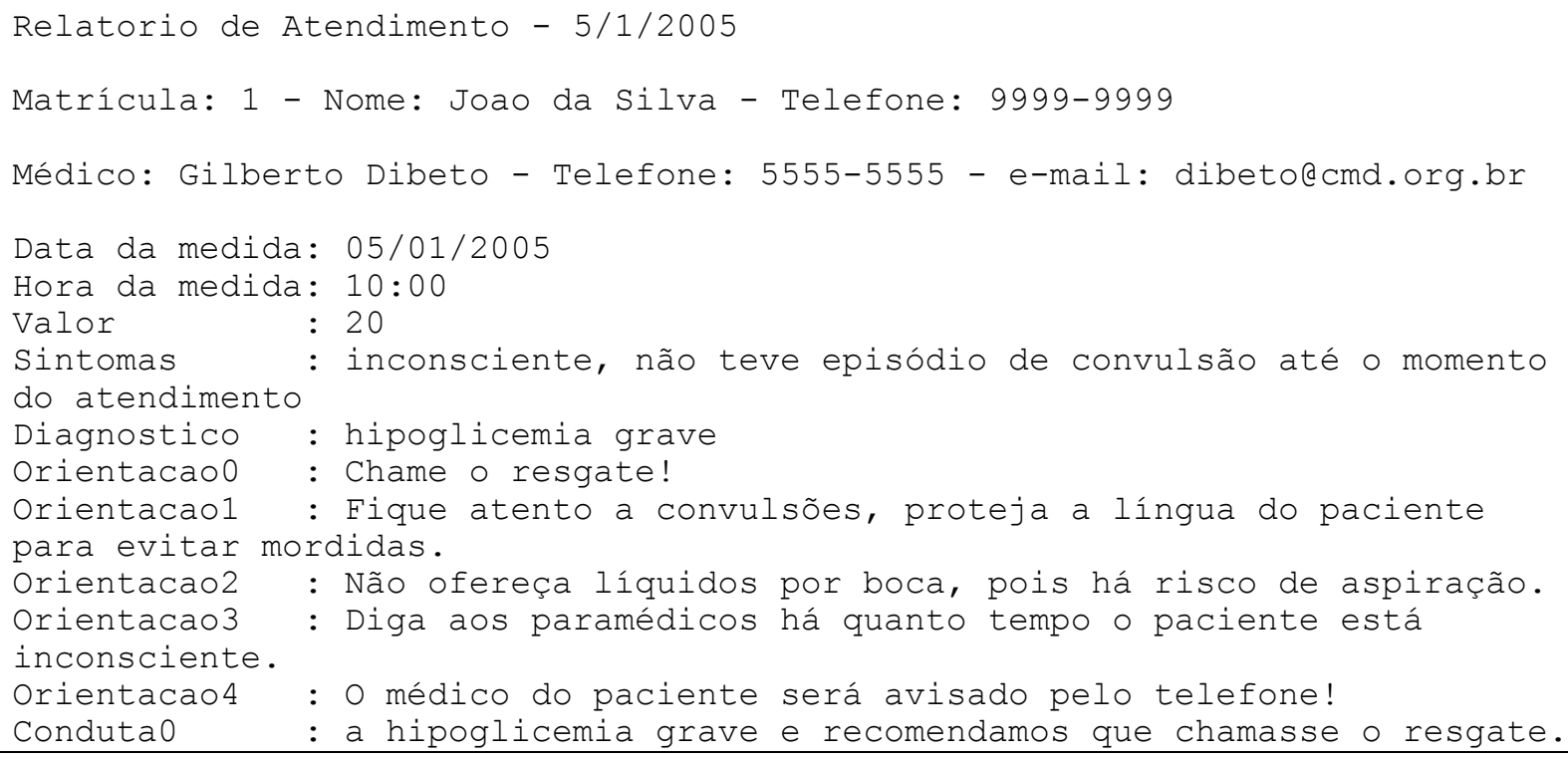

Quadro 5.15 - Relatório final emitido pelo sistema no caso clínico 5

\section{Simulação do caso clínico 6:}

A data utilizada foi 06/01/2005 e o valor de glicemia, 50. O paciente está consciente e confuso. O resultado encontra-se no quadro 5.16.

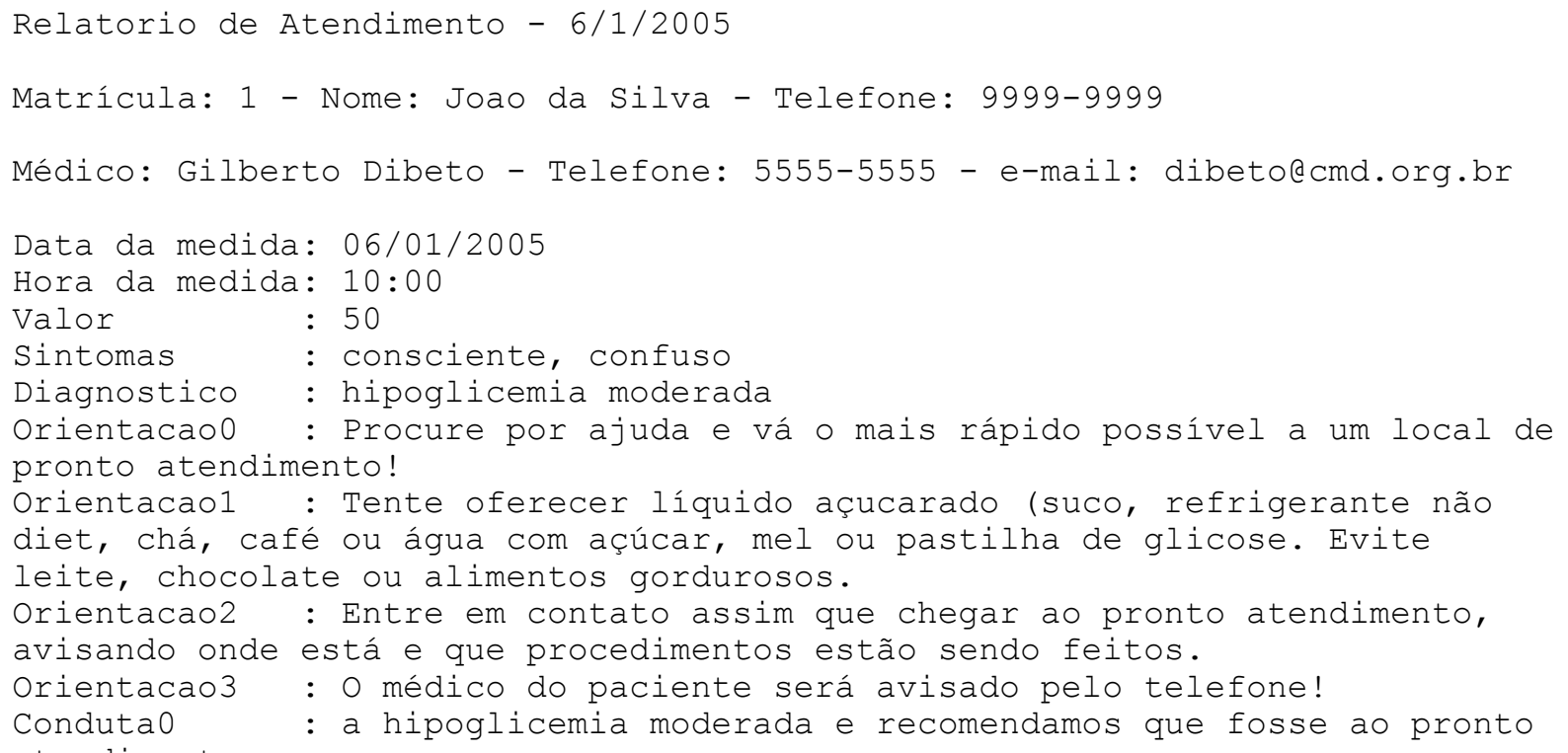




\section{Simulação do caso clínico 7:}

A data utilizada foi 07/01/2005 e o valor de glicemia, 55. O paciente está consciente e não está confuso. O resultado encontra-se no quadro 5.17 .

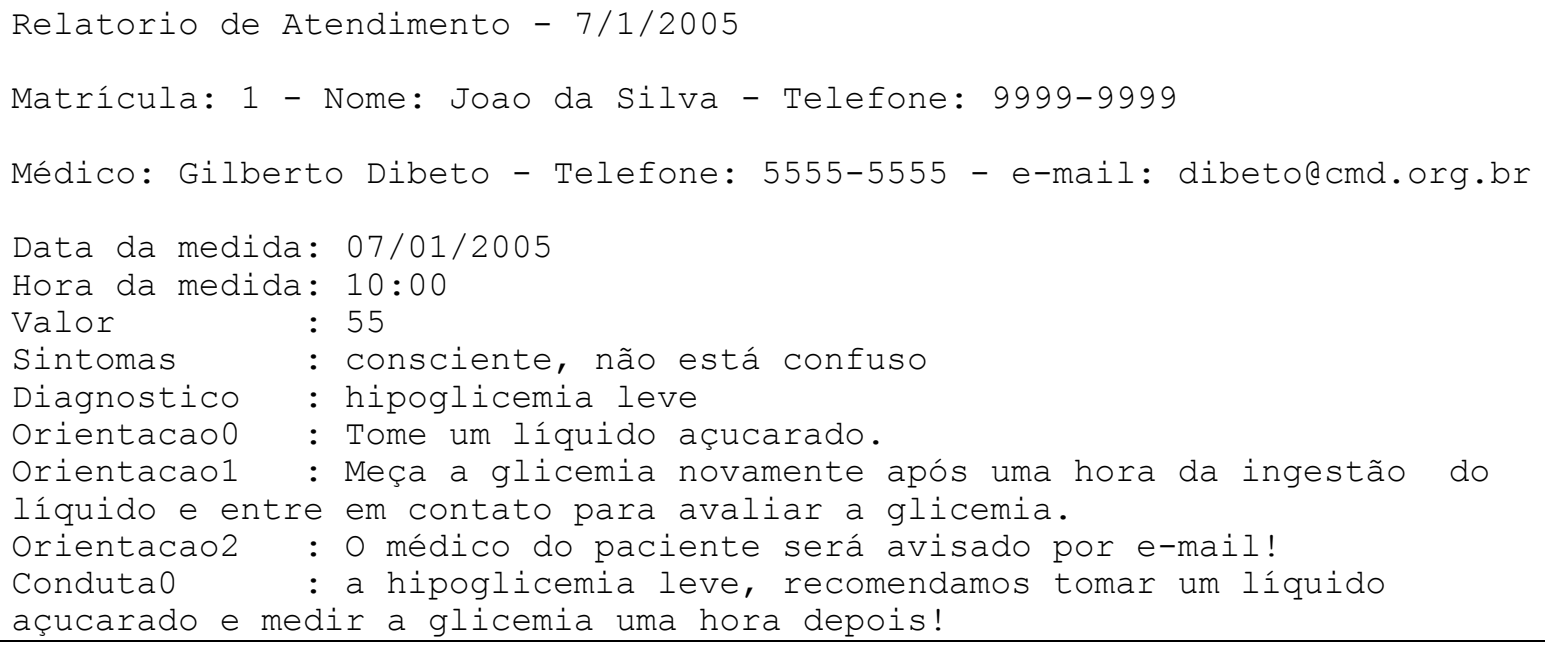

Quadro 5.17 - Relatório final emitido pelo sistema no caso clínico 7

\section{Simulação do caso clínico 8:}

A data utilizada foi 08/01/2005 e o valor de glicemia, 45. O paciente está inconsciente e não teve episódio de convulsão. O resultado encontra-se no quadro 5.19.

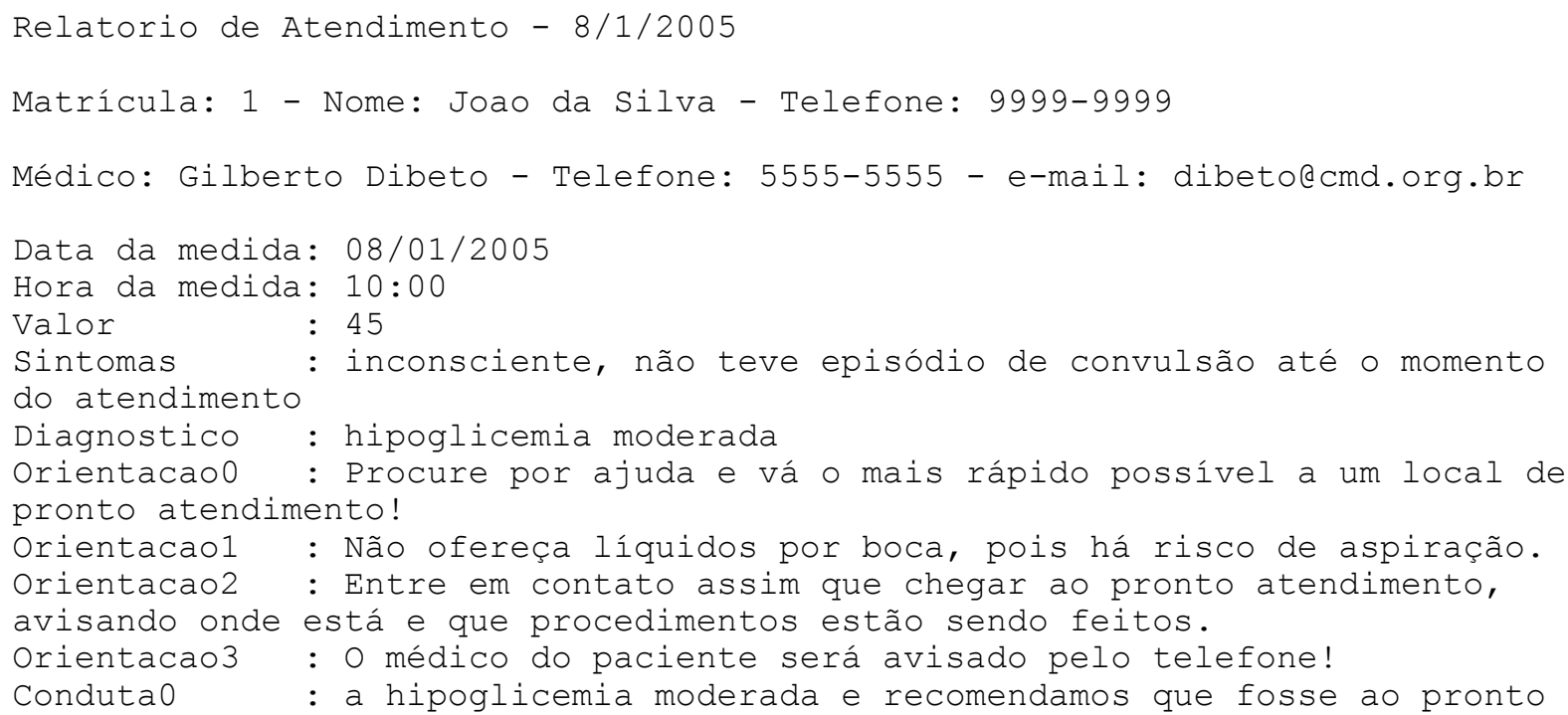




\section{Simulação do caso clínico 9:}

A data utilizada foi 09/01/2005 e o valor de glicemia, 180. O paciente está consciente e com infecção. O resultado encontra-se no quadro 5.19.

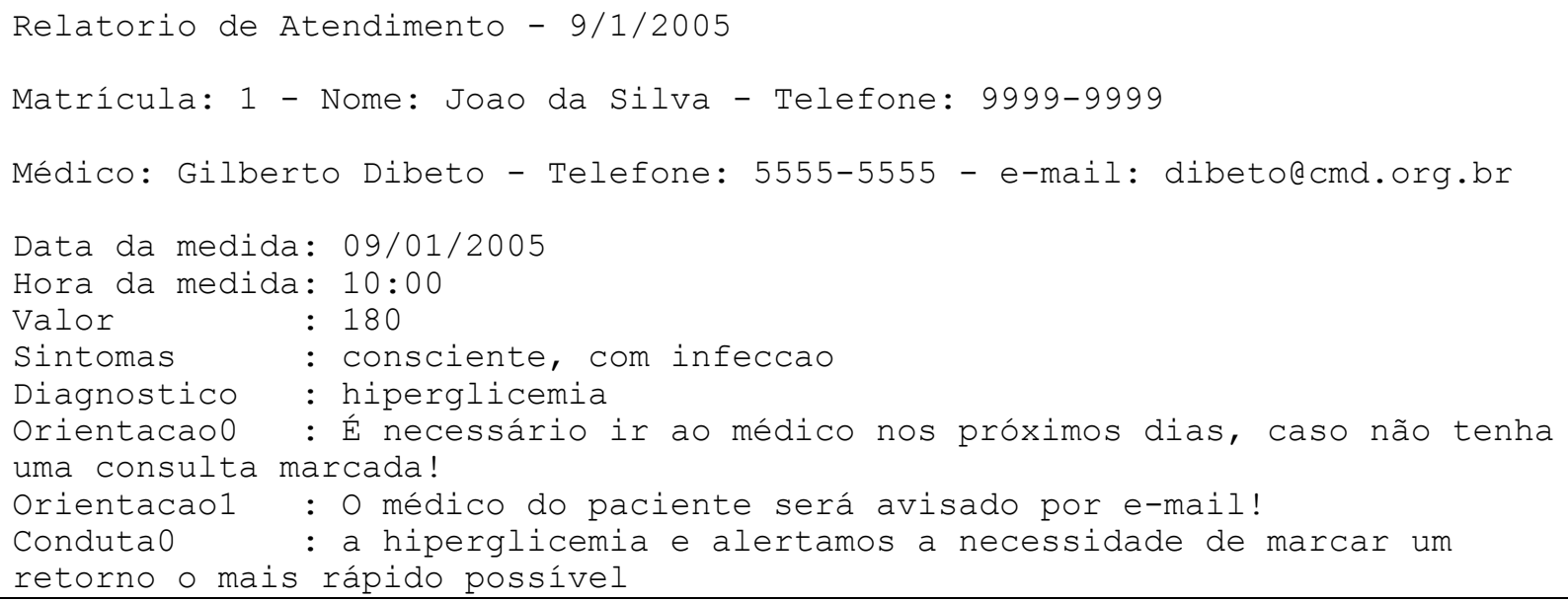

\section{Quadro 5.19 - Relatório final emitido pelo sistema no caso clínico 9}

\section{Simulação do caso clínico 10:}

A data utilizada foi 10/01/2005 e o valor de glicemia, 130. O paciente está consciente e sem infecção. O resultado encontra-se no quadro 5.20.

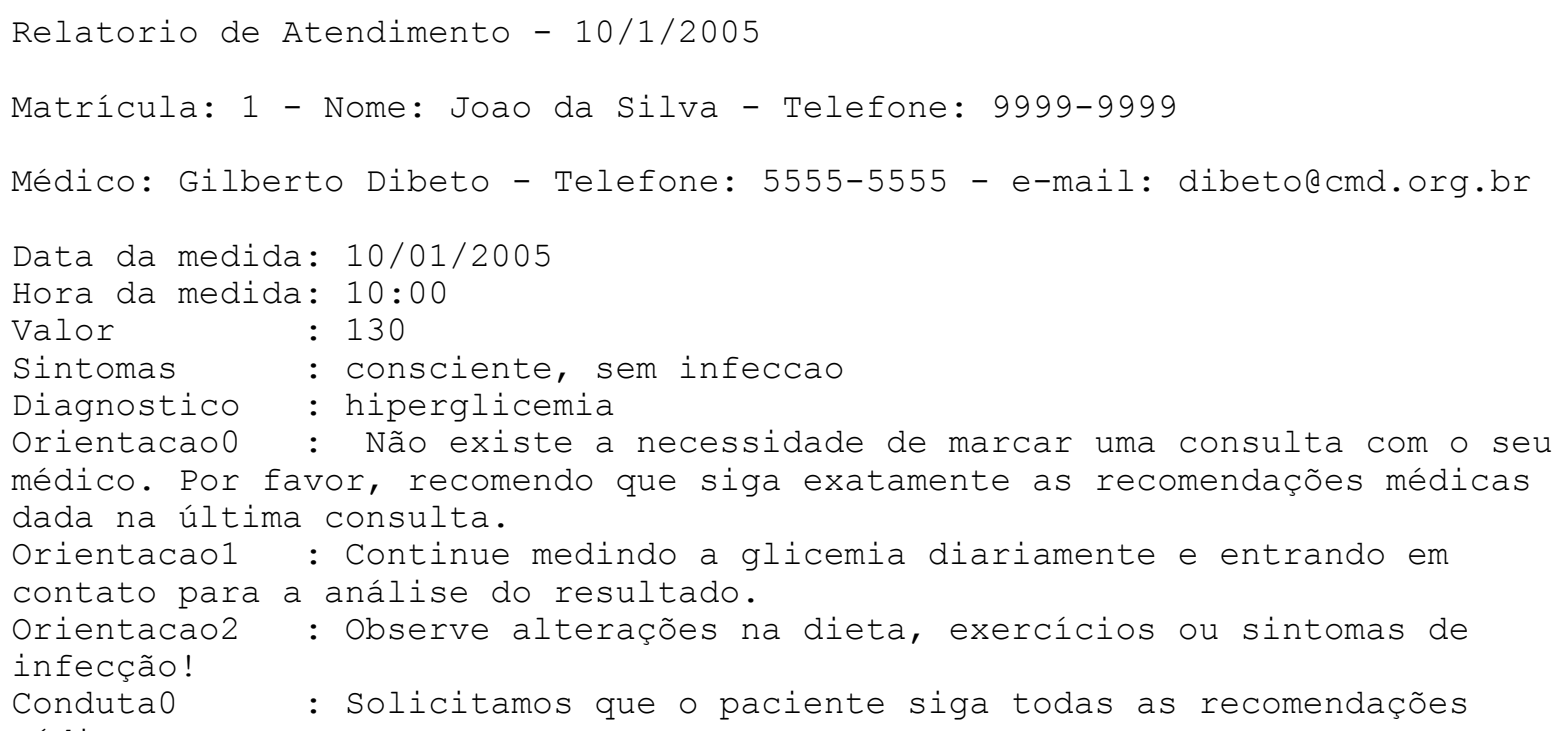

Quadro 5.20 - Relatório final emitido pelo sistema no caso clínico 10 


\section{Simulação do caso clínico 11:}

A data utilizada foi 11/01/2005 e o valor de glicemia, 195. O paciente está inconsciente. O resultado encontra-se no quadro 5.21.

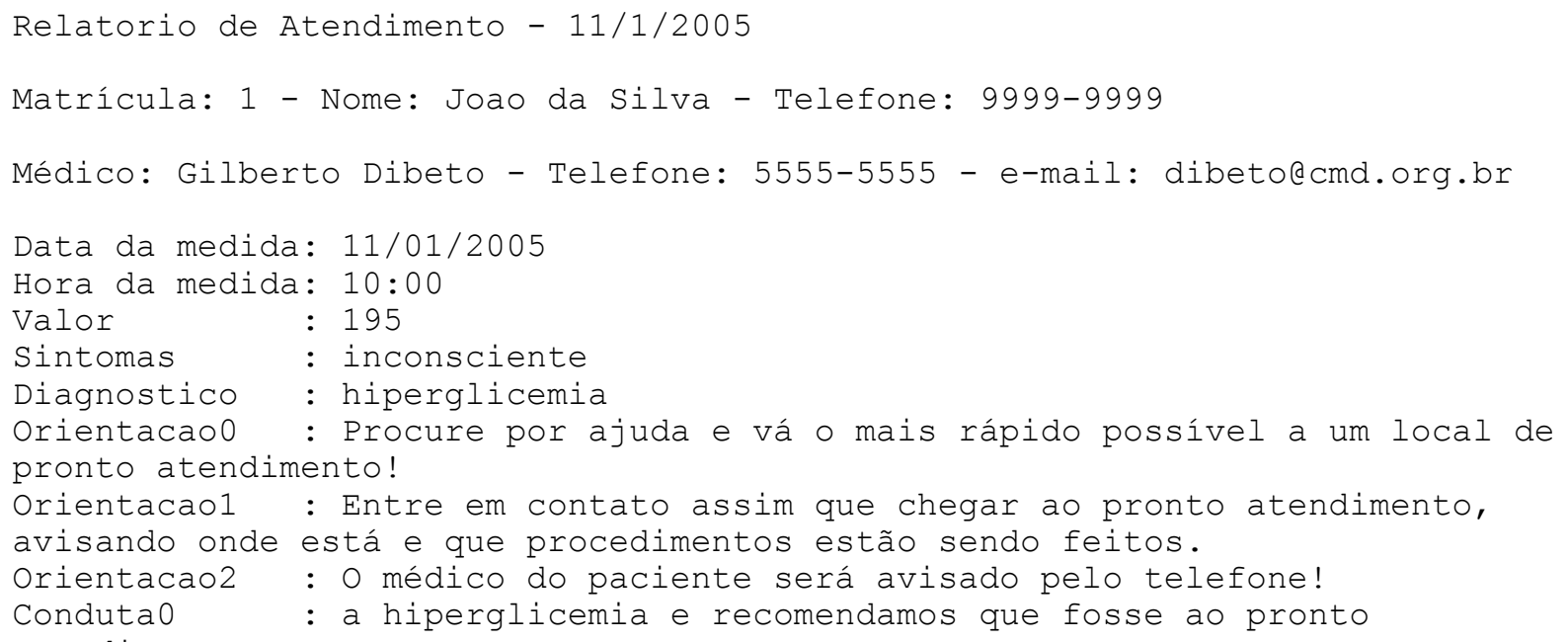

Quadro 5.21 - Relatório final emitido pelo sistema no caso clínico 11

\section{Simulação do caso clínico 12:}

A data utilizada foi 12/01/2005 e o valor de glicemia, 300. O paciente está consciente. O resultado encontra-se no quadro 5.22.

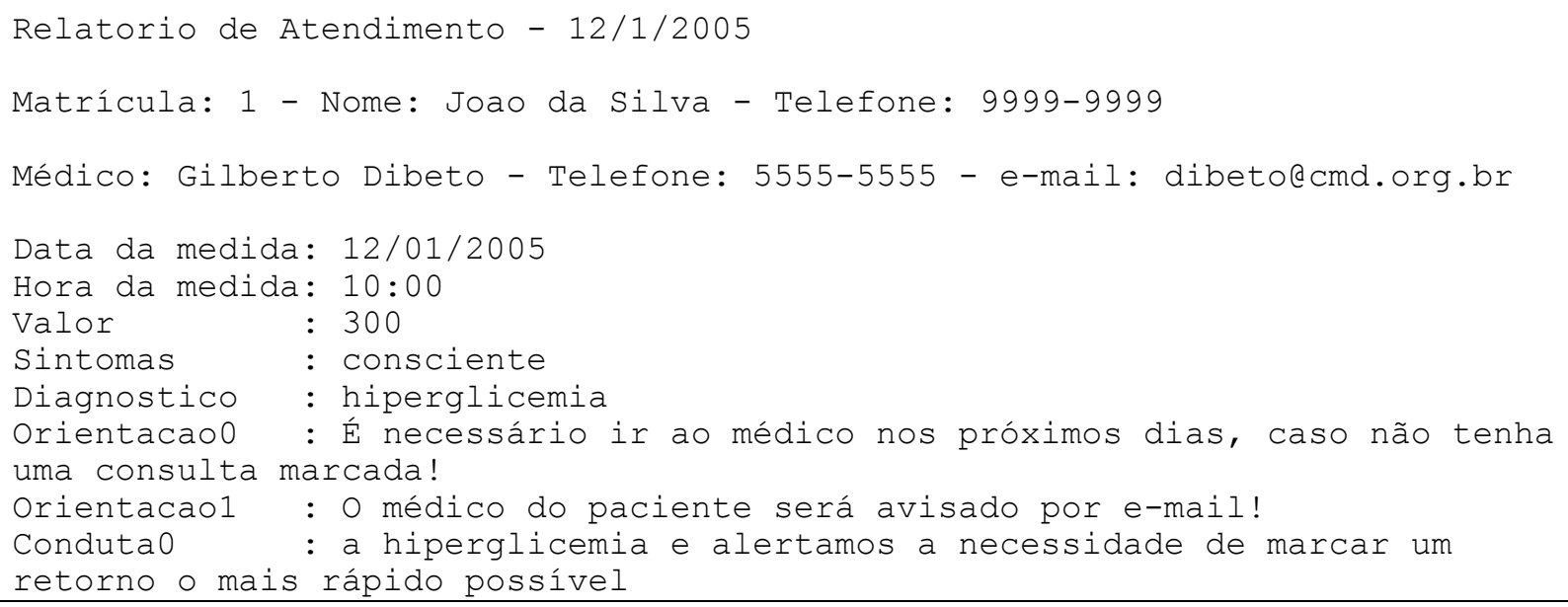

Quadro 5.22 - Relatório final emitido pelo sistema no caso clínico 12 


\section{Simulação do caso clínico 13:}

A data utilizada foi 13/01/2005 e o valor de glicemia, 500. O paciente está inconsciente. O resultado encontra-se no quadro 5.23.

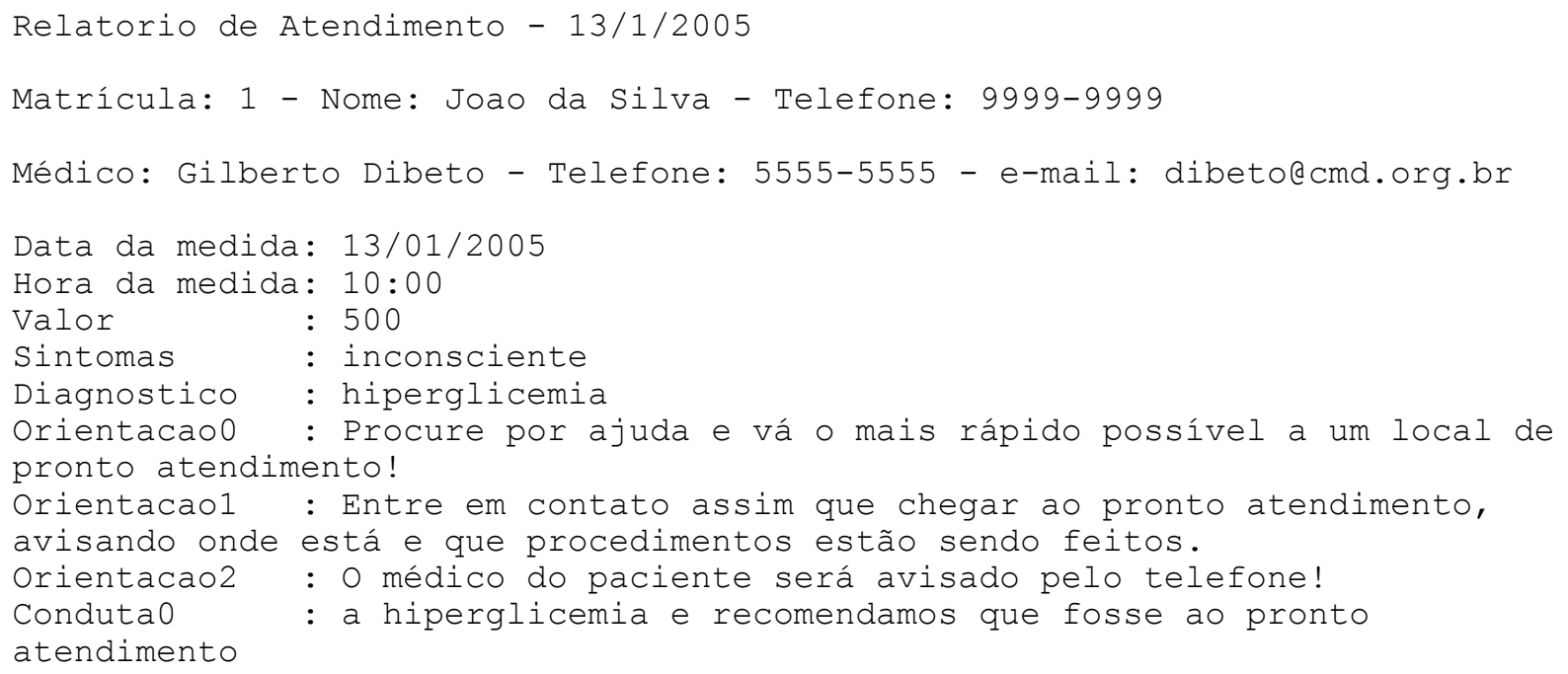

Quadro 5.23 - Relatório final emitido pelo sistema no caso clínico 13

\subsubsection{Análise dos Resultados}

Observou-se que em todas as simulações realizadas houve a cooperação entre os agentes, e em nenhum caso houve uma recusa ou falta de agentes para resolver os problemas. Além disso, a transparência no funcionamento foi evidente, pois a busca e a contratação de parceiros, ocorreu sem a necessidade de interferência do usuário; na verdade, ele nem sabia quando isso ocorria. Esse fato também demonstra que os agentes se comunicam quando desejam e necessitam.

O que se constatou é que o usuário não precisa conhecer as regras de negócio para executar o processo de identificação ou monitoração. Quando ocorre um problema e um novo plano é executado, o próprio agente decide executá-lo, fazendo com que o usuário consiga chegar a um de seus objetivos. Foi o que ocorreu, por exemplo, quando o paciente errou o número de matrícula. No momento em que o usuário digitou um número de matrícula inexistente, o agente atendente, constatando que a matrícula não existe, mudou o seu plano e iniciou uma identificação pelo nome do paciente e da mãe do contato. Todas essas operações foram 
realizadas de modo transparente ao usuário.

Os agentes, quando percebem que não podem executar os seus planos sozinhos, procuram e escolhem um parceiro capaz de realizar a ação necessária, demonstrando que raciocinam sobre os planos dos outros. É o que foi visto na contratação do agente diabetologista pelo agente enfermeiro.

A interação entre o agente e o seu ambiente composto por objetos atingiu o resultado esperado. Os agentes só tinham acesso aos objetos de sua responsabilidade ou que lhes eram entregues. A troca de mensagem entre o agente e o objeto ocorreu sem problemas e todas as informações necessárias para que o agente pudesse alcançar o seu objetivo foram obtidas. Caso tal fato não ocorresse, não teríamos sucesso na execução das simulações.

O sistema demonstrou que pode fornecer tanto as orientações e condutas de acordo com o esperado, quanto a identificação do paciente nas situações previstas. Isso reforça o fato de que, modelar o sistema primeiro, além de facilitar a sua implementação, permitiu que erros nos resultados esperados nas simulações não ocorressem, pois o que foi feito após as simulações foram acertos nas redações das orientações.

\subsection{Simulações para avaliar a potencialidade do modelo GRPC}

Conforme apresentado no capítulo 3, os meios que os médicos hoje utilizam para acompanhar os pacientes crônicos podem ser melhorados. Pretende-se com estas simulações demonstrar que o modelo pode ajudar a otimizar o agendamento de consultas presencias, quer seja por meio de orientações do sistema especialista ou pela indicação do médico do paciente, ao analisar as informarções coletadas de forma contínua.

O objetivo nessas simulações é analisar os resultados relacionados com a solicitação de marcação de consultas, de diagnósticos e da comunicação com o médico do paciente num período de 6 meses.

Nos próximos itens são apresentadas as adaptações feitas no sistema TeleDM para as simulações, as escolhas das situações simuladas, os resultados obtidos e as análises desses resultados. 


\subsubsection{Adaptações do Sistema TeleDM para a Simulação (TeleDM_Sim)}

Para simular os atendimentos de pacientes foi necessário realizar alterações no sistema TeleDM. Essa versão foi denominda de sistema TeleDM_Sim. O TeleDM_Sim, além de permitir simular em computador o atendimento a pacientes, define de forma aleatória o valor da glicemia e o estado clínico do paciente no momento da medida.

Dessa forma, no sistema TeleDM_Sim criou-se um agente paciente que é responsável por definir o valor da glicemia e o seu estado clínico em um atendimento. Com essa premissa, o objetivo do agente paciente foi estabelecido: fornecer a glicemia e fornecer o seu estado clínico. A partir desses objetivos, foram elaborados os planos e ações para que o agente paciente pudesse realizá-los. Para implementar o agente paciente, procedeu-se da mesma forma quando do desenvolvimento dos demais agentes, ou seja, a classe paciente é uma classe-filha da classe Person.

Nos agentes atendente, diabetologista e enfermeiro, acrescentaram-se objetivos e planos para que fizessem a interação com o agente paciente e não mais com o usuário do sistema. Não houve dificuldade em implementar tais modificações; foi necessário apenas criar novos objetivos e planos com plena reutilização das ações que não tinham interação direta com o usuário.

\subsubsection{Descrição dos casos}

Os elementos que variam em cada simulação são:

- A data da consulta - simula-se o atendimento diário em 6 meses;

- O valor da glicemia - a cada atendimento o valor da glicemia varia de forma aleatória;

- O estado clínico - dependendo do valor da glicemia o estado clínico é definido.

Na simulação, a data da consulta inicia-se em 01/03/2004 e termina em 30/08/2004, contabilizando 6 meses de acompanhamento. O mês para as simulações tem 30 dias, totalizando 180 atendimentos. O paciente é atendido somente uma vez a cada dia, às $10 \mathrm{~h} 00$. 
Não foi simulada a situação na qual o paciente necessita retornar com nova medida no mesmo dia, pois não foi avaliado o acompanhamento após intercorrências.

Inicialmente, a quantidade de pacientes seria cinco, com a glicemia variando entre 30 e 800; porém, notou-se que a oscilação de valores era muito grande.Por exemplo, num dia o paciente estava com a medida 40 e no dia seguinte, 700. Este tipo de episódio pode ocorrer, porém não é o mais comum. Assim, optou-se por ter um paciente de cada perfil. Entende-se por perfil a tendência do paciente para uma das três classificações de diagnóstico: hiperglicêmico, normoglicêmico e hipoglicêmico. Elaboraram-se quatro perfis de pacientes que foram simulados durante o período de 6 meses:

- Paciente sem controle - indivíduo que um dia pode ter uma glicemia muito baixa, e no outro, muito elevada. Os valores de glicemia variam entre 30 e 800 ;

- Paciente com tendência hipoglicêmica - indivíduo que pode ter hipoglicemia ou normoglicemia. Os valores de glicemia variam entre 30 e 100;

- Paciente com tendência hiperglicêmica - indivíduo que pode ter hiperglicemia ou normoglicemia. Os valores de glicemia variam entre 60 e 800 ;

- Paciente com tendência normoglicêmica - indivíduo que pode ter hiperglicemia não muito elevada, normoglicemia ou hipoglicemia leve. Os valores variam entre 50 e 150.

O estado clínico, por sua vez, depende do valor da glicemia escolhida de forma aleatória. Nesse caso verifica-se que o paciente diagnosticado como hipoglicêmico pode estar consciente ou confuso, enquanto que o hiperglicêmico pode estar consciente, confuso e/ou com infecção. Como não foram simulados casos não previstos pelo sistema, o paciente não apresenta outros tipos de estado clínico.

Resumindo, as variações dos elementos nas simulações sempre coincidem com um dos casos clínicos contidos na tabela 5.1. Os resultados e as análises das simulações realizadas são apresentados a seguir. 


\subsubsection{Resultados Obtidos}

Para cada perfil de paciente foi realizada pelo menos uma simulação com 180 atendimentos. Com o paciente com tendência normoglicêmica foram feitas três simulações, pois este é o tipo de paciente que mais se aproxima daquele que se beneficiará muito do modelo GRPC.

Dentre as simulações realizadas foram identificados os resultados que auxiliam na avaliação do modelo. Esses resultados estão relacionados com as seguintes características:

- O diagnóstico dado pelo sistema;

- A comunicação ou não com o médico do paciente;

- A solicitação de agendamento de consulta pelo sistema.

Desse modo, os resultados obtidos em cada simulação com relação às características apontadas e aos gráficos com os valores da glicemia sorteadas aleatoriamente no primeiro mês, correlacionadas com a data e a característica analisada, são apresentados a seguir. Optou-se por mostrar os gráficos considerando um período de 30 dias para facilitar a análise dos resultados.

a. Diagnóstico dado pelo sistema

Apesar do perfil de cada paciente simulado, existe uma variação no diagnóstico. A tabela 5.2 apresenta de forma resumida a quantidade de cada um dos diagnósticos nos perfis de paciente utilizados:

Tabela 5.2 - Tabela com a quantidade de diagnósticos por simulação

\begin{tabular}{lccc}
\hline Paciente & Normoglicêmico & Hiperglicêmico & Hipoglicêmico \\
\hline Sem controle & 11 & 157 & 12 \\
Tendência hipoglicêmica & 103 & 0 & 75 \\
Tendência hiperglicêmica & 9 & 171 & 0 \\
Tendência normoglicêmica 1 & 87 & 73 & 18 \\
Tendência normoglicêmica 2 & 159 & 7 & 14 \\
Tendência normoglicêmica 3 & 145 & 22 & 11 \\
\hline
\end{tabular}

Os próximos gráficos $(5.1,5.2,5.3,5.4,5.5$ e 5.6), com um período de 30 dias, correlacionam os dias, os diagnósticos e os valores da glicemia em cada simulação. Em cada valor de glicemia o seu diagnóstico é descrito de acordo com a legenda: 
- Normo - normoglicemia;

- Hiper - hiperglicemia;

- Hipo - hipoglicemia.

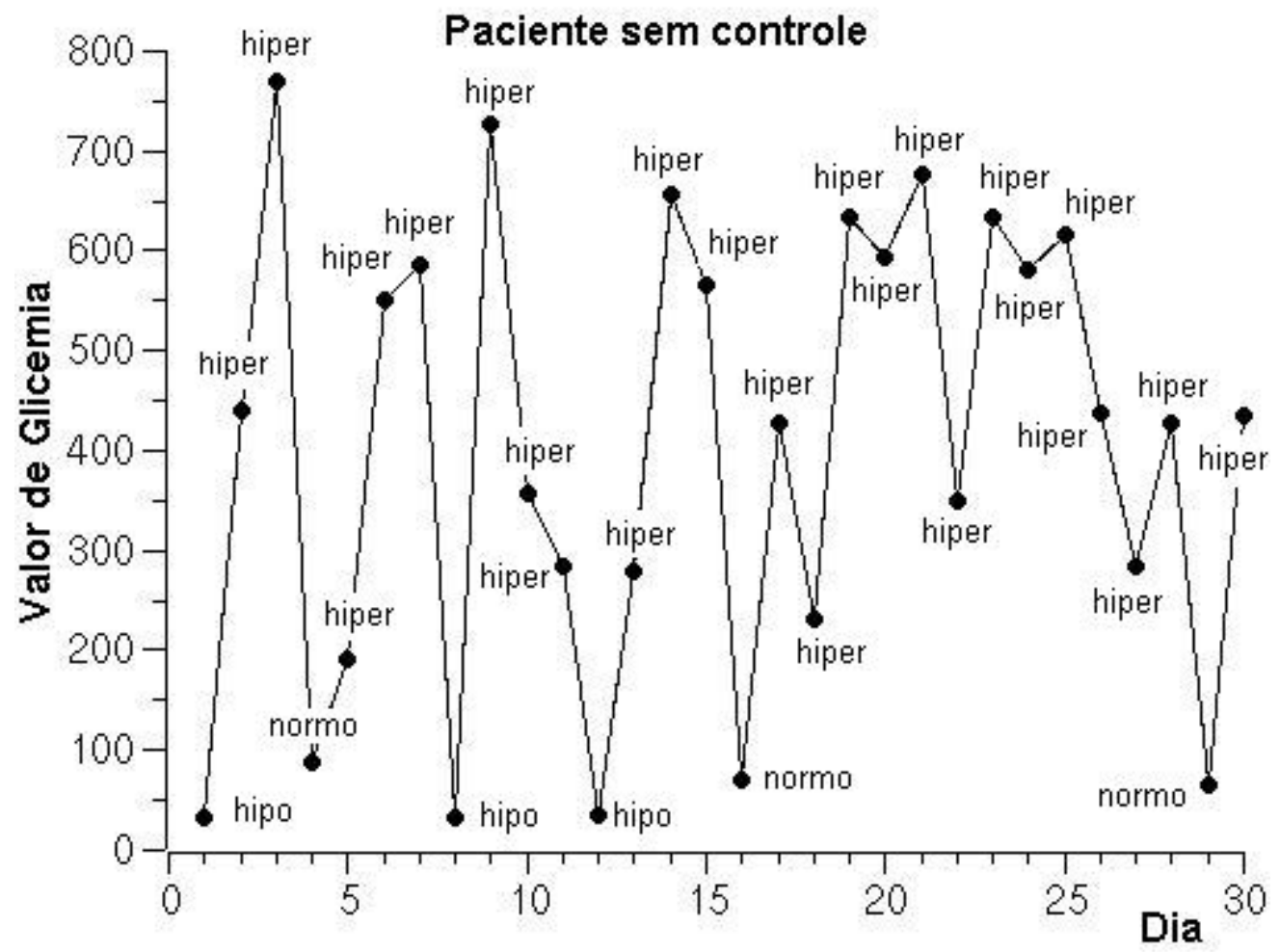

Gráfico 5.1 - Gráfico da simulação do paciente sem controle com os valores de glicemia e diagnósticos no período de 30 dias 


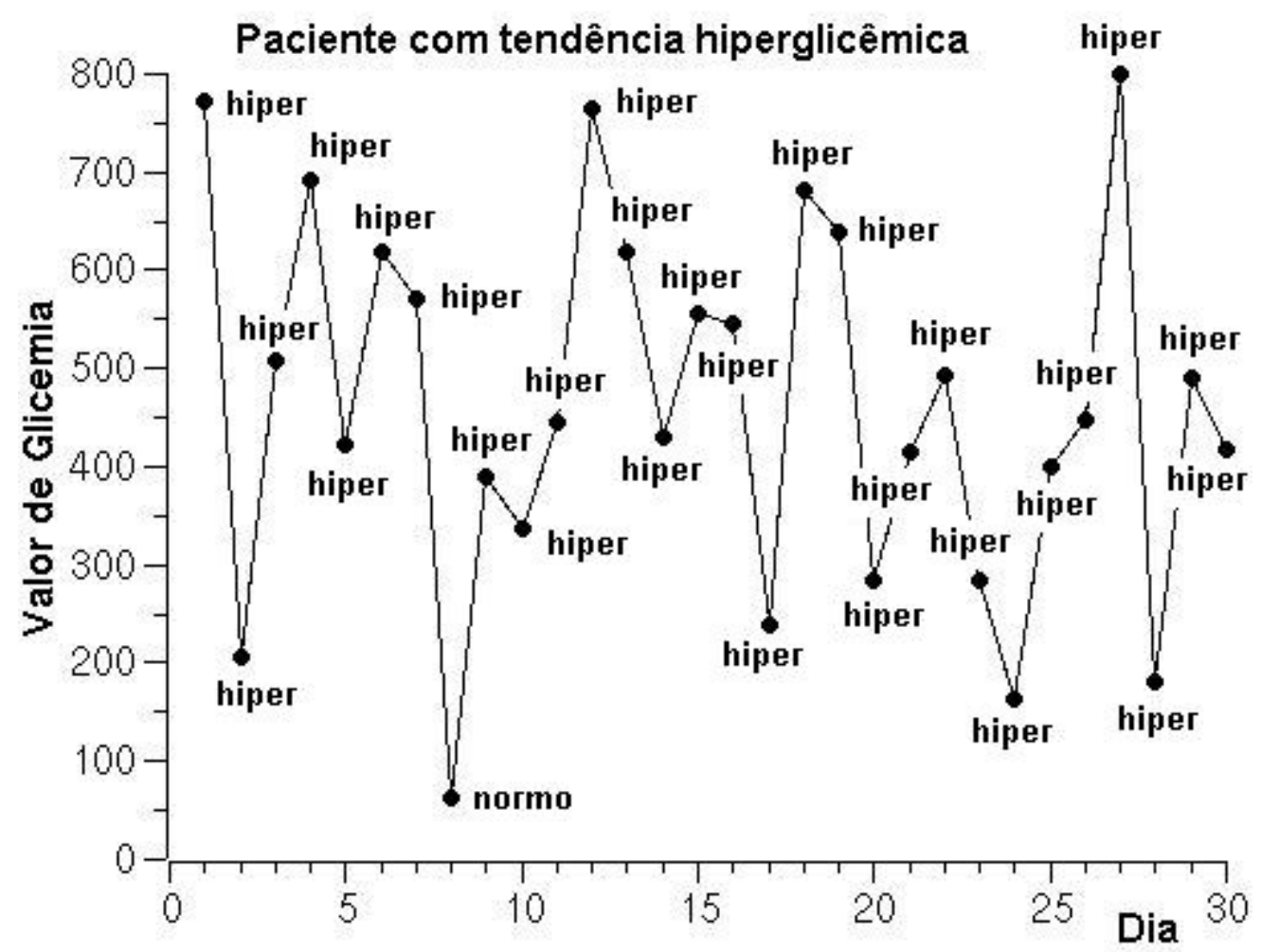

Gráfico 5.2 - Gráfico da simulação do paciente com tendência hiperglicêmica com os valores de glicemia e diagnósticos no período de 30 dias

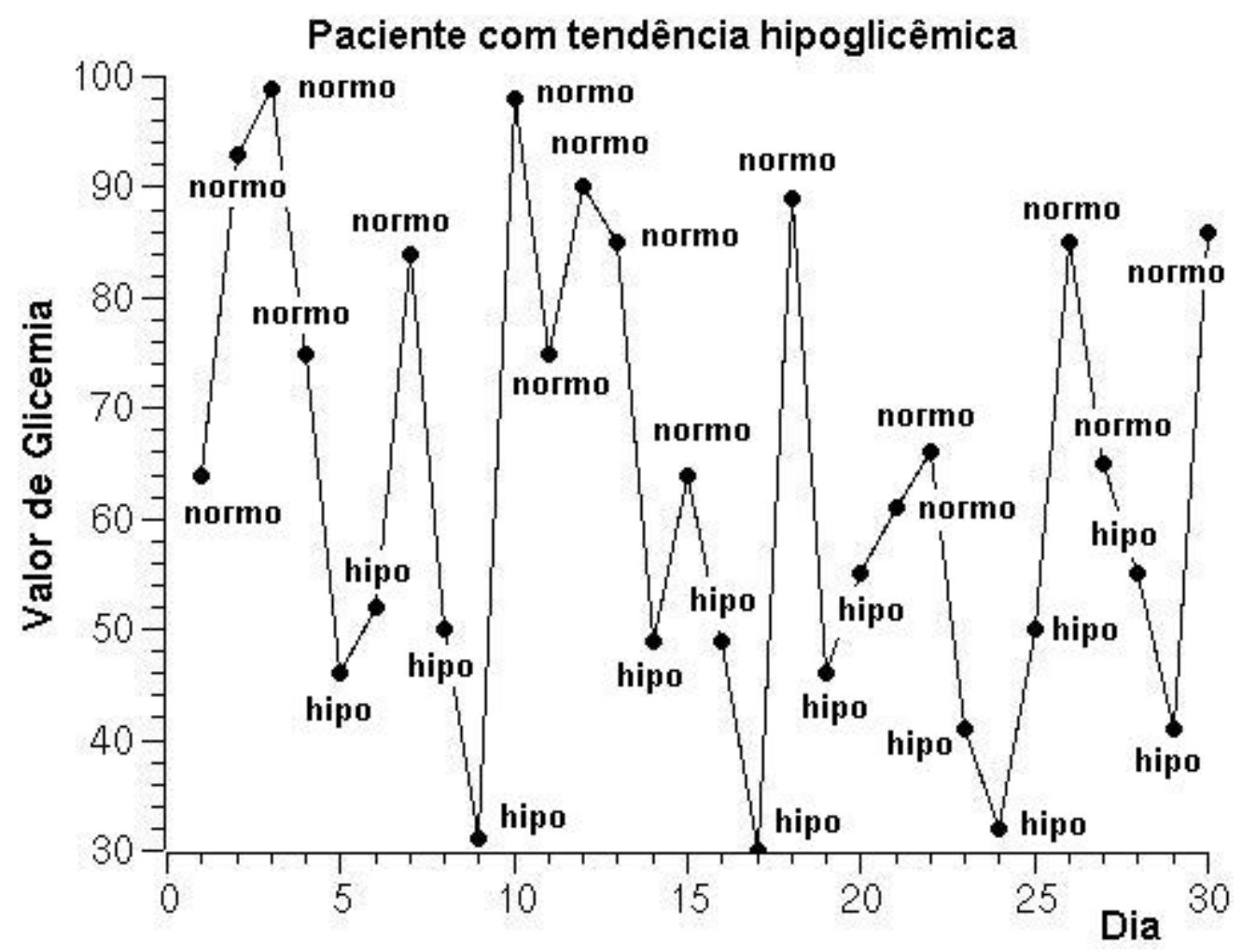

Gráfico 5.3 - Gráfico da simulação do paciente com tendência hipoglicêmica com os valores de glicemia e diagnósticos no período de 30 dias 


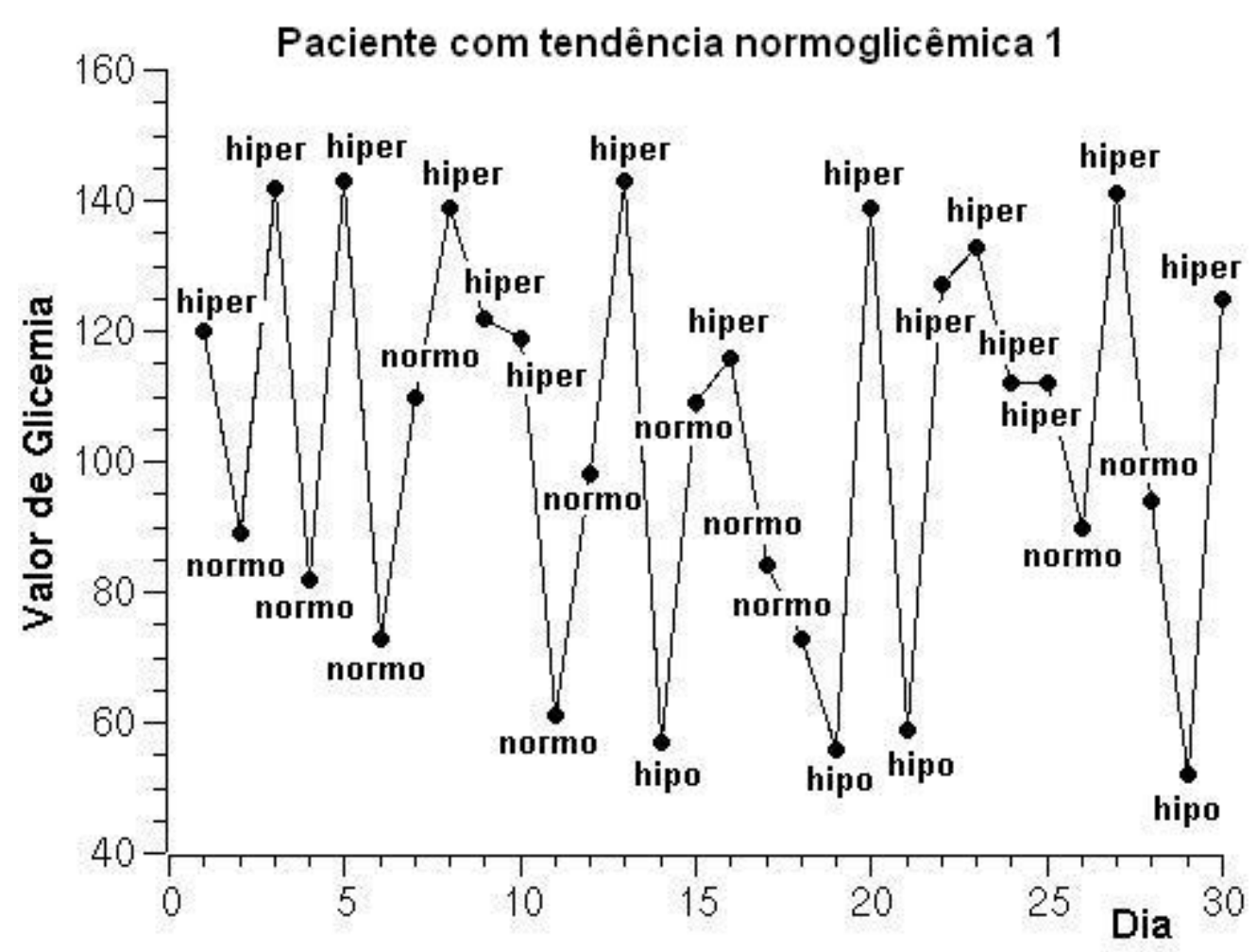

Gráfico 5.4 - Gráfico da simulação do paciente com tendência normoglicêmica 1 com os valores de glicemia e diagnósticos no período de 30 dias

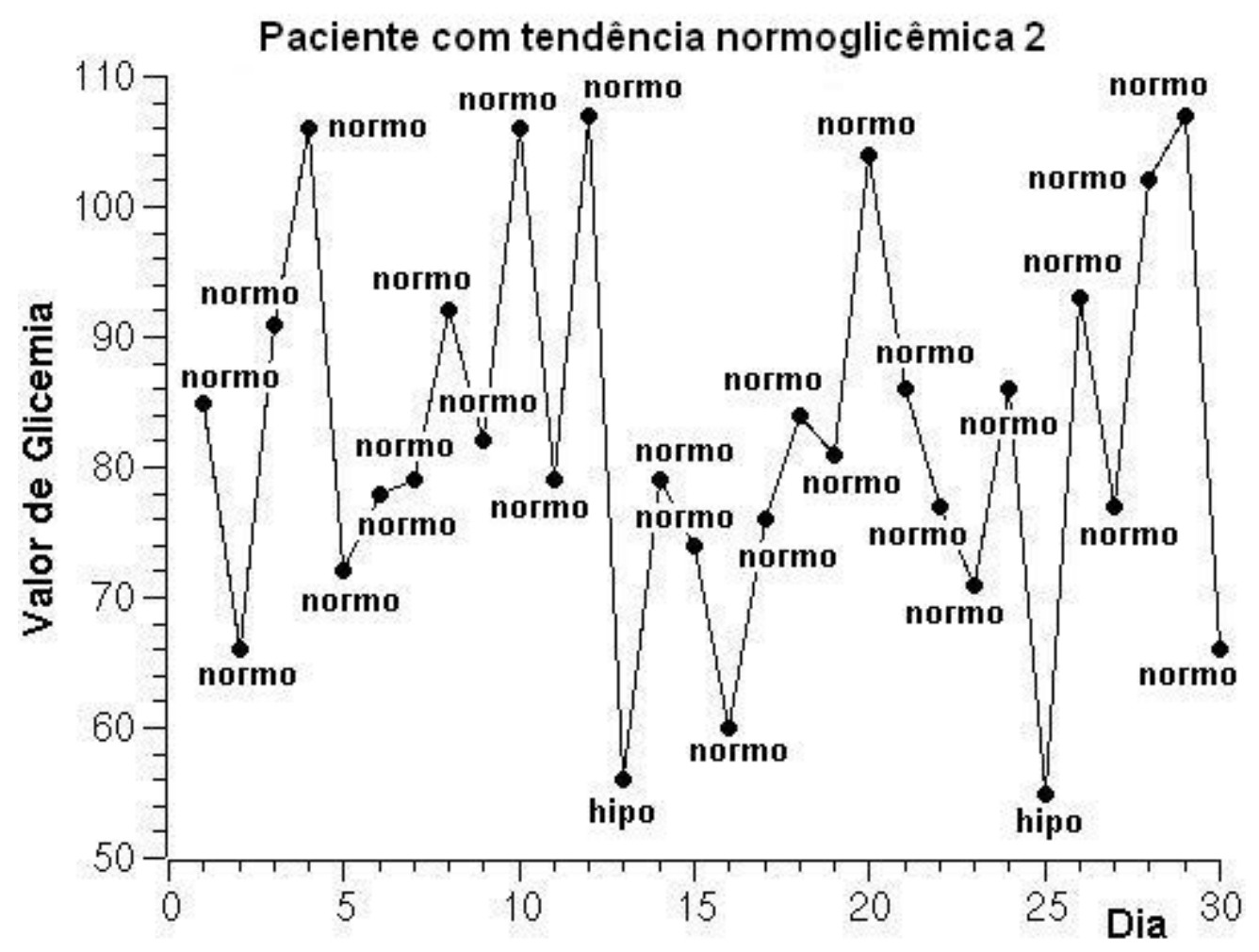

Gráfico 5.5 - Gráfico da simulação do paciente com tendência normoglicêmica 2 com os valores de glicemia e diagnósticos no período de 30 dias 


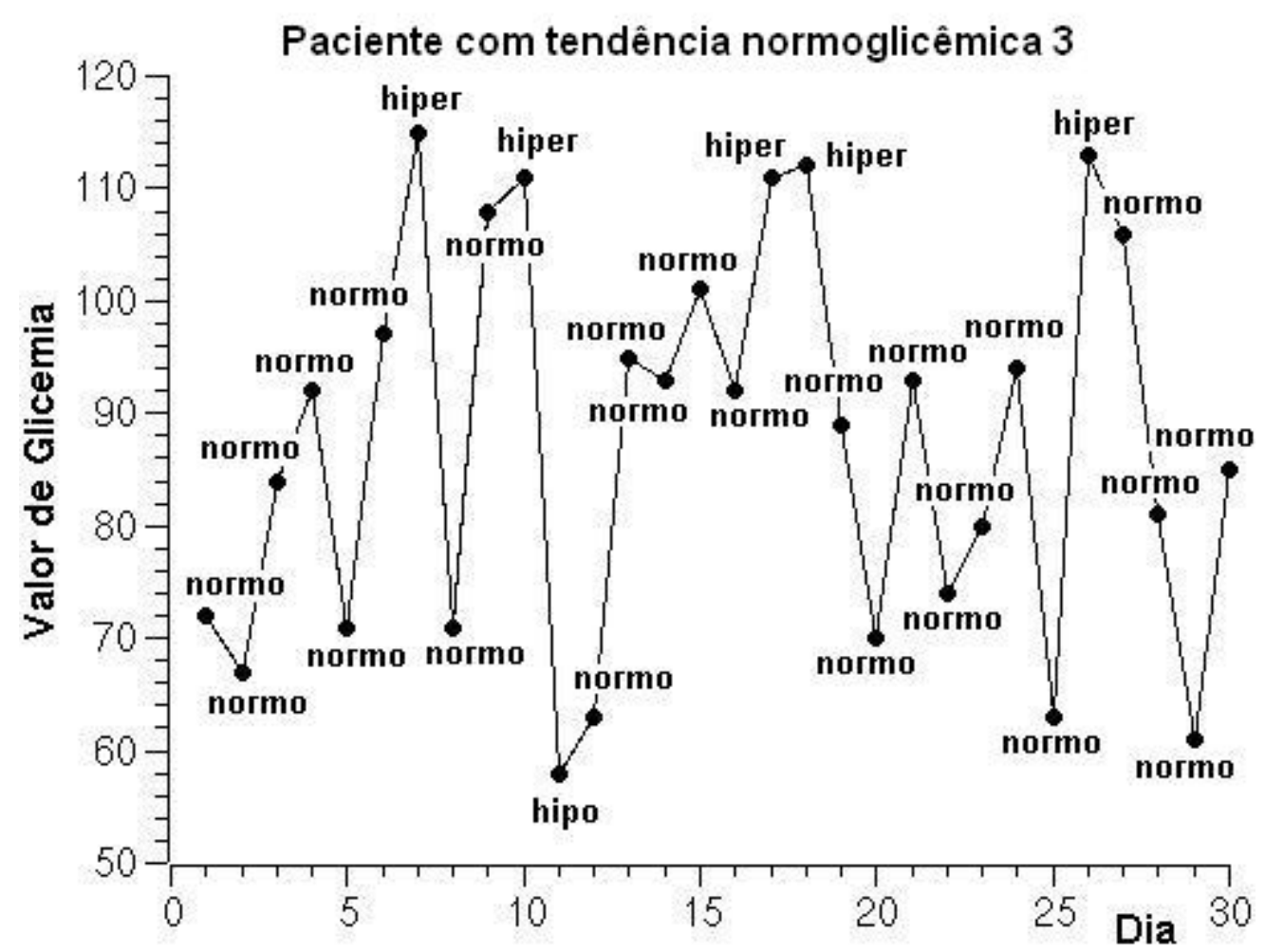

Gráfico 5.6 - Gráfico da simulação do paciente com tendência normoglicêmica 3 com os valores de glicemia e diagnósticos no período de 30 dias

b. Comunicação ou não com o médico do paciente

A necessidade de comunicação ou não com o médico a cada consulta foi quantificada e é apresentada de maneira resumida na tabela 5.3.

Tabela 5.3 - Tabela com a quantidade de comunicação com o médico

\begin{tabular}{lccc}
\hline Paciente & Não precisa se comunicar & Enviar e-mail & Telefonar \\
\hline Sem controle & 18 & 162 & 88 \\
Tendência hipoglicêmica & 105 & 75 & 57 \\
Tendência hiperglicêmica & 13 & 167 & 85 \\
Tendência normoglicêmica 1 & 119 & 61 & 7 \\
Tendência normoglicêmica 2 & 160 & 20 & 0 \\
Tendência normoglicêmica 3 & 155 & 25 & 0 \\
\hline
\end{tabular}

Os próximos gráficos $(5.7,5.8,5.9,5.10,5.11$ e 5.12), com um período de 30 dias, correlacionam os dias, o tipo de comunicação e os valores da glicemia em cada simulação. Em cada valor de glicemia, indica-se com a letra ' $M$ ' quando é enviado um e-mail ao médico e com a letra ' $\mathrm{T}$ ' quando, além do e-mail, entra-se em contato com o médico pelo telefone. 


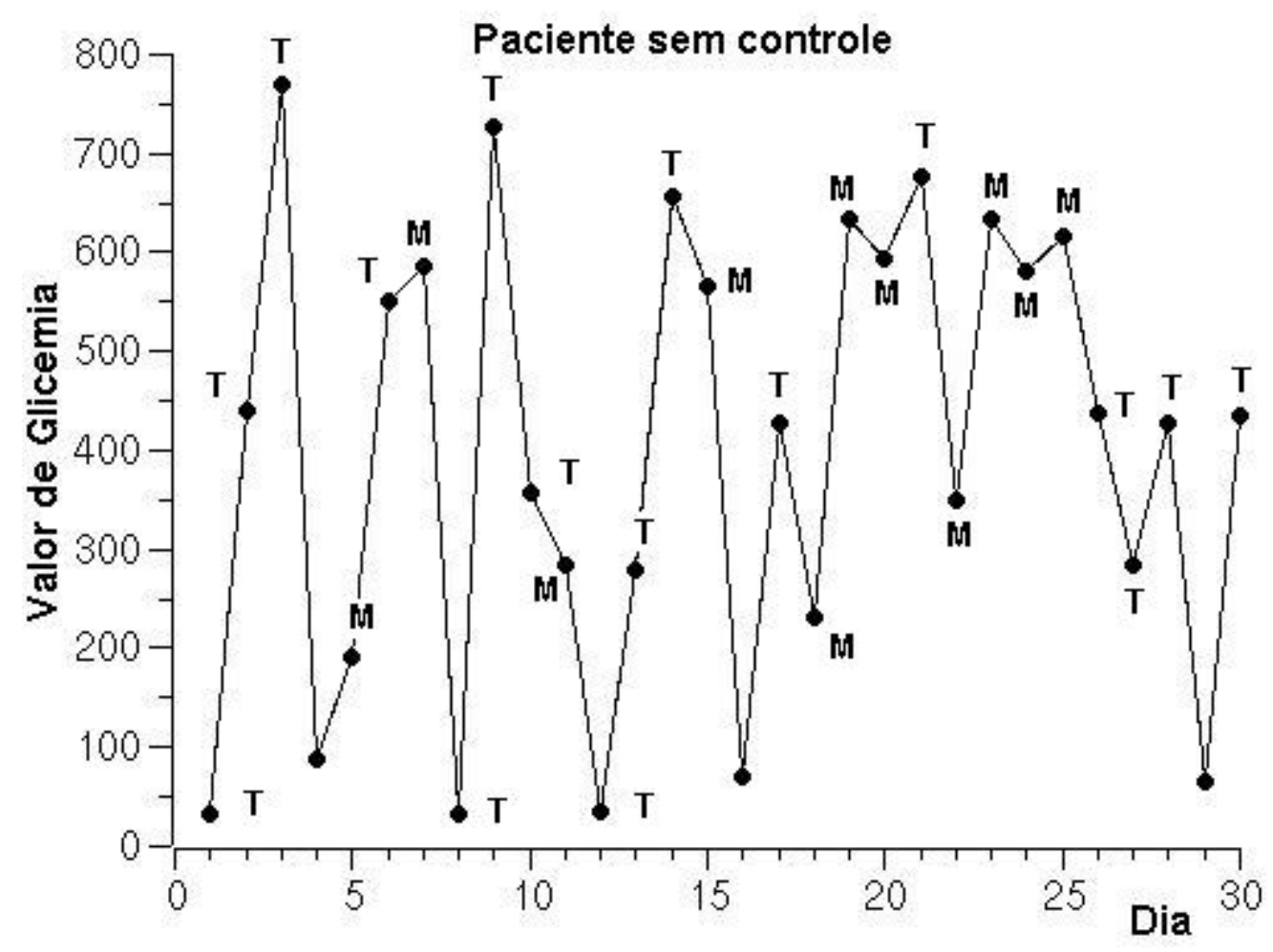

Gráfico 5.7 - Gráfico da simulação do paciente sem controle, com os valores de glicemia e tipo de comunicação no período de 30 dias

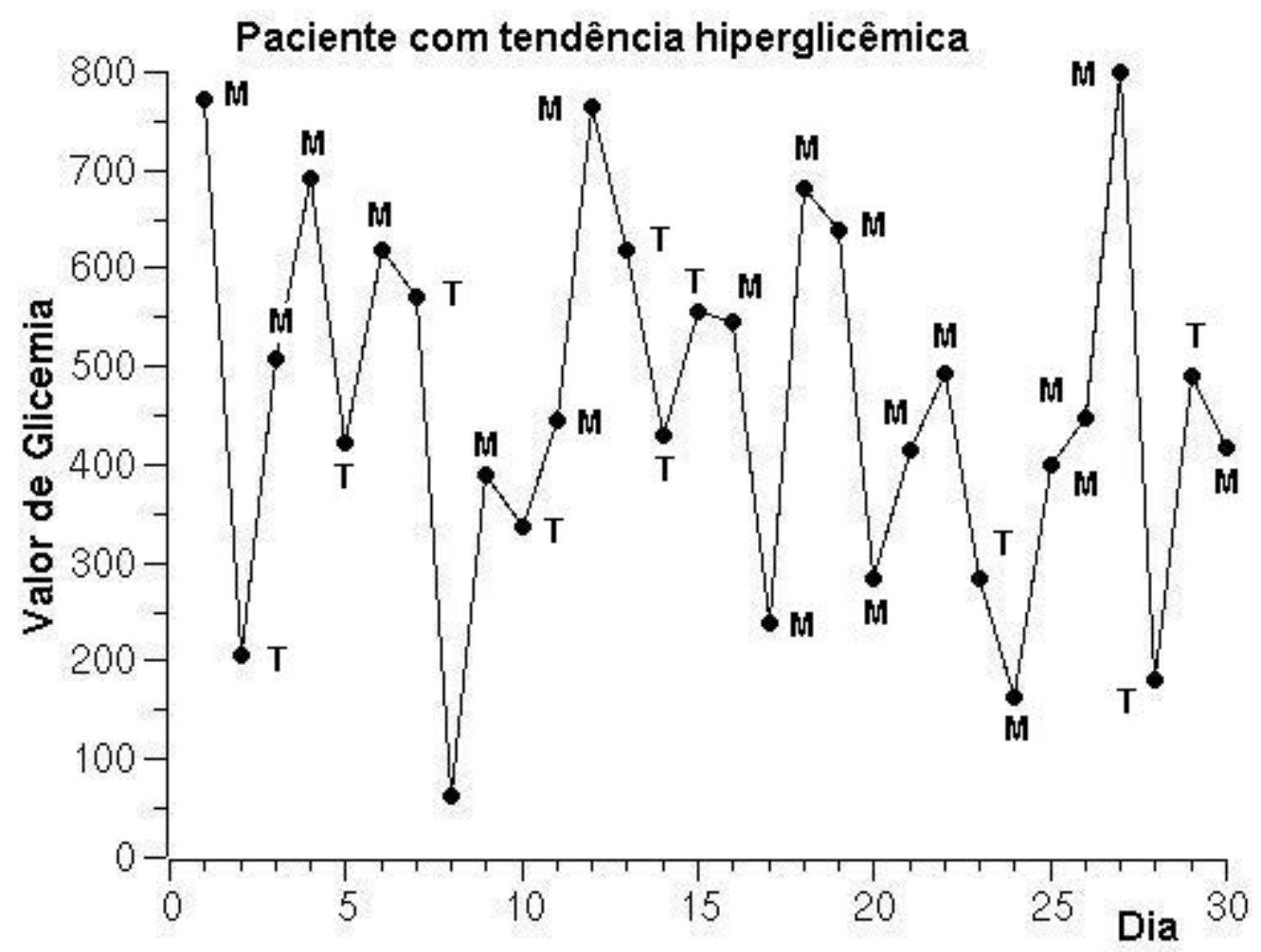

Gráfico 5.8 - Gráfico da simulação do paciente com tendência hiperglicêmica, com os valores de glicemia e tipo de comunicação no período de 30 dias 


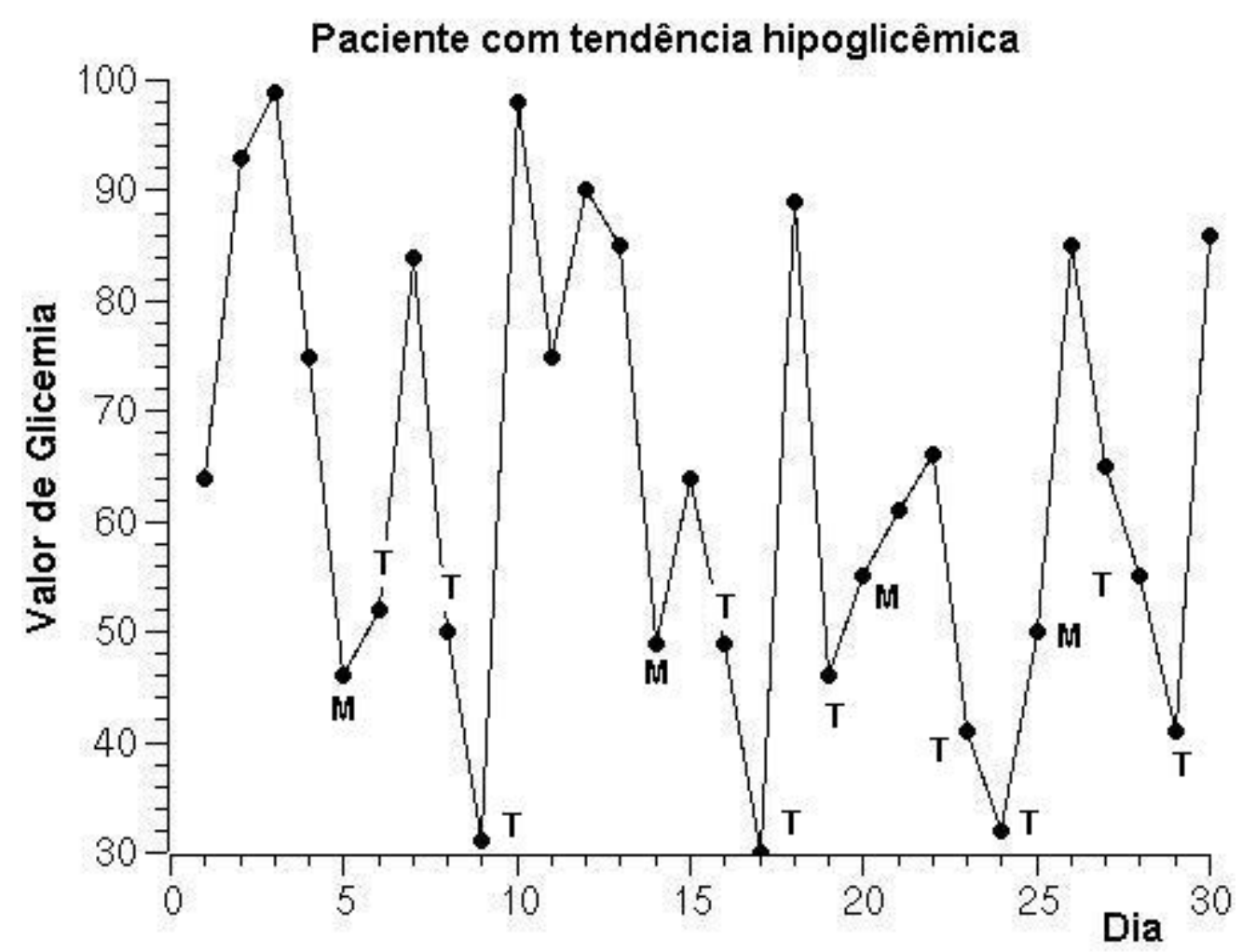

Gráfico 5.9 - Gráfico da simulação do paciente com tendência hipoglicêmica, com os valores de glicemia e tipo de comunicação no período de 30 dias

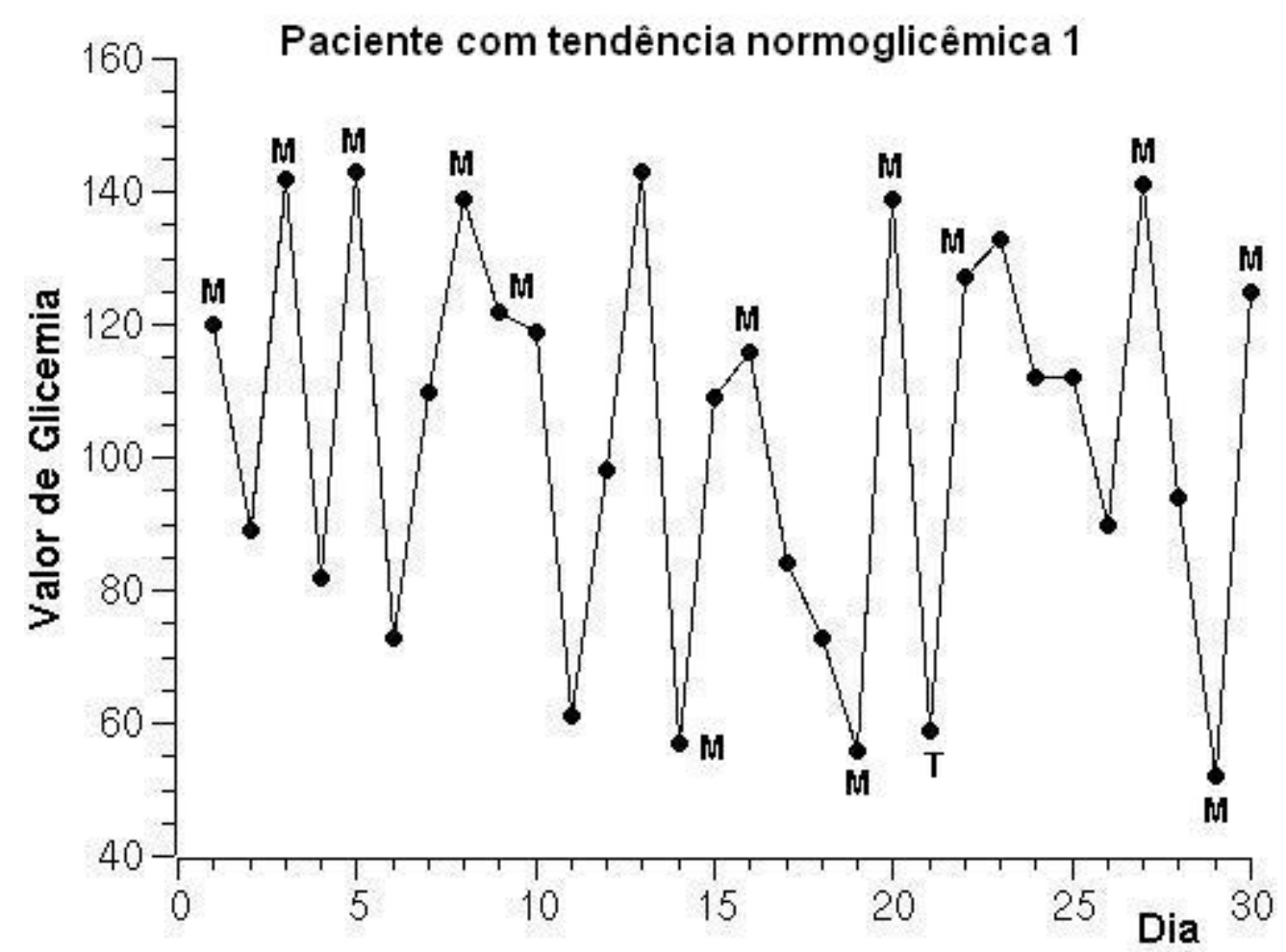

Gráfico 5.10 - Gráfico da simulação do paciente com tendência normoglicêmica 1, com os valores de glicemia e tipo de comunicação no período de 30 dias 


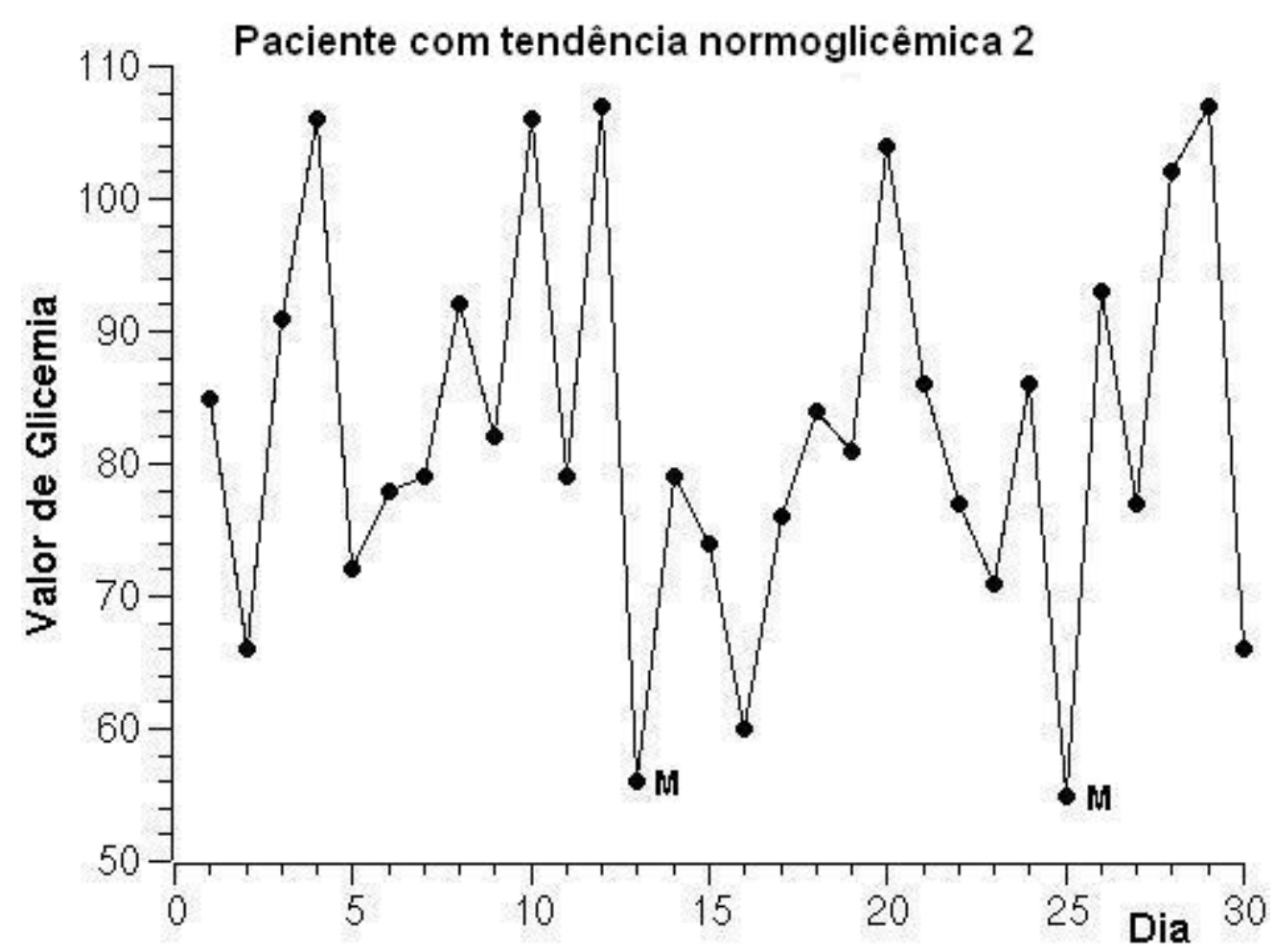

Gráfico 5.11 - Gráfico da simulação do paciente com tendência normoglicêmica 2, com os valores de glicemia e tipo de comunicação no período de 30 dias

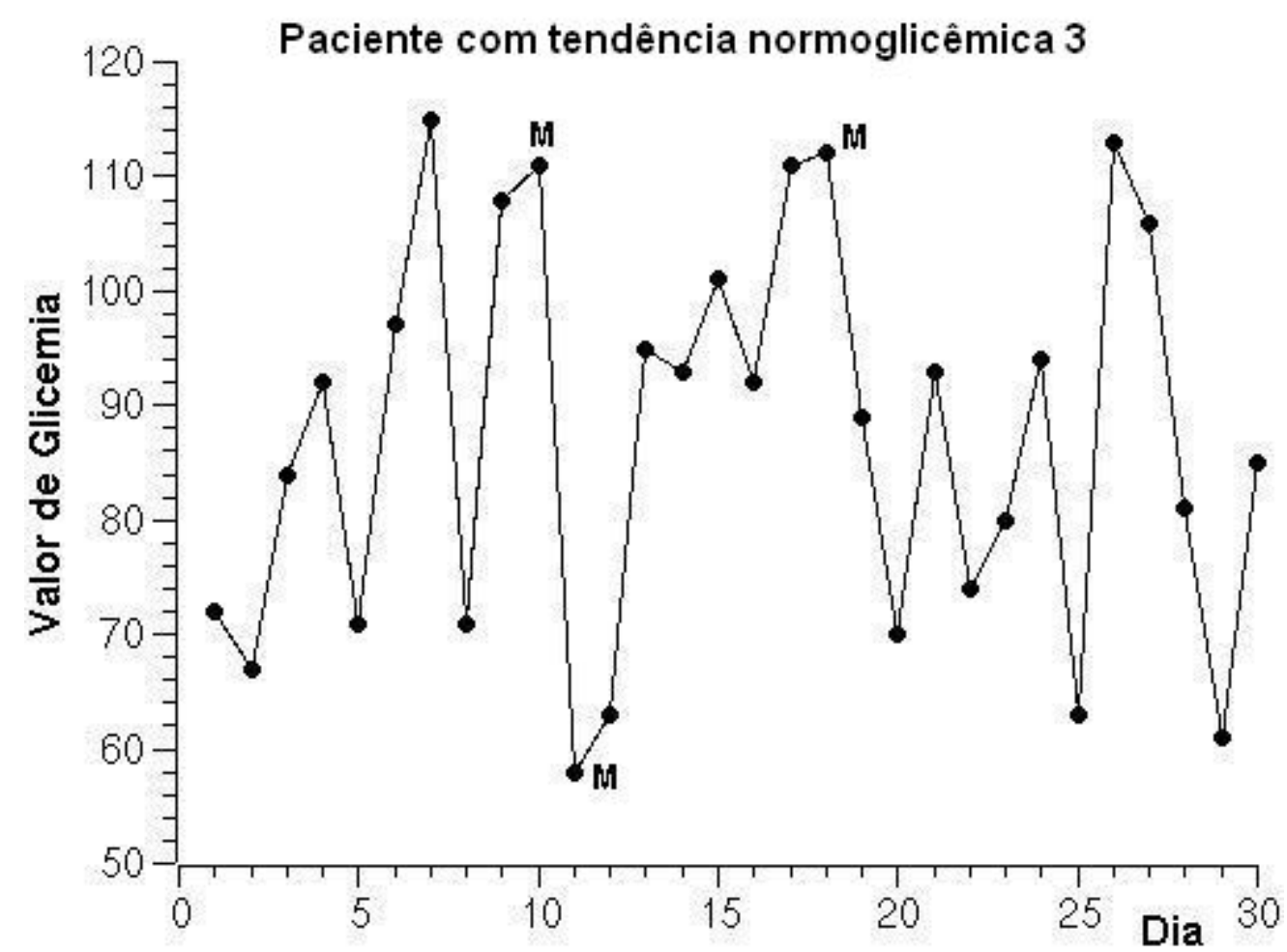

Gráfico 5.12 - Gráfico da simulação do paciente com tendência normoglicêmica 3, com os valores de glicemia e tipo de comunicação no período de 30 dias 
c. Solicitação de agendamento do paciente

$\mathrm{Na}$ tabela 5.4 tem-se a quantidade de solicitação de consultas presenciais pelo sistema em cada simulação.

\begin{tabular}{lc}
\hline \multicolumn{1}{c}{ Paciente } & Marcar consulta \\
\hline Sem controle & 72 \\
Tendência hipoglicêmica & 0 \\
Tendência hiperglicêmica & 82 \\
Tendência normoglicêmica 1 & 43 \\
Tendência normoglicêmica 2 & 6 \\
Tendência normoglicêmica 3 & 14 \\
\hline
\end{tabular}

Tabela 5.4 - Tabela com a quantidade de orientações por simulação

Os próximos gráficos $(5.13,5.14,5.15,5.16,5.17$ e 5.18), com um período de 30 dias, correlacionam os dias, a solicitação de consulta por parte do sistema e os valores da glicemia em cada simulação. Em cada valor de glicemia, indica-se com a letra 'C' quando é solicitado ao paciente marcar uma consulta.

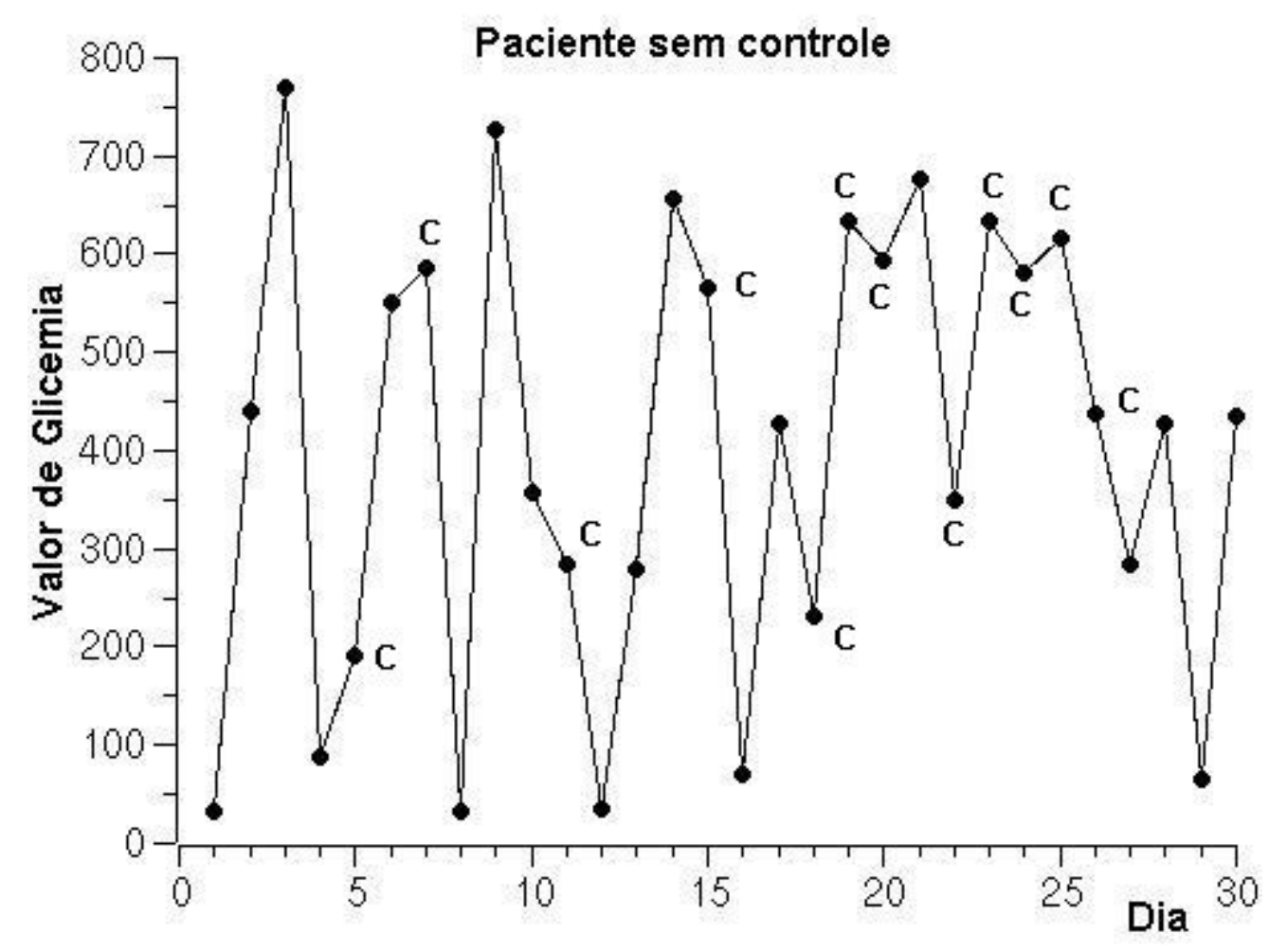

Gráfico 5.13 - Gráfico da simulação do paciente sem controle, com os valores de glicemia e solicitação de consulta presencial pelo sistema no período de 30 dias 


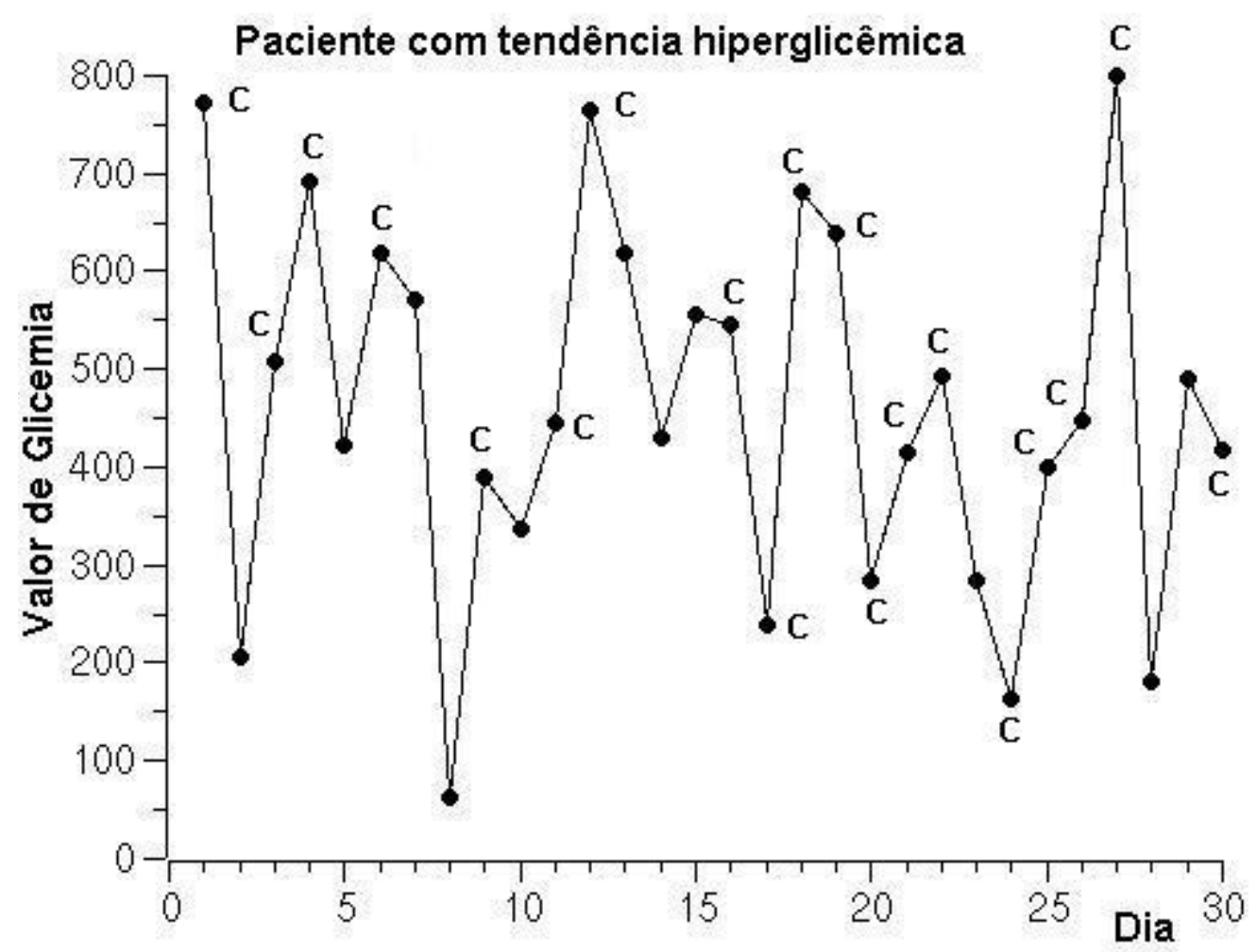

Gráfico 5.14 - Gráfico da simulação do paciente com tendência hiperglicêmica, com os valores de glicemia e solicitação de consulta presencial pelo sistema no período de 30 dias

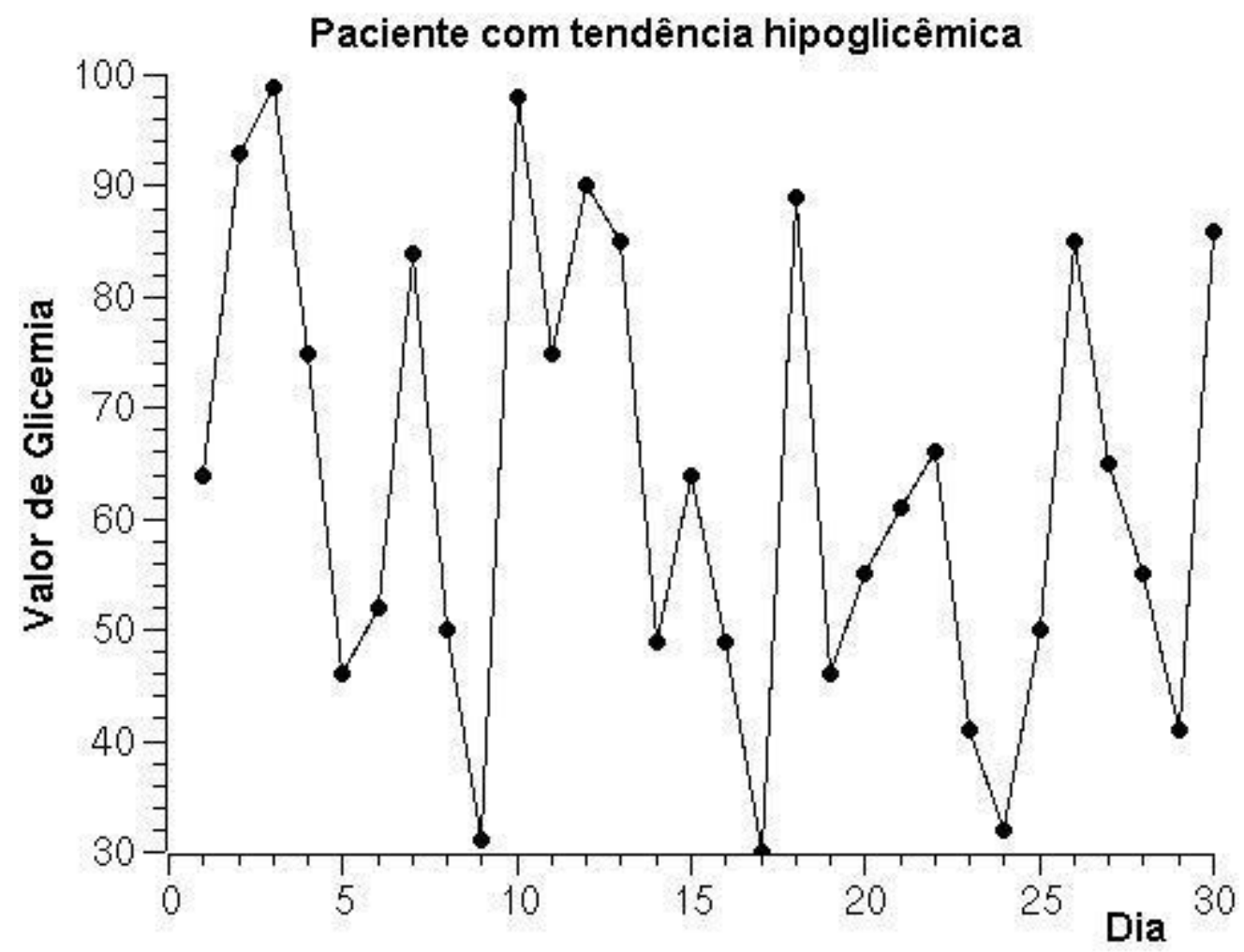

Gráfico 5.15 - Gráfico da simulação do paciente com tendência hipoglicêmica, com os valores de glicemia e solicitação de consulta presencial pelo sistema no período de 30 dias 


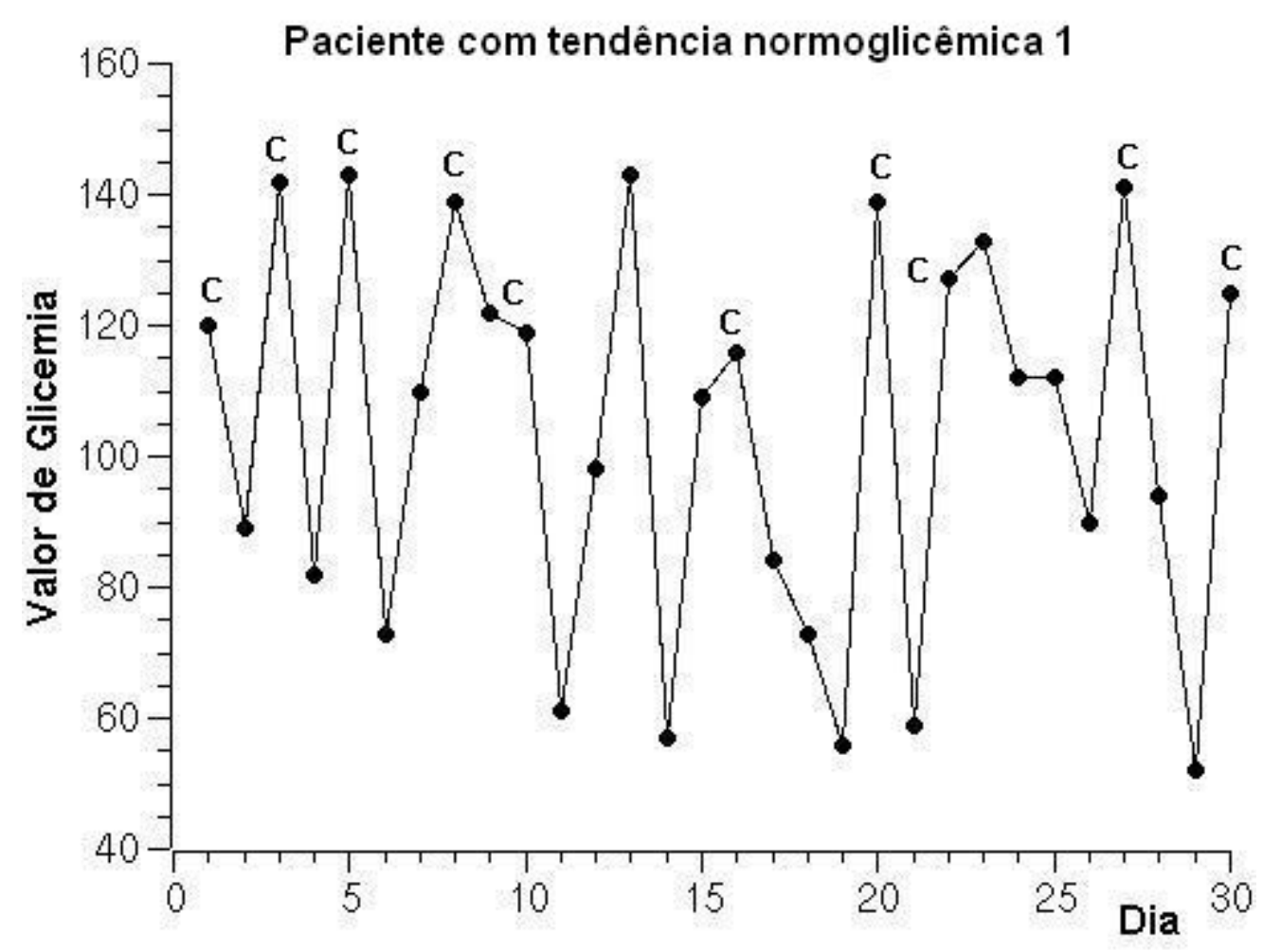

Gráfico 5.16 - Gráfico da simulação do paciente com tendência normoglicêmica 1, com os valores de glicemia e solicitação de consulta presencial pelo sistema no período de 30 dias

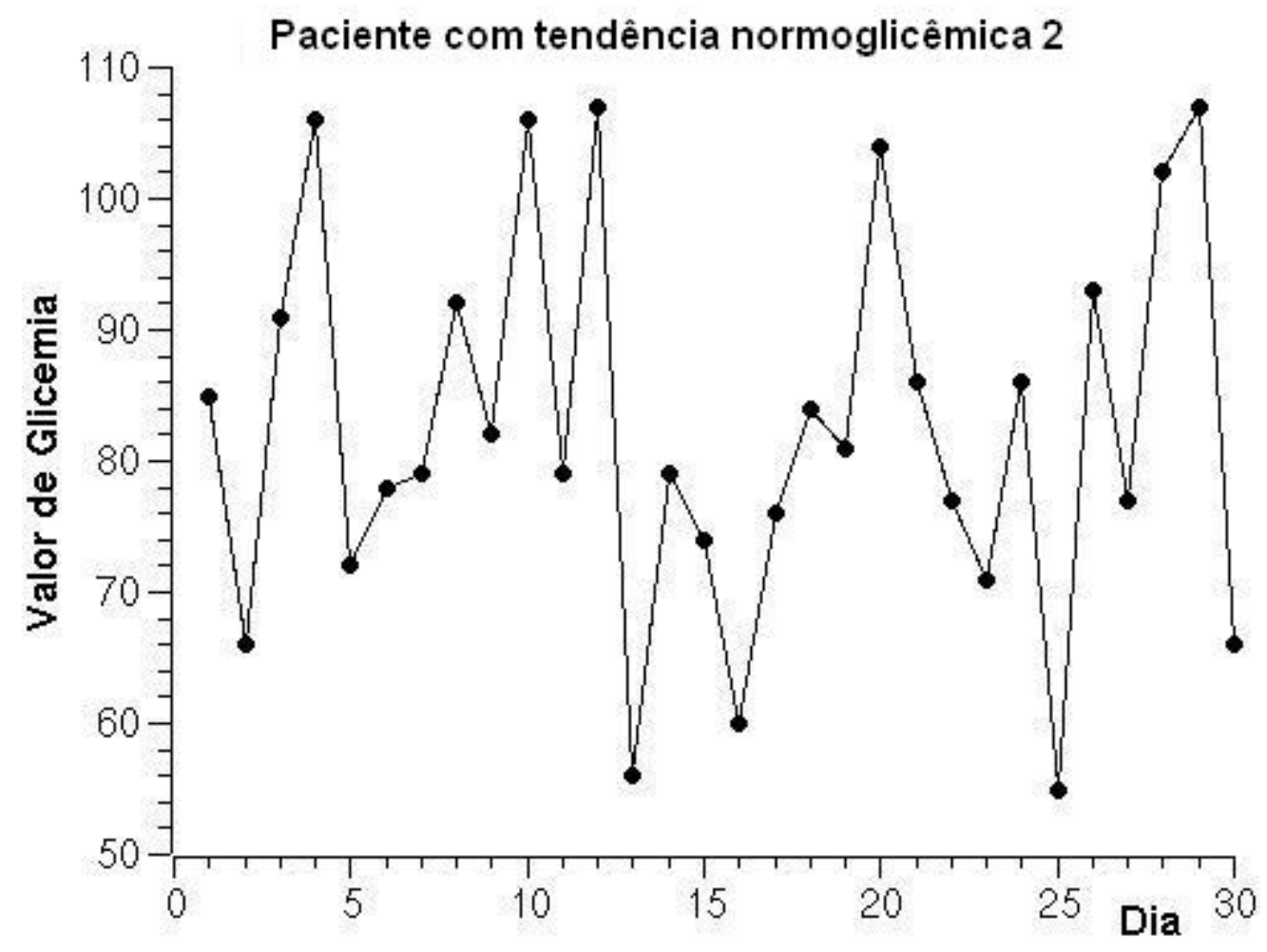

Gráfico 5.17 - Gráfico da simulação do paciente com tendência normoglicêmica 2, com os valores de glicemia e solicitação de consulta presencial pelo sistema no período de 30 dias 


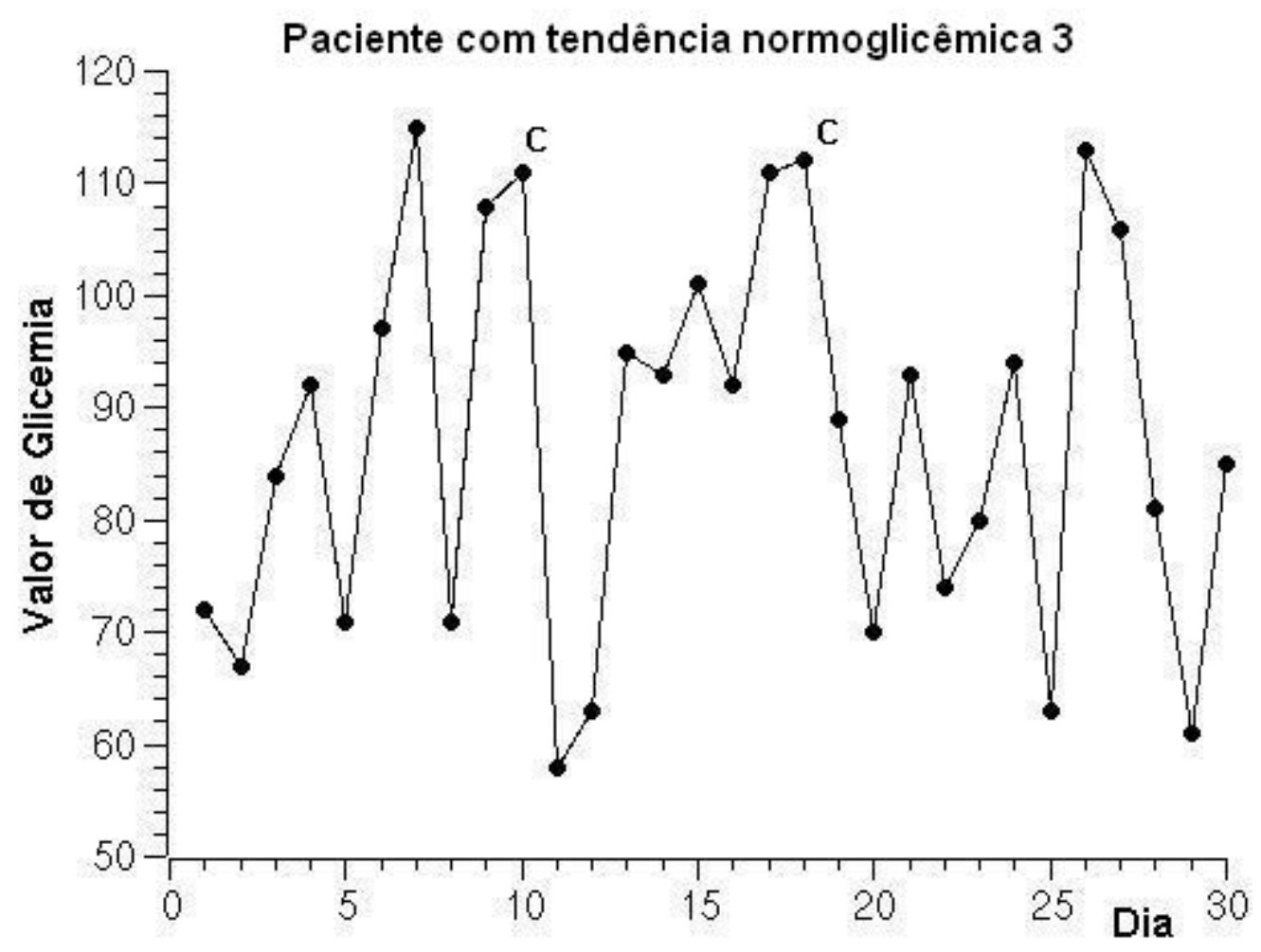

Gráfico 5.18 - Gráfico da simulação do paciente com tendência normoglicêmica 3, com os valores de glicemia e solicitação de consulta presencial pelo sistema no período de 30 dias

\subsubsection{Análise dos Resultados}

Ao analisar os resultados com relação aos diagnósticos obtidos percebeu-se, de acordo com os perfis definidos, que houve uma distribuição homogênea. Portanto, essas amostras podem ser utilizadas nas simulações para a análise do comportamento do modelo.

Nas situações de pacientes que não se controlam satisfatoriamente e que foram representados pelos perfis: sem controle, com tendência hipoglicêmica e hiperglicêmica, pode-se notar que a quantidade de comunicação com o médico é maior. Esse fato permite que o médico, nesses casos, possa ficar em estado de alerta, interferindo diretamente quando necessário. Além disso, a maior comunicação possibilita ao médico verificar o que acontece com esses pacientes e modificar a conduta.

Já nos casos de pacientes que melhor se controlam (com tendência normoglicêmica), a quantidade de intervenções imediatas (contato por telefone) é pequena (normoglicêmico 1) ou inexistente (normoglicêmico 2 e 3). A comunicação por e-mail também fica abaixo dos outros 
perfis, como pode ser observado ao analisar a tabela 5.26. De qualquer forma, nesses casos o médico também pode interferir sempre que achar necessário, não precisando esperar pela consulta presencial para tomar conhecimento do que aconteceu e, a partir desse momento, tomar alguma atitude.

Com relação à solicitação de consultas presenciais pelo sistema, nota-se que elas estão distribuídas de acordo com a necessidade do paciente, e não de acordo com o preconizado em manuais, livros e guias - por exemplo, marcar consultas a cada dois ou três meses quando o paciente encontra-se normoglicêmico e com nenhuma intercorrência recente. Por isso, provavelmente, com o uso do modelo GRPC, será possível otimizar a quantidade de consultas presenciais, pois o agendamento delas depende da disponibilidade do médico, do paciente e do sistema de saúde. O paciente nesse caso está ciente da necessidade e provavelmente terá um empenho maior para que a consulta presencial se realize.

Através dos gráficos conclui-se que, apesar de o sistema não prever os pedidos de consultas presenciais nos casos de hipoglicemia, os pacientes não deixam de ficar assistidos, pois o sistema auxilia nesse sentido, ao emitir alertas aos médicos. O sistema permite que o médico, além das consultas rotineiras para o acompanhamento do paciente, possa solicitar a qualquer momento o agendamento de uma consulta.

Além disso, os gráficos demonstram que é possível ter informações diárias dos pacientes, e com isso os médicos podem ter uma visão das medidas de glicemia do paciente e melhor acompanhá-lo, interferindo quando necessário.

Por fim, observou-se com relação ao uso do sistema que não houve dificuldade na adaptação do sistema TeleDM para comportar as simulações. Portanto, é provavel que se tenha facilidade de manutenção e agregação de novos requisitos ao sistema. 


\section{Conclusões e Caminhos em Continuidade}

Até o século passado a principal preocupação das organizações mundiais de saúde era com as doenças infecciosas. A principal característica dessas doenças é que não havia a necessidade de um acompanhamento e monitoramento prolongado; o importante era o tratamento e a prevenção. Com o intenso trabalho realizado pela saúde pública, foram obtidos bons resultados nessa área, o que permitiu o aumento da expectativa de vida da humanidade.

Com o aumento do tempo de vida da população, a incidência de doenças como hipertensão, diabetes mellitus e asma também aumentou e passou a ser um ponto de preocupação da saúde no século XXI. Essas doenças são ditas crônicas porque necessitam de um tratamento prolongado, em que muitas vezes não existe a cura, e sim uma convivência com elas, com o objetivo de obter qualidade de vida próxima à normal. A aderência ao tratamento e o acompanhamento adequado dos pacientes com doenças crônicas são necessários, pois é preciso conscientizá-los de seu estado clínico e fazer com que sigam corretamente o tratamento adequado. Tratar da doença não é entendido aqui como o único remédio; é preciso "olhar" e tratar o paciente. Essa mudança de abordagem, com atendimento centrado no paciente, é hoje foco de muita discussão e estudos.

Com o avanço da tecnologia, principalmente de seus ramos relacionados à informação, ocorreram mudanças nas relações sociais e econômicas. Devido a esss transformações, as organizações se viram obrigadas a modificar a abordagem de tratamento de seus clientes. Já não é mais suficiente apenas oferecer produtos e serviços. Com efeito o acesso à informação e ao produto é tão fácil que não apresenta barreiras ao cliente que deseja trocar ou adquirir um produto ou serviço. Estudos realizados por pesquisadores da área de administração e marketing demonstraram que a melhor abordagem é tentar reter o cliente, fazer com que ele se torne fiel à marca, através do acompanhamento de suas atividades junto à empresa. As organizações utilizaram-se da tecnologia para conseguir realizar o acompanhamento do cliente, tecnologia esta denominada CRM.

A saúde, por sua vez, utiliza-se da tecnologia com o objetivo de obter sucesso na monitoração e no acompanhamento de pacientes crônicos. O que tem se verificado nessas aplicações é que o objetivo continua focado no tratamento e acompanhamento da doença, e não do doente. 
Ao adaptar os conceitos da tecnologia CRM, elaborou-se o modelo GRPC, que possibilita um atendimento centrado no paciente, ao incentivar a gestão do relacionamento deste com o seu médico, por meio de acompanhamento personalizado. O modelo, ao utilizar outros meios de comunicação, como por exemplo a internet ou o telefone, permite atender as necessidades do paciente ao coletar o maior número de informações. Com isso, fornece uma orientação clínica adequada e estimula a aderência ao tratamento recomendado.

A tecnologia CRM e a criação de centrais de interação com o cliente permitiram que as empresas pudessem obter, integrar e processar as informações desses clientes e disponibilizálas para todas as áreas da empresa. No modelo GRPC, ao adaptar a arquitetura da tecnologia CRM, foi possível elaborar um aplicativo que integra o Eletronic Health Record (EHR), os sistemas de apoio à decisão e as soluções de telemedicina, para permitir o acompanhamento e monitoramento de pacientes crônicos. Verificou-se que somente o aplicativo não é o bastante para comportar o modelo; assim, as centrais de relacionamento de pacientes crônicos foram propostas para suportar toda a infra-estrutura, tanto as tecnológicas quanto a de recursos humanos.

O modelo GRPC, ao fornecer a oportunidade de comunicação entre o médico e seu paciente através de mais de um canal, sem depender somente das consultas presenciais, permite o acompanhamento contínuo desse paciente. Permite, também, o aumento do campo de atuação do médico, pois a assistência ao paciente não fica restrita somente ao atendimento em ambulatórios, hospitais, farmácias, pronto atendimento e consultórios.

Ao modelar uma central de monitoração de diabéticos, utilizando o modelo GRPC, foi possível determinar os requisitos necessários para a implantação do modelo. A modelagem dos processos da central de monitoração de diabéticos permitiu verificar que o modelo GRPC propõe uma outra forma de comunicação entre o médico e o paciente, além de mais uma possibilidade de organização do atendimento desse paciente.

Quanto ao desenvolvimento do software que permitiu realizar uma avaliação preliminar do comportamento da central, foi possível verificar que a modelagem de negócio ajudou a determinar qual o processo mais adequado para a simulação, além de auxiliar a definir os requisitos, o escopo e as limitações do sistema.

Na modelagem do sistema, ao seguir o mapeamento da arquitetura inicial a partir dos modelos 
de negócio, concluiu-se que este mapeamento é possível. Com relação ao proposto pela Rational University (92), algumas adaptações foram realizadas e acredita-se que com isso foi possível acrescentar melhorias no método de mapeamento. A forma de encontrar os possíveis casos de uso do sistema era muito vaga, já que no método original os processos de negócio do caso de uso de negócio são analisados para se encontrar os casos de uso do sistema. Percebeuse na prática que analisar o fluxo de trabalho e o detalhamento textual do caso de uso de negócio facilitou muito a definição dos casos de uso do sistema.

A modelagem de negócio da central de monitoração e o modelo de casos de uso do sistema permitiram encontrar com mais facilidade as características do sistema que auxiliaram na seleção da tecnologia para a sua implementação.

Ao utilizar a tecnologia orientada a agentes para o desenvolvimento do sistema TeleDM notou-se que determinar e encontrar os agentes não era simples e que não existia na literatura um método claro e fácil de aplicar. Ao analisar essa tecnologia, conclui-se que ela é uma boa opção na modelagem de elementos ativos, enquanto que a tecnologia de orientação a objetos permite uma boa modelagem de elementos passivos. Assim, propôs-se a utilização das duas tecnologias, de maneira que os agentes representariam os elementos ativos do sistema e os objetos os elementos passivos.

Apesar da indicação de vários autores (ver item 4.5.2) para utilizar os casos de uso na definição dos objetivos e planos dos agentes, verificou-se que não é tão simples encontrá-los a partir da especificação dos casos de uso. Devido a essa dificuldade, foi proposto, a partir dos casos de uso, elaborar cenários de modo a facilitar a definição dos objetivos e planos dos agentes.

Os estilos existentes para a elaboração do fluxo de eventos dos cenários, entretanto, não permitem representar a interação entre os agentes. Procurou-se, na redação de textos, um estilo que pudesse atender a necessidade de descrever a interação entre os agentes e, assim, encontrou-se o roteiro. Ao utilizar o roteiro para a descrição dos cenários, pode-se notar que a interação entre os agentes é representada pelo diálogo entre os personagens e a interação entre o agente e os seus objetos, pelos parágrafos do roteiro.

As simulações para validar o sistema demonstraram que a arquitetura projetada com a utilização da tecnologia orientada a agentes e objetos alcançou seus objetivos. Existe 
cooperação entre os agentes, há transparência no funcionamento e o sistema fornece as orientações e condutas de acordo com o esperado, assim como a identificação do paciente nas situações previstas.

Resultados preliminares das simulações demonstraram o potencial do modelo quanto à otimização da quantidade de consultas presenciais e ao acompanhamento do paciente crônico pelo médico. O sistema, ao emitir alertas ao médico e possibilitar que ele tenha informações contínuas dos valores de glicemia e do estado clínico do paciente, permite que se possa interferir imediatamente no tratamento do paciente, ao contrário do que ocorre na forma tradicional, em que se depende somente de resultados de exames apresentados nas consultas presenciais.

As simulações demonstraram que o sistema, ao solicitar a marcação de consultas, pode otimizar o agendamento de consultas presenciais de acordo com a necessidade do paciente.

Espera-se que em trabalhos futuros, com a aplicação do modelo em casos reais, seja possível comprovar que o modelo GRPC pode tornar o atendimento ao paciente crônico personalizado, com qualidade e permitir melhor qualidade de vida ao médico, ao paciente e a seus familiares. Além da viabilidade prática também é necessário fazer um estudo para verificar a viabilidade econômica do modelo. Finalmente, um outro trabalho a ser realizado é o estudo com "grupo controle" para comprovar que o modelo realmente aumenta a efetividade do tratamento.

Com relação ao sistema TeleDM, é preciso, no futuro, implementar as funcionalidades que atendam os demais requisitos e, na arquitetura analítica, verificar a possibilidade de utilizar os conceitos de datawarehouse e data mining.

A plataforma de agente CENINT que foi utilizada no sistema TeleDM, apesar de ter sido suficiente para o sistema desenvolvido, precisa ser melhorada, por exemplo no uso de padrões como o KQML ou FIPA-ACL para a implementação de seu ambiente de comunicação.

A obtenção de bons resultados com o uso de técnicas de roteiro para a representação da interação entre agentes, e entre agentes e seus objetos sugere que, no futuro, estudos podem ser feitos para analisar a utilização das técnicas cinematográficas na produção de software.

Este trabalho tem a motivação maior de ser um promotor de desenvolvimentos de soluções para problemas relacionados à qualidade de vida das pessoas. Nascido por inspiração do 
tratamento de pacientes crônicos, como os portadores de diabetes mellitus, busca apresentar propostas de soluções para o seu atendimento e para o desenvolvimento de ferramentas que auxiliem os pacientes e os profissionais de saúde no convívio com essa doença, enquanto as pesquisas médicas não apresentem terapêutica de cura. A abordagem interdisciplinar (médica e de tecnologia da informação) busca dar atratividade à pesquisa cruzada. A interdisciplinaridade tem como objetivos dar aos médicos um testemunho da possibilidade de avanços com a utilização da tecnologia da informação, bem como dar aos profissionais de tecnologia da informação um testemunho das possibilidades de aplicação de seus recursos na promoção direta da qualidade de vida das pessoas. Esse campo de pesquisa é altamente promissor, pois os avanços na área da tecnologia da informação vão, a cada dia, tornando possível novas formas de trato nas questões médicas. A redução do custo de utilização dessas novas tecnologias permite considerá-las para o aumento da abrangência e qualidade dos cuidados médicos que, por sua vez, estão diretamente ligados à qualidade de vida da população. 


\section{Referências}

(1) ARMOUR, F.; MILLER, G. Advanced use case modeling: software systems. $1^{\text {a }}$. edição. (s.1.): Addison-Wesley. 2001. 464 p.

(2) ARRUDA, P. M. Exigências para adesão ao tratamento pediátrico de febre reumática e diabetes mellitus tipo 1 e estratégias de enfrentamento do cuidador. 2002. 126 p. Tese (Doutorado) - Instituto de Psicologia da Universidade de Brasilia, Brasilia, 2002.

(3) ATREJA, A.; BELlAM, N.; LEVY, S. R. Strategies to enhance patient adherence: making it simple. Medscape General Medicine. (s. 1.), v. 7, n. 1, 2005. Disponível em: $<$ http://www.medscape.com/viewarticle/498339.html>. Acesso em: 15 Jul. 2005.

(4) BARROSO, H.C.; BATISTA, D.C. F.; LEITE, J. T. F.; SÁ, C. M. G.; QUIRINO, A. P.; AMARAL, R. N.; MOREIRA, M. F.; FILIZOLA, R. G.; FARIAS, M. B. Sistema de informação para acompanhamento de pacientes diabéticos. In: CONGRESSO BRASILEIRO DE INFORMÁTICA EM SAÚDE, 5., 1998, Ribeirão Preto, Anais... São Paulo: Sociedade Brasileira de Informática em Saúde, 1998. p. 517-518.

(5) BASS, L.; CLEMENTS, P.; KAZMAN, R. Software architecture in practice. 2a. edição. (s. 1.) Addison Wesley. 2003. 528 p. (SEI - Series in Software Engineering)

(6) Software architecture in practice. 1a. edição. (s.1.): Addison-Wesley, 1998.

(7) BECK, A.; ROBLIN, D.; SELBY, J.: HSU, J. Clinical integration at the service delivery level. California: Kaiser Permanente Georgia Research Department, May 2001. 46 p. (Technical Report).

(8) BELLIFEMINE, F.; POGGI, A.; RIMASSA, G. Jade, a FIPA-compliant agent framework. In: International Conference on Practical Application of Intelligent Agents and Multi-Agent Technology, 4., 1999, London, Proceedings... p. 97-108 Disponível em: < http://jade.tilab.com/papers/PAAM.pdf > Acesso em: 21/11/2005.

(9) BERGENTI, F.; POGGI, A. A development environment for the realization of open and scalable multi-agent systems. In: GARIJO, F. J.; BOMAN, M. (eds.), MultiAgent System Engineering: Proceedings of the 9th European Workshop on Modelling Autonomous Agents in a Multi-Agent World. (Lecture Notes in Computer Science, v. 1647). London: SpringVerlag, 1999, p. 52-62.

(10) BOAR, B. Tecnologia da informação: arte do planejamento estratégico. Trad. Daniel Vieira. 2a . edição. São Paulo:Editora Berkely, 2002, 339 p. 
BOISSER, O. Problème du controlê dans un système integré de vision: utilisation d'un système multi-agents. 1993. Tese (Thèse de Doctorat) - Institut National Polytechnique de Grenoble, Grenoble, January 1993. apud (105)

(12) BOOCH, G.; RUMBAUGH, J.; JACOBSON, I. The unified modeling language: user guide. (s. 1.): Addison-Wesley, 1999. 482 p.

(13) BUCHALLA, A. P. Dois remédios em um. Revista Veja. São Paulo, 01.10.2003, p. 56.

(14) CALDERA, J. Survivability requirements for the U.S. health care industry. 2000. 74 p. Dissertação (Master of Science in Information Networking) - Carnegie Mellon University, Pittsburgh, 2000.

(15) CARVAlHAES NETO, N. A importância do check-up na prática clínica. Diálogo Científico, São Paulo. ano 3, v. 1, n. 3, Maio/Junho 2005. p. 10-12.

(16) CARDOZO, E.; SICHMAN, J. S.; DEMAZEAU, Y. Using the active object model to implement multi-agent systems. In: IEEE INTERNATIONAL CONFERENCE ON TOOLS WITH ARTIFICIAL INTELligENCE, 5., 1993, Boston. Proceedings... (s. 1.): IEEE Computer Society Press., 1993. p. 70-77.

(17) CARNAHAN, L.; CARVER, G.; GRAY, M.; HOGAN, M.; HOPP, T.; HORLICK, J.; LYON, G.; MESSINA, E. Metrology for information technology: standard view, Gaithersburg, v. 5 n. 3., September-1997. Disponível em: < http://ois.nist.gov/nistpubs/technipubs/recent/search.cfm?dbibid=11804>. Acesso em: $22 / 11 / 2005$.

(18) CARSON, E. R.; CRAMP, D. G.; MORGAN, A.; ROUDSARI, A. B. Clinical decision support, systems methodology, and telemedicine: their role in the management of chronic disease. IEEE Transactions on Information Technology in Biomedicine, (s. 1.), v. 2, n. 2, p. 80-88. June 1998.

(19) CASTELlS, M. A sociedade em rede. Tradução: Roneide Venancio Majer com a colaboração de Klauss Brandini Gerhardt. 7ª Edição. São Paulo: Editora Paz e Terra. 2003. (A era da informação: economia, sociedade e cultura - volume 1).

(20) CELLER, B. G.; LOVELL, N. H.; BASILAKIS, J. Using information technology to improve the management of chronic disease. Medical Journal Australian, (s. 1.), v. 179, N. 5, p. 242-246. September, 2003.

(21) CHAU, P. Y. K.; HU, P. J. H. Techonology implementation for telemedicine programs. Communication of the ACM, New York, v. 47, n. 2, p. 87-92. February 2004.

(22) CHEBERLE, P. C. D. Fatores críticos de sucesso na implementação de tecnologia CRM. São Paulo, 2003. 192 p. Dissertação (Mestrado) - Faculdade de Economia, Administração e Contabilidade, Universidade de São Paulo, São Paulo, 2003. 
(23) CLEMENTS, P.; BACHMANN, F.; BASS, L.; GARLAN, D.; IVERS, J.; LITTLE, R.; NORD, R.; STAFFORD, J. Documenting software architectures: views and beyond. $1^{\mathrm{a}}$. edição. (s. 1.): Addison Wesley, 2003. 512 p. (SEI - Series in Software Engineering).

(24) COCKBURN, A. Writing effective use cases. $1^{\text {a }}$. edição. (s. 1.): Addison-Wesley, 2001. $270 \mathrm{p}$.

(25) COHEN, S.; SHABO, A. Electronic health record (EHR): standards survey. Haifa, Israel: IBM Haifa Research Lab. August, 2001. (Internal survey). Disponível em: $<$ http://www.haifa.ibm.com/projects/software/imr/papers/EHRSurvey.pdf $>$. Acesso em: 20. Jul. 2005.

(26) COMPARATO, D. Roteiro: arte e técnica de escrever para cinema e televisão. $4^{\mathrm{a}}$. edição, Rio de Janeiro:Nórdica, 1983. 262 p.

(27) CONRAD, D. A. Coordinting patient care services in regional health systems: the challenge of clinical integration. Hospital \& Health Service Administration. (s. 1.) v. 38 n. 4, p.491-508, 1993. (Winter).

(28) CRAMP, D. G.; CARSON, E. R. Health care planning and priority setting: a modeling approach. In:.MALEK, M (ed.). Setting Priorities in Health Care. Chichester: Wiley, 1994, pp. $95-102$.

(29) DAVENPORT, T. H. Reengenharia dos processos. $1^{\text {a }}$. edição. Rio de Janeiro: Editora Campus, 1994. 408 p.

(30) DIJKSTRA, E.W. A discipline of programming. 1 ${ }^{\text {a }}$ Edição. (Englewood Cliffs): Prentice Hall, 1976. 217 p.

(31) DiMATTEO, M. R. Variations in patients' adherence to medical recommendations: a quantitative review of 50 years of research. Med Care. (s. 1.), v. 42, n. 3, p. 200-209. March 2004. . Evidence-based strategies to foster adherence and improve patient outcomes. Journal of the American Academy Physician Assistants. (s. 1.), v. 17, n. 11, p. 18-21. Nov. 2004.

(33) EINHORN, J.; JO, C. H. A use-case based BDI agent software development process. In: INTERNATIONAL WORKSHOP ON AGENT-ORIENTED METHODOLOGIES OOPSLA-2003, 2., 2003, Anaheim. Proceedings... p.7-20. Disponível em: $<$ http://jo.ecs.fullerton.edu/research/amt2002/jo-einhorn-oopsla03-SV2.pdf $>$ Acesso em: $24 / 02 / 2006$.

(34) EPSTEIN, R. M. The science of patient-centered care. Journal of Family Practice. (s. 1.), v. 49, n. 9, p. 796-804. Sept, 2000. 
(35) ERIKSSON, H., PENKER, M.: Business modeling with UML: business patterns at work. $1^{\mathrm{a}}$. edição. (s. 1.): John Wiley \& Sons, 2000. 480 p.

(36) ERIKSSON, H.E.; PENKER, M.; LYONS, B.; FADO, D. UML 2 toolkit. Indianapolis: Wiley Publishing Inc, 2004. 511 p.

(37) FAZENDA, I. C. A., Integração e interdisciplinaridade no ensino brasileiro: efetividade ou ideologia. 4a . Edição. São Paulo: Editora Loyola, 1996.107 p. (Coleção "Realidade Educacional" - IV).

(38) U.S. DEPARTMENT OF HEALTH AND HUMAN SERVICES. U.S. food and drug administration, diabetes information: glucose meters \& diabetes management. Update in June, 14 2005. Disponível em: <http://www.fda.gov/diabetes/glucose.html $>$. Acesso em: 14 Jun. 2005.

(39) FERBER, J.; Multi-Agent systems: an introduction to distributed artificial intelligence. $1^{\text {a }}$. edição. (s. 1.): Addison Wesley, 1999. 528 p.

(40) CARDOSO, F.H. Prefácio. In: CASTELlS, M. (autor). A sociedade em rede. $1^{\mathrm{a}}$. Edição. São Paulo: Editora Paz e Terra. 1999. Prefácio, p. 35-37. (A era da informação: economia, sociedade e cultura - volume 1).

(41) FIELD, S. Manual do roteiro: fundamentos do texto cinematográfico. Trad. Álvaro Ramos. 15a . edição. Rio de Janeiro: Objetiva, 2001, 223 p.

(42) FOUNDATION FOR INTELLIGENT PHYSICAL AGENTS (FIPA). Site da Instituição. Disponível em: <http://www.fipa.org> Acesso em: 01/07/2005.

(43) FOLHA ON LINE. Pesquisa aponta que 48,1\% dos hipertensos não seguem tratamento. Folha on line, São Paulo, 26 abr. 2005. Disponível em: $<$ http://www1.folha.uol.com.br/folha/cotidiano/ult95u108376.shtml $>$. Acesso em: 26 abr. 2005.

(44) FOX, J.; THOMSOM, R. Decision support and disease management: a logic engineering approach. IEEE Transactions on Information Technology in Biomedicine, (s. 1.), v. 2, n. 4., p. 217-228. December 1998.

(45) GARCIA, A. C. B.; SICHMAN, J. S. Agentes e sistemas multiagentes. In: REZENDE, S. O. (Ed.). Sistemas Inteligentes: Fundamentos e Aplicações. $1^{\mathrm{a}}$. edição. Barueri: Editora Manole Ltda., 2003.

(46) GOLDSCHMIDT, P. G. HIT and MIS: implications of health information technology and medical information systems. Communications of the ACM., New York, v. 48., n. 10, p. 68-74. October 2005. 
(47) GOMEZ E. J.; HERNANDO, M. E.; GARCIA, A. et alii. Telemedicine as a tool for intensive management of diabetes: The DIABTel experience. Comput Methods Programs Biomed (s. 1.), v. 69, p. 163-177. 2002.

(48) GONÇALVES, A.P.C. Proposta de arquitetura aberta de central de atendimento. São Paulo, 2001. 138 p. Dissertação (Mestrado em Engenharia Elétrica) - Escola Politécnica , Universidade de São Paulo, São Paulo, 2001.

(49) HAMMER, M.; CHAMPY, J. Reengineering the corporation: a manifesto for business revolution. $1^{\text {a }}$. edição. New York: Hapercollins, 1993. 240 p.

(50) HEMMINGER, M. Disease-Monitoring devices. course CMSC828. Spring 2004. Disponível em: $<\mathrm{http} / /$ www.cs.umd.edu/hcil/iHealth/disease_monitor.htm>. Acesso em: 25 Oct. 2005.

(51) HEUMANN, J.: Introduction to business modeling using the unified modeling language (UML). 2003. Disponível em: <http://www128.ibm.com/developerworks/rational/library/360.html>. Acesso em: 05 Nov. 2005.

(52) CÓDIGO. In: HOUAISS, Dicionário da língua portuguesa. São Paulo: Objetiva, 2004. Disponível em: <http://houaiss.uol.com.br/busca.htm>. Acesso em: 21 Nov. 2005.

(53) DEPARTMENT OF HEALTH OF ENGLAND. The expert patient: a new approach to chronic disease management for the 21st century. 2001. Disponível em: $<$ http://www.dh.gov.uk/PublicationsAndStatistics/Publications/PublicationsPolicyAndGuidan ce/PublicationsPolicyAndGuidanceArticle/fs/en?CONTENT_ID=4006801\&chk=UQCoh9>. Acesso em: 04 Apr. 2004.

(54) HUHNS, M. N.; STEPHENS, L. M. Multi-Agent systems and societies of agents. WEISS, G. (ed.), Multi-agent Systems, (s. 1.): MIT Press, 1999.

(55) HYUK, A. K. et al Establishment of blood glucose monitoring system using the internet. Diabetes Care, (s. 1.), v. 27, n. 2, p. 478-483. February 2004.

(56) INTEGRATED DEFINITION METHODS (IDEF). Site da Instituição. Disponível em: $<$ http://www.idef.com>. Acesso em: 23 Jan. 2006.

(57) INMON, W. H. Building the data warehouse. $2^{\text {a }}$. edição. (s. 1.): Jonh Willey \& Sons, 1996. $401 \mathrm{p}$.

(58) ITO, M.; RAMOS, M. P.; RUSSO, E. K.; ADIB, S. A.; IOCHIDA, L. C.; FRANCO, L. J.; ANÇÃ̃, M. S.; SIGULEM, D. Use of computerized forms in diabetes mellitus clinic. In: World Congress on Medical Physics and Biomedical Engineering. Rio de Janeiro, 1994. Proceedings... (s. 1.),1994. p. 550. 
(59) ITO, M. Uma análise do fluxo de comunicação em organizações dinâmicas de agentes. São Paulo, 1999. 141 p. Dissertação (Mestrado em Engenharia Elétrica). Escola Politécnica, Universidade de São Paulo, São Paulo, 1999.

(60) JACKOWSKI, Z.: Business modeling with UML: a business process centred architecture. 2003.2 Disponível em: $<$ http://www.agilealliance.com/articles/jackowskizygmuntbusin/file>. Acesso em: 05 Nov. 2005 .

(61) JACOBSON, I., CHRISTERSON, M., JONSSON, P., ÖVERGAARD, G. ObjectOriented software engineering. $1^{\text {a }}$. edição. New York: Addison-Wesley, 1992. 528 p.

(62) JACOBSON, I.; BOOCH, G.; RUMBAUGH, J. The unified software development process. $1^{\text {a }}$. edição. (s. 1.):Addison Wesley,1999. 463 p.

(63) JENNINGS, N. R. Agent-Oriented Software Engineering. In: GARIJO, F. J.; BOMAN, M. (eds.). Multi agent system engineering: proceedings of the ninth european workshop on modelling autonomous agents in a multi-agent world, 1999. pp. 1-7. (Lectures Notes in Artificial Inteligence,1647).

(64) JOHNSON P.D.; TU S.; BOOTH N.; SUGDEN B.; PURVES I. N. Using scenarios in chronic disease management guidelines for primary care. In: AMIA SYMP 2000. 2000. Proceedings... $\quad$ p. 389-93. $<$ http://www.ncl.ac.uk/pahs/staff/research/publication/6503>. Acesso em: 20 Jul. 2003.

(65) JUCHEN, M.; BASTOS, R. Engenharia de sistemas multiagentes: uma investigação sobre o estado da arte. Porto Alegre: Faculdade de Informática - PUCRS, 2001. 43 p. (Technical Report Series, n. 014)

(66) KAVI, K.; KUNG, D. C.; BHAMBHANI, H.; PANCHOLI, G.; KANIKARLA, M. Extending UML to modeling and design of multi-agent systems. In: INTERNATIONAL WORKSHOP ON SOFTWARE ENGINEERING FOR LARGE-SCALE MULTI-AGENT SYSTEMS, 2., Proceedings... Disponível em: <http://citeseer.csail.mit.edu/575235.html>. Acesso em: 06 Dec. 2005

(67) KHUN, T. S., A estrutura das revoluções científicas. $1^{\text {a }}$. edição. São Paulo: Ed. Perspectiva, 1962. 264 p.

(68) KIMBALL, R. The data warehouse toolkit. $1^{\text {a }}$. edição. (s. 1.): John Willey \& Sons, 1996. $388 \mathrm{p}$.

(69) KLOETZEL, K. Medicina ambulatorial: princípios básicos. $1^{\text {a }}$. edição. São Paulo: Editora EPU, 1999. 293 p.

(70) KWON, H. S. et alii. Establishment of blood glucose monitoring system using the internet. Diabetes Care, (s. 1.), v. 27, p.478-483. 2004. 
(71) LAHTELA, J. T.; OKSA H.; SAARISTO, T.; KOIVULA T.; VALLI, T.; SALO, M. et alii. Experiences of a web-based regional diabetes management system. Diabetes Nutr Metab (s. 1.), v. 13, p. 246. 2000.

(72) LAHTELA, J. T.; LAMMINEN, H. Telemedical devices in diabetes management. Ann. Med., (s. 1.), v. 34, p. 241-247. 2002.

(73) LASTRES, H. M. M.; ALBAGLI, S. (Org.). Informação e globalização na era do conhecimento. $1^{\text {a }}$. edição. Rio de Janeiro: Editora Campus. 1999. 318 p.

(74) LEFFINGWELL, D.; WIDRIG, D. Managing software requirements: a use case approach. $2^{\text {a }}$. edição. (s. 1.): Addison-Wesley. 2003. 544 p.

(75) VIZENOR, L.; SMITH, B.; CEUSTERS, W. Foundation for the electronic health record: an ontological analysis of the HL7's reference information model. Disponível em: $<$ http://ontology.buffalo.edu/medo/HL7_2004.pdf> Acesso em: 04, Nov. 2005.

(76) MADRUGA, R. Guia de implementação de marketing de relacionamento e CRM. $1^{\text {a }}$. Edição. São Paulo:Editora Atlas. 2004. 251 p.

(77) MAKRIS, L.; KAMILATOS, I.; KOPSACHEILIS, E. V.; STRINTZIS. Teleworks: a CSCW application for remote medical diagnosis support and teleconsultation. IEEE Transactions on Information Technology in Biomedicine, (s. 1.), v 2, n. 2, p. 62-73. June 1998.

(78) McMAHON, G. T.; GOMES, H. E.; HU, T. M. J., HOHNE, S. H.; LEVINE, B. A.; CONLIN, P. R. Web-based care management in patients with poorly controlled diabetes. Diabetes Care, (s. 1.), v. 28, p.1624-1629. 2005.

(79) MEA, V. D. Agents acting and moving in healthcare scenario: a paradigm for telemedical collaboration. IEEE Transactions on Information Technology in Biomedicine, (s. 1.), v. 5, no. 1, p. 10-13. March 2001.

(80) MEYSTRE, S. The current state of telemonitoring: a comment on the literature. Telemedicine and e-Health, (s. 1.), v. 11, n 1, p. 63-69. 2005.

(81) NEGRÃO, S. Insulina: essencial no bom controle do diabetes. Revista de Bem com a Vida. São Paulo: Roche Diagnostics, ano 5, no. 19, p. 8-9. 2004.

(82) NATIONAL ELECTRONIC HEALTH RECORD TASKFORCE. A health information network for Australia. ISBN 064244668 7. Jul 2000. Disponível em: $<$ http://www.ahic.org.au/downloads/ehrrept.pdf $>$.

(83) NEIVA, P. Involução humana. Revista Veja, São Paulo, p.105-108. 20 Apr. 2005. 
(84) NATIONAL INSTITUTE of DIABETES and DIGESTIVE and KIDNEY DISEASE. Site da instituição. Disponível em: <http://diabetes.niddk.nih.gov>. Acesso em: 07 Jun. 2005 .

(85) NIGRIN, D. J.; KOHANE, I. S. Data mining by clinicians. In: AMIA'98 - ANNUAL SYNPOSIUM, 1998, Lake Buena Vista, Florida. Proceedings... Lake Buena Vista: American Medical Informatics Association, 1998. p. 957-961

(86) ODELL, J.; PARUNAK, H. V. D.; FLEISCHER, M.; BREUCKNER, S. Modeling agents and their environment. In: GIUNCHIGLIA, F., ODELL, J., WEIS, G. (eds.). AgentOriented Software Engineering III. (s. 1.): Springer-Verlag, 2002. (Lecture Notes in Computer Science, vol. 2585).

(87) ODELL, J. Objects and agents: how do they differ? Draft 2.2. 1999. Disponível em: $<$ http://www.agent.ai/doc/upload/200302/odel00_5.pdf >. Acesso em: 01 Jul. 2005.

(88) OLIVEIRA, A. M.; NOVAIS, E. S.; SILVA, I. Sistema de informação de marketing em unidades de informação. Biblios, (s. 1.), v. 5, n.18-19, p.30-38. Set. 2004.

(89) PEPPERS AND ROGERS GROUP. Call center 1 to 1. $1^{\text {a }}$. edição. São Paulo: Microsoft, 2001. 84 p. (CRM Series) Disponível em: <http://www.1to1.com.br/pag_guia.php3>. Acesso em: 23 Jan. 2006. Marketing 1 to 1. $3^{\mathrm{a}}$. edição. São Paulo: Microsoft, 2004. 108 p. (CRM Series).

(91) PRESSMAN, R. S. Engenharia de software. Tradução de Mônica Maria G. Travieso, Revisão técnica de Paulo César Masiero, José Carlos Maldonado, Fernão Stella R. Germano. 5a. Edição. Rio de Janeiro: Editora McGraw Hill. 2002. 802 p.

(92) RATIONAL UNIVERSITY. Business modeling with the UML: student manual. $1^{\text {a }}$. edição. Cupertino, California: Rational Software, May 2001. 174 p.

(93) REICHHELD, F. A estratégia da lealdade: a força invisível que mantém clientes. $1^{\mathrm{a}}$. edição. Rio de Janeiro:Campus, 1996. 388 p.

(94) ROBOCUP. Site da Instituição. Disponível em: <http://www.robocup.org/>. Acesso em: 23 Jan. 2006.

(95) RUSSELL, S.; NORVIG P. Artificial intelligence: a modern approach. $2^{\mathrm{a}}$. edição, (s. 1.): Prentice Hall, 2003, 1080 p.

(96) SALINESI, C. Authoring use case. In: ALEXANDER, I. F.; MAIDEN, N. P. (eds.). Scenarios, stories, use case: though the systems development life-cycle. $1^{\mathrm{a}}$. edição.. (s. 1.): John Wiley \& Sons, Ltd. 2004. Capítulo 8, p. 141-160 
(97) CONSENSO BRASILEIRO SOBRE DIABETES. Diagnóstico e classificação do diabetes mellitus e tratamento do diabetes mellitus tipo 2. (s. 1.): Sociedade Brasileira de Diabetes, 2000. 60 p.

(98) SCHLOEFFEL, P.; JESELON, P. Standards requirements for the EHR \& discharge/referral Plans. ISO/TC215. Draft v. 2.1. May, 31, 2002. Disponível em: < http://secure.cihi.ca/cihiweb/en/downloads/event_partner_jun02_adhoc_e.pdf $>$. Acesso em: 26 Jan. 2006.

(99) SCHWAMBACH, M. M.; PEZZIN, J.; FALBO, R. A. OplA: uma metodologia para o desenvolvimento de sistemas baseados em agentes e objetos. In: Jornada Iberoamericanas de Ingeniería del Software e Ingeniería del Conocimiento, 4., 2004, Madrid. Proceedings... Disponível em: <http://is.ls.fi.upm.es/jiisic04/Papers/46.pdf>. Acesso em: 21/11/2005.

(100) SCLIAR, M. Do mágico ao social: trajetória da saúde pública. $1^{a}$. edição. São Paulo: Editora Senac, 2002. 160 p.

(101) SERRA, L. A Essência do business intelligence. 1 ${ }^{a}$. edição. São Paulo: Editora Berkeley, 2002. 288 p.

(102) SHAPIRO, B.; SVIOKLA, J. (eds.). Mantendo clientes. São Paulo:Makron Books, 1995.

(103) SHORTLIFFE, E. H.; PERREAULT, L. E. Medical informatics: computers applications in health care. (s. 1.): Addison Wesley, 1990. 715 p.

(104) SICHMAN, J. S. Raciocínio social e organizacional em sistemas multiagents: avanços e perspectivas. 2003. 235 p. Livre Docência (Livre Docência em Engenharia Elétrica) - Escola Politécnica, Universidade de São Paulo, São Paulo, 2003.

(105) _ _ Du raisonnement social chez les agents: une approche fondée sur la théorie de la dépendance. 1995. Tese (Thèse de Doctorat) - Institut National Polytechnique de Grenoble, Grenoble, France, 1995.

(106) SICHMAN, J. S.; DEMAZEAU, Y. When can knowledge-based systems be called agents?. In: BRAZILIAM SYMPOSIUM ON ARTIFICIAL INTELLIGENCE, 9., 1992, Rio de Janeiro. Proceedings... Rio de Janeiro: Sociedade Brasileira de Inteligência Artificial, 1992. p. 172-185.

(107) SILVER, E. J.; WESTBROOK, L. E.; STEIN, R. E. K. Relationship of parental psychological distress to consequences of chronic health conditions in children. Journal of Pediatric Psychology, v. 23, p. 5-15. 1998.

(108) SIMCSIK, T. OSM: organização, sistemas e métodos. $1^{a}$. edição. São Paulo:Futura, 2001. 479 p. 
(109) SOMMERVILLE, I. Engenharia de software. Tradução de Maurício de Andrade; Revisão técnica de Prof. Dr. Kechi Hirama. $6^{a}$. Edição. São Paulo: Editora Addison Wesley. 2003. 592 p.

(110) STONE, M.; WOODCOCK, N. Marketing de relacionamento. $1^{\text {a }}$. edição. São Paulo:Littera Mundi, 1998.

(111) SYCARA, K.; PAOLUCCI, M.; VAN VELSEN, M.; GIAMPAPA, J. The retsina MAS infrastructure, (s. 1.): Kluwer Academic Publishers, 2001.

(112) THOMPSON, S. M.; DAHLQUIST, L. M.; KOENNING, G. M.; BARTHOLOMEW, L. K. Adherence facilitating behaviors of a multidisciplinary pediatric rheumatology staff. Journal of Pediatric Psychology, (s. 1.), v. 20, p. 291-297. 1995.

(113) TORRES, N. A. Competividade empresarial com a tecnologia da informação. $1^{\mathrm{a}}$. edição. São Paulo: Makron Books, 1995. 230 p.

(114) TSANG, M. W.; MOK, M.; KAM, G. et al. Improvement in diabetes control with a monitoring system based on a hand-held, touch screen electronic diary. J. Telemed Telecare, (s. 1.), v. 7, p. 47-50. 2001.

(115) TURBAN, E.; RAINER, JR., R. K.; POTTER, R. E. Introduction to information technology. $1^{\text {a }}$. edição. (s.1.):John Wiley\&Sons, 2001. 550 p.

(116) TURBAN, E.; ARONSON, J. E. Decision support systems and intelligent systems, 5a. edição. (s. 1.): Prentice Hall, 1998. 890 p.

(117) WEYNS, D.; STEEGMANS, E.; HOLVOET, T. Toward active perceptions in situated multi-agent systems. Journal on Applied Artificial Intelligence, (s. 1.), v. 18, p. 9-10. 2004.

(118) WEYNS, D.; HOLVOET, T. A formal model for situated multi-agent systems. formal approaches for multi-agent systems, v.63, n. 2. 2004. (Special Issue of Fundamenta Informaticae)

(119) WEYNS, D.; PARUNAK, V. D.; MICHEL, F.; HOLVOET, T.; FERBER, J. Environments for multiagent systems state-of-the-art and research challegens. In: ENVIRONMENTS FOR MULTI-AGENT SYSTEMS INTERNATIONAL WORKSHOP, 1. 2004, New York. Revised Selected Papers. (s. 1.): Spring-Verlag, Vol. 3374. 2005. Disponível em: <http://www.cs.kuleuven.ac.be/ danny/e4mas_survey_2004.pdf $>$. Acesso em: 26 Jan. 2006.

(120) WORLD HEALTH ORGANIZATION. Adherence to long-term therapies: evidence for action. 2003. 16 p. Disponível $<$ http://www.who.int/chronic_conditions/adherencereport/en/>. Acesso em: 26 Jan. 2006. 
(121) . Site da Instituição. Disponível em: <http://www.who.int>. Acesso em: 25 Jul.

2005. . Preparing a health care workforce for the 21st century: the challenge of chronic conditions. 2005. 65 p. Disponível em: $<$ http://www.who.int/chronic_conditions/workforce_report/en/>. Acesso em: 26 Jan. 2006.

(123) WINDLE, D. R.; ABREO, L. R. Software requirements: using the unified process. $1^{\mathrm{a}}$. edição. (s. 1.): Prentice Hall, 2001. 260 p.

(124) WIRTH, N. Systematic programming: an introduction. Englewood Cliffs, NJ: Prentice Hall, 1973. 169 p.

(125) WOOLDRIDGE, M. An introduction to multiagent systems. $1^{\text {a }}$. edição. (s. 1.): John Wiley \& Son., 2002. 348 p.

(126) WYNGAARDEN, J.B. et al. Tratado de medicina interna. 18 ${ }^{\mathrm{a}}$. Edição. Rio de Janeiro: Editora Guanabara, 1990. (volume 1).

(127) YAN, Q.; SHAN, L. J.; MAO, X. J.; QI, Z. C. Romas: a role-based modeling method for multi-agent system. Disponível em: <http://citeseer.csail.mit.edu/652950.html $>$. Acesso em: 06 Dec. 2005.

(128) YOUNG, R. J. Pro-Active call center treatement support to improve glucose control in type 2 diabetes: a randomized controlled trial. Diabetes Care, (s. 1.), v. 28, p. 278-282. 2005.

(129) YOURDON, E. Análise estruturada moderna. Tradução de Dalton Conde de Alencar. $3^{\mathrm{a}}$. Edição Americana. Rio de Janeiro: Editora Campus, 1990. 836 p. 
Apêndice 


\section{Apêndice $A$ - Relatório das ações executadas pelo agente diabetologista numa consulta}

O relatório apresentado a seguir constituem-se de ações executadas pelo agente diabetologista durante a análise do resultado de glicemia. $\mathrm{O}$ agente enfermeiro, de posse do resultado de exame, procura por um especialista que possa analisá-lo. O agente diabetologista, podendo executar a tarefa, se oferece para realizar a atividade. O agente enfermeiro, por sua vez, contrata-o e envia a ordem de serviço. Após a analise do resultado, verifica-se a necessidade de interação com o paciente para fornecer um laudo. Isso é feito pelo agente diabetologista, que pode então emitir a orientação final. As mensagens trocadas entre os agentes estão destacados em negrito.

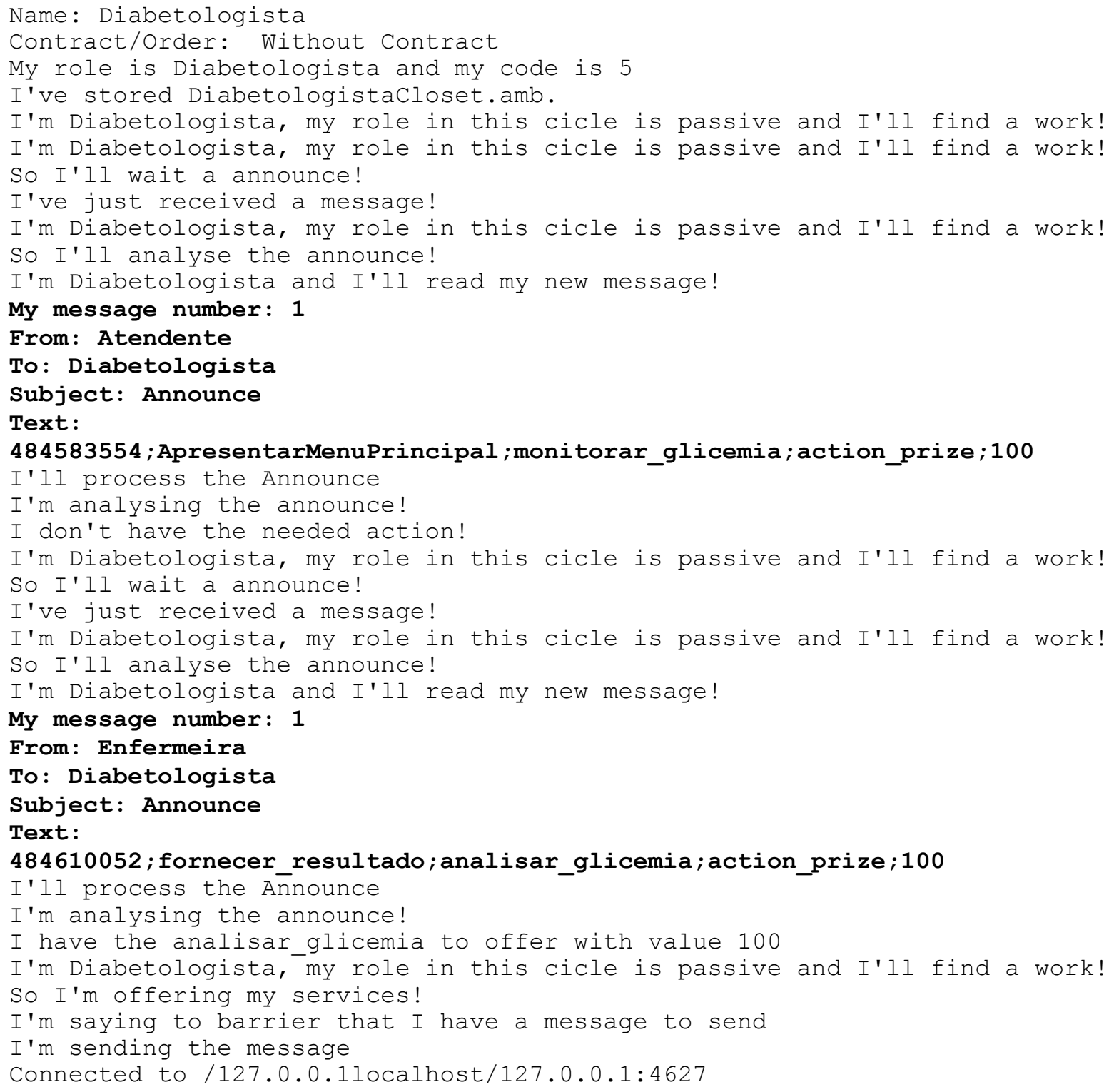




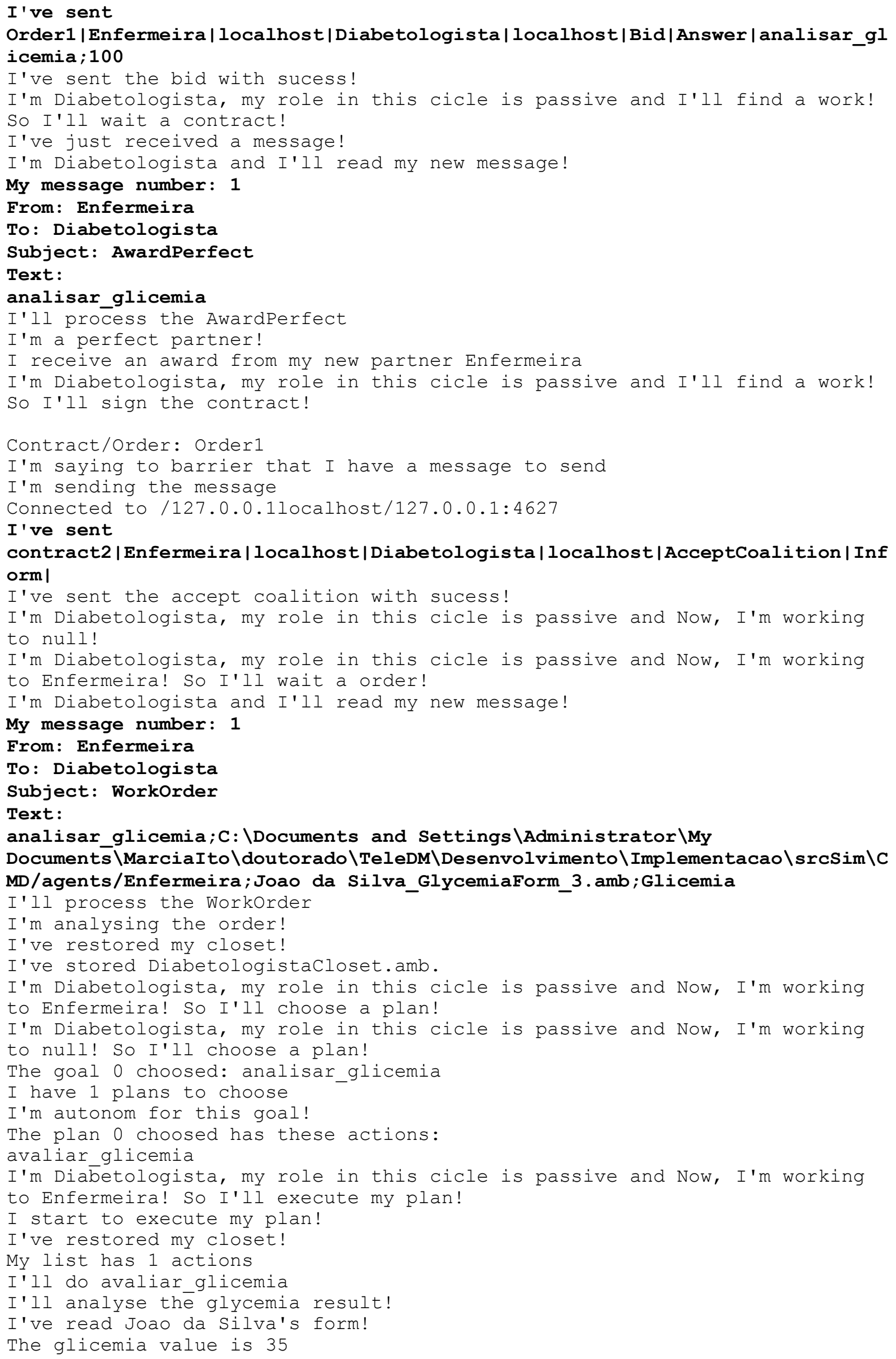


I'm saying that Joao da Silva has hipoglicemia so we have to continue the investigation!

I've write in the Joao da Silva's glycemia form! The name of the file is Joao da Silva_GlycemiaForm_3

The result of the avaliar $\bar{g} l i c e m i a$ is true

I've stored Diabetologistacloset.amb.

I have to execute this orientarHipoglicemia

I'm Diabetologista, my role in this cicle is passive and Now, I'm working to Enfermeira! So I'll choose a plan!

I'm Diabetologista, my role in this cicle is passive and Now, I'm working to null! So I'll choose a plan!

The goal 0 choosed: orientarHipoglicemia

I have 1 plans to choose

I'm autonom for this goal!

The plan 0 choosed has these actions:

investigar hipoglicemia

emitir_laūo

I'm Diābetologista, my role in this cicle is passive and Now, I'm working to Enfermeira! So I'll execute my plan!

I start to execute my plan!

I've restored my closet!

My list has 2 actions

I'll do investigar_hipoglicemia

I'll analyse the hypoglycemia result!

I've read Joao da Silva's form!

The patient Joao da Silva was classified as grave hypoglycemia

I'm asking if the patient is conscious!

The patient is conscious!

I've write in the Joao da Silva's glycemia form! The name of the file is

Joao da Silva_GlycemiaForm_3

I'm asking if the patient is confuse!

The patient isn't confuse!

I've write in the Joao da Silva's glycemia form! The name of the file is

Joao da Silva_GlycemiaForm_3

I've write in the Joao da Silva's glycemia form! The name of the file is

Joao da Silva GlycemiaForm 3

The result of the investigār_hipoglicemia is true

I'll do emitir_laudo

I'll write my conclusions!

Joao da Silva is hipoglicemia grave, so procure por ajuda e vá o mais

rápido possível a um local de pronto atendimento! o seu médico será avisado pelo telefone!

I've write in the Joao da Silva's glycemia form! The name of the file is

Joao da Silva_GlycemiaForm_3

The result of the emitir_läudo is true

I've stored Diabetologistacloset.amb.

I'm Diabetologista, my role in this cicle is passive and Now, I'm working

to Enfermeira! So I'll tell my partner that I've done the service, yet!

I've restored my closet!

This is the answer to analisar_glicemia

My message work done is:

analisar_glicemia; $Y$; $: \backslash$ Documents and Settings \Administrator $\backslash$ My

Documents $\backslash$ MarciaIto\doutorado \TeleDM \Desenvolvimento Implementacao\srcSim\C MD/agents/Diabetologista; Joao da Silva GlycemiaForm 3.amb;Glicemia

I'm saying to barrier that I have a message to send

I'm sending the message

Connected to /127.0.0.11ocalhost/127.0.0.1:4627

I've sent

Order1 | Enfermeira | localhost | Diabetologista | localhost | WorkDone | Inform| analis

ar glicemia; $; C$ : \Documents and Settings \Administrator $\backslash M y$

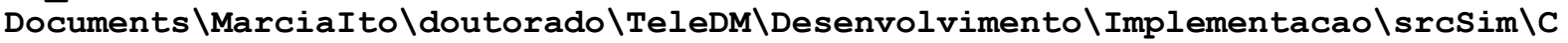

MD/agents/Diabetologista;Joao da Silva_GlycemiaForm_3.amb;Glicemia

I told my partner that I've done the work. So, I'li wait a order 
I'm Diabetologista, my role in this cicle is passive and Now, I'm working to Enfermeira! So I'll wait a order!

I'm Diabetologista and I'll read my new message!

My message number: 1

From: Enfermeira

To: Diabetologista

Subject: WorkConcluded

Text:

analisar glicemia

I'll process the WorkConcluded

My partner Enfermeira doesn't need my services. So I'll wait for another announce!

I'm Diabetologista, my role in this cicle is passive and I'll find a work! I'm Diabetologista, my role in this cicle is passive and I'll find a work! So I'll wait a announce!

I've just received a message!

I'm Diabetologista, my role in this cicle is passive and I'll find a work! So I'll analyse the announce!

I'm Diabetologista and I'll read my new message!

My message number: 1

\section{From: Atendente}

\section{To: Diabetologista}

Subject: End

Text:

I'll process the End

I'm ending my participation in this society...

I'm Diabetologista, my role in this cicle is passive and I'll finish the work!

I'm Diabetologista, my role in this cicle is I'll finish the work! and I'll finish the work!

I'm Diabetologista, my role in this cicle is I'll finish the work! and I'll finish the work! 


\section{Apêndice 2 - Implementação do Caso de Uso “Monitorar Níveis Glicêmicos”}

Nesse apêndice apresenta-se um exemplo da implementação de um dos casos de uso do sistema TeleDM. Optou-se pelo caso de uso "monitorar níveis glicêmicos", pois é o que apresenta as interações entre dois agentes e as análises do resultado de exame pelo agente diabetologista.

Inicialmente, encontrou-se os cenários e as cenas que se encontram sintetizadas na tabela A3.1.

Tabela A3.1 - Análise do fluxo de evento encontrando os cenário e as cenas no caso de uso "monitorar níveis glicêmicos".

\begin{tabular}{|c|c|c|}
\hline Fluxo de eventos & Cenário & Cenas \\
\hline Fluxo Básico & $\begin{array}{l}\text { Paciente } \\
\text { Normoglicêmico }\end{array}$ & $\begin{array}{l}\text { - } \text { Informar resultado de glicemia } \\
\text { - Analisar resultado } \\
\text { - Orientar paciente normoglicêmico } \\
\text { - } \quad \text { Terminar contato I } \\
\end{array}$ \\
\hline Fluxo Básico & $\begin{array}{l}\text { Paciente } \\
\text { Hiperglicêmico sem } \\
\text { intercorrência }\end{array}$ & $\begin{array}{l}\text { - } \text { Informar resultado de glicemia } \\
\text { - Analisar resultado } \\
\text { - } \text { Avaliar hiperglicemia } \\
\text { - } \text { Orientar paciente hiperglicêmico I } \\
\text { - Terminar contato I }\end{array}$ \\
\hline $\begin{array}{l}\text { Fluxo Alternativo: } \\
\text { Notificar o médico da } \\
\text { conduta dada ao } \\
\text { paciente }\end{array}$ & $\begin{array}{l}\text { Avisando médico por } e- \\
\text { mail de paciente com } \\
\text { hiperglicemia }\end{array}$ & $\begin{array}{l}\text { - } \text { Informar resultado de glicemia } \\
\text { - Analisar resultado } \\
\text { - } \quad \text { Orientar hiperglicemia paciente hiperglicêmico II } \\
\text { - } \quad \text { Avisar o médico por e-mail } \\
\text { - Terminar contato I }\end{array}$ \\
\hline $\begin{array}{l}\text { Fluxo Alternativo: } \\
\text { Notificar o médico da } \\
\text { conduta dada ao } \\
\text { paciente }\end{array}$ & $\begin{array}{l}\text { Avisando médico por } e- \\
\text { mail e telefone de } \\
\text { paciente com } \\
\text { hiperglicemia }\end{array}$ & $\begin{array}{l}\text { - } \text { Informar resultado de glicemia } \\
\text { - Analisar resultado } \\
\text { - } \text { Avaliar hiperglicemia } \\
\text { - } \text { Avisar o médico por e-mail e telefone } \\
\text { - } \text { Terminar contato II }\end{array}$ \\
\hline $\begin{array}{l}\text { Fluxo Alternativo: } \\
\text { Notificar o médico da } \\
\text { conduta dada ao } \\
\text { paciente }\end{array}$ & $\begin{array}{l}\text { Avisando médico por } e \text { - } \\
\text { mail de paciente com } \\
\text { hipoglicemia }\end{array}$ & $\begin{array}{l}\text { - } \text { Informar resultado de glicemia } \\
\text { - } \quad \text { Analisar resultado } \\
\text { - } \quad \text { Orientar pacienticente hipoglicêmico I } \\
\text { - } \quad \text { Avisar o médico por e-mail } \\
\text { - Terminar contato I }\end{array}$ \\
\hline $\begin{array}{l}\text { Fluxo Alternativo: } \\
\text { Notificar o médico da } \\
\text { conduta dada ao } \\
\text { paciente }\end{array}$ & $\begin{array}{l}\text { Avisando médico por } e- \\
\text { mail e telefone de } \\
\text { paciente com } \\
\text { hipoglicemia }\end{array}$ & $\begin{array}{l}\text { - } \quad \text { Informar resultado de glicemia } \\
\text { - Analisar resultado } \\
\text { - } \quad \text { Avaliar hipoglicemia } \\
\text { - } \quad \text { Avisar o médico por e-mail e telefone } \\
\text { - Terminar contato II }\end{array}$ \\
\hline
\end{tabular}


A descrição sumária de cada cena é listada a seguir:

- Informar resultado de glicemia - Os dados do paciente são encaminhados para o agente enfermeiro que abre uma ocorrência e um formulário de glicemia. $\mathrm{O}$ atendente da central informa para o agente enfermeiro a data, a hora e o resultado do exame do paciente. O agente enfermeiro percebe que não consegue analisar o resultado de exame e procura por um agente que o faça. O agente diabetologista se candidata e é contratado.

- Analisar o resultado - $\mathrm{O}$ agente diabetologista analisa o resultado do exame e emite o diagnóstico inicial.

- Avaliar hiperglicemia - $\mathrm{O}$ agente diabetologista constata que o diagnóstico inicial do paciente é hiperglicemia e realiza uma investigação para classificá-la.

- Avaliar hipoglicemia - $\mathrm{O}$ agente diabetologista constata que o diagnóstico inicial do paciente é hipoglicemia e realiza uma investigação para classificá-la.

- Orientar o paciente normoglicêmico - $\mathrm{O}$ agente diabetologista, ao constatar que o paciente está normoglicêmico, emite o laudo e as orientações a serem dadas ao paciente. Envia o resultado para o agente enfermeiro.

- Orientar o paciente hiperglicêmico I - O agente diabetologista avalia o paciente e conclui que ele está em estado hiperglicêmico, que merece atenção, porém não há necessidade de comunicar o médico sobre o fato. Escreve e envia o laudo para o agente enfermeiro.

- Orientar o paciente hiperglicêmico II - O agente diabetologista avalia o paciente e conclui que ele está em estado hiperglicêmico e que é preciso avisar o seu médico por e-mail sobre o fato. Escreve e envia o laudo para o agente enfermeiro.

- Orientar o paciente hiperglicêmico III - O agente diabetologista avalia o paciente e conclui que ele está em estado hiperglicêmico e que é preciso avisar imediatamente o seu médico sobre o fato. Escreve e envia o laudo para o agente enfermeiro.

- Orientar o paciente hipoglicêmico I - O agente diabetologista avalia o paciente e 
conclui que ele está em estado hipoglicêmico leve e que portanto é preciso avisar o seu médico por e-mail sobre o fato. Escreve e envia o laudo para o agente enfermeiro.

- Orientar o paciente hipoglicêmico II - O agente diabetologista avalia o paciente e conclui que ele está em estado hipoglicêmico moderado ou grave e que é preciso avisar imediatamente o seu médico sobre o fato. Escreve e envia o laudo para o agente enfermeiro.

- Avisar o médico por e-mail - O agente enfermeiro, ao receber o resultado da análise do resultado de exame, verifica que é preciso comunicar o médico. Resgata os dados do médico e envia-lhe o e-mail.

- Avisar o médico por e-mail e telefone - $\mathrm{O}$ agente enfermeiro, ao receber o resultado da análise do resultado de exame, verifica que é preciso comunicar imediatamente o médico. Resgata os dados do médico e envia-lhe o e-mail. No mesmo instante emite uma mensagem com os dados de telefone e nome do médico, para que o atendente entre em contato por telefone com o médico do paciente.

- Terminar contato I - $\mathrm{O}$ agente enfermeiro transmite a orientação dada pelo agente diabetologista à atendente da central. $\mathrm{O}$ agente enfermeiro transcreve o laudo do diabetologista para o formulário de glicemia e armazena-o.

- Terminar contato II - O agente enfermeiro transmite a orientação dada pelo agente diabetologista à atendente da central e solicita que o atendente entre em contato com o médico do paciente, fornecendo o nome e o número do telefone dele. $\mathrm{O}$ agente enfermeiro transcreve o laudo do diabetologista para o formulário de glicemia e armazena-o.

Em seguida, as cenas foram organizadas no diagrama de atividade que se encontra na Figura A3.1. 


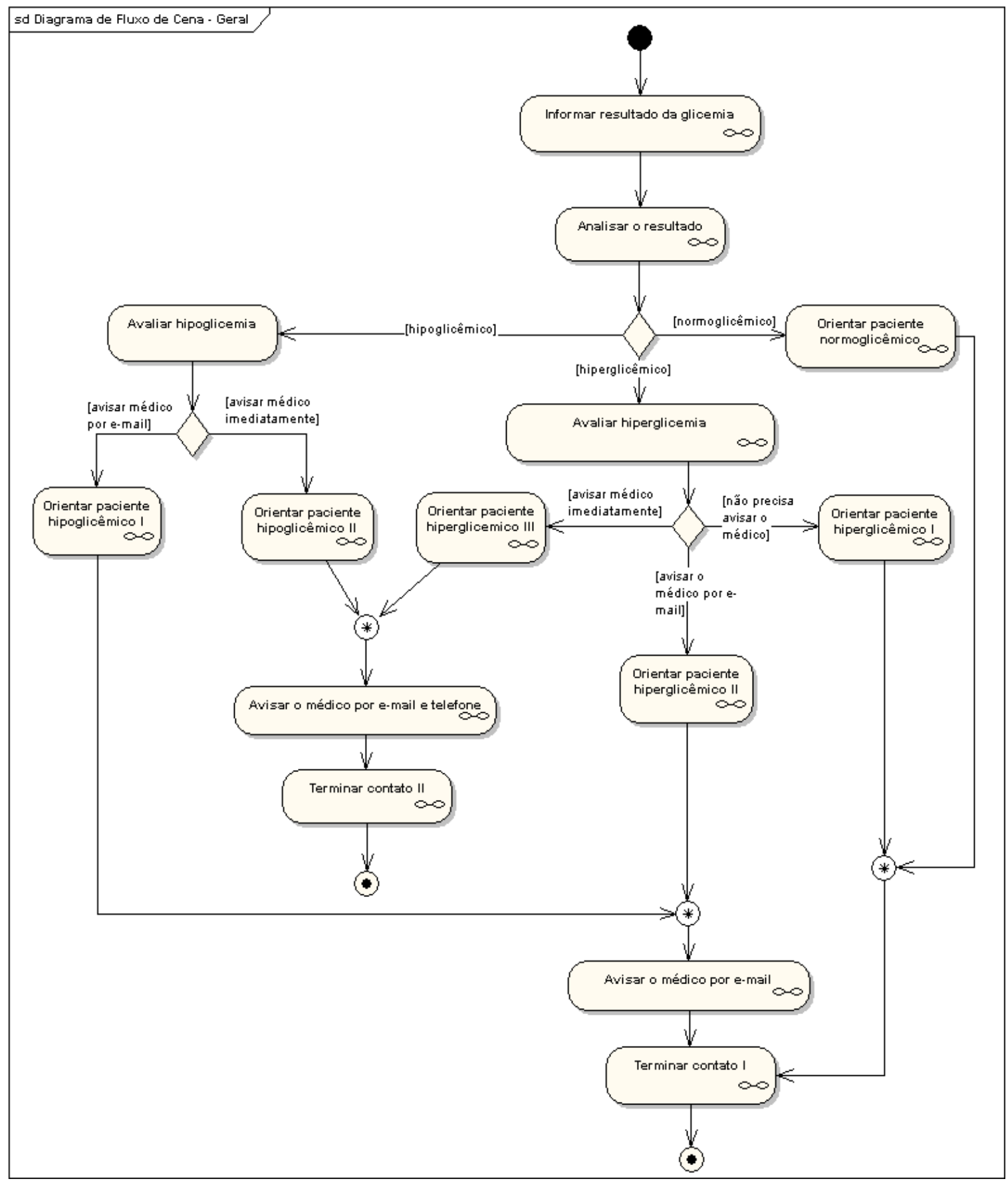

Figura A3.1 - O diagrama de atividade das cenas do caso de uso "monitorar níveis glicêmicos"

Na seqüência, os cenários foram detalhados em forma de roteiro. A seguir tem-se a descrição da cena "paciente normoglicêmico": 


\section{Cena: Informar resultado de glicemia}

- AGENTE-ATENDENTE aguarda a resposta do que o paciente deseja fazer.

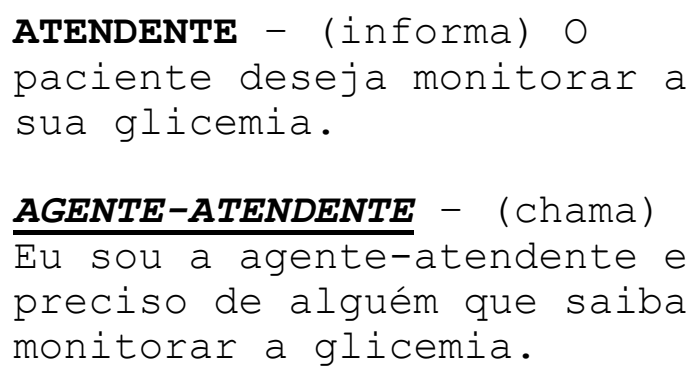

\section{AGENTE-ENFERMEIRO -}

(responde) OK.

A AGENTE-ENFERMEIRO abre uma ocorrência preenchendo a matrícula, data e hora de início do contato e começa a coleta do resultado da glicemia medida.

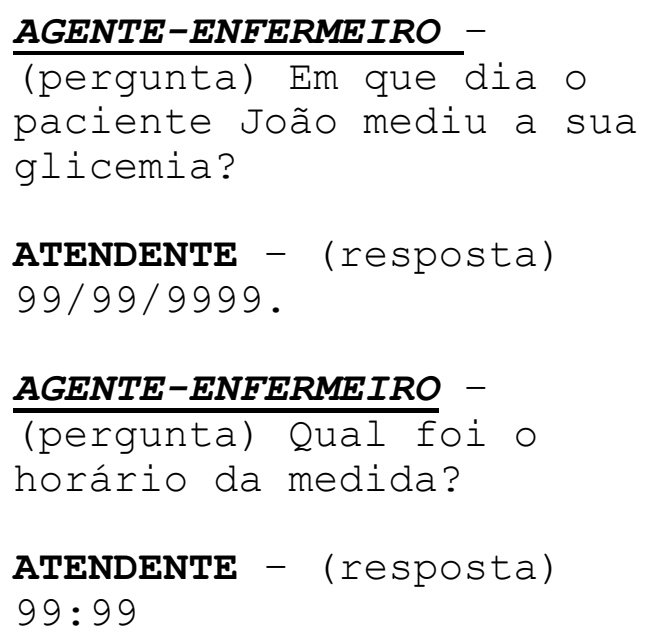


AGENTE-ENFERMEIRO -

(pergunta) Qual foi o

valor?

ATENDENTE - 80

O AGENTE-ENFERMEIRO pega um formulário de glicemia do paciente e o preenche com matrícula, data, hora e valor da glicemia.

AGENTE-ENFERMEIRO - (chama)

Eu sou a agente-enfermeiro

e preciso de alguém que

saiba analisar a glicemia.

AGENTE-DIABETOLOGISTA

(responde)Eu sou um agente-

diabetologista e posso

analisar a glicemia.

AGENTE-ENFERMEIRO -

(informa) Você está

contratado.

AGENTE-ENFERMEIRO -

(requisita) Preciso que

analise e forneça-me um

laudo do resultado de

glicemia do paciente E10-

001 . O valor de glicemia

dele foi 80 .

AGENTE-DIABETOLOGISTA

(informa) OK. 
A partir do detalhamento das cenas encontram-se os agentes e os objetos que eles manipulam.

Pela análise do roteiro de cada cena é possível encontrar os objetivos, planos e ações de cada agente que pertence ao caso de uso. A tabela A3.2 apresenta a análise feita no caso de uso "monitorar diabético".

Tabela A3.2 - Análise das cenas encontrando os agentes, os objetivos, os planos e as ações no caso de uso "monitorar níveis glicêmicos".

\begin{tabular}{|c|c|c|c|}
\hline Cena & Agente & Objetivo & Plano/açãa \\
\hline \multirow[t]{3}{*}{$\begin{array}{l}\text { Informar resultado } \\
\text { glicemia }\end{array}$} & Atendente & Monitorar glicemia & $\begin{array}{ll}\text { - } & \text { Coletar glicemia } \\
\text { - Apresentar menu principal }\end{array}$ \\
\hline & \multirow[t]{2}{*}{ Enfermeiro } & Coletar glicemia & $\begin{array}{ll} & \text { Abrir ocorrência } \\
\text { - } & \text { Perguntar data medição } \\
\text { - } & \text { Perguntar hora medição } \\
\end{array}$ \\
\hline & & Orientar paciente & $\begin{array}{ll}\text { - } & \text { Analisar resultado } \\
\text { - } & \text { Anotar resultado } \\
\text { - } & \text { Mostrar resultado }\end{array}$ \\
\hline Analisar o resultado & Diabetologista & Analisar resultado & $\begin{array}{ll}\text { - } & \text { Analisar glicemia } \\
\text { - } & \text { Emitir laudo } \\
\end{array}$ \\
\hline Avaliar hipoglicemia & Diabetologista & $\begin{array}{l}\text { Orientar } \\
\text { hipoglicemia }\end{array}$ & $\begin{array}{l}\text { - Investigar hipoglicemia } \\
\text { - Emitir laudo }\end{array}$ \\
\hline Avaliar hiperglicemia & Diabetologista & $\begin{array}{l}\text { Orientar } \\
\text { hiperglicemia }\end{array}$ & $\begin{array}{l}\text { - Investigar hiperglicemia } \\
\text { - Emitir laudo }\end{array}$ \\
\hline $\begin{array}{l}\text { Orientar paciente } \\
\text { normoglicêmico }\end{array}$ & Diabetologista & Analisar resultado & $\begin{array}{ll}\text { - } & \text { Analisar glicemia } \\
\text { - } & \text { Emitir laudo } \\
\end{array}$ \\
\hline $\begin{array}{l}\text { Orientar paciente } \\
\text { hiperglicêmico I, II, III }\end{array}$ & Diabetologista & $\begin{array}{l}\text { Orientar } \\
\text { hiperglicemia }\end{array}$ & $\begin{array}{l}\text { - Investigar hiperglicemia } \\
\text { - Emitir laudo }\end{array}$ \\
\hline $\begin{array}{l}\text { Orientar paciente } \\
\text { hipoglicêmico I, II }\end{array}$ & Diabetologista & $\begin{array}{l}\text { Orientar } \\
\text { hipoglicemia }\end{array}$ & $\begin{array}{ll} & \text { Investigar hipoglicemia } \\
\text { - } & \text { Emitir laudo } \\
\end{array}$ \\
\hline \multirow[t]{2}{*}{$\begin{array}{l}\text { Avisar médico por } e \text { - } \\
\text { mail }\end{array}$} & \multirow[t]{2}{*}{ Enfermeiro } & $\begin{array}{l}\text { Comunicar por } e- \\
\text { mail }\end{array}$ & $\begin{array}{l}\text { - } \quad \text { Buscar dados do médico } \\
\text { - Enviar e-mail }\end{array}$ \\
\hline & & $\begin{array}{l}\text { Buscar dados do } \\
\text { médico }\end{array}$ & $\begin{array}{l}\text { - } \quad \text { Procurar ficha paciente } \\
\text { - } \quad \text { Pegar dados do médico } \\
\end{array}$ \\
\hline \multirow[t]{2}{*}{$\begin{array}{l}\text { Avisar médico por } e- \\
\text { mail e telefone }\end{array}$} & \multirow[t]{2}{*}{ Enfermeiro } & $\begin{array}{l}\text { Comunicar por } \\
\text { telefone }\end{array}$ & $\begin{array}{l}\text { - } \text { Buscar dados do médico } \\
\text { - } \quad \text { Snviar } e \text {-mail } \\
\text { Solicitar telefonema }\end{array}$ \\
\hline & & $\begin{array}{l}\text { Buscar dados do } \\
\text { médico }\end{array}$ & $\begin{array}{l}\text { - Procurar ficha paciente } \\
\text { - Pegar dados do médico }\end{array}$ \\
\hline \multirow[t]{3}{*}{ Terminar contato I e II } & \multirow[t]{3}{*}{ Enfermeiro } & Orientar paciente & $\begin{array}{l}\text { - Analisar resultado } \\
\text { - Anotar resultado } \\
\text { - } \text { Mostrar resultado }\end{array}$ \\
\hline & & Terminar contato & $\begin{array}{l}\text { Escrever relatório } \\
\text { - } \text { Fechar ocorrência } \\
\text { glicemia } \\
\end{array}$ \\
\hline & & $\begin{array}{l}\text { Guardar formulário } \\
\text { de glicemia }\end{array}$ & $\begin{array}{l}\text { Salvar formulário de } \\
\text { glicemia }\end{array}$ \\
\hline
\end{tabular}


Após definir os objetivos, planos e ações dos agentes é possível implementar as ações nas suas respectivas classes. A seguir tem-se a codificação da ação "perguntar data medição" do agente enfermeiro. A interação entre o agente enfermeiro e os objetos "glicemia" (formulário de glicemia) e "contato" (ocorrência) estão destacados em negrito no código-fonte.

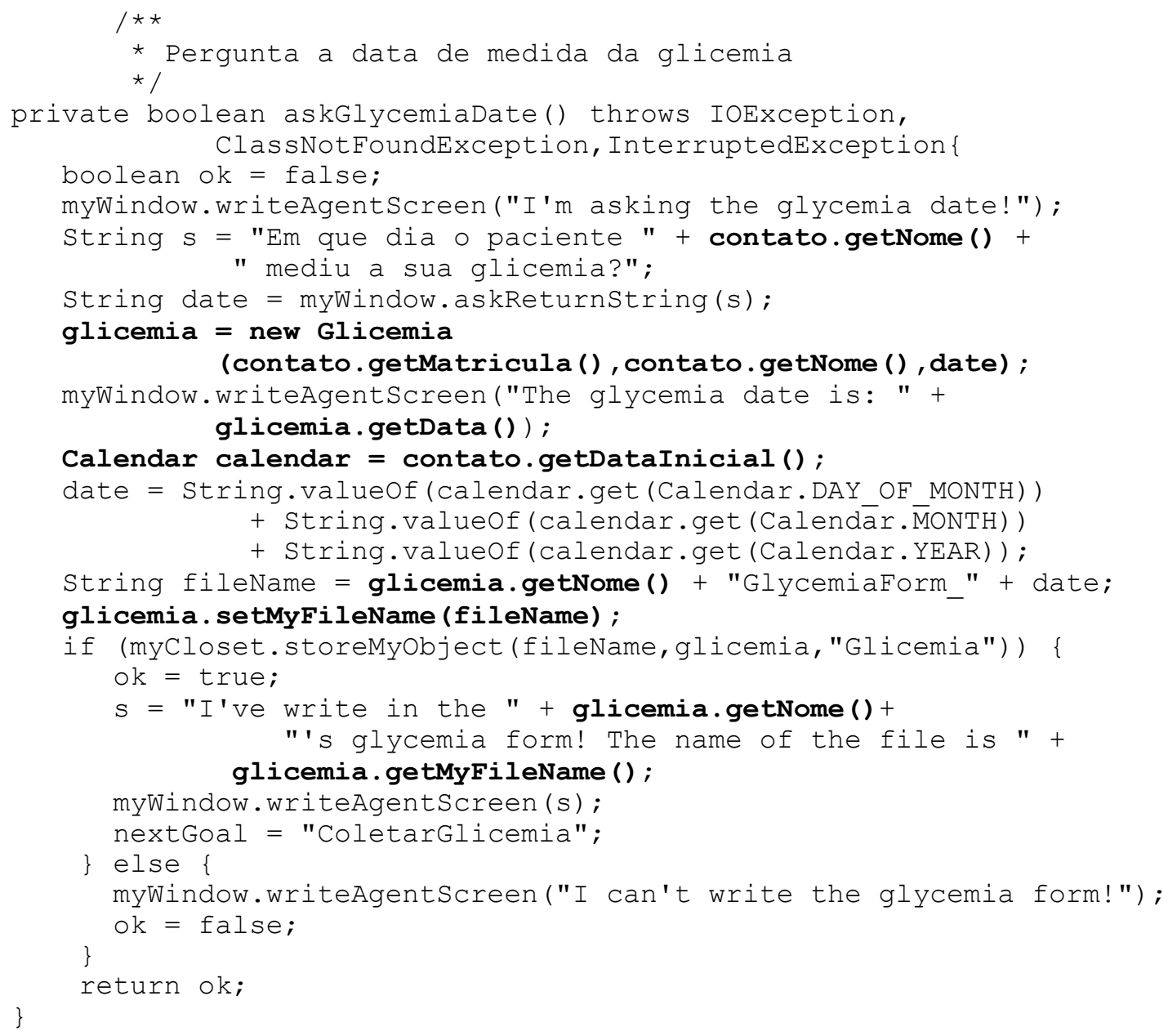

